\title{
Public health sector reform : the implementation of federal decentralisation in Sudan and its impact upon the sector of public health
}

Citation for published version (APA):

Elabassi, M. A. Y. (2003). Public health sector reform : the implementation of federal decentralisation in Sudan and its impact upon the sector of public health. [Doctoral Thesis, Maastricht University]. Datawyse / Universitaire Pers Maastricht. https://doi.org/10.26481/dis.20040122me

Document status and date:

Published: 01/01/2003

DOI:

10.26481/dis.20040122me

Document Version:

Publisher's PDF, also known as Version of record

Please check the document version of this publication:

- A submitted manuscript is the version of the article upon submission and before peer-review. There can be important differences between the submitted version and the official published version of record.

People interested in the research are advised to contact the author for the final version of the publication, or visit the DOI to the publisher's website.

- The final author version and the galley proof are versions of the publication after peer review.

- The final published version features the final layout of the paper including the volume, issue and page numbers.

Link to publication

\footnotetext{
General rights rights.

- You may freely distribute the URL identifying the publication in the public portal. please follow below link for the End User Agreement:

www.umlib.nl/taverne-license

Take down policy

If you believe that this document breaches copyright please contact us at:

repository@maastrichtuniversity.nl

providing details and we will investigate your claim.
}

Copyright and moral rights for the publications made accessible in the public portal are retained by the authors and/or other copyright owners and it is a condition of accessing publications that users recognise and abide by the legal requirements associated with these

- Users may download and print one copy of any publication from the public portal for the purpose of private study or research.

- You may not further distribute the material or use it for any profit-making activity or commercial gain

If the publication is distributed under the terms of Article $25 \mathrm{fa}$ of the Dutch Copyright Act, indicated by the "Taverne" license above, 


\section{Public health sector reform:}

The implementation of federal decentralisation in Sudan and its impact upon the sector of public health 
Layour by Marieke van Velden

Printed by Datawyse Universitaire Pers Maastricht:

ISBN 905278405 I

2003, Mohammed Ali Yehya Elabassi

No part of this book may be reproduced in any form, by any means without written permission from the copyright owner. 


\title{
Public health sector reform: \\ The implementation of federal decentralisation in Sudan and its impact upon the sector of public health
}

\author{
Proefschrift \\ ter verkrijging van de graad van doctor \\ aan de Universiteit Maastricht, \\ op gezag van de Rector Magnificus, \\ Prof. Mr. G.P.M.F. Mols \\ volgens het besluit van het College van Decanen, \\ in het openbaar te verdedigen \\ op donderdag 22 januari 2004 om 16.00 uur \\ door \\ Mohammed Ali Yehya Elabassi \\ Geboren te Nayala op 2 juni 1958
}

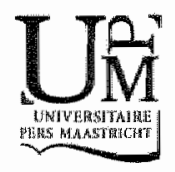




\section{Promotor:}

Prof. dr. J. A. M. Maarse

\section{Co-promotor:}

Dr. V.V. Moharir, Institute of Social Studies, Den Haag

\section{Beoordelingscommissie:}

Prof. dr. W. Groot (voorzitter)

Prof. dr. B. van de Borne

Dr. Kasturi Sen, University of Cambridge, England

Prof. dr. E. de Leeuw, Syddansk University, Odense, Denmark

Prof. dr. J. van der Zee 


\section{Contents}

\section{Chapter One}

General Introduction

1.1. Outline of the research theme ..............................................................

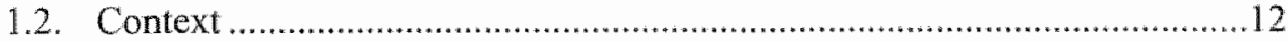

1.3. The development of the public health sector in Sudan ............................13

1.3.1. Development of health services ..............................................13

1.3.2. The organisation of health care ................................................ 15

1.3.3. Health care finance ............................................................... 16

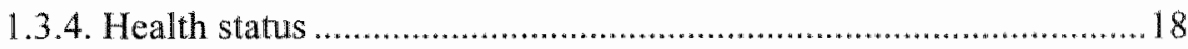

1.3.5. Experience with decentralisation in Sudanese health care ..............18

1.4. Lessons from international experience with decentralisation ....................19

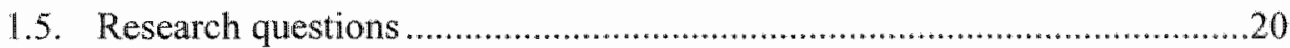

1.6. Analytical framework of the study ....................................................21

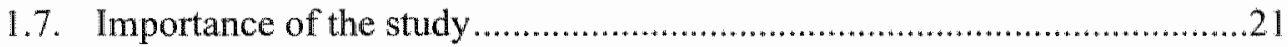

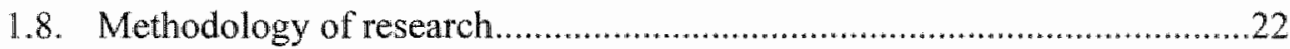

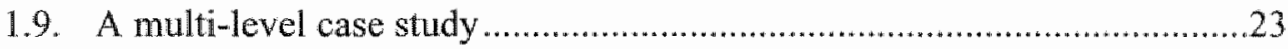

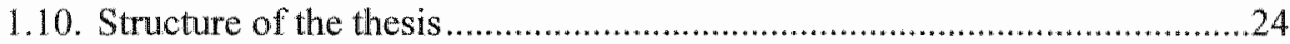

\section{Chapter two}

Decentralisation: Conceptual Issues....................................................... 25

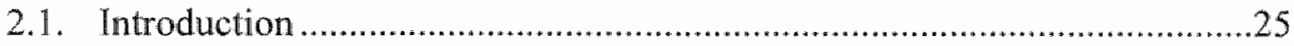

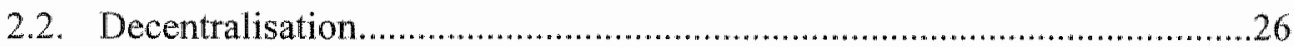

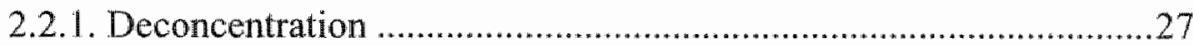

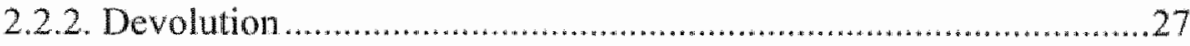

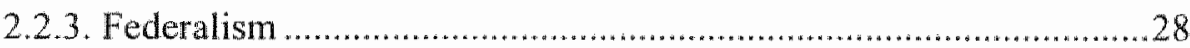

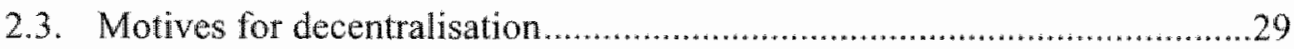

2.4. Some problems of decentralisation .......................................................30

2.5. Complexity of decentralisation in developing countries...........................3 30

2.6. Conditions for successful devolution and federalism ............................... 31

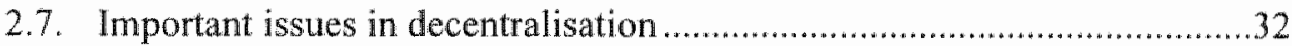

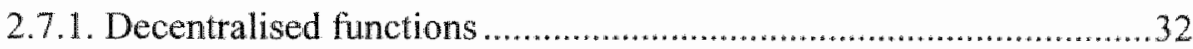

2.7.2. Number of levels in decentralisation............................................32

2.7.3. Identification of roles of different levels ........................................33

2.8. Decentralisation and financial relations ..............................................35

2.9. Decentralisation and human resources ..................................................36

2.10. Decentralisation in practice: between myth and reality ............................36

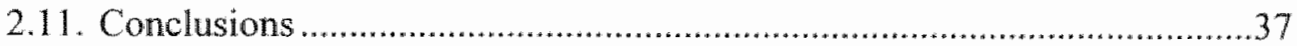




\section{Chapter three}

Towards an Analysis of Policy Implementation ..................................... 39

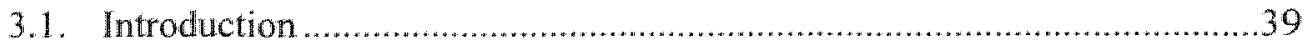

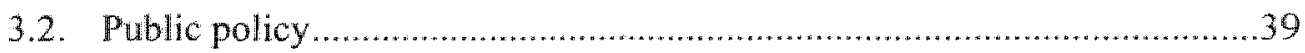

3.3. Types of public policy ....................................................................40 40

3.3.1. Constitutional and substantive (sectoral) policy .........................40

3.3.2. High politics and low politics policies ..........................................41

3.3.3. Distributive, redistributive and regulatory policies........................41

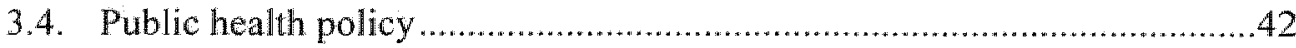

3.5. The stages of the policymaking process ...............................................43

3.6. An analysis of the pollicymaking process ..........................................43

3.6.1. The problem solving perspective .............................................. 43

3.6.2. The socio-political perspective ....................................................43

3.7. Policymaking in developing countries ..............................................44

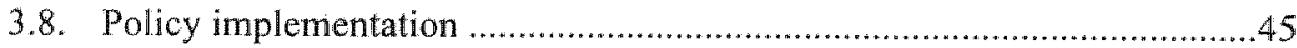

3.8.1. The linear approach to policy implementation.............................46

3.8.2. The interactive approach ........................................................46

3.9. Towards an analytical model of policy implementation .........................47

3.9.1. Policy goals and action programs ..............................................48

3.9.2. Policy content and implementation............................................55 50

3.9.3. Policy context and implementation ...........................................52

3.9.4. Outcomes.............................................................................. 54

3.10. Implementation as the link between policy formation and policy impact ..54

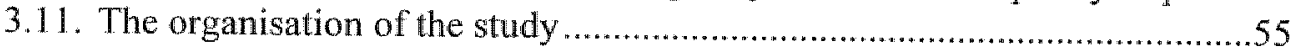

\section{Chapter Four}

The History of Decentralisation in Sudan and its Impact upon Health Policymaking

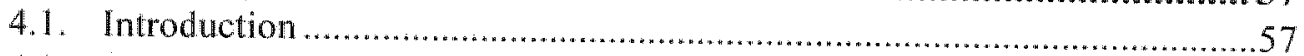

4.2. The Local Government Ordinance of 1951 ...........................................57

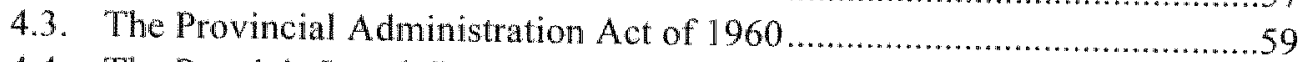

4.4. The People's Local Government System (1971) .......................................5 59

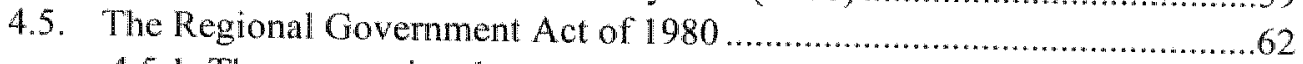

4.5.1. The new regional government structure .....................................63

4.5.2. The distribution of functions between levels of government ............64

4.5.3. The financial resources of the regions..........................................64

4.6. The Local Government Act of 1981 ...................................................65

4.7. The status of decentralisation after the transitional government (1985) .....67

4.8. The impact of decentralisation upon the health system .........................67

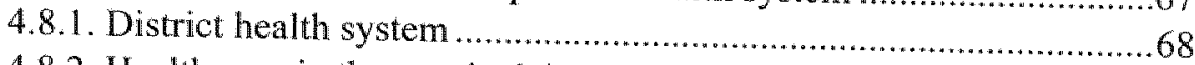

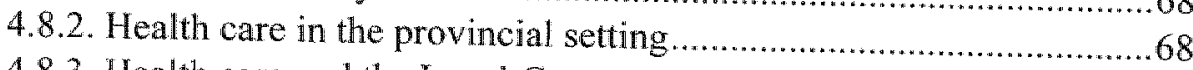

4.8.3. Health care and the Local Government Act of $1971 \ldots \ldots \ldots \ldots \ldots \ldots \ldots . . . .68$ 
4.9. The cumulative impact of decentralisation upon the health system ...........70

4.10. Conclusions ...................................................................................... 72

\section{Chapter Five}

Federal Decentralisation and its Impact upon the Public Health Sector

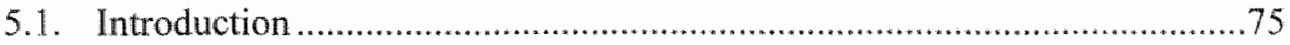

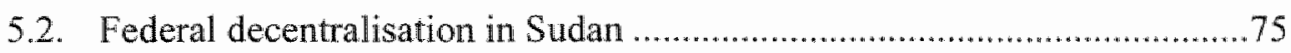

5.2.1. The new structure of government under federalism......................77

5.2.2. The distribution of power and tasks ...........................................8 80

5.2.3. Allocation of resources............................................................ 8 ]

5.2.4. National Fund for Support of States (NFSS) ................................82

5.2.5. Allocation of manpower ................................................................83

5.2.6. Mechanisms for intergovernmental coordination ..........................84

5.3. The organisation of the public health sector under federal government ....8 84

5.3.1. Federal-state relations in the public health sector ...........................84

5.3.2. The tasks of the state in the public health sector .............................86

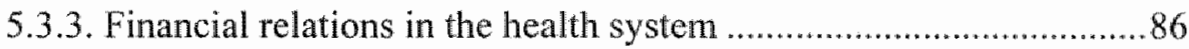

5.4. The development of public health policy.............................................8 87

5.4.1. Public health in the post independence era ..................................... 88

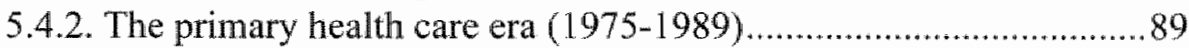

5.4.3. Health Salvation Program (1989-1992) ….....................................91

5.5.4. The public health component of the NHS of 1992-2002 _...............93

Policy guidelines ........................................................................99

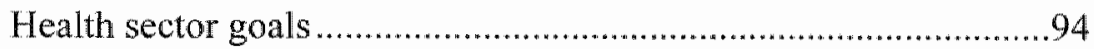

5.5.5. General remarks about the NHS .................................................9. 95

5.6. Review from the perspective of Grindle's model ....................................96

\section{Chapter Six}

Implementation at the federal level .......................................................99

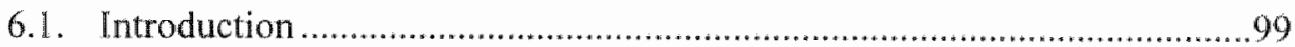

6.2. Past experience of policy implementation ................................................99

6.3. Changes required in the FMOH ........................................................101

6.3.1. Allocation of functions within the public health sector ............... 102

6.3.2. New functions of the Federal Ministry of Health ........................ 103

6.3.3. Senior political and administrative leadership ............................. 104

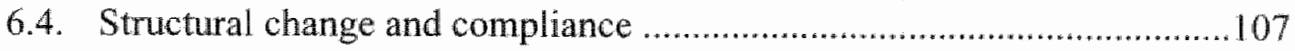

6.4.1. Consequences of structural change ........................................ 108

6.4.2. Compliance of the directors-general ....................................... 109

6.4.3. Compliance of the national program coordinators ......................111

6.5. Decentralisation and financial relations .......................................... 112 
6.6. Decentralisation and health planning ............................................... 114

6.7. Decentralisation and coordination...................................................115

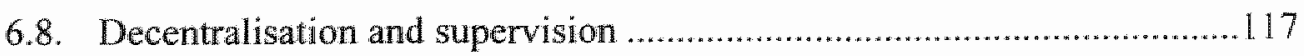

6.9. Capacity building for decentralisation ...............................................117

6.9.1. Capacity building at the federal level....................................... 117

6.9.2. Manpower development ..........................................................119

6.9.3. Federal directorate of manpower and training .............................119

6.9.4. Contribution of NGOs in capacity building in public health sector 120

6.9.5. Improving capacity building through the redistribution of staff ....12]

\section{Chapter Seven}

Implementation at the state level

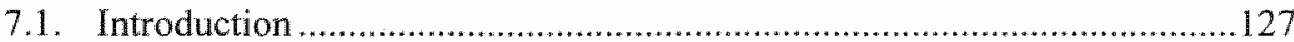

7.2. The role of the state in a federal structure ............................................ 128

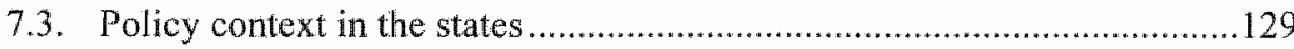

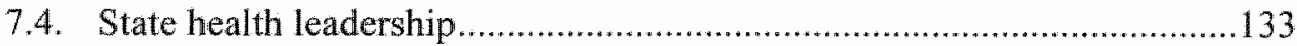

7.5. Organisational reform of the state ministries of health ..........................136

7.6. The role of the state in planning.......................................................... 140

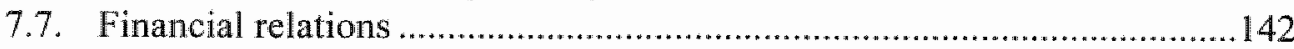

7.7.1. Financial relations from the perspective of the states ................... 144

7.7.2. Managing additional financial resources for health ......................145

7.7.3. Benefits from the federal health funds ...................................... 146

7.8. Developing capacity building in the states.........................................148

7.8.1. The development of human resources...................................... 149

7.8.2. Capacity building of physical resources...................................151

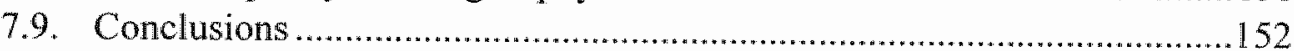

\section{Chapter Eight}

Implementation at the Local Level The Health Area Policy ............. 157

8.1. Introduction .............................................................................. 157

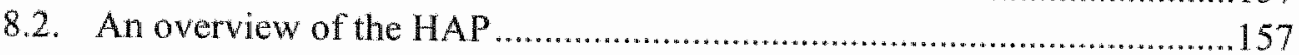

8.2.1. The administrative structure of the health area .......................... 158

8.2.2. The impact of federal reform on the HAP .................................. 159

8.3. Federal measures for HAP implementation ......................................... 160

8.4. Implementation of the HAP in four states.............................................. 164

8.4.1. State support for the HAP .................................................... 165

8.4.2. The implementation strategies of the four states selected.............167

8.4.3. Organisational change .............................................................. 169

8.4.4. Capacity building for the HAP .................................................... 169

8.4.5. Financial arrangements .................................................... 171

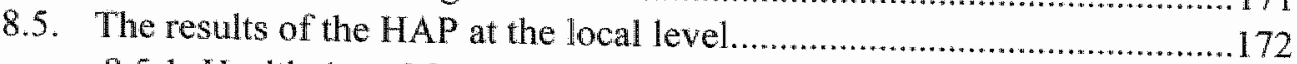

8.5.1. Health Area Management Teams ................................................ 172 
8.5.2. The first line health providers ................................................173

8.5.3. The local council ................................................................ 174

8.5.4. The integration of health services .......................................... 177

8.5.5. Community participation........................................................ 178

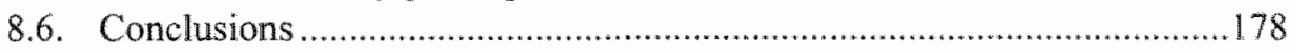

\section{Chapter 9}

Conclusions: the Implementation of Federal Decentralisation in the Public Health Sector 183

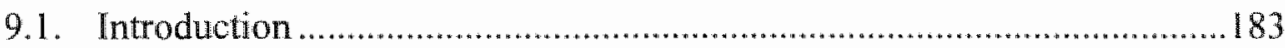

9.2. Development of federal reform ....................................................... 184

9.2.1. Past experience ................................................................. 184

9.2.2. Federal reform ................................................................... 185

9.3. Implementation of federal reform in the public health sector................. 185

9.3.1. Implementation at the federal level ........................................ 185

9.3.2. Implementation at the state level............................................186

9.3.3. Implementation at the local level .......................................... 187

9.4. Federal reform outcomes............................................................187

9.5. Explanation of the policy failure ........................................................ 188

9.5.1. Influence of policy formulation on policy failure ........................ 188

9.5.2. Influence of implementation on policy failure ............................. 189

9.6. Looking back at federal decentralisation: some reflections.................... 195

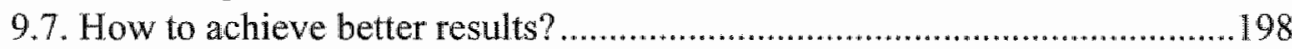

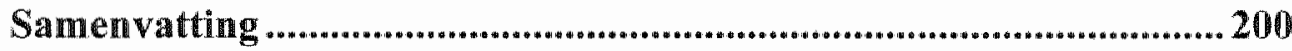

Annex 1:

Overview of Data collection at the federal level: ...................................204

Annex 2:

Overview of Data collection at the state level:

Annex 3:

Data collected at the local level (HEALTH AREA POLICY)........... 209

References................................................................................ 211

Curriculum Vitae ............................................................................. 219

Acknowledgements.................................................................... 221 



\section{Chapter One General Introduction}

\subsection{Outline of the research theme}

Health systems in most developing countries have serious problems. Health reforms, therefore, are inevitable (WHO, 1981; World Bank, 1993). Health reform is concerned with defining priorities, refining policies and reforming the institutions, which formulate and implement these policies (Cassels, 1995). With respect to institutional reform, decentralisation is one of the principle elements of health reforms across a wide range of countries (Collins, 1996). However, despite its vast popularity, decentralisation has seldom lived up to expectations. This is because in most cases policy makers have looked at decentralisation as a technical process and ignored its political and administrative implications. In Sudan, the situation was not different.

Sudan has been governed by many regimes of diverse ideologies and backgrounds since its independence in 1956. These regimes included military, multiparty, one party, communist and Islamic ideologies. No regime dared to deny the validity of decentralisation for such a vast and heterogeneous country like Sudan whatever its ideology. Hence, it has a rich history of decentralisation schemes. The cumulative impact of these schemes has been disappointing in terms of a real shift in decision-making. Permanent political instability is one of many causes of this failure. The impact of decentralisation on health care in terms of accessibility, integration of services and equality in the distribution of physical facilities and human resources alike is a negative one (Abdel Rahim, Alkaki, Elsayed, Nalder \& Gorosh, 1992; FMOH, 1993a; FMOH, 1996a).

Sudan has undergone quite a number of changes in its governance structure over the last fifty years. Many of these changes were directed at some form of decentralisation. Whilst some of the plans for decentralisation primarily focused upon the locality level, others were mainly directed at the intermediate level, that is the provincial or area level. In 1989, the government of General Bashier took the decision that Sudan's unitary system should be replaced by a federal structure. Consequently, twenty-six states were created, which were in turn divided into 634 localities. This constitutional reform involved all sectors of government policy including the public health sector. Now that the implementation of the new federal structure has been in progress for about a decade, it is time to systematically evaluate the implementation of the decentralised structure in the field of health. Such a systematic evaluation is a purpose of this study and up until now is the first of its kind.

We will present an analysis of the implementation of federal reform (decentralisation) and in particular, how federal reform has affected the political and admin- 
istrative structure of the public health sector as well as health policymaking. Our analysis will not only focus upon implementation at the federal level, but also at the state and the local level.

\subsection{Context}

Sudan is the largest country in Africa, covering one-eighth of the African continent with an area of $2.505,810 \mathrm{sq} . \mathrm{km}$. The vast country hosts climatic, ethnic, tribal, cultural and religious diversities. It is bordered by nine countries: Libya, Egypt, Eritrea, Ethiopia, Kenya, Uganda, Zaire, the Central African Republic and Chad. The population of Sudan was estimated at 31.809 million in 2001 , with an annual growth rate of about $2.3 \%$ (WHO, 2002). About $66.3 \%$ of the inhabitants live in rural areas, roughly about $25 \%$ are settled in urban areas and the rest $(8.5 \%)$ live as nomads. Most of the population is concentrated in the middle of the country, mainly in the states of Gezeira and Khartoum. This concentration has been caused, on the one hand, by propulsive factors like war and drought in other parts of the country, and on the other hand, by the pull factors such as aggregation of economic activities and the labour market in the centre of the country. The last census in 1993 indicated that $44 \%$ of the population was under 15 years. Today, the illiteracy rate is estimated at $53 \%$ and it is even worse for women.

Despite Sudan's numerous resources, the economy of the country is classified among the poorest in the world. The Gross National Income per capita in Sudan in 1999 was estimated at US $\$ 310$ (World Bank, 2000). In 1999, Sudan's GDP grew by $5.2 \%$ and it even reached $8.3 \%$ in 2000 , led mainly by agriculture, which accounts for an estimated $45 \%$ of the GDP. Inflation has slowed down dramatically after reaching $133 \%$ in the mid- 1990 s, and was measured at $8 \%$ in 2000. The general economic improvement has been helped by reforms introduced by the current regime. These reforms emphasise containing fiscal deficits, and limiting monetary growth and inflation. The key structural reforms aim at enhancing efficiency by liberalising trade, phasing out price controls, and privatising public enterprises.

More recently, Sudan has benefited from investment in oil production, which is expected to reduce the country's import bill and improve the availability of foreign exchange for development financing. However, economic progress has been constrained by the civil war, increasing military expenditure, social dislocation, deterioration of basic infrastructure and the lack of access to aid and foreign investments. Sudan is also vulnerable to external shocks, including floods and drought. As a result, poverty levels have risen despite growth, which led to migration from the rural to the urban areas. These migrations have put an extra burden on the public health sector. Furthermore, the deterioration in individual income has led to the migration of skilled labour force to the Gulf countries for a better life. A million migrants are estimated to have left since the seventies, 
which consequently affect all social services in the country (Ministry of Planning, 1993a).

Political trends in the country have also been major obstacles to development. Since its independence (1956), Sudan has experienced considerable political change with democratically elected governments and military regimes regularly often with contrasting ideologies replacing each other. The inability to generate and sustain development strategies and political stability has been detrimental to the country's development and to the management of the differences between the northern and the southern parts of the country. The result is the ongoing civil conflict, which has lasted for four decades and consequently affects every aspect of the Sudanese daily life.

\subsection{The development of the public health sector in Sudan}

\subsubsection{Development of health services}

The modern health care system in the Sudan is one of the oldest in Africa. Initially, it was established to provide medical services to the colonial army and its civil administration. The health system was western-oriented, urban based and emphasised curative services (Bayoumi, 1979). Also, an effective unit for environmental sanitation and control was established within the local government, which was supervised by the National Ministry of Health.

On achieving independence, Sudan inherited a disciplined health care system. The quality of services was given priority and the service was free for all. Since then, the health care infrastructure has undergone considerable expansion, which began in the early sixties. Over the last four decades, the number of health facilities has increased remarkably (table 1.1).

Table 1.1 Expansion of health care factilies (1979-1995)

\begin{tabular}{|c|c|c|c|c|c|c|}
\hline Years & Hospitals & Mospetal Beds & $\begin{array}{r}\text { Health Cen- } \\
\text { tres }\end{array}$ & $\begin{array}{r}\text { Dispen- } \\
\text { rinies } \\
\end{array}$ & $\begin{array}{r}\text { Dressing sta } \\
\text { tions }\end{array}$ & $\begin{array}{l}\mathrm{PHC} \\
\text { Units }\end{array}$ \\
\hline 1979 & 156 & 17004 & 212 & 870 & 1828 & 989 \\
\hline 1981 & 160 & 17300 & 206 & 790 & 1417 & 1580 \\
\hline 1983 & 171 & 17774 & 251 & 856 & 1396 & 2183 \\
\hline 1985 & 190 & 18594 & 288 & 977 & 1291 & 2725 \\
\hline 1987 & 200 & 18816 & 330 & 1145 & 1205 & 3080 \\
\hline 1991 & 205 & 19200 & 399 & 1224 & 1259 & 3200 \\
\hline 1993 & 216 & 20135 & 426 & 1271 & 1285 & 3155 \\
\hline 1995 & 228 & 21024 & 477 & 346 & 1388 & 3013 \\
\hline Cumulative & $+46 \%$ & $+23.6 \%$ & $+125 \%$ & $+55 \%$ & $-24 \%$ & $+205 \%$ \\
\hline
\end{tabular}

Source: FMOH, 1997a. 
However ${ }_{y}$ the distribution of the health facilities remained concentrated in the urban areas, namely Khartoum and the Central region (which includes Gezeira, White Nile, Blue Nile and Sennar states) (table 1.2).

Table 1.2 Distribution of health facilites by type and states, except for the South (1996)

\begin{tabular}{|c|c|c|c|c|c|c|c|c|c|}
\hline States & 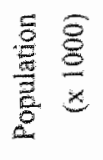 & $\frac{\dot{8}}{9}$ & $\frac{D}{8}$ & $\frac{g}{8} \frac{9}{5}$ & $\begin{array}{l}\frac{5}{5} \\
\frac{5}{5} \\
\frac{3}{x}\end{array}$ & 焉 & 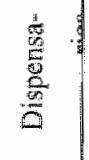 & 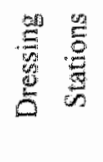 & 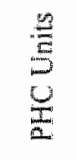 \\
\hline Khartoum & 4372 & 36 & 4042 & $\mathbb{1 1}$ & 6 & 83 & 208 & 19 & 24 \\
\hline Central Region States (4) & 6292 & 66 & 4985 & 11 & 13 & 228 & 454 & 624 & 369 \\
\hline Subtotal & 10664 & 102 & 9027 & 22 & 19 & 311 & 662 & 923 & 393 \\
\hline Other States (10) & 13957 & 115 & 10437 & 14 & 44 & 287 & 730 & 435 & 1179 \\
\hline Total & 24621 & 217 & 19464 & 36 & 63 & 598 & 1392 & 1358 & 1592 \\
\hline
\end{tabular}

Source: FMOH, $1998 \mathrm{~b}$.

Clarification: figwres are based on old region boundaries

The disparity in distribution of manpower between the various states is even more pronounced than in the health care facilities. Khartoum and Gezeira have the best health manpower population ratios (table 1.3).

During 1985-1993/94 general physicians and medical assistants (the backbone of the health services) suffered the greatest decline in numbers due to migration. Increasing economic pressures, declining salaries, poor work environment and lack of equipment and supplies in hospitals were all contributing factors towards migration. The same pattern of disparity is found in the distribution of sanitary facilities, coverage of safe water supply, immunization coverage for children and other aspects of public health services (MOH, 1987a; FMOH, 1993a.).

Table 1.3 Distribution of health workers by region per 100,000 population (1995)

\begin{tabular}{|l|l|l|l|l|l|}
\hline Region & Specialists & A.l Doctors & Technicians & Med. Assistants & Nurses \\
\hline Khartoum & 8.4 & 33.7 & 29 & 36.9 & 96.9 \\
\hline Central & 2 & 7.2 & 3.8 & 18.6 & 770 \\
\hline Northern & 2.3 & 10.0 & 6.4 & 32.8 & 126.1 \\
\hline Eastern & 2.1 & 7.3 & 3.0 & 18.7 & 41.6 \\
\hline Kordotan & 0.8 & 2.9 & 2.7 & 16.6 & 51.9 \\
\hline Darfur & 0.4 & 1.4 & 2.4 & 9.8 & 21.3 \\
\hline Equataria & 0.1 & 1.6 & 5.1 & 5.7 & 108.4 \\
\hline Bahr-elgazal. & 0.1 & 0.9 & 1.4 & 13.0 & 52.9 \\
\hline Upper Nile & 0.1 & 0.8 & 0.4 & 1.7 & 56.5 \\
\hline Sudan & 2.1 & 8.3 & 6.6 & 18.1 & 630 \\
\hline
\end{tabular}

Source: FMOH, 1995a. 


\subsubsection{The organisation of health care}

Public health services represent more than $90 \%$ of the health delivery system in Sudan. They include civil, military and police health care facilities. The rest are private health care facilities, mostly in the cities, and voluntary health services. Traditional health services still play a considerable role. However, they are not organised and not officially recognized.

The hierarchy of public health services consists of primary health care units (PHC unit), dispensaries, health centres, rural hospitals, specialized and teaching hospitals. A PHC unit is the first level facility in the health care system, providing services for a catchment population of 1,000-3,000. It is served by one health worker who is often assisted by a midwife. These peripheral units are designed and equipped to provide immunisation, basic antenatal care, and the dressing and treatment of minor diseases.

Dispensaries are usually located in larger villages; their catchment population ranges from 5,000 to 10000 . An experienced medical assistant, village midwifes and 1-2 nurses usually staff them. Larger dispensaries have inpatient facilities for up to 10 patients. Dispensaries are considered as the first line referral level for the PHC units.

Health centres are located in urban and rural settings. Urban centres are usually staffed by a medical officer and have some diagnostic facilities, e.g. x-ray, laboratories and support staff but no inpatient facilities. Experienced medical assistants and a health visitor staff these centres, and they are recognised in urban and rural settings by providing maternal and child health care.

Rural hospitals are located in the headquarters of local councils. They are the first level of referral for emergency medical care and inpatient diagnosiss and treatment of cases that cannot be treated at the lower level. They serve populations of up to 30,000 people. One or more medical officers staff them, and their capacity ranges from 50 to 100 beds. These hospitals are supposed to provide health services to the entire population of the rural council.

Teaching hospitals are located in the big cities, mainly in the capitals of the states. They are considered as tertiary level of services, and have bed capacities ranging from 200 to 1000 .

There are great disparities in the health services across Sudan (see tables 1.2 and 1.3).

When this is coupled with the problems of access caused by low population density, poor transportation and communication infrastructure, the regional disparities widen even further. In the South, most of the facilities have been subjected to destruction, movement or displacement of health personnel due to the civil war. 


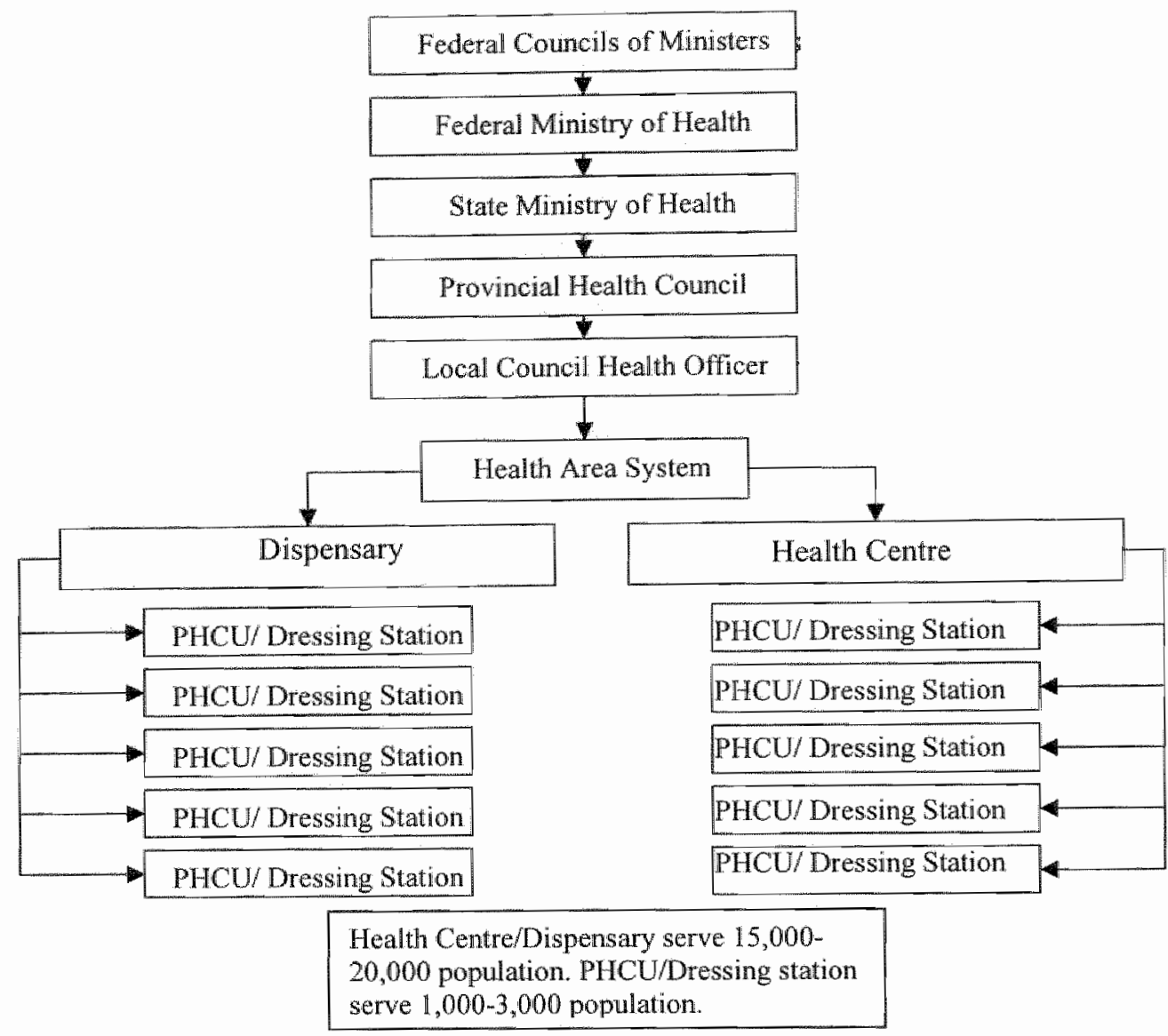

The administrative organization of the health system consists of the Federal Ministryof Health (FMOH) at the top, twenty-six State Ministries of Health and 634 Health Areas (figure 1.1). There is a Federal Government Chamber (FGCH), a Federal Ministerial Council (FMC) and a Federal Ministry of Finance (FMOF), which are all concerned with decentrallisation in the public health sector.

\subsubsection{Health care finance}

It is hardly possible to present an accurate picture of health expenditure in Sudan. This is even true for government expenditures. Complete and reliable statistical data on government expenditures on health do not exist. The unreliability of data sharply increases when private health expenditures are considered. Thus figures on health expenditures must be interpreted with great caution. 
Keeping this in mind, there are clear indications that the severe deterioration in the economic status of Sudan in the late 1980 s and mid 1990 sharply reduced the public (government) expenditure on health. This is reflected in the considerable drop of per capita expenditure on health, which decreased from 1.4 Sudanese pounds in 1987 to 0.24 pounds in 1994 (see table 1.4). The unfavourable economic environment has also affected the availability of health resources of all types and has prevented a more equal distribution of resources between the states. In the late 1990s health care finance somewhat improved as the private out-of-pocket payments increased.

Table 1.4 Real per capita GDP and actual health expenditures (1986/87-1993/94)

\begin{tabular}{|l|l|l|l|l|l|}
\hline Year & $\begin{array}{l}\text { Real GDP* (in mil } \\
\text { lion Sudanese } \\
\text { pounds Ls) }\end{array}$ & $\begin{array}{l}\text { Actual health expendi- } \\
\text { ture (in million Sudanese } \\
\text { pounds Ls) }\end{array}$ & $\begin{array}{l}\text { Actual health expendi- } \\
\text { ture (in million Sudanese } \\
\text { pounds Ls) }\end{array}$ & $\begin{array}{l}\text { Actual per } \\
\text { capita } \\
\text { health ex- } \\
\text { pends. (L.s) }\end{array}$ & $\begin{array}{l}\text { Change } \\
\text { (in \%) }\end{array}$ \\
\hline $86 / 87$ \\
$87 / 88$
\end{tabular}

Source: MOF, 1996.

Clarification: Constant prices $1981 / 82$.

Recently, WHO presented a more positive picture of health expenditures in Sudan. Total gowernment health expenditure was estimated at $4.1 \%$ of the GDP in 2000 and per capita health expenditures at 8 US $\$$ in the same year (UNDP, 2002). Government health expenditure was $21.2 \%$ of the total health expenditure of the country of which $6 \%$ came from external resources. The other sources were private, namely out-of-pocket expenditure, which accounted for $78.8 \%$ of total expenditure in 2000 (WHO, 2002). The World Bank recently estimated the government expenditure on health at $0.07 \%$ of the GDP in the year 2001 and $3 \%$ of total government expenditure (World Bank, 2003). This estimate confirms the observation in the WHO report that government expenditures on health represent only a small fraction of total health care expenditure. Importantly, the World Bank expresses its doubts about the reliability of the estimate of total health care expenditures because an estimate of private payments which constitute the bulk of health care expenditure is almost impossible. This raises more doubts about the per capita expenditure presented by the WHO. 


\subsubsection{Health status}

The health status of the Sudanese population for the year 1995 is in many respects similar to other developing countries in Sub-Saharan Africa: life expectancy at birth for the total population is 55.9 years; infant mortality rate is 70 per 1000 live births; under-five mortality rate is 113 per 1000 live births; maternal mortality rate is 36.5 per 10,000 live births. Accessibility to health services for the general population is $51 \%$. Birth attendance by a trained midwife is estimated at $18 \%$ of all deliveries $\left(\mathrm{FMOH}_{3}, 1993 \mathrm{a}\right)$. The incidence of disease is very high. The prevailing diseases are mostly infectious in nature and are associated with an unhealthy environment, inappropriate health practices, low standards of living, malnutrition, and poverty. They include malaria, diarrhoeal diseases, respiratory infections et cetera, which represent the leading causes of death in the country (FMOH, 1996a). In general, the health status in the country is poor and comes at the bottom when compared to other Arab countries (UNDP, 2002).

\subsubsection{Experience with decentralisation in Sudanese health care}

The experience with decentralisation in Sudan started with a district system in 1951 and went through many stages until it reached the federal system it has today. Decentralisation changed the administrative structure, having a negative cumulative effect. The health did not manage to achieve its goals of improving accessibility to services, community participation, integration of vertical programs and sustainable improvement of health (MOH, $1987 \mathrm{a}$; Abdel Rahim et al., 1992; FMOH, 1993a).

Main causes of this failure were the lack of financial resources and low political priority for health. In fact, most of local activity in the field of health is still related to vertical programs and is supported by international donors. Unfortunately, the scarcity of foreign donations led to rivalries among the agencies involved and attempts to divert these resources for personal and group interests.

The political context also had a negative impact upon decentralisation. Frequent changes in the political system from military to civil governments and vice versa hindered the implementation of decentralisation (Fadalla, 1996). The various regimes in power also differed in the priority they gave to health. For example, military regimes commonly gave more priority to national security matters while democratic governments tended to place a greater emphasis upon the interests of the tribal and religious leaders.

These differences in priority also had an adverse influence upon health services. Furthermore, there was a tendency on the part of the intermediate level government agencies to monopolise the decentralised decision-making powers for themselves at the expense of the local level. This happened, for instance, during the implementation of the Regional Act in 1980 (Moharir, 1986). 


\subsection{Lessons from international experience with decentralisation}

Decentralisation can be described as the transfer of authority from the national to sub-national government levels (Rondinelli, 1981b). It has become a standard component of health policy proclamations of various regimes across the political spectrum (Collins \& Green, 1994). Decentralisation is expected to facilitate participation, to encourage innovation, to increase access, and to improve the effectiveness and efficiency of a policy (Mills, Vaghaun, Smith \& Tabibaadeh, 1990; Collins, 1996; Bossert, 1996).

Despite the long history of decentralisation, there is a growing concern that it has mostly failed to achieve its objectives and even has effects that limit public health sector development (Collins, 1996). Many decentralisation programs were not well implemented. They failed to overcome the resistance in national or regional government to a transfer of power to local government and often led to recentralisation (Moharir, 1986; Mukwena, 2001). The literature on decentralisation has highlighted various factors affecting its implementation in developing countries. For instance, Borgenhammer (1993) has mentioned the following requirements for successful decentralization: sufficient local political, administrative and managerial capacity; ideological certainty in implementation of tasks; and readiness to accept several interpretations of one problem. According to Rondinelli, McCullough \& Johnson (1989), effectiveness in decentralization depends on the capacity and willingness of local level political and administrative leadership. This includes the willingness of local officials to support and perform decentralised management, the quality of local leadership and the attitude of rural people towards government.

Many studies of decentralisation in developing countries have revealed that without sufficient resources policies cannot be implemented effectively. As Maddick (1964) observed, allocating functions to the local level without providing the necessary resources is futile. Moreover, it is likely to cause a collapse of local government. The public will distrust it and individuals will be reluctant to serve either as voluntary councillors or paid staff, if nothing can be achieved. Nearly in all developing countries, the lack of independent sources of revenue weakens local institutions to function as autonomous bodies. The dependence on central government grants keeps local institutions under the control of the central bureaucracy. In both Tanzania and Papua New Guinea (PNG), lack of financial resources at the district and provincial level led to a continued reliance on funding from the central level, undermining the role of decentralised units, and also stretching the limited capacity of the centre. Local bodies in most developing countries still function as bureaucratic institutions of the centre rather than as generators of local values, preferences and aspirations (Rondinelli, 1981 b). The dominance of donor funding in Tanzania combined with the political influence of the donor organizations led to the imposition of vertical programs onto the decentralised system despite their negative consequences for the overall organisation. In $\mathrm{PNG}$, resource constraints combined with political power of the richer 
provinces generated increasing inequalities in resource allocation between provinces (Gilson \& Mills, 1995). The human resources and appropriate technical and managerial capacities to perform the assigned tasks at the state or local level are also of great importance (Rondinelli, Nellis \& Cheema, 1983; Saide \& Stewart, 2001).

The degree of commitment of political leaders to support decentralisation reform is also very important. For instance, in Tanzania and Sudan decentralisation and participation were promulgated by strong-willed presidents but they received only weak support from the bureaucracy and their own political parties (Rondinelli, 1981a). Even when there are commitment and consensus to adopt the policy, the question arises whether policy-makers take sufficient care of environmental, economic, social and political conditions. In most developing countries they are neglected in the policy formulation process (Grindle, 1980).

Overall experience confirms that, despite the popularity of decentralisation, its realisation is problematic. All of the above-mentioned problems of implementation are related to the socio-political context as well as the content of the decentralisation scheme. The need to understand the political context of decentralization has been stressed among others by Grindle (1980), Collins $(1996,2000)$ and Bossert (1996). Decentralisation is not a politically neutral change for political groups and for organisational relations. As a reform in the public sector, it can alter the complex relationships of power within the public sector, between different interest groups and the access of social and political groups to the centre of political decision-making and resources (Smith, 1979). Political considerations are thus inherent in any decentralisation endeavour. The political environment may facilitate but more often puts limits to decentralisation (Collins, 2000). Sometimes, it even turns out that decentralisation contrary to its declared goal of promoting popular participation, was used more as a guise for the extension of centralised decision-making by the ruling political parties (Conyers, 1981; Gilson, Kilima \& Tanner, 1995).

Despite the complexity of decentralisation, there have been very few critical appraisals of decentralisation in the public health sector in developing countries. Most of the studies used to deal with decentralisation as a technical issue ignoring its political nature. In addition it is important to consider the process by which decentralisation develops and is implemented to understand its complexity (Cheema \& Rondinelli, 1983; Bossert, 1996; Collins, 2000).

\subsection{Research questions}

This study deals with the implementation of decentralisation in the public health sector of Sudan. More concretely, we are interested in the process of implementation of federal reform in the public health sector since 1993.

The following research questions are central: 
1. How was federal decentralisation in the public health sector implemented in Sudan?

2. To what extent did federal decentralisation in the public health sector achieve its objectives?

3. Which factors affected the implementation of federal decentralisation in the public health sector and help to explain its achievements so far?

\subsection{Analytical framework of the study}

In order to find answers to our research questions, we will make use of an analytical model of implementation developed by Grindle (1980). A key assumption of this model is that implementation is not simply carrying out decisions that were taken in the stage of policy formation. Such a conceptualisation of implementation does not take account of its full complexity. Implementation is more than a technical or administrative process. It is also a socio-political process that heavily influences the results achieved with the policy implemented. Therefore, one may argue that a policy not only shapes implementation, but also that implementation shapes a policy. Thus, implementation is in a sense the Achilles heel of the policy process. It plays a decisive role in what really changes in the real world. Often, policies are not more than a set of political words designed to build up political legitimacy. They do not spend much attention to implementation and, at least in the developing countries, no specific resources are made available to put the policy in practice. No wonder that such a policy fails to achieve its objectives.

In this study we will adopt a process approach (Dror, 1989). We will not undertake an attempt to measure the ultimate impact of decentralisation in terms of health status, equity, quality of care or accessibility. That would be an impossible task because of the large number of factors having an impact upon each of these aspects. It would also be impossible to disentangle the specific impact of decentralisation in this respect. Furthermore, it often takes a long period before the effects of policy begin to materialise. Instead, we will look at how decentralisation - in particular federal decentralisation - affected the administrative structure of the public health sector and health policymaking. It is assumed that the administrative structure and decentralised health policymaking eventually influence each of the aforementioned aspects. For instance, if the implementation of decentralisation fails, it cannot contribute to better health outcomes, or to better accessibility of health services.

\subsection{Importance of the study}

Although there have been some studies of decentralisation in Sudan, our study differs from them in several aspects. We aim at a specific study of decentralisa- 
tion in the public health sector for the first time in the country. Furthermore, our goal is to present an empirical study of implementation of decentralisation, using a specific framework derived from the literature on decentralisation, public policy and health management. Finally, we will conceptualise health policy implementation as a political and administrative process in addition to a technical one.

\subsection{Methodology of research}

Crabtree \& Miller (1992) define five aims of scientific inquiry: identification, description, explanation generation, explanation testing, prescription and/or control. They group the first three aims under the collective term "exploratory" or qualitative research and define the remaining two as quantitative research which in their view is mainly directed at testing causal hypothesis and uses comparative research methods.

Other authors regard quantitative research as broader encompassing any form of numerical data collection including non-experimental research used for explorative purposes (Burns \& Grove, 1987). The term qualitative research is then reserved for the investigation of perceptions or meanings of concepts and how reality is experienced. Qualitative data collection uses observations, recordings and unstructured interviews (Miles \& Huberman, 1994; Bowling, 1997).

There is much debate on the merits of either quantitative research or qualitative research (Burnard \& Hannigan, 2000). Like Crabtree and Miller other recent authors avoid the discussion and propose both the use of qualitative and quantitative methods as tools to obtain information on a research topic (Paley, 2000). The choice of methods must be based upon the aims of the study and the research questions. A combination of methods is often applied in policy-oriented research, especially when exploring a phenomenon from different perspectives.

In this thesis we adopt a pragmatic view by using exploratory methods, which combine qualitative and quantitative data to fit with the aims of our research. Exploratory or descriptive research is appropriate to describe and explain an unstudied phenomenon (Seaman, 1998). These studies are conducted when relatively little is known about a research topic. They provide an accurate portrayal or account of the characteristics of an individual, group, situation or process (Burns \& Grove, 1987). Exploratory studies describe, compare and classify data and give insights into patterns and processes. Methods used in exploratory research are diverse and range from logical induction, observations, case studies, document analysis, structured and unstructured interviews to focus group discussions and surveys with open-ended and/or close-ended questions. Characteristics of this type of research are non-manipulation of variables and just focus on studying a phenomenon as it occurs in reality (Crabtree \& Miller, 1992).

The strength of the method of case studies is its ability to deal with a full variety of evidence, documents, artefacts, interviews and observations. However, there are concerns about their objectivity and generalisability (Yin, 1989; Seaman 
1998). There is a danger that the interpretation of the data is influenced by the values and perception of the researcher which can lead to subjectivity and inaccuracy.

While keeping the limitations of exploratory research in mind, we believe that for realising the aim of this study, namely to gain insight into the development and implementation of federal decentralisation in the health system in Sudan between 1993 and 1999, an exploratory approach is a the most appropriate choice. Our analysis is based mainly on secondary data in the form of previous studies of decentralisation in Sudan, relevant legislation on decentral isation, official reports of government agencies, aid agencies, reports of seminars and conferences on decentralisation and a series of open-ended in depth interviews and focus group discussions with the main actors involved in the process at the federal, state and local levels. The main objective of the focus group discussions was to verify the findings of our interviews and other sources of information. In our view the verification procedure has significantly contributed to the validity and reliability of our findings and conclusions.

\subsection{A multi-level case study}

In this study we will present the results of an exploratory investigation of how federal decentralisation has been implemented in Sudan. For that purpose we have conducted a muiti-level case-study. As a first step, we analysed the implementation of Federal reform and its impact upon the sector of public health at the federal level $(\mathrm{N}=1)$. The second step consisted of an analysis of the implementation process at the state level. We included all sixteen Northern states in our analysis. The other ten states, all located in the Southern part of the country, were not selected because of the ongoing war, lack of information and political instability. In addition, we performed an in-depth analysis in four out of the sixteen states $(N=4)$. The criteria used to select these four states were: (a) relative wealth and economic development; (b) level of access to political decision-making at the federall level; (c) availability of statistical records, reports, and so on; (d) geographical accessibility. Criteria (c) and (d) can be considered practical constraints. The following four states were selected: Khartoum State, Gezeira, North Kordofan and Kasala. The first two of these states are relatively wealthy in the Sudanese context and have good political connections with policymakers at the federal level. North Kordofan and Kasala are relatively poor states and miss good access to political decision-making, however they are not the worse. Finally, we studied the implementation of federal reform and its impact upon the sector of public health in 26 localities. These localities were taken from the four aforementioned states. We refer to the annexes 1-3 for further information on our selection procedure. 


\subsection{Strueture of the thesis}

This thesis comprises 9 chapters. Chapter 2 discusses essential theoretical concepts for the analysis of decentralisation. Chapter 3 addresses the relevant concepts in public policy, health policy and policy implementation, ending with an elaboration of our theoretical framework adapted from Grindle. Chapter 4 provides an overview of past experiences of decentralisation in Sudan with special reference to decentralisation in the public health sector. This chapter elaborates the main stages of decentralisation in Sudan and the implications for the public health sector. Chapter 5 discusses the development of health policy in the country. Chapter 6 analyses the implementation of the federal policy in health care at the federal level. This chapter explores how the Federal Ministry of Health and other important actors at the federal level played their role. The chapter also investigates the hidden and overt struggle between different interest groups within the Ministry of Health. The processes of restructuring, planning, financing and capacity building through which policy takes shape will be selected as the main focus of our investigation. Chapter 7 deals with the implementation process at the state level. At several places we will discuss in more detail how each of the four selected states (Khartoum, Gezeira, Kassala and North Kordofon) acted in the implementation process. We will compare structures, plans, capacity building, resources, strategies and political support. Chapter 8 focuses upon the implementation of Health Area Policy (HAP) in the Northern states with a special reference to the four selected states. The Health Area Policy was introduced in the late 1980 s to address the poor performance of health care in the country. Its main thrust was to strengthen the locality in the delivery of health services to its population. Chapter 9 is a concluding chapter, summarising the essential points of our analysis of the process of policy-making on the decentralisation in the public health sector on the basis of Grindle's model. 


\section{Chapter two \\ Decentralisation: Conceptual Issues}

\subsection{Introduction}

Decentralisation is an old phenomenon but is still dodging policy-makers in many developing countries. The current literature points to four phases of decentralisation in developing countries (Olowu, 2001). During the first phase running from the 1950 s to the early $1960 \mathrm{~s}$, the colonial administration promoted decentralisation of decision-making to local government as a necessary element in the structure of an independent democratic state (Conyers, 1983; Smith, 1985). It adopted the British or French model of government, which on the one hand promoted local government but at the same time kept its power and functions limited. During the second phase running from the early $1960 \mathrm{~s}$ to the late $1970 \mathrm{~s}$, independence brought the concerns of national unity to the fore, and for a while decentralisation took another direction. Local administration was brought under central control to hasten development and consolidate the nation-state via a single party or military state mechanism (Conyers, 1983; Mawhood, 1983). In the third phase running from the 1970 s to late 1980 s, decentralisation was encouraged again by international development agencies like the World Bank (Conyers, 1983) and bilateral donors like USAID (Leonard \& Marshall, 1982). In this period, decentralisation to local government and semiautonomous organisations was used as a mechanism to cut back central government expenditure and improve efficiency (Hyden, 1983). The last phase in decentralisation runs from the 1990 s to the present. It was triggered by the onset of democratisation and political liberalization. This phase involves a deliberate attempt to create local governments that are genuinely participatory and responsible to the local communities (Burns, Hambleton \& Hogget, 1994; Collins, 1996; Olowu, 2001; Bossert \& Beauvais, 2002).

In general, during the last four decades there has been a growing interest in decentralisation worldwide, especially in the developing countries such as India, Tanzania, Ethiopia, Sudan, Nigeria, South Africa, Ghana, Brazil and Mexico.

In the health area, several developing countries have used decentralisation to overcome problems in health delivery and financing. Decentralisation also represented a pivotal factor in the achievement of "Health for all by the year 2000 " campaign of the World Health Organisation (WHO, 1978; World Health Assembly, 1977). The World Bank has encouraged decentralisation consistently in its Annual Reports (1983, 1987 and 1993). Decentralisation is now seen as an effective tool to stimulate improvements in service delivery, to secure a better allocation of resources according to needs, to involve the community in decisions concerning priorities, and to facilitate a reduction of inequities in access to health. 
In the following brief literature review, we will discuss the definition of decentralisation, its forms, its multidimensional nature and complexity in the context of developing countries. Our discussion will mainly emphasise the devolution and federal forms of decentralisation, as they represent the focus of our study in this chapter: the implementation of federalism and local government in the public health sector in Sudan. The discussion of devolution will also involve the main issues related to its design and implementation.

\subsection{Decentralisation}

Decentralisation is not easily defined. It takes many forms and has several dimensions. It involves substantive institutional restructuring, and several variants may be operating at the same time within a country and even within a sector (Mills et al., 1990); thus, the term lacks specifity. However, it can be defined in general terms as a process of transfer of power, responsibilities and resources from the higher level of government to the lower level or levels (Cheema \& Rondinelli, 1983). The many forms of decentralisation have a variety of implications for autonomy and control as well as the balance between centralisation and decentralisation. In practice, this balance may be at different points of a continuum, depending on the socio-political environment and the orientation of political leadership.

Various types of decentralisation have been identified in the literature (Rondinelli, 1981 b; Mills et al., 1990; Bossert \& Beauvais, 2002). Firstly, it is important to distinguish between functional and territorial decentralisation (United Nations, 1965; Collins, 1994). Functional decentralisation involves the transfer of responsibility for specific functions, such as health care or education. Territorial decentralisation transfers responsibilities for a range of public services to a geographical agency (Mills et al., 1990). Where the coordination of a number of functions is important, as is in the case in the public health sector, the compatibility of the organisational arrangements in health and related functions will strongly influence the extent to which each agency can achieve its objectives. The organisation of health services may be decentralised in either way, but the Ministry of Health will probably have more power to influence local decisions under functional decentralisation than under territorial decentralisation, where health will be only one out of a number of government services that are being decentralised.

A second classification exists between market and intragovernmental decentralisation. Market decentralisation refers to the decentralisation of activity from governments to market or quasi-market agencies. Intragovernmental decentralisation refers to decentralisation within the government (Bennett, 1994); for instance, from the national level to the district or local level.

A third widely used taxonomy identifies four varieties of decentralisation: deconcentration, delegation, devolution and privatisation. The distinction between these forms is essentially about their legal status and scope (Rondinelli, 1981b). 
Finally, a distinction can be made between decentralisation in a unitary govemment and decentralisation in a federal structure. Federalism is considered the highest form of decentralisation, since here different levells of government are constitutionally provided with original authority for specific functions.

For the purpose of this study, we will focus on deconcentration, devolution and federalism. There are two reasons to focus on these areas. First, they are closely related to each other conceptually. They belong to the generic form of decentralisation that can be referred to as intra-governmental decentralisation. Secondly, federalism and devolution constitute the main focus of our study. We will begin with deconcentration as it is often confused with devolution.

\subsubsection{Deconcentration}

Deconcentration is the weakest form of decentralisation. It is often used in unitary states to redistribute decision-making as well as financial and management responsibilities among different levels of the government. It merely shifts responsibilities from central government officials in the capital city to those working in regions, provinces or districts. It creates a field administration or local administrative infrastructure under the supervision of central government ministries. In deconcentration, a direct hierarchical relationship between the central and local level is retained and the deconcentrated authority can be withdrawn at any time.

Under deconcentration, only administrative and not political authority is transferred to a lower level (Maddick, 1964). If we consider the implications of deconcentration in the Ministry of Health, it denotes the creation of one or more additional management levels; for example, a district and/or regional level can be created to which certain administrative functions may be transferred.

The requirements for successful deconcentration, according to Mills et al. (1990), are: "one or more senior staff with responsibility for managing health activities within the district and with clearly defined discretionary powers; a clearly defined population and geographical area for which the managers are responsible; an identifiable staffing establishment and budget; a mechanism for communicating the health development needs of the district to higher level planners".

\subsubsection{Devolution}

Devolution is a transfer of responsibility and authority for decision-making, finance, and management to separate autonomous units with corporate status within the public sector (e.g. provinces, states, municipalities). Devolution usually transfers responsibilities for services to sub-national units that ellect their own representatives, raise their own revenues, and have an independent authority to make investment decisions (Mawhood, 1983). In a devolved system the transfer is to legally or constitutionally established autonomous political authorities. 
The activities of central and local authorities are clearly differentiated and each has its own legal powers and responsibilities (Maddick, 1964; United Nations, 1965; Mils, 1994).

Devolution is a more contemporary process and is still uncommon in developing countries (Cheema \& Rondinelli, 1983). Among the few countries that have effectuated it are India, Nigeria, Papua New Guinea (PNG), South Africa, and Ethiopia. These countries have chosen to formally devolve a wide range of government functions, including health services, to lower government levels.

\subsubsection{Federalism}

Federalism is similar to devolution; however, in federalism the main territorial governments receive their powers not only from the national government but also from the constitution upon which the central or federal government is equally dependent for its sphere of jurisdiction (Collins, 1994). The two levels are thus co-ordinate and independent (Smith, 1985). There are deliberate constitutional obstacles to the federal govermment in altering the powers of the constituent units, their boundaries and forms of governments. There is also an independent Supreme Court to arbitrate in case of conflict between the two levels.

Countries have introduced federalism for different purposes; however, they share the common goal of benefiting from unity and diversity. Some countries build their federalism upon separate units like the provinces in Canada, the states in United States of America or the Länder in the Federal Republic of Germany. Federalism in developing countries is quite limited. In Africa, a few countries such as Nigeria, Ethiopia, and South Africa have a reasonable history of federalism. Other countries include Brazil and India. It is often assumed that federalism is a more extensive form of decentralisation than devolution, given the constitutional guarantee. However, some studies of federalism suggest that it may be mistaken to conclude that the extent of decentralisation can be inferred from the constitutional difference between devolution and federalism. As Smith (1985) points out, constitutions may well contradict the federal principles by allowing the centre to exercise substantial form of control over the regions. Moreover, the constitutional provisions may well mask a considerable degree of interdependence between the levels and even an enlargement of the central government's control upon lower government levels through planning, transfer of resources and centralisation in political parties. 
Table 2.1 Types of decentrallisation

\begin{tabular}{|c|c|}
\hline Type of decentrallisation & Definution \\
\hline $\begin{array}{l}\text { Deconcentration } \\
\text { (Administrative decentralisation) }\end{array}$ & $\begin{array}{l}\text { Decision-making is transferred to a lower administrative (civil ser- } \\
\text { vant level }\end{array}$ \\
\hline $\begin{array}{l}\text { Devolution (political decentralisa- } \\
\text { tion) }\end{array}$ & Decision-making is transferred to a tower government lowet \\
\hline Federalism & $\begin{array}{l}\text { Tasks are allowated on a constitutional basis to a lower governmen- } \\
\text { tal lewel. }\end{array}$ \\
\hline Market decentralisation. & $\begin{array}{l}\text { Tasks are transferred from public agencies to market., quasi-market } \\
\text { or semi-autonomous agencies }\end{array}$ \\
\hline
\end{tabular}

Source: WHO, 1997.

\subsection{Motives for decentralisation}

There are two main motives for decentralisation: political and administrative. The political motive is based upon democracy and equity arguments. Decentralisation is intended to give citizens or their elected representatives more power in public decision-making. Advocates of political decentralisation assume that decisions are made with greater participation of the population and their representatives will be better informed and more responsive to diverse interests in society than in a political system where decision-making is concentrated at the top level of national political authorities (Rondinelli et al., 1989; Conyers, 1983; Collins, 1996). The administrative motive behind decentralisation is principally related to efficiency arguments. Here, decentralisation is considered an instrument to reduce the work of the central government and to adapt a policy optimally to locall conditions (Rondinelli, 1981b; Collins, 1994).

Olowu (2001) suggests that two forces have contributed to devolutionary decentralisation in developing countries. The first force includes donor agencies and civil society actors, who aim at empowering the people by giving them greater opportunities for voice, self-governance, and resource mobilization. In particular, devolutionary decentralisation aims to remedy the three most serious institutional weaknesses of developing countries, namely weak accountability, poor integration in governance and poor quality of basic service delivery. The second force is that national political authorities see devolutionary decentralisation as an opportunity to dump responsibilities on lower levels of government, given the steady decline in financial and human resources or as a necessity for the very preservation of national political unity of the country in the face of ethnic pressures. "Federalism is not chosen for convenience but for survival" (Mawhood, 1984).

In reality, it is often difficult to pinpoint the real motives for choosing federalism. Motives stated formally in the legislation may be different from the real motives of policy-makers or the key political actors. For example, in politically less mature developing countries, a far-reaching form of devolution like federalism may 
be launched to gain political legitimacy for political leaders or to divert attention from other pressing economic problems. Sometimes, decentralisation is introduced to support locally dominant classes, to disperse and defuse social and political conflict or to extend government control to the local level (Collins, 1989). In the public health sector, the World Health Organisation has encouraged decentralisation in its "Global Health for All strategy" (WHO, 1978), which stresses its importance as a tool for both inter-sectoral collaboration and community participation. Public health sector decentralisation has an appeal to many because of its theoretical advantages such as the delivery of coherent health services reflecting local preferences, more effectiveness and efficiency, involvement of the local community and a more equitable access to health services (Mills et al., 1990).

\subsection{Some problems of decentralisation}

It is important to realise that decentralisation is subject to various constraints and may produce undesirable side effects (Rondinelli, 1981a; Saltman \& Figuerras, 1997; Olowu, 2001). Unfortunately, there is only limited empirical evidence from the developing countries in this respect (Mills et al., 1990; Collins, 1996; Bossert, 1996). The empirical literature on the actual experience of decentralisation in developing countries has only recently become available. Most of it is based on the mainstream literature of western scholars (Conyers, 1984; Collins, 2000; Bossert \& Beauvais, 2002). For that reason, there is as yet little evidence on actual experiences of decentralisation in developing countries.

Despite huge differences in context, some western experiences with decentralisation could be useful for the developing countries. These experiences inform us that an unquestioned acceptance of decentralisation can restrict our understanding of its effectiveness and problems in public health sector (Collins, 1996). Negative effects of decentralisation include fragmentation of health services, weakening of central health departments, inequity, political manipulation in favour of interests of some stakeholders, and weakening of the status of the public sector (Collins, 1996). One of the important obstacles of decentralisation in the context of developing countries is the local dependency phenomenon. In many cases, actors at the local level lack the self-confidence and the competency to take over their responsibilities. They are characterised by a culture of waiting for directives and guidelines from the centre (Mills et al., 1990).

\subsection{Complexity of decentralisation in developing countries}

Decentralisation is a complex phenomenon; therefore, its analysis is far from simple. Because decentralisation changes the mobilization and allocation of public resources, it affects a wide range of issues from service delivery to poverty reduction and macroeconomic stability. An analysis of decentralisation must take 
these issues into account: they are referred to in the literature as "cross cutting" issues (Olowu, 2001). Management of decentralisation also requires extensive knowledge of local institutions and a good understanding of the process of decentralisation, such as what drives decentralisation in a country (sector) and which stakeholders are involved.

Another aspect of the complexity of decentralisation is that it is often implemented as a broadly based reform that affects various sectors and levels of govermment. Outcomes reflect the interaction and coordination of policies between different tiers of government. In many countries, it is a considerable challenge to coordinate sectoral reforms undertaken by the central government with decentralisation of fiscal, political and administrative responsibilities to local government (Cassels, 1995; Olowu, 2001).

In developing countries, the design and implementation of decentralisation is even more complex. The dilemma of decentralisation for political leaders in developing countries is that they are simultaneously trying to build a nation and facilitate economic and social development as well as devolution of power within a hostile internal, external economic and political environment. In addition, most political leaders in developing countries look at decentralisation not as an end in itself but a means for realizing other more overriding individual and group political objectives (Collins, 1989). The unwillingness or inability of political leadership to learn from its own experience or that of other countries in designing decentralisation policies also adds to the very limited success of decentralisation endeavours in developing countries, particularly in Africa. Often, decentralisation in practice is marked by zigzag swings between devolution and deconcentration and frequent changes in decentralisation regimes, without providing sufficient time for any regime to get institutionalised (Rondinelli, 1981a; Mawhood, 1983; Hyden, 1983; Olowu \& Wunsch, 1990).

\subsection{Conditions for successful devolution and federalism}

Devolution usually faces serious problems of policy design and implementation in all countries, especially in poor African countries (Olowu, 2001). These problems are of a technical and political nature (Rondinelli, 1981b; Mawhood, 1983; Collins, 1989; WHO, 1997; Adamolekun, 1999;). These authors and others mention the following conditions for successful decentralisation: (a) a national political consensus on political values, norms, beliefs and on major development strategies; (b) a reasonable level of institutional capacity at different levels of government; (c) a reasonable level of economic development, permitting an adequate level of financial and manpower resources to each level of government; (d) a reasonable level of democratic political process permitting peaceful changes of regimes as a result of periodical election results; (e) willingness on the part of wealthier regions and social groups to share national wealth more equitably and 
to reallocate national resources to the poorest regions/social groups in the country; (f) the relative absence of continued crisis situations characterized by civil war, famine, external aggression, et cetera.

Many countries in the industrialized world institutionalised a federal system when most of the above pre-requisites were present (Mogedal, Steen \& Mpelumbe, 1995). In contrast, most developing countries did not wait until these prerequisites were met. Federalism was prematurely introduced with all the foreseeable and unavoidable tensions, set backs to development, and threats of secessions. The Sudanese experience presents a good example of a premature institutionalisation of a federal system, as we will see later. It is no wonder, therefore, that the experience with decentralisation is often a frustrating one.

\subsection{Important issues in decentralisation}

In this section we will briefly discuss some important issues in the design of a decentralised governance structure.

\subsubsection{Decentralised functions}

The organisational forms described earlier reflect different degrees of decentralisation of governmental authority as well as different approaches to decentralisation. It is appropriate to note that, while the legal framework of decentralisation is an important element, there are many other factors influencing the actual degree of autonomy enjoyed by the local bodies. These include control over resources, ability to mobilise political support, legitimacy of authority, capacity of local institutions, and the general climate of rules, regulations and expectations within which they operate (Lee \& Mills, 1982).

The form of decentralisation adopted in a health system will to a considerable extent determine the functions that a decentralised health unit can perform (Mills et al., 1990). These functions may be summarised broadly as: health legislation, policy making and planning, revenue raising, resource allocation, service provision, human resources development, health management and regulation, interagency and intersectoral co-ordination, health research, and community participation.

\subsubsection{Number of levels in decentralisation}

Decentralisation entails the subdivision of the state territory into smaller areas and the creation of political and administrative institutions in those areas. Some of the institutions so created may themselves find it necessary to practice further decentralisation, resulting in more than two levels. Bosserts (1996) points out that defining the appropriate levels for decentralising functions, responsibility and authority is a central issue. The number of levels chosen will strongly influence the degree of central influence and community involvement, as well as the 
direction and the extent of accountability. The question of how many levels are appropriate depends on the size of the country, the availability of resources and the political situation in the country. Mills et al. (1990) suggests that having more than four management levels (for example, national, regional, district, and local) commonly results in a costly and cumbersome bureaucratic organisation. In large countries with a strong federal system of government where health is frequently a state responsibility, there are not often more than three levels within the state itself (Mills et al., 1990).

The interactions between the different management levels depend on the type of decentralisation. In the current literature, the term "Intergovernmental Relations" is commonly used to describe the interactions between the different levels. Although the word 'level' implies a juxtaposition of higher and lower levels, there is a lot of empirical evidence in the literature to emphasise cooperation among the levels of government and de-emphasise the idea of a hierarchical relationship (Adamolekun, 1999). The intergovernmental relations in federal or devolutionary decentralisation involve three major topics: power, fiscal and administrative relations. Each is important in shaping the process and defining the results product of decentralisation; however, it often happens that one or more of them are neglected.

According to Mills (1994), it is clear that decentralisation cannot be reduced to simplistic statements about weakening the centre and strengthening the periphery or cutting off the periphery from the centre. Neither can a simple dichotomy be set up between centralisation and decentralisation. The transfer of authority in reality involves a range of organisational and political complexities. It is important to understand how health care fits into the overall changes within the government structure. For example, decentralisation within the Ministry of Health cannot be separated from broader changes in public service, local government, social security agencies, and the financial operations of the government.

\subsubsection{Identification of roles of different levels}

The decentralisation of health services to lower government levels implies a need for an appropriate division of functions between the different levels of government. This is difficult to achieve in practice and can lead to problematic overlap where functions and responsibilities are caught in the "frontier areas between levels" (Collins, 1994). Some countries tend to define in detail the roles of each level for decentralisation in the public health sector to avoid potential conflicts. However, the issue is whether they stick to their own functions in practice. The generall pattern of functions of each level can be summarised as follows: 


\section{National Ministry of Health}

The National Ministry of Health represents a source of general guidance, technical reference and support to all sub-national levels (Mills et al., 1990; Collins, 1994) Thus, the national health ministry is primarily a national policy-making and coordinating institution, with only an indirect control over the operation of health services or programs. Its main functions commonly are:

- Policy formulation and setting of national priorities;

- Development of regional planning guidelines;

o Allocation of resources, monitoring and evaluation of the effectiveness, efficiency and responsiveness of the national health system;

o Regulation of health personnel development;

o Control/coordination of national level health organisations and research institutes;

- Liaising with international health organisations and aid agencies (Hogget, 1991; Carter, 1989).

Through theses functions it is responsible for providing favourable conditions to states for the successful implementation of policies.

\section{Regional, state or provincial level}

The functions at this level vary widely between countries. In some countries they are similar to those of the central ministries. In other countries the regional, state or provincial authorities are, in fact, not more than an intermediate hierarchical level in bureaucracy with little authority or power of their own. In particular, control over personnel and finance may range from very limited to quite extensive. Regions and provinces are commonly given the following functions: regional health planning, program monitoring and evaluation, coordination of regional health activities, management of regional hospitals, regional health personnel management, regulation of regional financial arrangements, managerial and technical supervision as well as support of district health teams.

\section{District level and similar units}

The district can be described as the peripheral level of authority, in which all local level services in different sectors are coordinated. Therefore, districts are commonly seen as the organisational level that actually implements health services and disease control programs. It is also the level with the critical function of co-ordinating and interpreting the (top-down) requirements of central government and the (bottom-up) needs of local communities and their local health leaders. Districts are often given the following main functions: running of the district hospital services; supervision of sub-district health facilities; management and control of local health budgets; co-ordination and supervision of all government, non-government and private health services within the districts; promotion of intersectoral collaboration at local government level and encouragement of com- 
munity participation in management, planning, financing and supervision of local health services.

The clear identification of responsibilities at each level of authority is an ideal that barely exists in the real world. The specification of responsibilities at each level determines lines of accountability and the capacity needed at each level to accomplish its tasks within the decentralised structure. Strengthening each level with appropriate capacity, structures and systems requires specific attention. The word appropriate is important here because central level officials should possess policy-making skills and develop monitoring skills to keep up with what is happening at the lower level. The lower level officials must develop skills that are more operational and related to service delivery and enforcing regulations. Moreover, "healthy' relations between officials at different levels and within the same level are of major significance. Mills (1994) points out the possible decentralisation of authority at each level such as health area boards, health management teams, local health boards, hospital management boards, health centre advisory committees and regional/district health authorities. Irrespective of whether they are fully elected, partially elected or fully appointed, they have to carry the responsibilities of adopting decentralisation at their level. The lack of clarification of roles may trigger conflicts and adversely affect implementation.

\subsection{Decentralisation and financial relations}

Decentralisation involves higher costs for the new institutions, new staffing procedures and training for all concerned (WHO, 1.997). In the short run, resources must be mobilised to put decentralisation into practice. In developing countries, the design of decentralisation is commonly not preceded by feasibility studies to establish such administrative costs before hand. On the contrary, in most cases decentralisation is introduced to resolve fiscal crises and so countries lack the resources to meet these costs anyway.

In general, decentralisation (devolution) can only succeed if it is pursued on a sound economic basis. Its aim should not be to transfer central problems to the periphery, but rather to enable regional handling of responsibilities that do not necessarilly have to be managed centrally.

In the fiscal intergovernmental relations there are three main issues: revenues, transfer of resources and expenditures. In general, the centre has access to greater tax revenue than the regions or local government. Accordingly, the centre has a responsibility to redistribute resources appropriately to all regions and to safeguard the interests of the most disadvantaged regions. This function results in a greater dependence of local administration upon the central government. The balance in financial relations needs special attention in order to produce a sustainable and equitable distribution of resources. This implies that there should be an appropriate mechanism to balance the intergovernmental transfer system. Un- 
fortunately, the prevailing approach in developing countries for intergovernmental transfers is mostly an ad hoc one, resulting in great uncertainty, disparities and lack of transparency.

\subsection{Decentralisation and human resources}

The process of devolution involves strategic decisions on new roles and responsibilities. Human resources represent a crucial issue in devolution, as several levels need specific capacity to perform their new roles adequately. A variety of planning, training, financing and management problems may lead to inadequate numbers of staff and deterioration of skills and morale. Other issues include organisational and structural topics, health resources development, sustaining appropriate training capacity, ensuring managerial and technical competence and securing adequate performance. The importance of the national level in guiding the allocation of human resources within a national regulating framework should not be underestimated. It safeguards an acceptable level of equity in the distribution of human resources. Human resources issues emerge as part of the process itself providing information on the availability of human resources, difficulties in revising organisational structures, the complexity of transferring human resources, shortage of time required for the desired changes and the possible negative distorting impact of professional associations, unions and registration bodies on the process. All these technical, managerial and political issues represent crucial factors that can influence the actual process and outcomes of decentralisation.

\subsection{Decentralisation in practice: between myth and reality}

It is important to make a clear distinction between the formal design of decentralisation and its actual form in practice. The tendency in many developing countries has been to decentralise authority to local bodies with a formal political and administrative line upward to the central government. In many instances, the ruling elites at the centre resist the devolution process in order not to loose their political grip on power. But this is usually hidden under pretences of preserwing national cohesion or integrity of nationally delivered services. As Smith (1985) points out, the introduction of field administration units of central departments is often confused with devolution to more autonomous local government. As such, it may be politically useful for a government to create the impression that it is strengthening the autonomy of local community, when in reality it is strengthening the position of its own political and administrative functionaries in the field. Sometimes, the formal decentralisation of authority to the regional and local levels is subordinated to the regional or local unit of the single party ruling the country. The Council executives wield power over the elected councils in such situations (Moharir, 1986; Ayee, 1996). What is presented as decentralisation proves 
to be, centralisation of power, as the central government retains or even extends its presence and hold over the periphery. The so-called decentralisation sometimes appears as nothing more than the hidden extension of central control over local government. The latter may be strongly controlled by a centralised single political party or directed by the central government through policy directives, planning, financial control and/ or central personnel management (Moharir, 1986; Collins, 1989; Godinho, 1990; Ayee, 1996). What is formally decentralised in law or on paper is again re-centralised at the national level through such extra-constitutional mechanisms. This underlines the importance of a strong sustainable political commitment to counteract re-centralizing tendencies. Hence, it is necessary to examine empirically where in actual practice decisions are being taken: are they taken in the field or in the national ministries? Also for decentralisation the well-known proverb holds that the proof is in the eating of the pudding.

\subsection{Conclusions}

In this chapter, we discussed several conceptual issues related to decentralisation. Decentralisation has been used by different people to indicate different things. However, its common theme indicates a transfer of decision-making responsibility, resources and functions from the centre to the bodies outside the centre. The two major aims of decentralisation are to promote democracy and increase efficiency.

Decentralisation is a complex multidimensional process involving multiple processes at several levels and many actors. This complexity makes the implementation of decentralisation more a political game rather than merely an administrative process. 



\section{Chapter three \\ Towards an Analysis of Policy Implementation}

\subsection{Introduction}

In this study we aim at an empirical investigation of decentralisation in the public health sector in Sudan. More specifically, we seek an explanation for the poor experience with decentralisation so far. In order to conduct such a study, an analytical model is needed. The purpose of this chapter is to briefly examine the literature on policy making and implementation. Our examination results in the presentation of a model or framework that is derived from Grindle (1980). This model does not consider policy implementation as a mere technical process following policy formation, but emphasises its socio-political character.

\subsection{Public policy}

The literature available on public policy is very varied. Contributions come from different disciplines, particularly political science, public administration, economics, sociology, and management (Walt, 1996). Our purpose is to identify some of the main concepts that are relevant for our research objective in this study.

A public policy differs from private policy in the sense that a public policy is directed at the population at large or at a significant part of it. Furthermore, it is authoritative. In enforcing it, the state can use its authority. There are many definitions of public policy; nevertheless, there is a general agreement that a public policy is a statement of intent to solve or minimize a particular problem. A policy always involves a choice: it includes the declaration of one or more goals, plus the selection of some instruments of implementation to use in achieving those goals. A statement of intent that only defines goals but provides no guidance on instruments of implementation is not a policy but merely a dream.

Easton (1953) sees the process of public pollicy-making as a means of allocating values and resources: "A policy consists of a web of decisions and actions that allocate values" (Ham, 1992, p. 130). Decentralisation is an example of such a value. Easton uses values in a broad sense to encompass the whole range of rewards and sanctions that those in the position of authority are able to allocate. It is clear from Easton's definition that the study of policy examines both decisions and actions, thereby emphasising the importance of implementation.

The importance of action is also explicit in Anderson's view when he defines a policy as "a purposive course of action followed by an actor or set of actors in dealing with a problem or matter of concern" $(1975, \mathrm{p} .3)$. Thus, a policy is more 
than a single plan. As Walt states: "Policy is used to denote a series of more or less related activities and their intended and unintended consequences for those concerned, rather than a discrete decision" (1994, p. 41). The unintended consequences can be both desirable and undesirable. For example, a decentralisation policy may cement nation building or increase the tendency towards secession.

\subsection{Types of public policy}

The topic under consideration is concerned with the implementation of decentralisation in Sudan"s public health sector. This gives rise to the question: what type of policy is decentralisation? The literature on public policy presents various classifications of public policies. In our review, we will focus on three relevant classifications.

\subsubsection{Constitutional and substantive (sectoral) policy}

A constitutional policy is concerned with decision rules and decision structures. Who decides upon what? Who is responsible for what? Constitutional policies are about power distribution in society. Decentralisation is a typical example of a constitutional policy. By contrast, a substantive policy is concerned with the goals and instruments within a specific policy sector, for instance, health, education or the industry. A substantive policy may also be called a sectoral policy.

There are two points to consider. First, it is important to note that constitutional policy-making heavily influences substantive policymaking. For instance, it may be hypothesised that substantive policymaking on health in a decentralised structure will be different from policymaking in a centralised structure. The constitutional structure may also be restructured (centralised or decentralised) in order to move towards another way of substantive policymaking and to increase the effectiveness and legitimacy of substantive policies. A second observation is that the distinction between constitutional and substantive policymaking is not always clear-cut, because substantive policies often contain constitutional elements. For instance, a policy on vaccination will define decision-making procedures, a division of tasks, and so on. Nevertheless, one may argue that a constitutional policy is of a generic type. It defines a policymaking structure without reference to any specific policy sector. In other words, it cuts across various sectors in public policy-making and affects the entire population and other sectoral policies. By contrast, a substantive or sectoral policy, such as health policy or industrial policy only applies to the institutions, programs and individuals directly engaged in that sector. 


\subsubsection{High politics and low politics policies}

Walt (1994) classifies policies into high politics and low politics policies. High politics policies are concerned with the maintenance of core values, including national self-preservation, the protection of key interests and long-term objectives of the state. These policies affect everyone, particularly those in power. They are usually the domain of the highest government level and are often passed as laws by the legislature. In contrast, low politics policies are not involved in the fundamental issues or strategic interests of the state or with elite groups within the state. They are usually communicated through circulars or letters rather than through legislation. They are often considered technical and left to specialists to deal with.

In general, policies concerned with national security, major economic issues such as structural adjustment, decentralisation or land reforms are considered high politics. Health policies are viewed as a low politics issue in developing countries. High politics policies get considerable attention from the senior political executives and other political leaders as well as the legislature, interests groups, media or research scholars. Low politics policies, such as public health policy, are often created in much oblivion, out of the glare and gaze of the media and society at large. Although public health should be very important for everybody as it affects each and every individual, its overall importance in the governmental hierarchy of developing countries is generally very low.

It is evident from studies in developing countries that in terms of political significance the ministry of health tends to be near the bottom of the governmental hierarchy. The Minister of Health is commonly low in prestige and resources, both financially and politically (Foltz, 1996). His or her low prestige and the concurrent low political visibility of the public health sector mean that the formulation and implementation of a far-reaching change in health policies require additional high-level political and administrative support. Thus, unless senior political leaders like the President or Prime Minister take a personal interest in it and at the administrative level strategic ministries like the Ministry of Finance or Ministry of Planning give their active support, the realisation of public health policies becomes difficult. In Sudan, the Minister of Health has to invite the President of the country to patronise programs like child immunization or malaria eradication to get visibility and wider political and social support.

\subsubsection{Distributive, redistributive and regulatory policies}

The distinction between distributive, redistributive and regulatory policies has received considerable attention of research scholars in public policy. The distinction was originally developed by Lowi (Cobb \& Elder, 1983) to emphasise the impact of the type of policy upon the policy process. A distributive policy is one, which provides benefits like health and education services to all or some groups in the society without taking them away from others. A redistribution policy 
deals with reallocations of costs and benefits: there are always winners and losers. A regulatory policy deals with legislative intervention in the form of laws regulating the behaviour of individuals and social groups.

Distributive policies are generally relatively easy to implement. Political conflicts tend to be limited. Redistributive policies on the other hand are often difficult to implement; they face considerable opposition from those whose vested interests are affected adversely. The implementation of regulatory policies depends upon the type of behaviour being regulated. A policy like compulsory family planning may be opposed vehemently by a religious and conservative society, whereas speed limits on driving of cars may be more willingly accepted.

\subsection{Public health policy}

A public health policy is one that addresses health problems. However, the term health itself has many definitions. In the past health was used to be defined negatively as the absence of illness or disease. In 1947, the WHO defined health positively as: "a state of complete physical, mental and social well-being and not merely absence of disease or infirmity" (WHO, 1978). Given this definition of health, it is clear that health policy is not exclusively related to medical care. Walt iterates this view in her following definition: "Health policy embraces courses of action that affect the set of institutions, organisations, services, and funding arrangements of the health system. It goes beyond the health services to include intended and unintended actions by public, private and voluntary organisations, which have an impact on health" (Walt, 1994, p. 41). This means that a health policy is not only concerned with medical issues and health care delivery but also with the impact of environmental and socio-economic factors upon health. The causes of many health care problems such as poverty and malnutrition conditions may lie in sectors other than health. Therefore, Decker (1989) defined health policy as "a policy aimed at maintenance or improvement of the health status of (part of) the population through the employment of means aimed at the determinants of health (including the health care)" (De Leeuw, 1989).

The shift from a limited biomedical technical view to a comprehensive sociopolitical process has affected the content of health policies. This is clearly illustrated by the emergence of the concept of Primary Health Care (PHC), which includes services such as the promotion of food supply and proper nutrition, an adequate supply of safe water and adequate sanitation. It requires the involvement of all related sectors and various aspects of development such as agriculture, food, industry, education, housing, public works, communications, et cetera. Furthermore, PHC relies on community involvement and participation, as well as the involvement of all kinds of paramedical professionals like midwives, nurses and traditional health practitioners. In addition, it involves decentralisation as a strategy (WHO, 1978). 


\subsection{The stages of the policymaking process}

The policymaking process is often divided into three phases: policy formulation, policy implementation and policy evaluation. Some analysts even propose six stages in the policy process: initiation, estimation, selection, implementation, evaluation and termination (Bratton \& Rothschild, 1992). These divisions suggest that, conceptually, a policy process can be visualised in different stages. However, in reality these stages overlap; often there are no clear dividing lines. Some stages may be skipped altogether. Others may occur simultaneously, as when a policy is implemented and modified at the same time (Foltz, 1996). Implementation may have a significant impact upon the content of a policy. In other words, it is too simplistic to say that the content of a policy only depends upon the formulation stage. Policies are commonly shaped during formulation and implementation (Brewer, 1973).

\subsection{An analysis of the policymaking process}

Policymaking can be conceptualised as a problem-solving as well as a sociopolitical process.

\subsubsection{The problem solving perspective}

From the problem-solving perspective, emphasis is put on seeking a technical and optimal (rational) solution to a policy problem. The policymaker must present a structural analysis of a problem, define goals, set priorities, identify alternative instruments to use in achieving those goals (that is, to solve the problem), and then to select the best approach. The problem solving perspective is linked to the rationalist tradition in policymaking. It is the domain of experienced technocrats who are well-trained in a rationalist approach to policy problems (Lyden \& Miller, 1972).

The problem solving approach has always played a prominent role in health policymaking (Foltz, 1996). This may reflect the influence of epidemiologists and economists in health planning at the expense of analysts from the social sciences such as political science, sociology, and anthropology (Walt \& Gilson, 1994). Moreover, the technical orientation of health policy plays a role in giving it an apolitical image in the developing countries (Walt, 1996). Health policy is often seen as largely uncontroversial. It is treated as a low politics issue on the political agenda and considered the domain of the medical profession.

\subsubsection{The socio-political perspective}

From a socio-political perspective, policymaking is viewed as a political process where agencies with different interests seek to retain or enlarge their power base. 
Policy decisions do not simply reflect the best solution to a problem, but are instead heavily influenced by political interests and the power balance (dominance of medical doctors in the health field) in the policy-making arena. Political bargaining predominates over problem-solving. Private interests and power struggles also hinder policy implementation. The overall political context (e.g. stability and ideology of the political regime) and the social context (e.g. the prevalence of corruption or the illiteracy of the population) also heavily influence policymaking. Policy implementation is not understood as a technical process following the politics of policy formation but, alternatively, as the continuation of the policy formation process in another setting with sometimes other agencies. Of course, technical issues may turn out to be very important during implementation. Thus, policy implementation includes both technical aspects and sociopolitical aspects (Barrett \& Fudge, 1981).

The socio-political perspective is connected with Lindblom's model of incrementalist decision-making in policymaking. Incrementalists assume that decisionmaking is an interactive process of mutual adjustment and that the way decisionmakers really make decisions is by looking at the general problem and adjusting their responses to those of other actors. The decision-making process is incremental. It does not start with objectives, but begins with what already exists and where one can go from there (Lindblom, 1959). Policies are also incremental because they often require political compromises between different values and individuals in society (Segalï, 1983).

The incremental view of the policy process has gained considerable recognition for the simple reason that it appears to describe most aptly what decision-makers actually do. It also casts some shadow on the validity of the more mechanical approaches of the rationalists.

\subsection{Policymaking in developing countries}

The study of policymaking in the developing countries is quite limited. The bulk of the policy literature deals with experiences in western political systems. The application of the conclusions of this literature to developing countries needs adjustment, as there are factors unique at work here such as the dominance of the ruling elites, charismatic leadership, ethnicity and tribalism, great scarcity of resources and backwardness (Ellis, 1996). Consequently, in developing countries the policy enviromment is quite different from that in industrialised countries (Grindle \& Thomas, 1991). Few developing countries have consistently practiced democracy. Interest groups are less visible in policymaking and policy implementation. The political and administrative environment of policymaking in developing countries is fragile and vulnerable to political instability. The survival of civil servants is not dependent on competence and neutrality, but on the main- 
tenance of strong patron-client relationships that cut across bureaucratic structures.

In developed countries, the activities of public officials and their commitment to policy change are often determined by the particular way in which societal interests are organised and articulated. This perspective is difficult to apply in many developing countries, where votes and lobby activities are not useful currencies for converting societal preferences into public policies (Grindle \& Thomas, 1991). Many policies may never be discussed outside the halls of government. In such countries, a model of policy change that takes the activities of organised interests in society as a starting point may be misleading. In fact, in many developing countries, interest groups are not well organised and do not put effective pressure upon the policy elite. Often, they do not even have access to the policymaking process. The elite, comprised of military rulers, technocrats, dominant politicians, professionals, and bureaucrats, dominates the policy process. The policymaking process is usually highly centralised, as all these elites are concentrated in the centre or hold power at the local level. Policies are formulated to serve the interest of these groups, and, consequently, neglect the community opinion. Sometimes, the elite introduces ambitious policies to gain the willingness of the community to support their legitimacy, despite the elite's awareness of the impossibility of realising such policy goals (Mawhood, 1984).

\subsection{Policy implementation}

Policy implementation in simple terms is to put policy into action. Implementation may be defined as the ability to forge subsequent links in a causal chain so as to obtain the desired results (Strauss, 1978). It involves the operationalisation of the policy and the creation of 'a policy delivery system', in which specific means are designed to arrive at particular ends (Van Meter \& Van Horn, 1975, p. 446). Implementation is an important part of the policy process: without implementation a policy will not realise its goals. In the real world there often appears to be a major gap between formulation and implementation (Stewart, 1991). Most governments do not have efficient procedures for policy implementation or even completely neglect this phase during policy formation. Conflicts in policy formation are solved by a compromise formula that leads to a continuation of the political struggle during policy implementation (Grindle, 1980). Another key issue is, of course, that policy makers usually neglect to create the basic conditions for effective implementation. That is, they do not care about whether the prerequisites for effective implementation, for instance in terms of financial and human resources, have been sufficiently met (Rondinelli, $1981 \mathrm{~b}$ ). 


\subsubsection{The linear approach to policy implementation}

The linear approach to policy implementation is related to the problem solving rational perspective. It perceives the policy process as linear with a clear dividing line between policy formulation and policy execution. This approach conceptualises policy formulation as a political process concerned with values and with what government feels it ought to do. Implementation, on the other hand, is perceived as a managerial or administrative process. In this approach, it is assumed that policy formulation occurs within the national government or at the international level between donors and national policy makers. Policy implementation is conceptualised as being a largely technical and politically neutral process at the national and sub-national level. In the case of health policies, decisions by politicians and bureaucrats within the Ministry of Health are communicated to planners in the health-planning unit (who may or may not have been involved in policy formulation), who operationalise them into appropriate programs and guidelines. These are transferred then to the health authorities at the provincial or district level or to health care institutions (hospitals or health centres) to be executed (Walt, 1994). This approach draws upon an ideal model of "perfect implementation".

In this managerial perspective the problems of implementation are defined in terms of co-ordination, control or obtaining compliance with policy. Such a policy-centred or top-down view of the process treats the implementers as agents of the policy makers and tends to play down issues of power relations, the pressure placed on implementers by local groups, and the conflicting interests of the agencies responsible for policymaking and those responsible for execution.

Despite the conceptual problems of this model, it is widely used in implementation studies (Grindle \& Thomas, 1991). Many international agencies have widely used the linear model in their explanation of unsuccessful policy implementation. Hence, they emphasise the importance of strengthening the implementing agencies. Evaluation studies of decentralisation have also followed this linear approach to policy implementation for a long time (Bossert, 1996; Olowu, 2001).

\subsubsection{The interactive approach}

In contrast to the linear view of the policy process, the interactive model views the implementation as a complex and interactive process in which the implementing agencies have influence on the policy being executed. This approach is strongly linked to the socio-political perspective on the policymaking process (Stone, 1997). It considers policymaking as an evolutionary interactive phenomenon. As such, policy implementation is an ongoing process of decisionmaking by a variety of actors. The ultimate outcome of a policy is determined by the content of the program being pursued and by the interaction of the implementing agencies within a politico-administrative context. Policy formation and 
policy implementation are interdependent and the analyst must consider them in combination at all times (Fudge \& Barrett, 1981; Hogwood \& Gunn; 1984; Walt, 1994). Thus, in the interactive approach, the implementers may change the design of the policy or redefine the objectives of the policy to bring it closer to the problem and local situation. In this perspective, the policy-action relationship should be regarded as a process of interaction, conflict, and negotiation, which takes place over time between those seeking to put the policy into effect and those upon whom its execution depends on (Fudge \& Barrett, 1981). Grindle and Thomas (1991) indicate that implementation is often the most crucial phase of the policy process and that the outcomes of implementation efforts are highly variable, ranging from successful to unsuccessful. This range of outcomes results from the fact that implementation is an interactive and ongoing process of decision-making by the policy elite, managers and target population. Decision makers and implementing agencies inevitably face opposition in bringing the reform initiative into practice. Consequently, it is important to consider the feasibility of change in terms of support and opposition. We take the position that the policy implementation is an interactive process that involves both political and administrative processes.

\subsection{Towards an analytical model of policy implementation}

Earlier in this chapter, decentralisation was conceptualised as a redistributive policy. Decentralisation redistributes power. The implementation of such a policy not only involves technical and administrative issues. In many respects, it is a socio-political process, as well. Due to this mixture of technical and sociopolitical aspects we will use Grindle's model (1980) of implementation for our empirical investigation (see figure 3.1). It is an interactive explanatory model, which places emphasis upon unravelling the dynamics of implementation through an analysis of the operationalisation of the policy at different levels of government. The model consists of the following blocks:

o An analysis of the policy goals and the action programs to achieve these goals.

- An analysis of the factors that affect implementation. Here a distinction is made between the content of the policy and the context of implementation.

- An analysis of the policy's outcomes.

We will elaborate further on each block in the subsequent sections. 


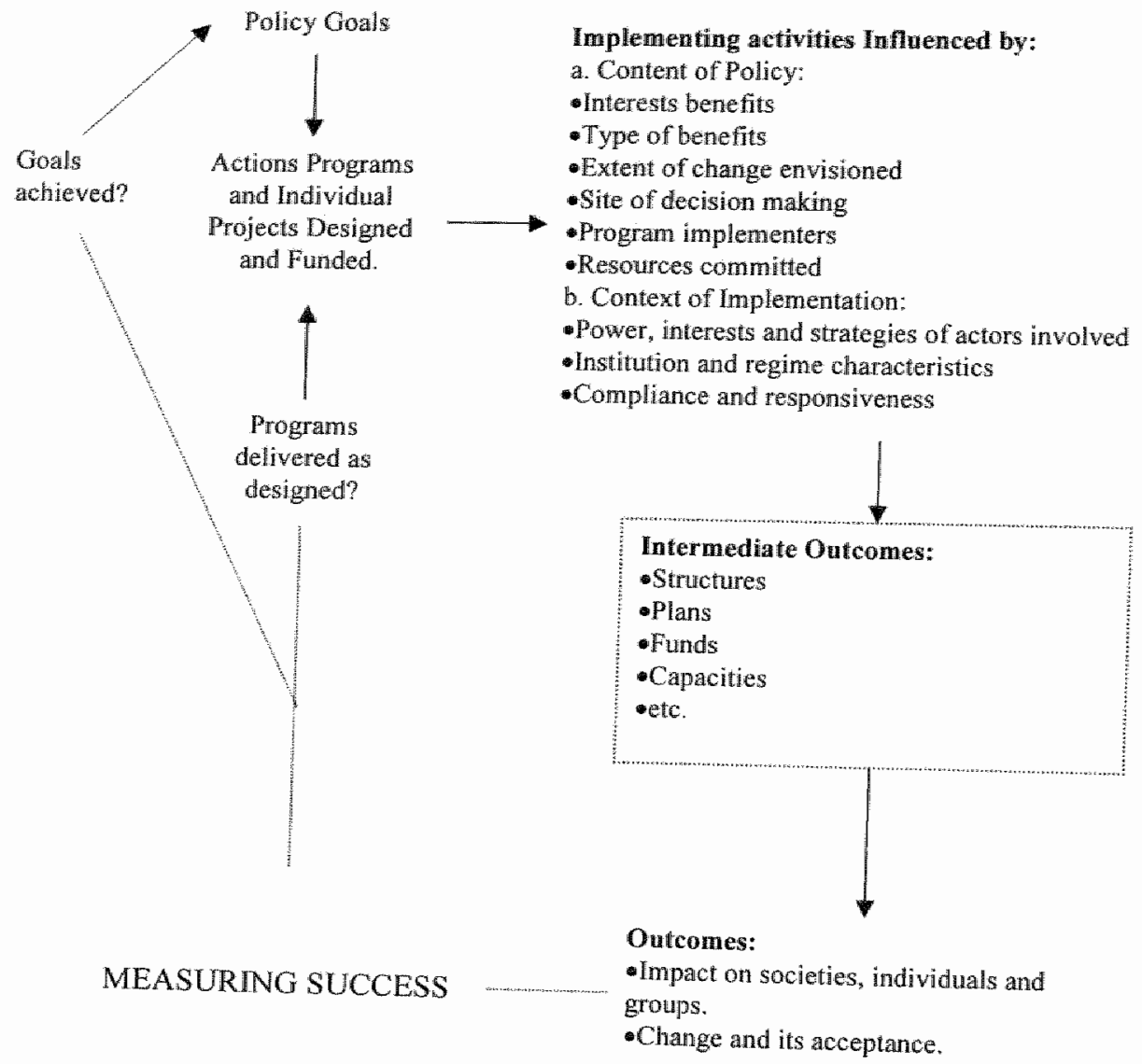

Source: Grindle, 1980.

Clarification: the intermediate outcomes are added to the original model.

\subsubsection{Policy goals and action programs}

As we stated earlier, our conviction is that a clear demarcation between policy formulation and policy implementation is illusory. Policies not only shape implementation, but implementation also shapes policies. The final product is only partly influenced by political decision-making in the stage of policy formation. The way that a policy is executed is also an important factor.

Grindle postulates that the goals and action program of a policy form a startingpoint for an empirical investigation of policy implementation. In order to study the implementation process, we must first have a clear idea of what should be 
Viewed from an implementation perspective, several observations can be made about policy goals and action programs. Policy implementation often turns out to be a neglected issue. That is, policymakers do not develop a plan of action to achieve their goals. They seem to believe that policies are self-executing, but that is not a correct attitude. This seems to be particularly true of the developing countries where policies often appear mainly verbal statements without concrete action. In taking this approach, policymakers do not create sufficient conditions for effective implementation. In our view, systematic attention to policy implementation in the stage of policy formation is a prerequisite for the successful implementation of any policy. Logically this means that policy formation must be based upon a proper situational analysis, which considers power relations, the availability of required political, administrative, technical and financial resources, and the overall feasibility of the policy.

One of the decisions made during policy formulation is who is to be charged with the execution of programs. Such decisions can affect how a policy is pursued later; for example, there may be great disparities in the capacity of various bureaucratic agencies to manage the program successfully. Some will have greater expertise and more dedicated personnel than others. Moreover, variations in resources between the different geographical areas will influence the implementation process.

Policy goals are often vaguely formulated. The consequence of this is that they must be interpreted by the agencies involved in implementation. This may inevitably lead to distortions, the more so because the implementing agencies will have their own particular interests and policy goals. Policy goals may also be conflicting, which inevitably gives rise to a continuation of political struggles during policy implementation.

Another important prerequisite for effective implementation is that the implementing agencies are properly informed about the content of the policy and what they are expected to do. Unfortunately, however, it often turns out that implementation is heavily affected by information problems. Consequently, implementing agencies simply do not know what they should do in implementing the policy. This can lead to a "wait and sea" approach.

In the next chapters, we will see that all these problems were present in the implementation of the federal decentralisation policy in Sudan. This constitutional reform was quite a complicated process from an implementation perspective, but the political decision makers did not consider the implementation issues in much detail. A clear implementation strategy was entirely missing, to such an extent that the policy was not properly designed. 


\subsubsection{Policy content and implementation}

According to Grindle, several aspects of a policy's content may have a significant impact upon policy implementation and, subsequently, on policy outcomes. We will briefly discuss each aspect.

\section{Interests affected}

Public policies aim to introduce changes in social, economic and political relationships: these changes affect the interests of individuals and groups. Hence, they may trigger opposition from those whose interests are adversely affected. A decentralisation policy transfers financial, human and political resources from the centre to the lower level in government against the vested interests of the central political and bureaucratic elites. To preserve their interests, the elites usually resist the policy or, at the very least, do not support it wholeheartedly (Chikulo, 1989). Unless the policy is strongly supported by the political leadership, it has only a small chance of being realized. Developing countries have experienced a strong opposition to decentralisation and sometimes re-centralization due to the lack of support from officials in charge (Moharir, 1986). On the other hand, a policy may affect some groups in a positive way. The political and administrative elites at the local level may have more access to decision-making, training, and resources; consequently they will be more motivated to support decentralisation.

\section{Type of benefits}

The type of program determines to a large extent the feasibility of its implementation. If the program includes the distribution of a collective good such as provision of immunisation for the whole community, it will be easier to implement than a program that only provides benefits to specific target groups. The latter programs often trigger competition and conflicts.

If the benefits to the population are long-term, they may not be clearly visible. For example, the reorganisation of primary health services will lead to greater accessibility to care in the long run but not in the short term. Thus, the public may benefit over the long term from reorganisation of a ministry or the creation of a PHC system, but the immediate direct impact is felt by officials, health managers and professionals who have to change their behaviour, and rules, as well as relinquish accustomed forms of control and responsibility.

In the case of opposition from within the bureaucracy, implementation may be delayed or even aborted. Administrators are likely to feel the costs long before the public recognises the benefits. Unless policy makers (politicians) can mobilise countervailing support for the policy in the public arena, it is unlikely that the policy will be implemented as intended. If the policy needs a short duration for actual implementation, it will have a better chance of success because it is less likely to encounter organised resistance or the entrance of new actors in the proc- 
ess, leadership changes and so on. Rapid implementation of the policy means that interest groups are somewhat taken by surprise, and have little time to organise their opposition to the policy. The visibility of the reform may affect public reaction too. If a policy change does not require major administrative resources or high technical skills to sustain it, it is more likely to be implemented.

\section{Extent of change envisioned}

The type of change required by the policy is an important factor in implementation. For instance, if the policy targets a change in strongly held cultural values like the introduction of family planning in religious groups, it will be quite difficult to implement. Similarly, a policy with long-term objectives is more difficult to implement than a policy with short-term objectives. An example of this in the public health sector is the tendency for the curative service facilities to receive the enthusiastic support of the community, while the sanitary and preventive health activities receive little support. When the policy involves major macro or systemic decisions aimed at the introduction of changes in the social, political, and economic relationships and behaviour, it may be difficult to implement them due to stiff resistance, particularly from adversely affected interest groups. Even with micro sectoral policies, governments will be cautious on introducing such policies if they anticipate strong reactions. If the new policy requires only a marginal change from the status quo, the risks of error are far less. Certain interests are likely to be less affected, the amount of information needed is smaller and capital and other costs are generally lower. All these parameters affect the probability of successful implementation.

\section{Site of implementation}

The content of a policy influences the site of its implementation. Typically in decentralisation, policy implementation involves many actors at different government levels. This necessitates a high degree of coordination to implement the policy effectively, which often appears very difficult. This point is illustrated by Walt (1994) in her study on the legislative change of children's homes in Uganda. She found that six ministries and a number of NGOS (Nongovernmental organizations) were involved in the implementation process. The multiple agencies proved to be a source of great coordination problems that could not be effectively overcome. If the number of implementing agencies is limited, the policy implementation will be relatively easier.

\section{Implementers}

Implementation performance depends upon the background, orientation, capacity and commitment to policy objectives of the individuals and agencies charged with policy implementation. As we have highlighted, in decentralisation the implementers (implementing agencies) are at different levels of government and 
their capacities, skills, dedication and commitment may differ greatly. Some agencies are politically supported and have good access to resources: others lack such support and access and sanctions for implementers to use in accomplishing the policy change.

\section{Resources committed}

The policy type and content determine the type and the amount of resources allocated to policy implementation (Grindle \& Thomas, 1991). The resources required for implementation can be political, financial, managerial and technical. In the case of decentralisation, all of these resources are required. In developing countries, however, they are often not available (Mukwena, 2001).

In a situation of political uncertainty or instability, financial resources are usually very limited. For instance, in Uganda, communities and health workers emphasised that the low salaries had a significant effect on the quality of and accessibility to the health centres, because health workers were often absent from their posts in search of alternative sources of income (Macrae, Zwi \& Birungi, 1993).

\subsubsection{Policy context and implementation}

The policy context or environment is the arena in which a particular policy process takes place. Generally, the environment consists of institutional and individual actors, interest groups as well as the citizenry. The actual policy environment differs from country to country depending on its form of government and also varies according to the content of the policy concerned. The influence of the policy context on the implementation process has been acknowledged by several authors (Anderson, 1975; Grindle, 1980; Thomas \& Grindle, 1991; Wait \& Gilson, 1995; Barker 1996). Despite various definitions of the context, almost all these scholars give the social, the political and the economic environment a prominent place in the definition of the policy context. For Grindle, the policy context includes the power, the interests and strategies of the actors involved, the institution and regime characteristics as well as compliance and responsiveness. We will briefly elaborate each of these factors.

\section{Power, interests and strategies of actors}

In Grindle"s model there are many actors, including implementers (implementing agencies) who take decisions on the implementation strategy, the selection of program activities and the allocation of resources. By doing so, they try to influence the implementation process. These actors involve national level planners, national, regional, and local politicians, economic elite groups, recipient groups, (especially at the local level), and bureaucratic implementers at the senior, middle and lower level. They may be intensely or marginally involved in the policy implementation, depending on the content of the program and the form in which it is administered. Each of them may have a particular interest in the program and 
may try to secure his or her interests by making demands on the allocation procedures. This frequently results in conflicts, the outcome of which is determined by the strategies, resources, and power position of each of the actors involved. The policy that is finally implemented, may therefore be the result of a political calculus of interests and groups who have been competing for scarce resources, the responses of implementing officials, and the actions of the political elite, all interacting within a given institutional context (Grindle, 1980). Analysis of implementation of a specific policy, therefore, needs to consider the power capabilities of the actors involved, their interests and strategies for achieving them, and the characteristics of the regime in which they interact.

\section{Institutions and regime characteristics}

The political regime is one of the most important factors influencing the policy process, and implementation in particular, especially in policies like decentralisation. The type of political regime determines the policies that will be preferred, how far participation in policymaking will be encouraged and who will be the main beneficiaries. While liberal democracies encourage direct and indirect participation, authoritarian regimes formulate their policies with very little public involvement (Walt, 1994).

The political regime determines the most vital elements of the policy process, namely financial resources and legislative power. Through these two factors the regime determines the level of autonomy that local bodies enjoy. Some regimes launch certain policies to gain popular support to substantiate their legitimacy. However, they know that the probability of successful implementation is negligible. In addition, regime characteristics largely influence the manner in which the institutions and organisations of the state will function. In open liberal democracies, institutions are required to function within the framework of the constitution and law and are evaluated on the basis of their transparency, accountability and commitment to pollicy objectives. In authoritarian regimes, on the other hand, the survival and fortunes of institutions depend above all upon their loyalty to regime philosophy and leadership. In such regimes, there often exists a big gap between the formal legislation and the actual performance of these institutions. Most institutions lack sufficient funds, adequately trained staff and substantive authority to realise policy objectives. Consequently, there is a phenomenon referred to as institutional devaluation.

\section{Compliance and responsiveness}

Implementation of complex policies like decentralisation involves far-reaching programmatic and behavioural changes such as giving up control over programs, resources, and patronage. Implementation of such policies also involves a proacm tive approach on the part of central and state government institutions to help the weaker groups and disadvantaged states, which need preferential treatment to secure resource allocation and build capacity. This process calls for the compliance 
of the civil servants, external funding agencies and NGOs. Implementation of policies like decentralisation also involves the compliance of the public at large and specific groups. Compliance here involves not only obeying laws and paying taxes, but also participating in local level decision-making.

The other aspect of importance is the responsiveness of the policy actors to those who are supposed to benefit from the policy. Sometimes, due to hasty action, unawareness or underestimation, politicians and administrators introduce policies that are not acceptable to communities simply because the population does not feel that these policies are beneficial to them. Regime characteristics may also influence the compliance and responsiveness of actors involved. In democratic societies the compliance with laws and policies of its citizens and administrators often does not appear to be a serious problem. In authoritarian regimes, it must often be enforced through coercion and will not be easy to sustain.

\subsubsection{Outcomes}

The final part of Grindle's model is concerned with the outcomes of a policy. Policy outcomes depend upon how the policy has been implemented. An analysis of outcomes can be restricted to the question to what extent the declared policy goals have been achieved. The researcher can broaden his/her analysis in various ways. One way is to investigate how the outcomes are appreciated by the beneficiaries of that policy or by the actors involved. Another way is to investigate the unintended outcomes of the policy. These outcomes may be expected or unexpected and may be considered positively or negatively depending upon the criteria being used.

Furthermore, it is helpful to make a distinction between the intermediate and ultimate outcomes of a policy. Intermediate outcomes refer to the process of implementation. They measure the way a policy is implemented. For instance, if policy implementation requires the introduction of the new planning system or a fundamental reorganisation of the Ministry of Health, a researcher can investigate to what extent the introduction of the new planning or the reorganisation have been really put into practice. In the literature, the intermediate outcomes are also referred to as policy performance or policy output (Van Meter \&Van Horn, 1975).

\subsection{Implementation as the link between policy formation and policy impact}

The success of a policy can be evaluated on the basis of its ultimate outcomes, in particular the extent to which the intended outcomes (declared policy goals) have been realized. An evaluation of a decentralisation policy can be conducted with reference to the realisation of its objectives. The objectives may include the ac- 
tual shift of decision-making power from the capital to the periphery, the use of autonomy by decentralised units in favour of the welfare of the local population, the effective and efficient delivery of services to the people, and the participation of local population in local level decision-making.

Many of the above-mentioned outcomes take a long time to materialise. Alternatively, one can assess the possible outcomes of decentralisation by analysing the intermediate outcomes of implementation. Analysing how the policy is operationalised during implementation through planning, organizing and reorganizing, capacity building and resource allocating in different programs and projects will give us a good picture of what the ultimate outcomes are likely to be. If the implementation fails, it is very unlikely that the policy will achieve its objectives. Thus, an evaluation of implementation process is performed by investigating the intermediate outcomes as an estimate of the ultimate impact (outcomes) of federal decentralisation upon the public health sector in Sudan.

\subsection{The organisation of the study}

This study presents an analysis of the implementation of federal decentralisation in the public health sector. This analysis will be conducted at three levels, namely the federal level, the state level and the local level. We first analyse implementation at the federal level. The results of this implementation process (intermediate outcomes) will influence the content and context of implementation at the state level. The second step consists of an analysis of implementation at state level. The outcomes of this process will influence the content and context of implementation at the local. The analysis of implementation at the local level is the third level of analysis. The organisation of this study is visualised in figure 3.2. 
Figure 3.2 Framework for analysis of policy implementation process

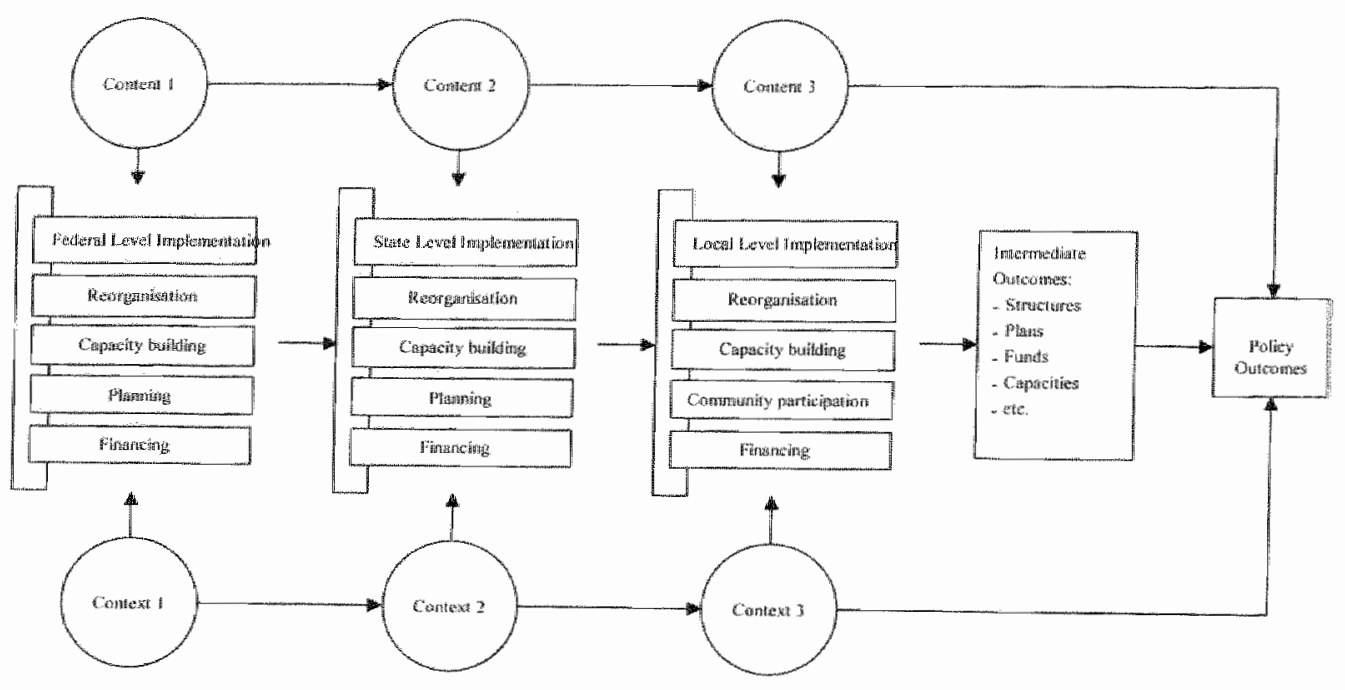




\section{Chapter Four \\ The History of Decentralisation in Sudan and its Impact upon Health Policymaking}

\subsection{Introduction}

Decentralisation has been a preoccupation of all regimes that have ruled Sudan throughout its modern history. During the English colonisation (1898-1956), the colonialists used the indirect rule with involvement of the tribal chiefs to practice a kind of deconcentration, and since 1945, Sudan has witnessed a remarkable alternation between various forms of decentralisation (Norris, 1983). Since Sudan's independence the main legislation on decentralisation includes the Local Government Ordinance of 1951, the Provincial Council Act of 1960, the Local Government Act of 1971, the Regional Government Act of 1980 and the Local Government Act of 1981 . These are all summarised in table 4.1, which can be found after paragraph 4.6 .

However, implementation of decentralisation under these acts was unsatisfactory in terms of the actual shift towards devolution, community participation and development (Fadalla, 1996), despite the valid the conclusion of the Milner Report in 1891 that a centralized bureaucratic government is absolutely unsuitable for Sudan (Howell, 1974). Even during the Military regime (1969 - 1984), President Nimeiri (1971) confirmed that the administration of Sudan from its capital Khartoum was practically impossible. His policy of more or less self-rule for the South and regional autonomy for the North continued until the introduction of the current federal system in the Act of 1991(Act of 1991). The type of decentralisation seen in each period also affected the decision-making pattern in the public health sector. In this chapter, we will briefly review the main stages of decentralisation in Sudan and consider their impact on the public health sector.

\subsection{The Local Government Ordinance of 1951}

In 1946, the English colonialists adopted the system of indirect rule through tribal chiefs to manage the country. After a period of practice, an English expert in local government dr. Marshall was invited to report on the policy and practice of local government in Sudan. He recommended the formation of elected autonomous local councils, based upon the British model. Marshall's belief in local councils rested upon the value of a multipurpose authority, large enough to carry out primary local services, yet sufficiently small to permit local participation in a meaningful sense. He accepted the continuation of the role of the traditional leaders and the native administration, although he also recommended their 
gradual exclusion from management in the long term. Thus, his approach was both pragmatic and incremental (Mawhood, 1993).

The Local Government Ordinance of 1951 translated his recommendations into government decisions. A Ministry of Local Government (MOLG) was created to act as a clearinghouse in the central government for local affairs. The new Ministry was given the task of coordinating the work of the field administration of all central ministries and of acting as the representative of the national government in the development and supervision of local government authorities in the country. Local councils consisted of town councils in urban areas and district councils in rural areas. These bodies were the main structure for popular participation. Local councils had their own financial resources and staff to provide important local services and to implement laws at the local level (Bakheit, 1974). The provinces mostiy operated as a coordinating intermediate level. Their main function was to deal with security and to carry out some other tasks delegated to them by central ministries.

The local councils gradually developed their responsibility for local affairs including the election of the chairmen. Each council had subcommittees to carry out its tasks in finance and personnel, planning, education, public health and other fields. Local Councils were also involved in carrying out other tasks prescribed by the Ministry of Local Government. They were offered some resources to enable them to carry out their tasks effectively. These resources included tax funding by the government, local taxes, charges, dues and fees, which were lawfully payable and grants-in-aid for specific services in which the central government had special interest.

The local councils were staffed by locally recruited personnel and others seconded from central cadres in the more senior posts. Considerable functions and powers were transferred to these councils. The independence in 1956 did not disrupt this development and by 1960 over eighty local councils had acquired full status with a substantial range of powers. The Abu-Rannat Commission, which was installed to examine the overall lack of coordination within the provinces, particularly between the local councils and the central government field agencies at the locallevel, confirmed the appropriateness of this structure in 1960 (Howell, 1974).

Although the local councils still received official support after independence, they operated with declining effectiveness. Rapid indigenisation (replacing centrally seconded personnel by local ones) of the central civil services deprived them of experienced and sympathetic tutelage. In addition, public demands, created by the modernisation of services, far outstripped resources. The weaknesses of local councils increased their dependency upon the centre. This tendency was further encouraged by numerous personality-oriented political parties competing for support by making extravagant promises (Fadalla, 1979). 


\subsection{The Provincial Administration Act of 1960}

In 1960, the Provincial Administration Act was introduced to solve the problems addressed by the Abu-Rannat Committee. The Act aimed to strengthen the role of provinces to provide an intermediate structure, which was capable of coordinating government activities in the province. The Act established a Provincial Council and a Provincial Executive Authority in each province. The council operated as a semi-elected body with 40 members including the departmental heads within the province as ex-officio members (Republic of Sudan, 1961). The Chairman of the Provincial Executive Authority, who was ex-officio a representative of the central government. He was appointed by the Supreme Council of Armed Forces and responsible for the good government of the province as well as the coordination of all activities of the government in the province (AlTeraifi \& Idris, 1987). From this brief description it is obvious that the Provincial Government Act of 1960 when compared to the Local Government Ordinance of 1951 was a move in the direction of centralisation.

The Provincial Councils were held responsible for the promotion and supervision of local authorities in their area as well as for the passing of the annual budget of the Local Councils. They were recuired to deliver a number of local services such as education, health, agriculture, welfare and public works. The rest of public affairs in the province were under the direct responsibility of the central ministries.

The Provincial Authority was the executive body in the province. It consisted of senior representatives of the national ministries and provincial departments under the chairmanship of the Provincial Commissioner who had to report to MOLG. The members of the Provincial Authority were held accountable by the Provincial Council for their actions. The Provincial Councils received their revenues from the central government; furthermore, they were empowered to levy taxes, charges or dues to supplement their revenues.

This administrative structure survived until 1964 when the military regime was succeeded by a multiparty one. The new government abolished the Provincial Councils and entrusted all their powers and functions to the Provincial Authority. The Chairman of the province, known as Commissioner, was made responsible for the maintenance of law and order in the province. He was accountable to the Minister of Interior (Sudan Ministerial Council, 1964). Despite these changes in the Provincial Act of 1960 , the Province was retained as a basic area authority with its own revenues.

\subsection{The People's Local Govermment System (1971)}

In 1969 the May Revolution regime led by Nimeiri gained power through a military coup. The army attempted to overhaul the local government structure and 
focused on the Province as the primary unit through which to achieve more decentralisation. The aim of the new regime was to bring the revolution to the grass-roots level, thus promoting an ambitious program of economic and social change by encouraging public participation in government (Bakheit, 1969). However, as in the approach of the other one party regimes, participation had to take place within the framework of a single party. The system strengthened the role of women, excluded the influence of conservatives, and ensured predominant roles that were played by supporters of the Revolution and the regime. Thus, decentralisation came under full political control.

The new structure consisted of a pyramid of more than 5000 rural and urban councils, a substantial increase when compared to the earlier 87 municipal, town and rural councils that existed before in the entire country. All local councils were placed under the People's Provincial Executive Council (PPEC), which was established in each province. This Council consisted of representatives selected by local councils, occupational groups and senior public officials in the provincial administration. The PPEC had a broad range of legislative powers over provincial and local administration. It was the only body in the province with corporate status and financial autonomy at the sub-national level. The corporate status of the local councils was abolished. The PPEC reviewed the provincial budget before it was submitted to the national government and also had to approve the local governments' budgets. It was empowered to propose development projects and to recommend national policies to the President, relevant ministers and the People's Assembly. Furthermore, it was allowed to delegate power over social and economic services to local councils and to authorize them to levy some taxes and other revenues (Ministry of Local Government, 1971; Bakheit, 1971). This process meant decentralisation from the centre to the province but recentralisation from the local councils to the province, thereby abolishing rural and local district autonomy.

The functions delegated to the PPEC included education, public health, agriculture, community development, livestock, minor public works, housing and social welfare. The Commissioner, appointed by the President, headed the political, legislative and administrative authority in the province. He was responsible for planning, integrating and directing the public services devolved to the province. He was also the head of the provincial branch of the Sudan Socialist Union, the only political party allowed to function. Within the hierarchy of authority, the former Local Councils lacked independent financial and human resources and became largelly dependent on what the Provincial Councils were prepared to allocate (Davey, Gleutworth, Khalifa \& Idris, 1976). In practice the new administrative arrangements negated twenty years of experience acquired in building up the local councils as useful autonomous units.

Under the 1971 Act the national Ministry of Health lost many of its functions to the provinces. In practice, however, these functions came under the control of 
MOLG, which approved all provincial budgets and to which the provincial Commissioner had to report. This development was opposed by other central ministries. To reduce its tremendous centralising influence, the MOLG itself became a target for change. During the twenty-two years (1954-1976) of its existence, the MOLG exercised close control over local authorities. However, it was neither able to secure a reasonable share of national resources for local authorities nor was it in a position to protect them from their functions being stripped away from them by central government departments (Norris, 1983). In 1977 the MOLG was dissolved, and at the same time a new Office of Local Government Affairs with a reduced staff and only a limited coordinating role was attached to the President's office. Most of its other powers were transferred to the PPEC. To demonstrate the President's commitment to decentralisation, seven other central ministries were abolished in 1979. The functions of these ministries were transferred to the Provincial Authority. In addition, four other ministries including $\mathrm{MOH}$ had their powers reduced, while the powers of other ministries, among which the Ministry of Finance, were redefined in favour of the local councils (ElRayah \& Taban, 1979). The new arrangement was considered necessary to empower the PPEC and to allow it to function more independently. The President himself assumed the status of the Patron of Local Government Affairs to underscore the high priority he personally gave to the decentralisation program. On occasions he intervened to accelerate the process of decentralisation directly. He tried to use coercion and threats to get a quick response from recalcitrant civil servants in Khartoum who were transferred to provinces. This policy led to a frontal confrontation with the Association of Administrative Officers whose members threatened to resign en bloc and refused to move to the regions (Moharir, 1986). The threat and coercion of an authoritarian military President failed to overcome bureaucratic resistance.

The provincial governments were offered revenues in the form of funds from the central government in order to support their expanding responsibilities. It was assumed that the Provincial budget formed the basis of the national budget, a relationship confirmed by the Presidential Decree 41/79 (EI-Rayah \&Taban, 1979). The transfer of central funds to the provincial governments increased from 25.7 million LS (Sudanese Pounds) in 1969/70 to 127 million in 1979/80 (MOF, 1980), apparently an impressive indication of the decentralisation of financial resources, notwithstanding rapid inflation.

By 1979 the control of most public services had been transferred to PPEC. Popular participation was encouraged at all levels, but only through the one-party mechanism. Initially, the 1971 Act was implemented with great enthusiasm. However, there were defects in the new system, which lay in the scale and comprehensiveness of the reform program (Norris, 1983). Consequently it proved to be very difficult to develop well-functioning local institutions. The inability of the central government to provide local governments with necessary financial re- 
sources and management skills in order to fulfil the aroused expectations was another problem (Rondinelli, 1981a). The public service was not equipped to introduce the required changes in a short time. In addition, local sources of revenue did not increase because of extreme poverty and a deteriorating economy. The Provincial budgets faced a lot of constraints and became totally dependent upon central grants. The planning and implementation of development projects suffered from an inadequate technical and administrative manpower (ElKhalifa, 1980). This process could not conceal a drastic form of national control, supported by the powers of tutelage conferred on the Ministry of Finance by Decree No. $4 / 75$ of October 1979. The negative impact of this control was increased by the fact that even the approved budgets could not be implemented because of cash flow difficulties (Norris, 1983). The Provincial Councils, and therefore the levels below, lacked knowledge of what resources they could expect on which to plan and to set priorities. Most of the budget was devoted to staff salaries (Ibrahim, 1982).

Difficulties arising from the shortage of finance extended to the availability of skilled staff, overburdening the Provincial office itself and creating serious bottlenecks. Some measures were undertaken to resolve these problems. The number of provinces was increased from 9 to 18 and a Deputy Commissioner as a first assistant to the Commissioner was appointed in recognition of the excessive burden on the Commissioner (Norris, 1983). However, these measures failed. The dilemma was to achieve efficient decentralisation at a tolerable cost to the centre in political, financial and administrative terms. This proved a virtually impossible objective to achieve.

A further source of concern was the realisation of public participation. Despite the formal opportunities for involvement in council work, the actual participation remained limited, symbolic and subordinate to the discipline of the single party regime (EIKhalifa, 1980). The exclusion of those connected with the Native Administration in the past from the electoral process on political grounds also applied to their families and relatives (Abdel Gadir, 1981). Moreover, in actual practice the concept of popular participation was mostly reduced to financial support to pay for the services through self-help programs (ElArifi, 1978).

Ultimately, the Local Government Act of 1971 did not meet its objectives. The PPEC's did not devolve elements of their authority to lower level councils. To correct this situation the regime enacted the Regional Government Act of 1980.

\subsection{The Regional Government Act of 1980}

Regionalisation in terms of devolution to autonomous legislative and executive organs had been introduced in 1972 in South Sudan as a result of the rapprochement between the North and the South. A higher level of autonomy was granted to the Southern provinces under the Self-governing Act of 1973 (Moharir, 1986). 
President Nimeiri proposed to divide the North into regions to accelerate decentralisation in the country. This proposal was induced by the shortcomings of the Local Government Act 1971 and motivated by the Southem region experience (Al Assam, 1983). The Regional Government Act of 1980 was preceded by an intensive evaluation of the past experiences of decentralisation (Al Assam, 1983; Hamid, 1988). The Third Congress of the Sudan Socialist Union (the single political party) recommended the development of five regions in the North (Sudan Socialist Union, 1980) and the President issued the Regional Government Act of 1980 in the North accordingly. The Act was subsequently enshrined in the Constitution of 1980, which provided it with a special prestige (Al Assam, 1983).

\subsubsection{The new regional government structure}

In the new regional system, the presidential form of government remained the same. The North was divided into five regions drawn from the previous 10 provinces. The South remained under the regional self-government system introduced in 1973. Only, the previous monolithic one Southern region was now divided into three separate autonomous regions. Khartoum as the seat of the national government enjoyed a special status. The Central government remained involved in the administration of Khartoum, since its Commissioner received a cabinet minister's rank and reported to the President (Al Assam, 1983). The regional administration consisted of a governor, a deputy governor, a Council of Regional Ministers (consisting of five ministers) and the semi-elected People's Regional Assembly. The Regional Assemblies included elected and selected members, but the selected members were not to exceed ten percent. However, both selected and elected members had to be members of the Sudan Socialist Union, the only party allowed to exist. Forty percent of the Assembly seats were reserved for special representatives of the workers' trade unions, farmers, women's associations, and the army, which were also Functional Organisations of the Sudan Socialist Union. The regional ministers, appointed by the governor, were also members of the Assembly and of the SSU.

The President selected the regional govemor from three candidates elected by a joint meeting of the Regional Assembly and Regional Conference of the Sudanese Socialist Union. The term of office for the governor and the Regional Assembly was set at 4 years. The governor, who could be re-appointed, was responsible to the President and the People's Regional Assembly. The President could also remove the governor if he lost confidence in him or on the recommendation of a two-thirds majority in a joint meeting of the People's Regional Assembly and Sudan Socialist Union (SSU). Furthermore, he could dissolve the People's Regional Assembly in the public interest. Obviously, these measures represented non-democratic centralising factors and compromised the autonomy of the regions (Salih, 1989). 


\subsubsection{The distribution of functions between levels of government}

The Regional Government Act of 1980 attempted to specify the distribution of functions to different levels in the Constitution. In general, the distribution of powers indicated that national government was assigned functions whose importance and significance in the opinion of the lawmakers transcended regional boundaries. The regional governments were generally allocated functions with a restricted geographical, political and cultural impact. The regional government's functions were described in Article 6 of the Act. However, despite its attempt to specify functions, the 1980 Act proved to be very ambiguous with regard to giving a clear-cut description of the functions of the various levels of government. This was partly because the allocation was done on an institutional rather than functional basis: it listed institutions belonging to the centre or to the region. The division of functions followed the common principle of reserving functions of national importance, of sovereignty or of an inter-state nature for the centre, and allocating the delivery of social services, such as health, education or social welfare to the region. There was no concurrent list of subjects on which both centre and region could legislate. Those functions that were not reserved for the centre or were not prohibited to the region belonged to the region (Moharir, 1986).

Since sectors like health, transport, labour or social welfare were not mentioned in the centre's list, the role of the central ministries in these areas remained unclear. They still functioned and did not undergo major reductions in their budget or staff in spite of the transfer of their responsibilities to the regions. On the other hand, there were still many central concerns such as interstate vaccination and control of epidemics, that were not allocated to the regions, but they were not listed either.

Although the regional list was quite comprehensive, it differed only little from the list of functions provided to the Provincial Government under the People's Local Government Act 1971. The 1980 legislation made no clear distinction between the functions of the central, regional and district level in the spheres of health, education, transportation, and industry to name but a few.

\subsubsection{The financial resources of the regions}

The People"s Regional Assembly was empowered by the Regional Government Act of 1980 to pass its own budget and to obtain its revenues from direct and indirect regional government taxes, regional industrial and agricultural activities and trade, and central government grants and loans. However, the Regional Government Act prohibited regional governments from levying taxes such as taxes on import and export, excise duties, capital profit tax and public service benefits (pensions). To avoid inequalities in taxes, a permanent Fiscal Review Board was established to study periodically the intergovernmental financial relationship and 
to make necessary recommendations. Unfortunately, this was an unproductive endeavour.

\subsection{The Local Government Act of 1981}

The introduction of the Regional Government Act of 1980 necessitated the reorganisation of local government in order to cope with the new situation. Consequently, the People"s Local Government Act of 1971 was replaced by the Local Government Act of 1981 (Salih, 1989). A fundamental feature of the 1981 reorganisation was the abolition of the PPECs and their replacement by Area Councils, which were corporate bodies with an independent budget, and financial autonomy. The Area Councils had to operate as an intermediate executive authority responsible for many functions such as:

o Primary and intermediate education; public health including dispensaries,

o Economic development including planning roads,

o Drainage and water supplies,

- Agricultural and veterinary extension work,

o Culture and sports,

- Social affairs and self-help schemes,

- Labour and regulation of employment,

o Licensing, price and commodity control,

- The maintenance of public order (Al Assam, 1983).

Simultaneously, the country was divided into some eighty councils, twenty-five of which were in the Southern region. The role of the Provincial Commissioner was radically redefined. His responsibility was restricted to the security of the province through the supervision of police, prisons and fire brigades. The right to inspect councils rested with the regional ministries, but the Commissioners also had powers to investigate, report and revise. This resulted in a power struggle between the regional ministries and the Commissioners.

The financial basis was not fundamentally changed, although regional grants to the councils were envisaged. There was, nonetheless, no formula for the allocation of these grants. Precise guidance as to the extent to which functions were to be decentralised to the councils were also missing. The Act provided a broad framework, permitting considerable regional discretion and variation, even through the need for a resolute and informed settlement of financial distribution was crucial. This discrepancy was not resolved (Malik, 1982), despite the genuine effort to achieve decentralisation of responsibility from both the Central government to the regional level and from the regions to the Areas. Without sufficient financial resources the good intentions could not be realised. 
Table 4.1. The main features of decentralisation in Sudan

\begin{tabular}{|c|c|c|c|}
\hline Legislation & $\begin{array}{l}\text { Number and } \\
\text { Names of } \\
\text { layers }\end{array}$ & Main Features and changes & $\begin{array}{l}\text { Form of } \\
\text { Decentralisation }\end{array}$ \\
\hline $\begin{array}{l}\text { Local Cow- } \\
\text { emment Ordi- } \\
\text { namce of } 1951 \\
(1956-1960)\end{array}$ & $\begin{array}{l}\text { 1. National } \\
\text { Level } \\
\text { 2-Provinces } \\
\text { (9) } \\
\text { 3- Local } \\
\text { Councils }(87)\end{array}$ & $\begin{array}{l}\text { 1-Elected } 87 \text { local councils as the } \\
\text { main level } \\
2 \text {-Province is for security and co- } \\
\text { ordination of field offices of central } \\
\text { ministries in province }\end{array}$ & $\begin{array}{l}\text { Devolution at local level and } \\
\text { multi-party democratic govm } \\
\text { ermment at the centre }\end{array}$ \\
\hline $\begin{array}{l}\text { Provincial } \\
\text { Administration } \\
\text { Act of } 1960 \\
(1960 \times 1969)\end{array}$ & $\begin{array}{l}\text { 1-National } \\
\text { Level } \\
\text { 2- Provinces } \\
\text { (9) } \\
\text { 3- Local } \\
\text { Councils (87) }\end{array}$ & $\begin{array}{l}\text { 1- Number of local Councils re- } \\
\text { mains the same } \\
\text { 2-Strengthening the coordinating } \\
\text { role of the province }\end{array}$ & $\begin{array}{l}\text { Devolution at local level and } \\
\text { deconcentration at the province } \\
\text { level. Brief periods of millitary } \\
\text { \& democratic government }\end{array}$ \\
\hline $\begin{array}{l}\text { People's Local } \\
\text { Govermment } \\
\text { Act of } 1971 \\
(1971-1980)\end{array}$ & $\begin{array}{l}\text { 1-National } \\
\text { 2- Provinces } \\
(15) \\
\text { 3-Local } \\
\text { Councils } \\
(5600)\end{array}$ & $\begin{array}{l}\text { 1-Number of local councils in- } \\
\text { creased to more than } 5000 \text {, they are } \\
\text { no longer autonomous and corpo- } \\
\text { rate. } \\
\text { 2- Province becones the main level } \\
\text { below centre with most social ser- } \\
\text { vices functions but with sem- } \\
\text { elected/appointed provincial coun- } \\
\text { cil. Provincial Govt. subordinated } \\
\text { to ruling single party. } \\
\text { 3-MOLG dissolved to prevent re- } \\
\text { centralisation. }\end{array}$ & $\begin{array}{l}\text { 1. Recentralisation at provincial } \\
\text { level from local level } \\
\text { 2. Entire local gowernment put } \\
\text { under the tutelage of ruling sin- } \\
\text { gle party. } \\
\text { 3. Indirect central control ower } \\
\text { local government increased. }\end{array}$ \\
\hline $\begin{array}{l}\text { Regional Gov- } \\
\text { ernment Act of } \\
1980 \\
(1980-89)\end{array}$ & $\begin{array}{l}\text { 1-National } \\
\text { 2-Regions (5 } \\
\text { in the North + } \\
\text { Kharoum) } \\
\text { 3-Province } \\
\text { (15) } \\
\text { 4-Local } \\
\text { Councils } \\
(5600)\end{array}$ & $\begin{array}{l}\text { 1-Introduction of regions in North } \\
\text { 2-Regional Ministries } \\
\text { 3-Elected Regional Assembly } \\
\text { 4. Governor appointed by President } \\
\text { from } 3 \text { Regional Assenbly nomi- } \\
\text { nees }\end{array}$ & $\begin{array}{l}\text { 1. Devolution at the regional } \\
\text { level } \\
2 . \text { Hold of single pariy some- } \\
\text { what reduced. Nimeiri replaced } \\
\text { in } 1983 \text { by a transitional mili- } \\
\text { tary government and later in } \\
1985 \text { by a democratic govern- } \\
\text { ment. }\end{array}$ \\
\hline $\begin{array}{l}\text { Local Gow- } \\
\text { ermment Act of } \\
1981 \\
(1981-1989)\end{array}$ & $\begin{array}{l}\text { 1-National } \\
\text { 2-Regions }(9) \\
\text { 3-Local Ar- } \\
\text { as (85) } \\
\text { 4-Local } \\
\text { Councils } \\
(5600)\end{array}$ & $\begin{array}{l}\text { 1-Introduction of the Area Level to } \\
\text { replace the Province. } \\
2 \text {-Southern region divided into } 3 \\
\text { regions }\end{array}$ & $\begin{array}{l}\text { 1. Devolution at the regional } \\
\text { level and the area level from } \\
1985 \text {. } \\
\text { 2. New regional governors to } \\
\text { represent different parties. }\end{array}$ \\
\hline
\end{tabular}




\subsection{The status of decentralisation after the transitional government (1985)}

The elected coalition government of Sadig El-Mahdi in 1985 did not initiate any major changes in the prevailing system except the replacement of the regional governors by new ones representing the different political parties in the coalition. Since the political parties had no firm base in the regions, most regional policies were made in the capital (Khartoum) and no Regional Assemblies were elected which resulted in a strong tendency towards centralisation.

Indecision, corruption, the worsening war in the South and the failure to take effective action contributed to an overthrow of the government in 1989 by the present Military President Al Basheir (Fadalla, 1996). In order to consolidate its power the new regime appointed military officers as governors of the regions supported by regional ministers. The representatives of local government institutions were fired and administration below the regional level fell almost entirely into the hands of Government Executive officials. The Area Councils were renamed as provinces and functioned under an appointed Provincial Commissioner. The executive officers of the urban and rural levels continued to coordinate and maintain local services. Local Popular Committees were established to run public services at the village and the neighbourhood level as an important means of achieving popular participation, and to fill the political vacuum left by the banning of political parties.

However, the regime also considered it very opportune to come up with a radical decentralisation policy, which not only had to overcome the inadequacies of the existing system but also to increase its legitimacy. Thus, the regime proclaimed in 1991 the adoption of a federal system in the country through the Constitutional Act No. 4. Principally, the former nine regions were just renamed states. Later in 1993, the country was further divided into twenty-six federal states, followed by a series of constitutional acts that resulted in present ambitious Federal System of 1993. This will be the main focus of our discussion in the next chapter.

\subsection{The impact of decentralisation upon the health system}

It is essential to point out that the decentralisation experienced by the health system of Sudan did not originate from planned public health sector initiatives but instead resulted from political factors outside the public health sector. The changes made to the health system at the different levels during each regime were initiated in accordance with the general scheme of decentralisation. The adaptive responses of the $\mathrm{MOH}$ to the general scheme varied from time to time, both in type and magnitude. In the following section, we will discuss the process in more detail. 


\subsubsection{District health system}

During the colonisation period health services were provided for the colonisation troops and workers, who stayed mainly in the centre and in big towns. In the late period of the British colonisation the Medical Administration was established to address the health problems of the entire population (Bayoumi, 1979). The Medical Administration worked according to a district system adopted in the general administration of the country, i.e. the Marshall Act 1951. The local administration (district) was responsible for running all public services including health. However, the overall plans were prepared by the central Ministry of Health (MOH). The ministry produced a number of five or ten-year health plans that were implemented at the district level, a process that was coordinated by the MOLG. The MOH received annual reports from districts in order to monitor, follow up and financing. The plans in that period were characterized by an absolute dichotomy between curative and preventive services with a clear bias towards the curative services (Abdel Rahim et al., 1992). Within this system, the leadership of health services at the district level was in the hands of a medical inspector, who was a medical doctor and who was assisted by three or four mid-level health supervisors.

\subsubsection{Health care in the provincial setting}

The Provincial Government Act of 1960 introduced some limited changes in the health system. One of the main changes of this Act was the co-ordination of all public services in the province including health by the Provincial Executive Council. It also initiated a number of committees for planning among which the Provincial Health Committee that dealt with public health issues such as dressing stations, dispensaries, drainage and public sanitation. The chief of the committee was the Assistant Commissioner for health in the province, who also represented the $\mathrm{MOH}$. The committee worked within the framework of the central plan prepared by the National Committee for Health. The MOH also established a department for rural health and provincial affairs to supervise and coordinate the health services in the provinces. The exact responsibilities of this new department were not clear and led to confusion over who was responsible for what.

\subsubsection{Health care and the Local Government Act of 1971}

The most drastic changes to the administrative system of health care were associated with the Local Government Act of 1971, implemented by the May Revolution of Niemeri. As we have seen, Niemeiri's strategy was to organise participation in government affairs at the grass root level that was channelled and controlled through the one party mechanism. The new structure consisted of a pyramid of over 5000 local councils that drastically changed the original district boundaries. The new system led to community participation in the finance of 
public services, especially in the field of education and health. The infrastructure of health services was improved and many new services were financed by selfhelp programs.

This development in the health service encouraged the $\mathrm{MOH}$ to adopt the Primary Health Care Program (PHC) in 1976, two years before the Alma Ata declaration of 1978. It established two National Committees to plan the PHC program in the Southern and the Northern regions. The adoption of PHC initiated impor tant changes in the health system. People were encouraged to build primary health care units, health centres and hospitals according to their own ability and not according to a plan of the MOH or the local health authority. The MOH, due to the difficulty of running these services, transferred the responsibility of the PHC's services to local administration while retaining the hospitals under its direct control. This step further complicated the dichotomy between preventive and curative services. While health facilities were expanding, the MOH budget remained static, and most of it was spent on salaries and hospital care $(\mathrm{MOH}$, 1988).

The self-help initiative failed to sustain the PHC programs, and the leadership of the PHC services at the local and peripheral level failed. In fact, the organisational structure proved inadequate. Management support was also lacking. The MOH focused on its vertical programs and neglected the organisational problems in the PHC. These programs were relatively easy to conduct and produced results in a short time; however, they were also expensive and lacked sustainability too. Clearly, the $\mathrm{MOH}$ could not cope with the new circumstances brought about by the 1971 Act and the PHC adoption. Both policies called for real devolutionary decentralisation and community involvement in managerial and financial aspects. The $\mathrm{MOH}$ retained its structure and responsibilities preferring deconcentration with top-down planning for most of the health services activities (Abdel Rahim et al. 1992),

\subsubsection{Health care and the Regional Government Act of 1980}

The introduction of the Regional Government System in 1980 represented a fur ther step towards decentralisation by way of the transfer of all social services to lower government levels. During this process the $\mathrm{MOH}$ itself had to be reduced in size, and the regional ministries had to take over many of its tasks. The regional Ministries of Social Services became fully responsible for health in their regions with the exception of the Central region and Khartoum, which had separate Regional Ministries of Health.

In principle with the new Act, the role of the Central $\mathrm{MOH}$ had to be restricted to general health policy development, health research, health manpower development, health legislation and management of national referral and teaching hospitals (MOH, 1988). Thus, the MOH itself became a target for change, and many 
of its functions had to be devolved to the regions. As a result, the size and the structure of the central MOH were expected to shrink; however, this development did not take place. The $\mathrm{MOH}$ continued it's operational role in vertical programs and teaching hospitals. Neither a transfer of authority to the regions nor a reduction in the number of $\mathrm{MOH}$ staff occurred. Human resources recruitment, training, and salaries remained within the $\mathrm{MOH}$, especially for the doctors and the technicians. The National $\mathrm{MOH}$ retained its hold on the financial resources as reflected in table 4.2. No managerial or planning staff were transferred to the regions.

Table 4.2 Changes in the budget of the National Minisiry of Health before and after the regionalisation (in Sudanese Pounds)

\begin{tabular}{|l|l|l|l|}
\hline Years & $\begin{array}{l}\text { Salaries } \\
\text { (Chapter 1) }\end{array}$ & Repair and Maintenance (Chapter 2) & $\begin{array}{l}\text { Development Budget } \\
\text { (Chapter 3) }\end{array}$ \\
\hline $1979-80$ & 9293145 & 3620000 & 122755 \\
\hline $1980-81$ & 10803165 & 2644000 & 185772 \\
\hline $1981-82$ & 18071250 & 3113000 & 524206 \\
\hline $1982-83$ & 22695500 & 7700000 & - \\
\hline
\end{tabular}

Source: Moharir, 1986. Clarification. prices adjusted.

The Regional Minister of Health assisted by the regional director was responsible for the health affairs in his region and had to report to the governor. There was a services committee (including health) in each Regional Assembly to discuss the region's health problems and plans. However, there was no clear coordination between the centre and the regions. At the same time the Regional Authorities were unable to perform their functions of planning, implementation and evaluation of services. Budgeting and financial contro $\$$ on expenditure also deteriorated (MOH, 1987a). These problems were attributed to the ambiguous distribution of functions, lack of skilled personnel and poor institutional capacity building.

\subsection{The cumulative impact of decentralisation upon the health sys- tem}

A study on the MOH conducted by the Sudan Academy of Administrative Sciences in 1989 revealed that the introduction of the regional government had negatively affected the integration of the health services. The Central-region relations in the public health sector were not clear, and for about four years the $\mathrm{MOH}$ could not maintain the new presumed structure. There was no unity of command, and the tools for coordination between the centre and regions were poorly designed. There was no two-way flow of information. All this resulted in conflicts and fragmented health authority. The Central $\mathrm{MOH}$ was still directly implementing programs in the regions without involving the regional ministries. Clear examples of this are the Blue Nile Health Project and the Malaria Control Program. 
While these programs were implemented in the Central region, the Regional $\mathrm{MOH}$ did not have any influence on or even formal access to the reports. This was also the case with manpower affairs. In so many cases the central $\mathrm{MOH}$ nominated certain persons for training courses without consulting their regional authorities. The central $\mathrm{MOH}$ also complained of irregular and incomplete regional reports (Sudan Academy for Administrative Sciences, 1990).

At the locall level, the health services were also in a poor condition. There were conflicts between the Local Councils and the regional ministers. The regions had only limited resources to meet increasing health cost. This situation was exacerbated by the lack of skilled staff, poor planning, absence of priority setting and deficient supervision. Powerful incentives to promote PHC were also missing. In fact, the implementation of regionalisation, which was expected to lead to devolution in services along with access and improvement in quality, complicated the situation even further.

In a study conducted by the $\mathrm{MOH}$ on the evaluation of the health status (1985b), it was confirmed that the failure in most cases was due to organisational factors. Among the causes of this failure were:

o The population growth over the last thirty years, which had led to an increase in the density of the average district population, ranging from 250,000 to 750,000 people scattered over numerous small rural communities. This and the drive to increase the coverage of the PHC program resulted in an increased number of PHCs and basic health units within the district. In many instances, they exceeded 100 units, an unmanageable number for one centre without sufficient logistics.

- Difficulty in transport, created by the immense size of the districts impeded effective supervision and communication within the district.

- A succession of local government laws (decentralisation trials) had created numerous new rural and urban councils in place of the district system. This development stripped the district health team of their original advantage of being proximal to the administrative and decision-making centre at that level.

o The original dichotomy between preventive and curative services was further augmented by the Local Government Act of 1981, which passed on the administrative and financial responsibilities for the PHC units to the local government authorities without sufficient resources while hospitals with most of the qualified specialist staff and equipment remained with the central $\mathrm{MOH}$.

- Finally, the failure of the MOH to cope with successive changes in the administrative system by adopting supervision, monitoring and research functions. 


\subsection{Conclusions}

This chapter presented a brief history of decentralisation in Sudan. This history can be summarised in a few general observations. To begin with, decentralisation of the political and administrative structure has been a permanent topic in policymaking in Sudan for the last 50 years, and all military and democratic regimes showed a keen interest in it. However, the topic was never settled satisfactorily. Further, it is no exaggeration to conclude that Sudan has witnessed an avalanche of decentralisation plans during this time. After the Local Government Ordinance of 1951 came the Provincial Administration Act of 1960, which was in turn replaced by the People's Local Government system in 1971. This system survived untill 1980 until the Regional Government Act was introduced, which was followed in turn by the Local Government Act of 1981. In 1991 the regime proclaimed the adoption of a new federal system, which is still in place today, although it has undergone several changes since its inception.

One may conclude from this brief overview of decentralisation that Sudan has never experienced a stable government. The ongoing changes in its political and administrative system have not only consumed a great deal of political energy at all levels of government, but have also been a source of permanent instability that has had an adversarial impact upon policymaking in various sectors such as public health sector.

Although from time to time many functions of the central government were transferred to the region/province/district and formally the decentralisation structure appeared to be devolutionary, in reality this was negated by many other factors. These included subordinating the decentralisation structures to the one party mechanism, centralising control of financial and manpower resources, the appointment of important political executives at lower levels by central political leadership, subordination of elected to nominated members of councils, and giving more autonomy to a level at the cost of other.

In the legislation on decentralisation, decisions regarding the number of levels, the power assigned to each level, the composition of the local councils, and the way of selection/election of the local council members, were always taken on political grounds to placate the supporters of other parties and to provide patronage to it's own supporters.

If one takes a closer look at what has happened over the last fifty years, it is clear, with a few exceptions, that decentralisation has always been more focused upon the relationship between the national and the regional or provincial level than upon the local level. To some extent, this is not surprising, since Sudan is a vast country that cannot be ruled effectively from one single centre. Effective government is not possible without an intermediate level between the national and the local level. But the focus upon the regional or provincial level meant that the local level was usually neglected, and that from the viewpoint of the local level, decentralisation implied recentralisation to the regional or provincial level. 
A closer look at Sudan's experience with decentralisation also leads us to the conclusion that the process has only partially if ever completed. Policymakers have never been really interested in how to implement it and, more concretely, how to create the conditions for the effective implementation of decentralisation. Despite the constant interest in decentralisation, it did not result in a genuine, democratic, participatory, devolutionary type of decentralisation. Although the stated motivation for decentralisation was development and participation, the real motives were often the realisation of other higher-level political agendas such as building political legitimacy, getting rid of the supporters of previous regimes from political office, and diverting attention from the deteriorating economic situation or other problems in the country. Thus, decentralisation often meant little more than a set of verbal statements of the new political leadership expressing the need for decentralisation, followed by a badly designed legislation.

Finally, in the last section of this chapter we investigated how decentralisation politics affected the health system. The most important conclusion to draw here is that health care always had to follow the new political mode. When a new plan for decentralisation was announced and implemented, it also had an impact on the administration of the health care system. 



\section{Chapter Five \\ Federal Decentralisation and its Impact upon the Public Health Sector}

\subsection{Introduction}

The purpose of this chapter is threefold. First, we will present a brief overview of the main aspects of the development of the federal government structure in Sudan. We will discuss its historical background, its principles and its structure. Furthermore, we will consider some of the basic problems encountered in federal reform development. The second theme of this chapter will discuss the implications of the federal reform for the administrative (governance) structure of the public health sector. Finally, we will address the development of health policymaking in Sudan emphasising the main features of the current health policy.

\subsection{Federal decentralisation in Sudan}

The idea of federalism has always been present in Sudanese politics since its independence in 1956. It was often presented as an appropriate solution to the Southern conflict and to other regional problems resulting from underdevelopment (Hamid, 1988; Karsany, 1998). However, the post independence central ruling elites did not support federalism and instead implemented their various plans of decentralisation between 1951 and 1989 (chapter 4). Thus, one cannot say that the current federalism has emerged out of the blue. In a sense, it is a result of old intentions and past experiences.

In June 1989, the Salvation Revolution of General Al Basheir seized power from the elected government of Al Sadig Al Mahdi through a military coup (Fadalla, 1996). The new regime convened a national conference in October 1989 to address the buming Southern civil war issue. The conference considered the previous experiences of peace negotiations and constraints that had thwarted past attempts at decentralisation (ElTahir, 1999; Ibrahim, 1999). The conference recommended a federal system for the entire country as the best solution to resolve the conflicts engendered by regional, cultural, and developmental disparities and to encourage a sense of nation building and citizenship (ElTahir, 1999). Thus, the Salvation Revolution of AI Basheir considered federalism a principal pillar in its manifesto to resolve the multitude of problems of the country, especially the Southern civil war that had hindered the former regimes in achieving political legitimacy.

The new regime's desire to achieve legitimacy quickly was paramount. To create a democratic image, it held various conferences to encourage popular participa- 
tion. These conferences discussed issues such as peace and war in the South, the state of the economy, new forms of political organisation in the country, health issues and education policies. In 1991, the regime took a bold and unprecedented step in policymaking and planning by convening the Global National Strategy Conference (GNSC). It was the regime's first major attempt to discuss comprehensive strategic planning across the country. 6580 citizens representing the public and private sector attended the conference, including individuals from the Sudanese academia, professional, and scientific circles, from all states (Sudan Republic, 1992). The outcome of the conference was the Comprehensive National Strategy (CNS) of 1992-2002. The CNS became the master document for planning in the country. In this study, we are mainly interested in the components of the CNS, which provided the basic impetus for the current health reform policy, namely the federal structure and the public health sector strategy.

Based upon the quasi-federal system inherited from the former regimes and the recommendations of the CNS, the new regime issued a series of Constitutional Acts and Decrees to develop the present federal system. All this happened with great speed. At times a new Decree was launched before the implementation of an earlier Decree had been started. The reasons for such hasty action were situational factors like the regime's need for legitimacy and circumstantial factors like the Southern Peace Agreement of 1997. The revolutionary, military and centralised nature of the regime also facilitated the cascade of Decrees. The total number of Decrees reached fourteen between the years 1991 and 1998, finally resulting in the Constitution of 1998. The most salient Decrees are summarised in table 5.1. 
Table 5.1 Milestones of Decrees and Acts on federalism

\begin{tabular}{|c|c|c|c|}
\hline No. & Year & Aspects of change & Comments \\
\hline $\begin{array}{l}\text { Constimutional Decree } \\
\text { No. } 4 \text { and Local } \\
\text { Gowernment Act of } \\
199 \$\end{array}$ & 1991 & $\begin{array}{l}\text { Changed the nine regions into } \\
\text { nine federal states. Distributed } \\
\text { authorities, tasks and resources } \\
\text { between the centre, states and } \\
\text { localities. }\end{array}$ & $\begin{array}{l}\text { Unified the system in the South and } \\
\text { North and rounded the Federal sys- } \\
\text { tem. Redistributed the Provinces } \\
\text { and established the Political System } \\
\text { Act to prowide local participation. }\end{array}$ \\
\hline $\begin{array}{l}\text { Constitutional Decree } \\
\text { No. } 10\end{array}$ & 1993 & $\begin{array}{l}\text { Increased the number of states } \\
\text { from } 9 \text { to } 26\end{array}$ & $\begin{array}{l}\text { Represented the most ambitious } \\
\text { change, against the static position } \\
\text { of financial and manpower re- } \\
\text { sources. }\end{array}$ \\
\hline $\begin{array}{l}\text { Constitutional Decree } \\
\text { No. } 11\end{array}$ & 1993 & $\begin{array}{l}\text { Detailed Organisation of the Fed- } \\
\text { eral System and Institutions }\end{array}$ & $\begin{array}{l}\text { Provided four-levels: Federal, State } \\
\text { (Willayia), Province and Locality } \\
\text { (Malhallia). Determined the rela- } \\
\text { tions between the levels and within } \\
\text { them. }\end{array}$ \\
\hline $\begin{array}{l}\text { Constitutional Decree } \\
\text { No. } 12 \text { and Local } \\
\text { Government of Act } \\
\text { of } 1995\end{array}$ & 1994 & $\begin{array}{l}\text { Redistribution of functions, pow- } \\
\text { ers and resources between the } \\
\text { federal and state levels to provide } \\
\text { more autonomy to locality. }\end{array}$ & $\begin{array}{l}\text { Excluded the provincial level from } \\
\text { performing any administrative task } \\
\text { and empowered the local levell by } \\
\text { issuing the Local Government Act } \\
\text { of } 1995 \text {. }\end{array}$ \\
\hline $\begin{array}{l}\text { Constitutional Decree } \\
\text { No. } 14\end{array}$ & 1997 & $\begin{array}{l}\text { Further redistribution in powers } \\
\text { and resources to accommodate the } \\
\text { Peace Agreement with South } \\
1997 \text {. Introduced a High-level } \\
\text { Committee for Resource Alloca- } \\
\text { tion. }\end{array}$ & $\begin{array}{l}\text { Introduced to accommodate the } \\
\text { Peace Agreement of } 1997 \text { with one } \\
\text { faction of the Rebels (Elnasir } \\
\text { group). Specified certain resources } \\
\text { for the South. }\end{array}$ \\
\hline $\begin{array}{l}\text { Sudam Constitution of } \\
1998 \text { and Local Cov- } \\
\text { emment Act of } 1998\end{array}$ & 1998 & $\begin{array}{l}\text { Unified and consolidated all con- } \\
\text { stitutional Decrees into a single } \\
\text { document. Rectified the gaps }\end{array}$ & $\begin{array}{l}\text { Established the Constitutional Rela- } \\
\text { tions and replaced Local Govern- } \\
\text { ment Act of } 1995\end{array}$ \\
\hline
\end{tabular}

Source: Federal Government Chamber, 1998.

\subsubsection{The new structure of government under federalism}

As a result of the series of constitutional Decrees and the new constitution of 1998 , the structure of government changed as shown in figure 5.1 below. In accordance with the new Constitution, the government structure of Sudan consisted of three levels. Note that the former provincial level in the government structure no longer played a role in administrative affairs, since it was excluded by the Constitutional Decree No. 12. Nevertheless, the Provincial Commissioners were not completely abolished in the new structure, but subordinated to the state without any administrative power. Their main task was to mobilise political support for the regime at the provincial level.

Each level had its executive and legislative arm, including the local level. The President, his assistants, the Ministerial Council, twenty federal ministries, the National Assembly and the Constitutional Court constituted the federal level. The 
state level consisted of twenty-six states, sixteen in the North and ten in the South. Common criteria for defining states and deciding upon their borders were surface area, the weight of popular participation, economic independence, social homogeneity, administrative cohesiveness, security status and geographical situation (Smith, 1979). However, these criteria were not always strictly followed in Sudan: regional, tribal and political considerations often dominated (Elnaeem, 1999). In this respect, Sudan did not differ from many other African countries (Ellis, 1996). Little attention was paid to the availability of resources, infrastructure and/or aspects of efficiency. This was due to the hot political issue of instability in the country, the regional and tribal pressures, and the lack of a sound information base (Magzoob, 1999a). The extension of the number of states to twenty-six may have perhaps been good from the perspective of decentralisation and participation, but created problems from the viewpoint of the status of the economy and the tremendous scarcity of financial and human resources. If the resources and manpower constraints could not sustain the previous nine regions, how then could the present further deteriorated resource situation sustain twentysix autonomous, decision-making structures with the corresponding executive, legislative and bureaucratic set-up? Without adequate resources, any autonony of the states is likely to be frustrated.

Each state government consisted of a governor, appointed by the President out of three candidates proposed by the state elite, six or seven state ministers, the state Judiciary and the state Assembly as the legislative organ. The Commissioners of the Provinces operated under the state level.

The third tier of government was the local level consisting of 634 localities. Each locality had a corporate character with an executive office and a legislative council. General criteria for the establishment of a locality were population density of not less than 30,000 , a reasonable level of social services and an acceptable level of resources (Federal Government Chamber, 1995). The application of the last two criteria depended on value judgments rather than upon concrete empirical data. The relationships between the three levels of governments are presented in figure 5.2 .

The change in the government structure between 1990 and 2000 was expensive. Administrative costs increased by $80 \%$ over these years (Ahmed et al., 2002). This burden was too great for a country with limited capacity. 
Figure 5.1 The new federal government structure in Sudan as from 1994

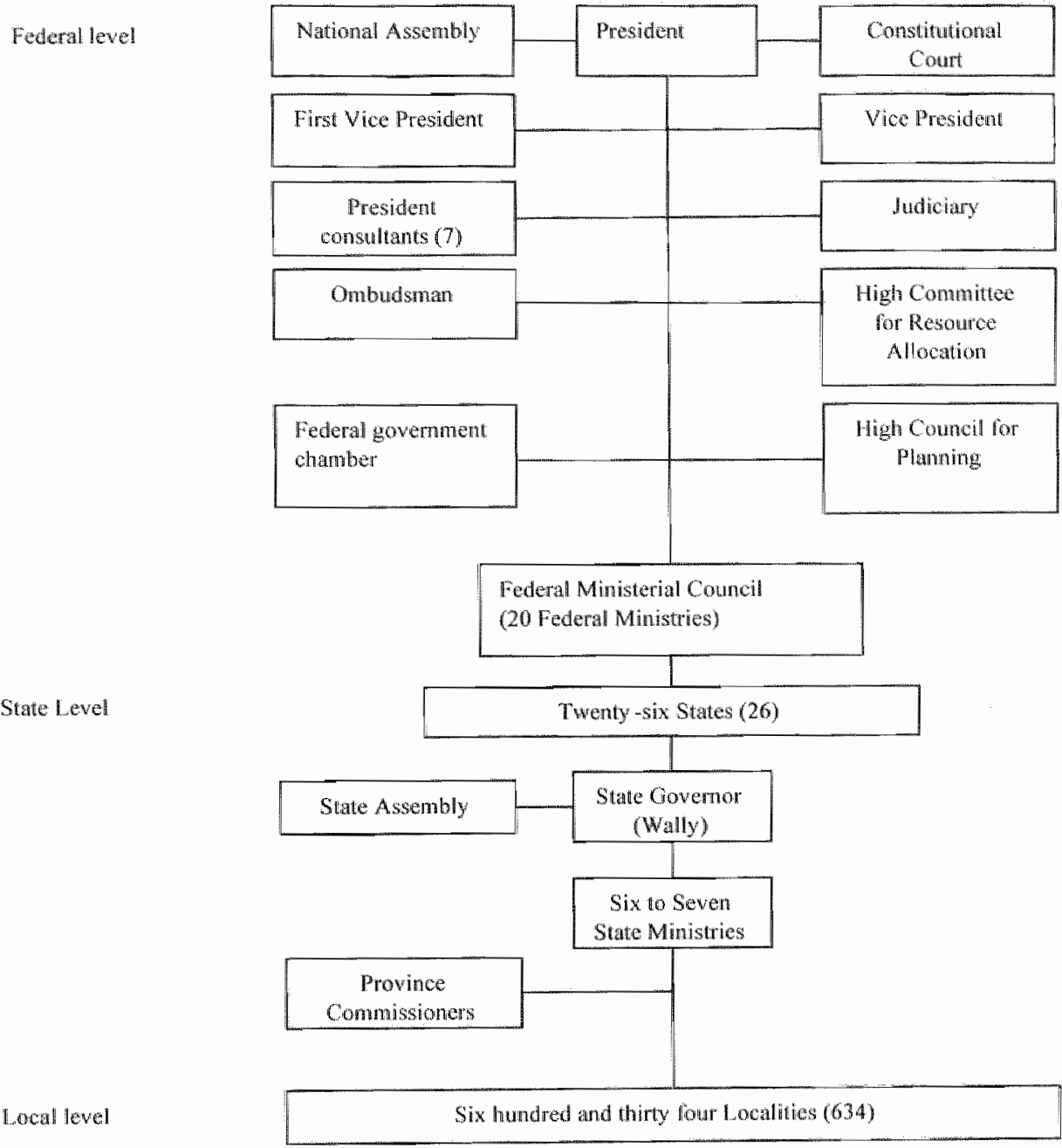




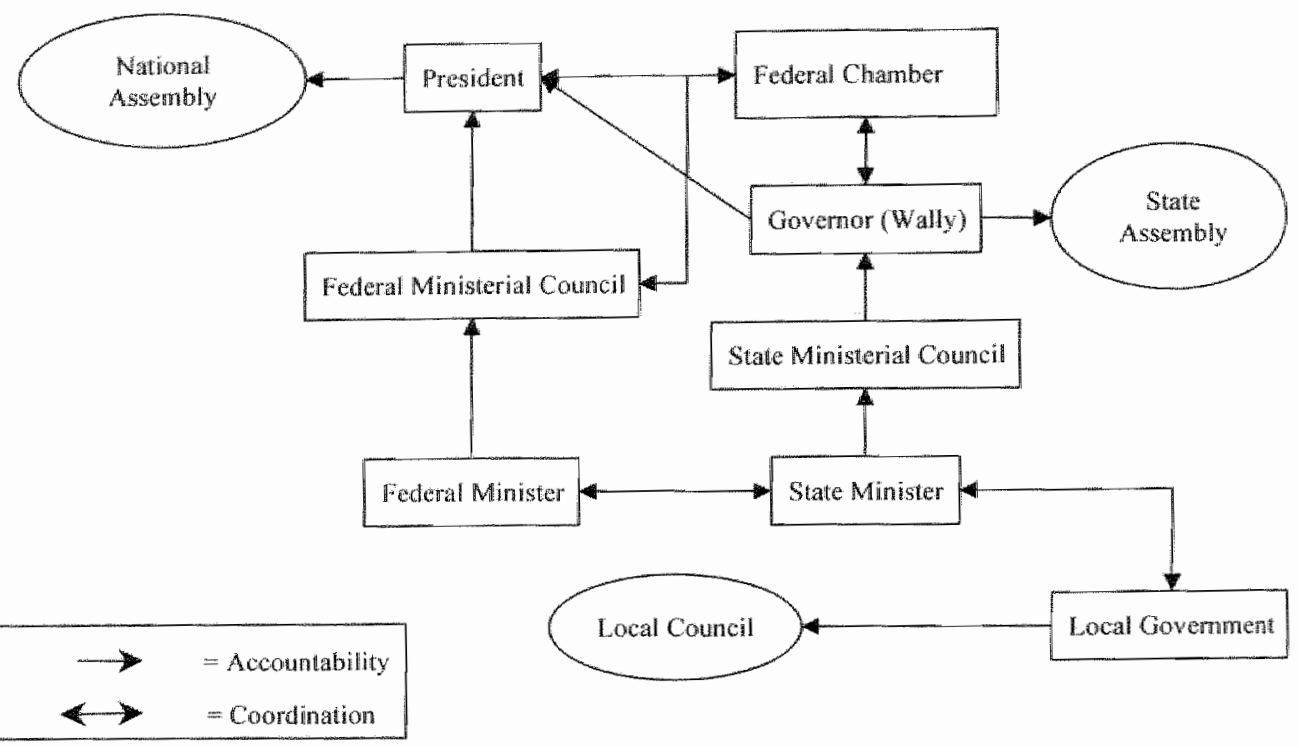

\subsubsection{The distribution of power and tasks}

The general theme in the distribution of power was to make the federal level exclusively responsible for four policy fields: foreign relations, defence and national security, and economy and inter-state affairs. Health, education, internal security and social welfare all became shared responsibilities of the federal and state level (Minister of Justice Republic of Sudan, 1998).

The distribution of power from the federal level to the state level followed an incremental pattern. This can be seen from the consecutive constitutional changes between 1991 and 1998. The Constitution of 1998 presented the last major step in the distribution of power and consolidated the allocation of tasks into three lists: federal, state and concurrent tasks. The concurrent list contained all policy fields with a shared responsibility. Legislation in these fields could be passed both at the federal and state level. However, in the case of conflicts the federal legislation prevailed. This government structure carried the risk of encouraging recentralization and contradicted the principles of federalism, namely that each level of government should have its own, original, autonomous policy tasks and responsibilities.

Although the Constitution defined the Locality (Mahalia) as the third administrative level in the division of authority, it was actually treated as subordinate to the state, which reversed the accountability of the localities. Instead of being accountable to their populace, they were only made accountable to the state author- 
ity. The relationship continued the hegemony of the states over the localities, thus repeating the experience of the Provincial Government Act of 1971. The new arrangement gave the state the opportunity to restrict the autonomy of the localities, which had already occurred on many earlier occasions (see chapter 4). In 1997, the governor (Wally) of the Southern Kordofan state even dissolved all local councils in the state (Elnaeem, 1999, personal interview). The governor justified his action by referring to the irresponsible expenditure of resources by the elites in the localities (Personal Interview with the governor, 1998). In order to protect the autonomy of the local government, the Local Government Act of 1995 was replaced with the Local Government Act of 1998. The new Act was intended to reorganise the state-locality relationship in favour of the locality. It prohibited the state governor from dissolving Local Councils.

\subsubsection{Allocation of resources}

Previous policies in Sudan paid a lot of attention to the distribution of authority. In comparison, the distribution of resources received minimal attention. As a result, resource distribution was arbitrary, inadequate, and inequitable and subject to personal and political bias (Fadalla, 1986), which in turn, resulted in a wide range of inequalities. In this respect, the current federal structure was unique because the importance of the distribution of resources was emphasised from the very beginning. The Constitution of 1998 is the last landmark in the distribution of resources. In section three it allocates financial powers and sources of revenue to each level of government (table 5.2).

The specification of sources of revenue for each level obviously improved clarity. But the revenue-generating capacity of each level depends upon productivity and the ability to utilize them. In this respect it is important to note that the sources of state revenue and localities are inelastic, difficult to collect and, in fact, offer little scope for generating revenue in the absence of substantial economic growth. Another hindrance is that the localities are likely to be on the losing side, due to the arrangement that $40 \%$ of the states business taxes must be passed to the localities, whereas the localities must pass $40 \%$ of their agricultural tax to the states. In most states business activities are still very limited, and agriculture is more pervasive. 
Table 5.2 Distribution of financial resources between the federal, state and locality level

\begin{tabular}{|c|c|c|c|}
\hline $\begin{array}{l}\text { Sources of } \\
\text { revenue }\end{array}$ & Federal level & State level: & Locality levell \\
\hline A & $\begin{array}{l}\text { Custom revenues and } \\
\text { revenues of international } \\
\text { ports and airports. }\end{array}$ & $\begin{array}{l}\text { Business profit tax pro- } \\
\text { wided a percentage to be } \\
\text { specified by federal law } \\
\text { allocated to localities. }\end{array}$ & Estales tax \\
\hline$B$ & $\begin{array}{l}\text { Company profit tax, per- } \\
\text { sonal income tax and } \\
\text { stang duty on federal } \\
\text { and interstate dealings. }\end{array}$ & $\begin{array}{l}\text { State industries' excise } \\
\text { duties }\end{array}$ & Sales tax \\
\hline $\mathrm{C}$ & $\begin{array}{l}\text { Profits of national pro- } \\
\text { jects, provided that a } \\
\text { share of these be allo- } \\
\text { cated to the states } \\
\text { which extend services to } \\
\text { the projects }\end{array}$ & State license fees & $\begin{array}{l}\text { Agricultural and animal produc- } \\
\text { tion tax, provided that there shall } \\
\text { be allocated a percentage to the } \\
\text { state by a federallaw }\end{array}$ \\
\hline $\mathrm{D}$ & $\begin{array}{l}\text { Law of Federal industries } \\
\text { excise }\end{array}$ & State taxes and fees & $\begin{array}{l}\text { Local and river means of trans- } \\
\text { port levies }\end{array}$ \\
\hline $\mathrm{E}$ & $\begin{array}{l}\text { Expatriates }{ }^{*} \text { tax and for- } \\
\text { eign institutions and ac- } \\
\text { tivities }{ }^{*} \text { tax }\end{array}$ & State projects profits & $\begin{array}{l}\text { Excise duties on local industry } \\
\text { and artisans }\end{array}$ \\
\hline$F$ & $\begin{array}{l}\text { Any other taxes or fees } \\
\text { that do not affect the } \\
\text { state's or local Govern- } \\
\text { ment's Resources }\end{array}$ & $\begin{array}{l}\text { Internal grants, loans and } \\
\text { credit facilities }\end{array}$ & Any other local sources \\
\hline $\mathrm{Gi}$ & $\begin{array}{l}\text { Grants, loans and } \\
\text { credit facilities }\end{array}$ & & \\
\hline
\end{tabular}

Source: Sudan Federal Chamber, 1998b.

\subsubsection{National Fund for Support of States (NFSS)}

The President issued an Act in 1999 to address the issue of finding an appropriate balance between the allocation of tasks, authority and financial resources to each level. Problems arose because the less developed states had to perform the same tasks as other well developed states whilst their own sources of revenue were quite limited. To address this situation, a National Fund for the Support of States was established and a National Committee was set up to manage this fund (Constitutional Decree No. 14, 1997; Sudan Republican Palace, 1999). The NFSS was supplied with resources from the Federal Ministry of Finance, International Aid Organisations and contributions of the richer states. The NFSS was also involved in investments and business activities, which could make a profit. The National Fund for Support of States (NFSS) developed a set of criteria for the reallocation of resources between the states but did not consider the reallocation between the federal level and the states (Magzoob, 1999a). However, in reality, it was difficult to use the criteria because relevant and reliable information from the states 
was lacking. Consequently, political and professional interests often influenced the actual allocation of resources (Eisa, 2002).

Despite serious problems, one must conclude that the initiative to introduce a NFSS represented a remarkable step forward. All previous decentralisation plans had completely neglected this issue with devastating consequence for the performance of the public health sector at the local level. Thus, the 1998 Constitution was an improvement on the experiences of the past. Unfortunately, the tax raising capacity of the states and particularly the localities remained far below that of the federal government. This created a big problem for the health and education sectors, which were given far less priority at the federal level than national defence and security.

\subsubsection{Allocation of manpower}

Another problem encountered in the distribution of power and resources was the concentration of the national elite and the senior public bureaucrats in the centre. The federal policy intention was to transfer a considerable part of its staff to the states and the local level. Implementing such redistribution was obviously at the expense of the federal level and therefore, negatively affected its performance. The allocation of manpower also conflicted with the personal interests of the employees and was, therefore, often resisted by them. As we have seen, this experience was not a new phenomenon in Sudan, which has previously encountered similar problems (see chapter 4).

The legislation on federalism did not clearly regulate the distribution of manpower. It classified employees into three groups: leading posts, higher grade posts and lower grade posts. The Federal Ministerial Council was held responsible for controlling the appointment and promotion of the leading posts. The highgrade posts were placed under the control of the Federal Minister for Manpower. The lower grade posts came under the responsibility of the state government. This regulation meant that the states lacked control over their senior staff, who looked more to the central government than their immediate supervisors for promotion. This proved to be an important centralistic element in the federal structure. A similar situation occurred in the relationship between the state and local level, as the state was responsible for the appointment of the local staff. This arrangement obviously restricted the autonomy of the locality, which fostered a culture of dependency and waiting for instructions. The General Law for Public Service and Administrative Reform of 1995 focused on the rights of and penalties for workers, but did not clarify the role of capacity building in the federal context (General Law for Public Services, 1997). 


\subsubsection{Mechanisms for intergovernmental coordination}

The Constitution made the Constitutional Court (CC), the Federal Ministerial Council (FMC) and the Federal Government Chamber (FGC) responsible for coordination of the relations between the three levels and resolution of intergovermmental conflicts. The FMC put this into practice through the coordination of all national policies and plans and review of performance reports. The $\mathrm{CC}$ was given the task of resolving conflicts between the different government levels on legislative issues. While respecting the responsibilities of the federal and state government, the FGC had to coordinate, communicate and organise conferences between the governor and states agencies and between the Presidency and federal agencies. The FGC was also made responsible for the setting up and supervision of the National Fund for State Support in order to achieve a fairer distribution of resources and to support those states in need.

So far, we have briefly described the constitutional arrangements made to introduce a federal government system in Sudan. Beyond any doubt, these arrangements were quite important to Sudan. Yet, the actual impact of federalism upon policymaking depends on how the federal arrangements are interpreted and how they are executed in concrete situations. This will be the subject of analysis in the following chapters. We will first examine the implications of the federal system for the public health sector in the next section.

\subsection{The organisation of the public health sector under federal gov- ermment}

The organisation of the public health sector to a large extent reflects the overall political-administrative federal structure of the government. It consists of the Federal Ministry of Health (FMOH), the State Ministries of Health (SMOH) and the Local Health Authorities. At each level there is a legislative body to deal with health legislation, which includes: the Committee on Social Affairs in the National Assembly, the Committee on Social Affairs in the State Assembly, and the Health Area Council at the local level. To execute a policy successfully at all three levels requires a clear distribution of roles to avoid overlap, dilution of responsibilities and conflicts.

\subsubsection{Federal-state relations in the public health sector}

As mentioned earlier, the Constitution of 1998 divided the responsibilities of the public health sector into a federal and concurrent list of tasks and responsibilities. The only task that was specified exclusively for the federal level by the Constitution was epidemic control. The rest of the health tasks and responsibilities were included in the concurrent list where both the federal and state government could legislate. The localities were not considered in the constitution, which was a clear 
indication that they were considered subordinate to the state level. The Federal Council of Ministers and the Federal Government Chamber acting as coordinating bodies were charged with the further elaboration of the division of tasks between the federal and the state levels. The FMOH could also issue regulations on coordination, but these were subjected to the approval of the Federal Ministerial Council. This complicated structure obviously prevented state autonomy, as did the open-ended scope of the central government to legislate on state matters and control state resources.

According to the spirit of federalism, the FMOH and the SMOH should have a horizontal rather than a vertical relationship. In this situation, the state minister is not subordinate to the federal minister. The Constitution defines these relations as follows: "There shall be between a federal and state minister a relationship of coordination, cooperation and complementation of the federal and state roles" (Sudan Federal Chamber, 1998b). "In the case of a dispute over the residual powers between a state and the federal organs, the dispute shall be referred to the Constitutional Court" (Constitutional Decree No. 14, 1997). In article 119 under the heading 'Request of data', the Constitution imposes upon the states the obligation to supply federal organs with all the information required.

The new institutional arrangements made the $\mathrm{SMOH}$ responsible for health within the state territory. The state minister was accountable to the state governor and the State Assembly instead of the FMOH. In other words, there was no longer a hierarchical relationship. In the past, the Regional Ministries of Health had been directly responsible to the National $\mathrm{MOH}$. However, the various Decrees, acts and articles of the Constitution created so much ambiguity on the relationship between the federal and state level in health affairs, that further legislation was needed to clarify roles at both levels. The National Health Council, composed of representatives from both levels, was created to judge the tasks of every level in addition to the activity of the FMC and the FGC (FMOH, 1997).

Today, there is still no consensus or approved legislation that specifies the tasks of each level. The unendorsed proposal of the General Health Law of 1998 states that the responsibilities of the FMOH include the following tasks: the development of national health policies and plans; overall health legislation; the control and notification of epidemics; coordination of international aid and relations; identification of standards for health services, equipment, supplies and manpower; and health research and training. Thus, following the formal description of the responsibilities of the FMOH, its tasks are mainly concerned with ensuring uniformity in the health system, development, support and external relations. The execution of concrete programs and services falls outside its formal responsibilities and is, therefore, left to the states and localities. 


\subsubsection{The tasks of the state in the public health sector}

There is no defined list of responsibilities for the state in the public health sector. All its responsibilities are defined in the concurrent list introduced by the Constitution of 1998. In the absence of further legislation, the actual role played by each state depends on the background and initiative of leadership. The draft of the General Health Law of 1998 described the functions of the SMOH as follows:

o Develop state health plans within the overall framework of national health policies, submit these to the federal level for finance and supervise their implementation at lower levels.

- Execute national health programs in coordination with the federal level.

o Participate in the control of epidemics and endemic diseases.

o Train paramedical personnel in collaboration with the FMOH.

o Supervise and assist localities in executing their health care responsibilities.

- Submit health reports and any required information to the federal level.

o Develop information systems to support state and the federal planning.

The SMOH is required to devolve substantial responsibilities to the local governments (localities), which is the lowest government level of the public health sector in Sudan. The role and position of health managers in the localities and communities must be strengthened to empower them as important actors in the management of the health system. The health responsibilities at the local level are mainly concerned with primary health care, environmental health and secondary health care services. They are summarized in the Health Area Policy, as we will see later in chapter 8 . Since the new arrangements have also made the state responsible for health affairs within its territory, the state should invest in capacity building at the local level allowing it to fulfil its responsibilities and thus enabling it to perform in its new role.

The allocation of tasks to each level of government was fine theoretically, but in practice it turned out to be much more complicated. Often, large gaps arose between the allocation of tasks in theory and practice between the states and the localities on the one hand and the states and the federal level on the other hand. Subsequently, the allocation of tasks was often a source of confusion and conflict between the government agencies involved.

\subsubsection{Financial relations in the health system}

Federal arrangements also required changes in the financial relationship in order to give more autonomy to the lower government levels. In the past public funding for health was channelled through the Federal Ministry of Finance to the FMOH and from there to lower-level government. The federal arrangements changed this relationship. After federal reform, the bulk of the funds flow from 
the Federal Ministry of Finance or the National State Support Fund to the State Ministry of Finance and from there to the SMOH. The intention behind this arrangement is to give the states greater autonomy as separate units allowing them to play a major role in implementation. In addition, the states are obliged to spend part of their own resources on financing health activities. A further source of state revenue is international aid. At present, the international aid flows to the states through the Directorate of International Relations in the FMOH. However, some NGOs transfer their financial assistance through other agencies than the FMOH, for instance the Federal Ministry of Finance or the National Population Council. This arrangement reduces the control that the federal health authorities have upon the international aid funds. A similar structure is found at the local level. Local health authorities receive their revenues for health in theory from three sources: (a) the State Ministry of Health; (b) local taxes and revenues; (c) national or international NGOs which prefer to work directly with communities. The latter arrangement also reduces the supervisory opportunities of state health authorities upon the local level. Figure 5.3 visualises this complicated system of financial relations in the public health sector.

Figure 5.3 Financial flows in the new federal organisation of health

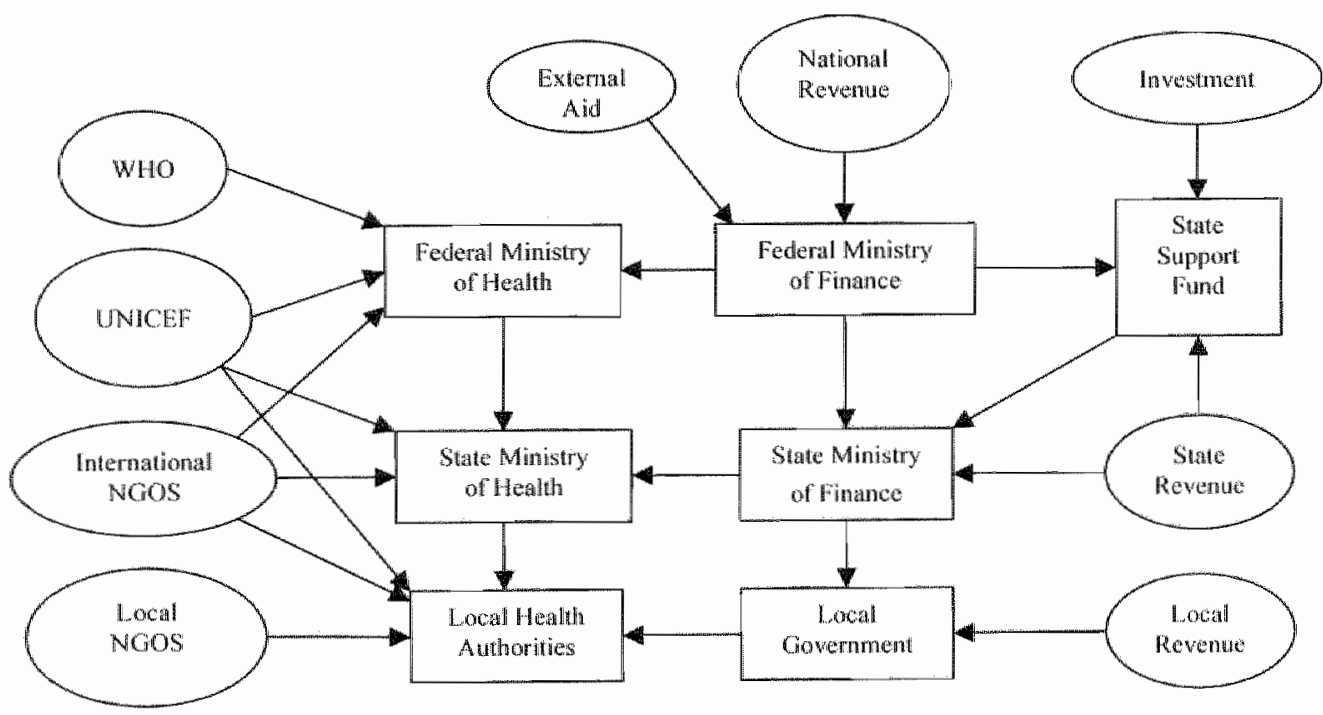

Direction of flow of money

\subsection{The development of public health policy}

The Salvation Revolution of General Al Bashier did not only mean the replacement of the former government structure by a federal system. Another important 
initiative was the Comprehensive National Strategy (CNS). This was initiated by the regime as 10-year (1992-2002) strategy to lead the development plans in the country in all areas. The CNS also had a separate section on public health policy. In this section we will give a brief overview of the main elements of the National Health Strategy. But before starting with this overview, we will first give a short description of the stages preceding the National Health Strategy, which involved the post independence era (1956-1975), the primary health care era (1976-1989) and the period of the Health Salvation Program (1989-1992).

\subsubsection{Public health in the post independence era}

Health services in the post independence era were based upon the Colonial Medical Service (Bayoumi, 1979). The post independence period consisted of three plans, namely the plan for 1951-1961, the plan for 1961-1971 and the plan for 1971-1975. These plans stressed three issues, namely: an emphasis upon preventive medicine and public health activities; the need for specialised clinical services; and an extension of the health services' network to include rural areas. The development of a health care policy followed a top-down approach and was mainly done by medical elites who usually neglected to consider implementation issues. Implementation of the plans faced various difficulties due to contextual factors such as fluctuations in budgets, rising cost of world commodity prices or limited capacity building potential .The preventive services suffered most from these difficulties (Bayoumi, 1979).

In the later stage of this era, health plans were incorporated in overall plans for the Economic and Social Development of Sudan. Bloss (1968) described these plans as unrealistic because they did not consider the financial and human resources needed for implementation.. At the end of the era, the need for primary health care activities was emphasised to increase the provision of basic health services for the entire population. In addition, there was a clear need for training and adequate health manpower was required for preventive activities and the consolidation of curative health services ( $\mathrm{MOH}, 1970)$.

The policymaking process in the post independence period followed a statecentred approach. The technical staff in the ministry worked in close collaboration with the National Planning Commission. In this period political intervention in health affairs was minimal. Popular involvement was also absent. Health services were free and tax funded. A particular point of significance was the almost complete control of the policy process by the medical elite at all government levels (Bayoumi, 1979). This explains the bias towards curative medicine at the expense of preventive medicine. 
Table 5.3 External assistance for PHC (1977-1984)

\begin{tabular}{|c|c|c|c|}
\hline Donor & Anount & Form & Notes \\
\hline India 1977 & $\begin{array}{l}100,000 \text { Indian } \\
\text { rupees }\end{array}$ & Medicines & $\begin{array}{l}\text { S. Kordofan, W. Nile and } \\
\text { Northern P. benefited }\end{array}$ \\
\hline Pakistan 1977 & $\begin{array}{l}100,000 \text { Pakistan } \\
\text { rupees }\end{array}$ & Equipment & $\begin{array}{l}\text { S. Kordofan, W. Nile and } \\
\text { Northem Prowinces }\end{array}$ \\
\hline $\begin{array}{l}\text { The Netherlands } \\
1980-84\end{array}$ & $\begin{array}{l}11,000,000 \\
\text { Guilders }\end{array}$ & Equipment, trucks and construction & $\begin{array}{l}\text { Jongli, Kassala, North and } \\
\text { South Darfur }\end{array}$ \\
\hline Qatar 1979 & $\begin{array}{l}84 \text { Toyota Vehi- } \\
\text { cles }\end{array}$ & Vehicies for training activities & All provinces \\
\hline Irand 1977 & 1000,000 US\$ & Medicinas & All provinees \\
\hline WHO $1977-84$ & $\begin{array}{l}77=\text { US\$ } \\
350,000 \\
78-84=300,000 \\
85=30,000\end{array}$ & $\begin{array}{l}\text { Experts, vehicles, office materials, } \\
\text { equipment and salaries }\end{array}$ & All provinces \\
\hline $\begin{array}{l}\text { UN1CEF 1977- } \\
84\end{array}$ & $\begin{array}{l}\text { US\$ } 600,000 / \\
\text { yearly }\end{array}$ & $\begin{array}{l}45 \text { courses, equipment, instruments, } \\
\text { medicines, curricuium development, } \\
\text { wehicles }\end{array}$ & All provinces \\
\hline $\begin{array}{l}\text { ACORD. } 1978 \text { - } \\
80\end{array}$ & US $\$ 105,000$ & $\begin{array}{l}\text { Construction, transport, training and } \\
\text { research }\end{array}$ & North Kordofan \\
\hline IDRC. 1978-81 & US\$ 53,000 & Research project & Conmunity participation \\
\hline CRS 1979 & US\$ 32,000 & Training courses & Orientation Courses \\
\hline WFP $1979-83$ & USS 612,000 & Food stuff (Nutrition) & For CHWs under traiming \\
\hline ADB. $1981-84$ & $\begin{array}{l}\text { US\$7000,000 } \\
\text { loan }\end{array}$ & Construction & $\begin{array}{l}\text { Blue and White Nile, } \\
\text { North and South Dartur }\end{array}$ \\
\hline USAID 1979-83 & $\begin{array}{l}\text { US } \$ 5,863,000 \\
\text { US } \$ 30,000,000\end{array}$ & $\begin{array}{l}\text { Construction, consultants training, in- } \\
\text { struments, vehicles, trucks, equipment } \\
\text { and medicines }\end{array}$ & $\begin{array}{l}\text { The first for Northern } \\
\text { Sudan. } \\
\text { Second (BaharelGazal) }\end{array}$ \\
\hline
\end{tabular}

Source: Baroudi, 1984.

\subsubsection{The primary health care era (1975-1989)}

This period lasted from 1976 until 1989. It witnessed the worldwide encouragement of a PHC approach triggered by the Alma-Ata Declaration. This period saw a positive change for public health, and the political context was favourable for PHC. Sudan benefited from a relatively stable political regime. The war had come to an end, and the regime stimulated popular participation to increase the responsiveness of its policies. There was a lot of motivation and commitment at all levels. Financial and technical support for the development of PHC came from the WHO and many other international organisations and countries, e.g. UNICEF, WFP or USAID (see table 5.3). 
At the National level, there was also a clear political support for PHC. In addition, the President and his party, the Sudanese Socialist Union, showed public commitment to PHC (MOH, 1981). At the provincial and the local level, the policy was enthusiastically accepted. Indicators of this support were the relatively huge resources contributed by self-help programs and the recruitment of a large number of Community Health Workers (CHWs) in a very short period of time (see table 5.4).

Table 5.4 Required and achieved PHC activities

\begin{tabular}{|l|l|l|}
\hline Iten & Required (1978-1983) & Realized/Obtained \\
\hline PHC training centes & 30 & 30 \\
\hline Community Health Workers, Tutors & 59 & 59 \\
\hline Disperasaries & 396 & 388 \\
\hline Community Health Units & 1980 & 2288 \\
\hline Community Heatth Workers & 2730 & 2453 \\
\hline Orientation Courses & 92 & 92 \\
\hline Refreshment Courses & 32 & 32 \\
\hline Managerial courses & 8 & 8 \\
\hline
\end{tabular}

Source: $\mathrm{MOH}_{3} 1983$.

The policy makers envisaged a plan of action that identified three main components: capacity building, facilities and supplies. The action plan was associated with financial commitments. The implementation of the program achieved many of its main targets as is illustrated in table 5.4. Community participation included a self-help program, supervision of local PHC services and material inputs in PHC activities. The external assistance recruited through PHC donors' conference resulted in a series of organisations and countries assisting Sudan. The plan was accompanied by various evaluations. They revealed that health policy over the period 1978/79-1983/84 achieved many of its objectives through organised policy development, political support, international inputs, and regional, provincial and community enthusiasm. However, some constraints were also identified namely:

a) Lack of integration between health promotion, preventive and curative health services;

b) A complete separation of PHC and vertical programs;

c) A decreasing community support due to declined popularity of the regime. Each of these factors contributed to the gradual cessation of the sustainability of the PHC initiative. By the end of the first stage of the program, the Ministry decided to conduct an in depth general review to prepare a plan for the future.

Since 1983, the political, economic and social crisis has had a negative impact upon the continuity of the PHC initiative. The general review was delayed and the abrupt change in the Nimeri regime disturbed the administrative system with 
adverse consequences for social services including health. Public health financing dropped to $1.3 \%$ of GDP in 1983 compared to $5.4 \%$ in 1972 , and many external funds stopped (ElBeely, 1999). These conditions had a devastating impact upon the implementation of PHC programs.

In 1987, the MOH assisted by WHO conducted an overall review of PHC performance. The report identified a large range of problems occurring in management, finance, integration, supervision and monitoring. It also observed a clear tendency towards curative activities, a serious lack of leadership and an unstable local government (MOH, 1987b; WHO, 1987a). Based on this report, in March 1988 the MOH began to develop the National Plan of Health for All (HFA) by 2000. The new policy tried to address the above-mentioned shortcomings and build on the principles of HFA 2000 and the PHC approach as outlined by the WHO (WHO, 1981). Its implementation was just beginning when the regime was replaced by a Military coup in 1989 when a new stage of policy reform was initiated.

\subsubsection{Health Salvation Program (1989-1992)}

When the Salvation Revolution of Al Basheir seized power in 1989, it announced a comprehensive reform of all aspects of socio-economic development to overcome the overall deterioration in the country. A high level technical committee was installed in 1990 to conduct an administrative salvation reform of the public services. The committee initiated a proposal for the salvation of the health services in coordination with the appointed steering Committee of the Medical Alliances and Health Professionals. The proposal was discussed by experts from different branches of the medical profession and endorsed by a seminar of representatives of all concerned with the public health sector.

The proposal summarised the deterioration of the public health sector in the period that followed 1983, and discussed a number of systemic problems. These problems included inadequate financing, a low service coverage, an inequitable distribution of services, an overemphasis on curative care, fragmented vertical programming, poorly managed facilities, inefficient institutions and personnel, and under-regulation of private health services. They ascribed these problems to a lack of political and popular commitment and, an absence of a comprehensive health policy covering manpower training, incentives, and specification of roles and regulations (Sudan Medical Association, 1990).

The proposal recommended the following objectives:

a) To build a political and popular commitment to health care;

b) To develop appropriate and realistic health polices;

c) To improve the administrative capabilities of the public health sector;

d) To improve the morale of health professionals and workers; 
e) To increase the cost effectiveness of health programs and

f) To develop alternative methods of financing, including community participation.

The proposal also recommended a Health Salvation Committee to implement these recommendations.

In accordance with the proposal, the government established a Committee for Salvation in the public health sector in 1991. Three main members of this Committee came from outside the $\mathrm{MOH}$, namely the Chairman, the Secretary General, and the Finance Secretary, who were all strong proponents of the regime. A supervisor from the Central Organisation for Administrative Reform was added to the Committee. Most of the other members of the Committee were regine supporters from the public health sector.

The Committee sought to develop a national consensus through holding a National Conference on the Public Health Sector. For this purpose, it carried out a pilot project in the immediate vicinity of Khartoum. Furthermore, it established several subcommittees. During its activities, the Health Salvation Cormmittees and the MOH bureaucracy were involved in a number of conflicts on priorities, strategies, resource allocation, and implementation arrangements (Personal interview with former undersecretary). Despite these conflicts, the various subcommittees managed to rehabilitate the major hospitals in urban areas. The catering. and cleaning services in the hospitals were privatised. In addition, it managed to reduce the pressure on teaching hospitals by rehabilitating peripheral hospitals and by opening seventeen new health centres. Many hospitals received new equipment. In addition, the subcommittees reorganised the environmental sanitation activities and set up a drug revolving fund. The target of self-help contributions increased by more than $300 \%$. The result clearly indicated that a systematic and planned approach could improve the performance of the health system.

Based on the positive results, the government aimed to extend this successful approach to the entire country. However, as is so often the case, such a success cannot be easily extended to other areas and settings. The successful reproduction of a project often fails because it must be transferred to a completely different environment, with different financial and human resources for example. The early relative success of the Salvation stage was due to the fact that there was a strong political, administrative, financial and technical commitment to reform. The interventions were based upon a systematic approach that encouraged the participation and involvement of the people. The regime's highest priority was to establish legitimacy and to reform the non-controversial public health sector from which all sections of population could benefit. Because of the political momentum involved, the immediate results were satisfactory. However, sustaining a similar performance throughout the country for a long period of time would require a solid institutional structure across the country as well as adequate financial and human resources. Many of the rural areas lacked such a structure, how- 
ever, and the costs and difficulties involved in relocating professionals from urban to rural areas and the training of new professionals were immense. Sustaining political interest and motivation at sub-national level also proved to be very difficull. In addition, there were problems of bureaucratic vertical programming, absence of strong societal interest organisations such as political parties at the grass-root level, lack of awareness for health services and the gradual deterioration of government institutions in the rural areas.

\subsubsection{The public health component of the NHS of 1992-2002}

In order to give concrete shape to the ideas of the Salvation Program, a subcommittee was entrusted with the development of a ten-year National Health Strategy within the Global Conference for a Comprehensive National Strategy (CNS) in 1991. The National Health Strategy (NHS) was a substantive Public Health component of the CNS, comprised of ten middle size pages. Its introduction stated that: "Health development is a continuous task in the society, and one of the basic factors for the realization of its renaissance and development. It is important that there be a harmony between social progress, including health and the society"s economic development. Each one is a guarantee for the realization of the other, and both guarantee the establishment of the global civilization renaissance, fostering strength harnessing existence and values" (Sudan Republic, 1992, p. 85). The introduction went on to emphasise that health is a responsibility of the whole nation and not only the public health sector, "health in this context ceases to be a service sector only, to become a major social objective, where the efforts of all the sectors join together to achieve its comprehensiveness" (Sudan Republic, 1992, p. 85). Thus, the NHS stressed the responsibility of society as a whole towards the public health sector. Further, the document stated "health services development with a view to provide health for all is the responsibility of the whole society" (ibd). In order to achieve this, the NHS adopted the philosophy of basic health care and the PHC approach, where health services should be made accessible to the entire population. Three tiers of statements on policy guidelines, sectoral goals, and priority issues underpin the NHS's broad philosophy.

Nevertheless, despite the intention of NHS to deliver PHC it never paid due attention to the Health Area Policy (HAP), which is the main instrument for implementation of PHC at the local level.

\section{Policy guidelines}

As stated in the NHS: "The following policy guidelines emanated from the global guidelines of the social development sector:

- Man is the goal of the social development and its means, and social justice is its ultimate noble goal. 
o The family constitutes the first nucleus of society, and it must be given the attention it deserves, improving its potentialities and ensuring its basic needs and protection. The adoption of the proactive and solidarity and family's concept and its legislation into law, is indispensable in enabling it to full its great social responsibility.

o Social development is a common effort and the fruit of work of solidarity between the citizen, the state and society.

- Popular participation is a comerstone of social welfare and development.

- Education aims to at inculcating religious doctrine and good social customs, and working towards strengthening national unity, allegiance to the nation, participation in its construction, and the protection of its environment" (Sudan Republic, 1992, p. 85).

\section{Health sector goals}

NHS formulated the following goals for the public health sector:

- The generalising of basic health care in terms of health improvement, prevention, treatment and rehabilitation in all parts of the country.

- Decreasing child mortality to less than $2 \%$.

- Generalising of maternal care programs all over of the country and the improvement of their quality.

- Eradicating chronic and contagious diseases resulting from malnutrition.

o Promoting of the environment, its protection and the prevention of its pollution.

- Generalising the vaccination to attain 100\% coverage.

- Rehabilitating of hospitals; raising their capabilities and making the available hospital beds according to internationally recognized standards ( 3 beds per 1000 persons); consolidating medical services to dispense people from the need to be treated abroad.

- Decreasing sick-leave time of workers by $20 \%$.

- Making medicines easily available.

o Establishing medical industries to produce hospital instruments, surgical, medical and laboratory, doubling what is available and to attain selfsufficiency in the basic equipment.

- Developing human resources: doctors, technicians, assistants and nurses.

- Updating health information systems, generalising them and giving attention to health education and health awareness.

\section{Priority issues}

The NHS stated the following priority issues that represent the typical health problems seen in developing countries:

o high maternal and child mortality;

- malnutrition and poor environmental sanitation; 
o the deterioration of health care facilities;

0 insufficient availability of medicines and medical supplies;

0 inadequate human resources for health;

- poor health financing;

- lack of appropriate health information and statistics.

The NHS defined six to twelve objectives, strategies and programs to address these priority issues, which resulted in a total of seventy eight specific objectives that should be achieved within ten years (CNS, 1992). For example:

o In mother and child health care, the specific objectives included: the generalisation of vaccination for children under 5 years to achieve $100 \%$ coverage; the decrease of child mortality from 123 per 1000 to 45 per 1000 ; the decrease of maternal mortality from 552 per 100,000 to 225 per 100,000 ; the development of a national program for school health, et cetera.

- With regard to communicable diseases, the specific objectives included: the eradication of malaria, billharzias, tuberculosis, leprosy, et cetera; the adoption of multiple interventions to combat and eradicate these diseases including the availability of safe drinking water, health education and combating disease carriers.

- In curative medicine the specific objectives included: the rehabilitation of all health facilities and the establishment of new ones to achieve internationally acceptable rates such as a health centre for 20,000 citizens, a rural hospital for 40,000 citizens, et cetera.

o In health financing the proposals included: an increase of government investments in health; encouragement of community financing; support from Sudanese who are working abroad; encouragement of private health practice and organisation of insurance systems.

o In health information and statistics, the objectives included: setting up a national institute for information system; training of staff to support information systems and increase of data available to decision makers and planners at all levels.

\subsubsection{General remarks about the NHS}

In general, the NHS addressed health promotion as well as protective, preventive and curative aspects of health care. Nevertheless, it introduced a number of problems in its structure, presentation and contents, which were due to the contextual elements that influenced the process of policy development. Due to the lack of planning experts in the committee, the NHS strategy lacked a proper presentation. The way the programs were written lacked a sound scientific view of programming. The general goals were mixed with programs, programs with strategies, general objectives with specific objectives and the outcomes with program 
outputs. Also, the policy lacked a systematic integrated pattern in its presentation. In fact, its formulation only reflected the concerns and interests of the different participants.

The NHS also included unrealistic targets that neglected the reality of the existing human and physical resources of the country. In some instances, it even contained contradictory objectives such as increasing hospital beds and reducing curative services.

Though the NHS began with a comprehensive introduction, it lost its comprehensiveness when it reached the program level. There were also inconsistencies beiween the policy and programs. While recognizing many of the problems of the sector, the NHS appeared to be a long list of special interest programs. Each disease and program priority was included, based largely on the old public health paradigm, while little attention was paid to the methods of financing health services, the role of the existing public health sector institutions, or the regulation of the private sector. Also, it tended to concentrate on curative aspects, which can be explained by the dominance of the clinicians in the committee who also had little experience with implementation issues.

Thus, the NHS tended to be more or less a health care policy rather than a health policy with a comprehensive view on health care. The CNS conference was a good opportunity to make use of the different experts in developing a healthy public policy, but that did not occur due to many barriers. Among these barriers was the common belief among politicians that health is the prime responsibility of medical doctors. Moreover, the Committee could have used the global conference to advocate the priority of health to other sectors' committees. It could have stimulated all participants of the conference to consider health issues in their sectoral policies. However, none of this occurred. The Committee was dominated by academics, especially regime proponents, with only a minimal representation for the MOH. The then MOH Undersecretary wrote a memorandum expressing his frustration on undermining the role of $\mathrm{MOH}$ in the process of policy-making (Khairy, 1992). Thus, the NHS was more the outcome of a politically oriented conference rather than a systematic problem solving activity.

\subsection{Review from the perspective of Grindle's model}

This chapter addressed three issues. Firstly, we presented an overview of federal reform in Sudan. Secondly, we investigated its consequences for the administrative structure of the public health sector. Thirdly, we briefly explored health policy development in Sudan since 1956. Special attention was given to the current National Health Strategy.

According to Grindle's model, an investigation of policy implementation must start with an analysis of the plan and programs that will be implemented. In other words, the policy content must be studied as well as the process of policy devel- 
opment. The policy content can be conceptualised as the result or outcome of policy development. From this perspective, the following observations can be made. Each of these observations has important implication for the process of implementation.

Federal reform was introduced by the political regime in response to many contextual factors. The motives for choosing federalism were an interest in the ending of the civil war and a desire for rapid progress in development as a means of building political legitimacy. Due to these intentions the policy process was conducted at a great speed. It resulted in an ambitious and in many respects unrealistic federal reform that did not take into account the multitude of problems that the country faced such as the enormous lack of financial, administrative and technical resources.

The regime benefited from its military background and revolutionary nature. It effectively placed a centralised grip upon the legislative process. However, little attention was paid to the development of a common understanding, and achieving consensus and commitment from the important political and sociall groups as well as the civil service in order to facilitate implementation. Despite the organisation of a Comprehensive National Conference, community involvement was of a limited symbolic value. The policy process followed a top-down approach. Agencies, which would be directly involved in the implementation process, were not really consulted and had only a marginal influence on the political decisionmaking of federal reform.

Federal legislation consisted mainly of general statements, which needed further operationalisation and more detailed action programs in order to be put into practice successfully. Operationalisation includes the specification of roles, intergovernmental relations, financial relations, manpower, means of coordination and, moreover, the instruments for concrete implementation. Given its redistributive character, the operationalisation of federal reform could be expected to be a very complicated process. Federal reform affected the power and interests of many actors at all levels of government. Furthermore, there were various potential conflicts built into reform. In the next chapters, we will investigate how the implementation of federal reform in the public health sector proceeded at the federal, state and local level.

This brings us to the second topic of discussion in this chapter, which was concerned with the impact of federal reform upon the administrative and governance structure of the public health sector. The impact was great, at least in theory: federal reform should have resulted in a new distribution of tasks, powers, financial relations and manpower. But, as with federal reform in general, a great deal of operationalisation was required in order to make the new arrangements functional. And, again, there were many potential conflicts built into the new administrative structure, for instance with respect to the formulation of concurrent tasks and the complicated mechanisms of intergovernmental coordination. 
Finally, we presented a brief description of health policy development. Here, we observed that the health policy process was continuously dominated by the medical profession and used to follow a top-down approach. Health was also considered a low priority in the federal political agenda. Policy development was influenced by the same contextual factors that affected federal reform. Being part of the Comprehensive National strategy, the National Health Strategy consisted of a heterogeneous set of general and often ambiguous goals, which required further refinement and elaboration in order to be exectuted effectively. A major problem was that these goals could be interpreted in different ways or could be given different priority and that no serious attention had been given to the development of a concrete and realistic action program to facilitate their implementation. The National Health Strategy was not supported by clear commitments on human and financial resources. In fact, a large gap existed between the goals of the National Health Strategy on the one hand and the human and financial resources available for their implementation on the other hand.

To conclude, we can say that the chance of successful implementation of federal reform in the public health sector and the National Health Strategy was poor. The content of federal reform and the National Health Strategy suffered from many problems that also manifested themselves in the implementation process. The following chapters will consider this process in detail. 


\section{Chapter Six \\ Implementation at the federal level}

\subsection{Introduction}

In the previous chapter we described the developments in the public health sector within the context of ongoing decentralisation. From this chapter onwards, we will analyse the implementation of the federal reform in the public health sector since 1993. This chapter focuses on the Federal Ministry of Health (FMOH), which was required to adapt its structure and processes to its new tasks and responsibilities after the introduction of the new federal structure. The implementation of federal reform at the federal level can be conceptualised as the first important step in the implementation process. One may expect implementation failures at the federal level to influence the process and outcomes of federal reform at lower government levels.

The chapter begins with a discussion on the role of the FMOH and other federal agencies involved in decentralisation. We will continue with an analysis of the actions carried out by them, particularly with regard to changes in structure, planning, financing coordination, monitoring, and capacity building. Finally, we will consider the results of these actions and compare them to the objectives that they were expected to reach. The data for our analysis is taken from structured and semi-structured interviews held with the main actors involved, focus group discussions and the official records available. An overview of interviews and guidelines for focus group discussions used can be found in the annexsee annex 1).

\subsection{Past experience of policy implementation}

In Sudan, there has never been a great awareness of the multi-dimensional and complex nature of public policies such as decentralisation. Generally speaking, the approach to the implementation of major policy decisions has been simillar to that of routine decisions. Policy designs rarely pay attention to the implementation of the policy, or to its political dimension. In the public health sector, political executives and senior administrators tend to consider health policy-making as a technical affair, requiring only medical knowledge. The administrative and political feasibillity of policies is never being seriously examined or questioned. The strategy and policy documents are often prepared by experts from outside the FMOH as was the case with the Comprehensive National Health Strategy of 1992.

Sudan's record on policy implementation is not encouraging. Many ambitious policies faced considerable political and bureaucratic indifference and, at times, 
even outright resistance (Maddick, 1981; Rondinelli, 1981a; Moharir, 1986). As Grindle and others observed, political affairs play an important dimension in the success or failure of a policy. In developing countries, political influence is often absent or hidden during the policy formulation stage; however, it is immediately obvious during implementation (Grindle, 1980; Grindle \& Thomas, 1991). The chance that implementation will be neglected is very high when it requires the cooperation of many agencies within the same government level (horizontal cooperation) and cooperation between the different government levels (vertical cooperation).

Implementation can generally be considered the 'Achilles heel' (the most vulnerable part) of the policy process, particularly in developing countries (Iglesias, 1978). The implementation of decentralisation in developing countries has generally enjoyed very limited success (Rondinelli, $1981 \mathrm{~b}$; Mawhood, 1983; Conyers, 1984; Moharir, 1986; Wunch \& Olowu, 1990; Bossert, 1996; Collins 2000; Olowu, 2001). An explanation for this lies in the redistributive nature of decentralisation, which dictates that political and administrative power and access to resources are shared. This often provokes overt or covert resistance.

Federal reform affected the FMOH in two ways. First, most of its executive functions in service delivery (e.g. running hospitals) were taken away, and second, it had to reorient its role in national policymaking. Its main responsibilities included formulation of general health policy and planning, supervision of the implementation of health programs throughout the country, health research and coordination of external agencies. This process of reorientation and transferral of tasks, resources and personnel to sub-national levels as well as the adoption of a new role in policymaking required difficult structural and attitudinal changes (European Commission, 1996). Consequently, the successful implementation of this ambitious decentralisation program in the public health sector strongly depended upon the supportive and facilitative role of the FMOH.

An added complexity of decentralisation in the public health sectors of developing countries is that it is often introduced for political reasons and must be implemented with great speed. Consequently, there is not enough time for adlequate preparation for implementation. To add further complication, in developing countries the public health sector does not usually have a great deal of visible political appeal and as such does not receive priority in the appointment of senior officials or in the allocation of resources (Walt, 1994). In addition, there are problems concerning the background of political executives and senior administrators. They often lack necessary experience in health care or in policymaking on complex health care issues. In Sudan, senior administrators in the public health sector mostly have a background in medical science and not in policymaking and management. 
Based upon her investigation of the experiences of policy implementation in many developing countries, Conyers (1986) formulated a number of prerequisites for the successful implementation of a policy. These prerequisites can be applied to the public health sector of Sudan in the following way:

o High-level political support for decentralisation, particularly for public health, as its political lobby in developing countries is mostly non-existent.

- Restructure of the FMOH so it can function in its new role, including organisational arrangements for the high level monitoring and steering of implementation.

o Involve the relevant stakeholders in designing and executing the implementation of decentralisation.

o Enhance the capacity of the relevant federal agencies and particularly the newly created structures at the state and locality level.

o Periodical review of the progress of implementation with the intention of bringing problems and issues to the notice of the relevant bodies for taking remedial action.

\subsection{Changes required in the $\mathbf{F M O H}$}

The new role and responsibilities of the FMOH were laid down in various constitutional amendments, new health legislation, Presidential Decrees issued during implementation, and executive instructions. The organisational structure of the FMOH had to be adapted in view of its new responsibilities. In addition, policymaking and planning had to be restructured, and the staff had to be trained and motivated. The size of the ministry had to be drastically reduced as most personnel-intensive service functions were transferred to lower government levels. The remaining staff would be few in number and needed to be highlly experienced and trained for its new functions, which included policy planning, supervision of implementation, identification of bottlenecks and utilisation of administrative and political resources to find possible solutions. The staff required skills, knowledge and experience in policy analysis, implementation analysis, troubleshooting, persuasion, and motivation.

The challenges facing the FMOH could not be met without support. For this purpose, there were other federal agencies involved such as the Federal Ministry of Finance, the Federal Ministry of Manpower and Labour Force, the Federal Ministerial Council, the Federal Government Chamber and, finally, the Federal Parliament. Decentralisation in the public health sector demanded an active support from all these federal organisations to help improve the legal, regulatory, financial, procurement, management and human resources necessary for decentralisation. The FMOH had to mobilise this support. Important determinants of successful decentralisation were the orientation and motivation 
of political and administrative leadership. In this chapter, we will consider specific actions taken by the FMOH.

To study the implementation process, we will briefly review the legislation on decentralisation, the decisions taken by the high level authorities and the relevant documents such as departmental plans, budgets, internal and external interaction of agencies, conference reports and internal dynamics in the FMOH.

\subsubsection{Allocation of functions within the public health sector}

It is often difficult to pinpoint the exact date of the beginning of the implementation of a policy. We take February 1994 as the starting point of federal decentralisation in the public health sector, when the twenty-six new states came into being and when all-important positions at the federal and state level had been filled. These appointments included the Federal Minister of Health, the twenty-six State Ministers of Health and the members of the Federal Government Chamber and the Federal Ministerial Council charged with the implementation of the federal reform.

The allocation of functions to the federal, state and local level in the public health sector was done through Constitutional Decrees 10,12, and 14 and the Constitution of 1998. These charged the Federal Government Chamber and Federal Ministerial Council with the task of coordinating the implementation of federal decentralisation. One of their main responsibilities was to review previous legislation regarding centre-region-locality relationships, which could be abolished, amended or replaced.

In contrast to the incredible speed with which the constitutional changes were rushed through, the creation of supplementary legislation by the Federal Government Chamber and Federal Ministerial Council or the FMOH was hindered by delays and received little enthusiasm. According to Articles 10, 11 and 12 of the Constitution, public health was part of the concurrent list under which both the federal and the state legislatures were given authority to legislate. The specification of which public health sector responsibilities would remain at the federal level and which would be transferred to the state and locality level was very important. This task was assigned to the four main federal organisations, namely the Federal Government Chamber, the Federal Ministerial Council, the Attomey General and the FMOH, with the latter being the leading agency. The National Health Council was created as an advisory organ to stimulate, facilitate and coordinate the health decentralisation process.

In practice, the whole process proceeded rather slowly. Out of twenty-nine health related laws, which needed adjustment, only three were revised. These were the General Health Law 1975, the Environmental Health Law of 1997 and the School Health Act of 1998. The reasons for this delay were numerous, ranging from lack of enthusiasm amongst the FMOH's leadership and staff to the reform, 
inadequate follow up of the Federal Government Chamber and Federal Ministerial Council and, most importantly, the absence of any high level political pressure to expedite implementation. For example, the Secretary-General of the National Health Council did not issue a single memorandum to the parties involved in order to encourage, stimulate or clarify their role. The delay in the whole process and the lack of enthusiasm among federal agencies to expedite implementation created a vacuum, in which all actors interpreted the general constitutional provisions concerning their responsibilities in their own interest.

Nevertheless, some initiatives were taken such as the Federal Ministerial Council Act 489 of 1996 on the organisational structure of the FMOH. However, these initiatives were restricted mainly to description of the tasks of the directorates in the FMOH without actually clarifying the scope and limits of federal interventions under the concurrent legislative role. The guidelines issued by the Federal Government Chamber on the application of the federal system to the public health sector were another initiative, which included a specification of the functions at the local level (Federal Government Chamber, 1998). Neither the Federal Minister nor the Undersecretary of Health was consulted concerning these initiatives, and as a result, proposals lacked political support, specificity and administrative feasibility. We can conclude, therefore, that the effectuation of the constitutional provisions for the implementation of decentralisation in the public health sector at different levels was intermittent, delayed, fragmented and lacked consensus among the stakeholders involved.

\subsubsection{New functions of the Federal Ministry of Health}

The Federal Ministerial Council Warrant No. 489 of 1996 and the modified General Health Law of 1998 listed the FMOH's tasks as the following:

o Health policy formulation, national health legislation and strategic health planning.

o Definition of national health standards.

o Human resource development.

- Overall monitoring and evaluation of national health policies.

o Coordination, regulation and promotion of international relations.

These tasks obviously needed further specification. They should have been brought to the notice of all those concerned and agreed upon by all stakeholders, but, this did not happen (FMOH, 1997a). The federal level's and the constituent states' lack of experience with concurrent powers led to permanent confusion and ambiguity in the implementation process. 


\subsubsection{Senior political and administrative leadership}

As stated earlier, the FMOH was required to play a crucial facilitative role in the implementation of the decentralisation program in the public health sector. The Federal Minister of Health and the Undersecretary were required to play key roles in this process. However, their performance depended very much on their background, their attitude to change, and their desire to expedite the implementation process. Tables 6.1 and 6.2 show the professional background, policy and management capacity, period of term, and orientation towards federal reform of these top-level incumbents.

As can be seen in these two tables, there was a very high turnover in both positions, the average ministerial period being no more than two years. The term of the undersecretary was even shorter; in one instance it was only one year. This rapid succession within the two leading positions disrupted continuity and prevented the development of a long-term strategy for change. The Federal Minister of Health and the Undersecretary did not provide sustained leadership to the public health sector as a whole, and the staff members of the FMOH in particular were not enthusiastic about giving up their functions and privileges.

The appointments to the aforementioned posts and those of the directors-general of the various divisions within the FMOH were based on political patronage. In this context, it is important to remember that the new regime had come into power through a military coup. The regime's main priority was to build up legitimacy and to block its opponents from access to power. The main criteria for appointment to these posts were not experience or professional background but the loyalty of the incumbent to the regime and its political priorities. It can be seen in table 6.1 that two of the Ministers of Health had a military background. The third Minister of Health was a former secondary school teacher, and not one of three had any previous experience in health or social affairs.

The approach of all three ministers to decentralisation was lukewarm, passive and formal. None of them visibly mobilised the ministry to actively implement the decentralisation program. The first minister (1993-1995) concentrated mostly on the routine restructuring of the FMOH without paying much attention to building the capacity of the states and localities. The third minister (1998-2000) focused on the vertical programs mainly because they were financed by outside organisations like WHO, UNICEF, which had liquid cash. Only the second minister (1995-98) demonstrated some interest in supporting the constituent states. She showed an interest in organising seminars and conferences to discuss some of the implementation issues, encouraged planning and research activities, had good contacts with the NGOs, good working relations with the Federal Government Chamber and direct contact with the party leadership in the public health sector. 
Table 6.1 Information on the background on the Federal Ministers of Health (1993-2000)

\begin{tabular}{|c|c|c|c|}
\hline Durration & $18.1 .1993-20.4 .1996$ & $20.4 .1996-8.3 .1998$ & $8.3 .1998-24.1 .2000$ \\
\hline $\begin{array}{l}\text { Basis for } \\
\text { appointment }\end{array}$ & Political patronage & $\begin{array}{l}\text { Women's representation, loyal ty } \\
\text { to the Regine }\end{array}$ & Political patronage \\
\hline Background & Military & $\begin{array}{l}\text { Teacher, } \\
\text { State Minister for Refingees }\end{array}$ & Military \\
\hline $\begin{array}{l}\text { Past experience in } \\
\text { health affairs }\end{array}$ & None & None & None \\
\hline $\begin{array}{l}\text { Priorities in public } \\
\text { health sector }\end{array}$ & $\begin{array}{l}\text { Floods, war, } \\
\text { restructuring of federal } \\
\text { MOH }\end{array}$ & $\begin{array}{l}\text { Support to states, conferences, } \\
\text { support of PHC, interest in } \\
\text { planning and research, contacts } \\
\text { with NGOs, Federal } \\
\text { Government Chamber and the } \\
\text { party leadership }\end{array}$ & $\begin{array}{l}\text { Vertical programs of } \\
\text { FMOH }\end{array}$ \\
\hline Main constrainis & $\begin{array}{l}\text { Low priority for health } \\
\text { matters, ambiguous } \\
\text { interdepartmental } \\
\text { relations }\end{array}$ & $\begin{array}{l}\text { Conflicts with MOF, conflicts } \\
\text { with Khartoum State Ministry of } \\
\text { Health, lack of visible high } \\
\text { political support }\end{array}$ & $\begin{array}{l}\text { Fragmentation of FMOH } \\
\text { departments, undear } \\
\text { wision of FMOH }\end{array}$ \\
\hline $\begin{array}{l}\text { Main actors relied } \\
\text { upon in decision- } \\
\text { making }\end{array}$ & Medical specialists & $\begin{array}{l}\text { Regime proponents outside and } \\
\text { inside the ministry }\end{array}$ & Ministry Bureaucrats \\
\hline
\end{tabular}

Source: Interviews supported by FMOH records.

All three ministers faced many constraints. The two ministers with a military background felt the constraints of the low political priority for health in the federal government, the presence of ambiguous vertical and horizontal relationships and the fragmentation of work between the directorates of the FMOH. The main constraint felt by the minister who was formerly a teacher related to conflict with powerful constituent states like Khartoum and the lack of visible, higher level political support in overcoming this conflict.

All ministers had to rely on internal or external actors because of their lack of experience in public health sector policy management. Whereas the inclination of the two ministers with a military background was to rely internally on either the medical professionals or the bureaucrats in the ministry, the minister with a teaching background mainly relied on regime proponents from outside and inside the ministry. In all instances, the results were far from optimal. The medical professionals always tried to safeguard their hegemony in decision-making by placing a strong emphasis upon curative rather than preventive medicine. Their technical approach to policy issues also prevented them from considering the role of politics in implementation. The bureaucrats, though more sensitive to policy and management issues, were more concerned with maintaining their vested 
interests and extra income, which they generated from attending conferences and other activities in the vertical programs. They hardly ever identified themselves with the view of the states or the localities. Instead, they continued the status quo and tried to keep their hold, even on matters that had been constitutionally transferred to the lower levels. The involvement of the regime proponents outside the ministry could have been useful in bringing in some fresh ideas on the rapid implementation of decentralisation, but their main concern was also to ensure their own personal and party interests in the process.

The lack of relevant professional experience on the part of the minister could, perhaps, have been compensated by that of the senior permanent staff in the ministry, namely the undersecretary and the directors-general of the various directorates. However, as we will illustrate below, this did not happen. Table 6.2 shows that all five incumbents of the undersecretary's post had some professional background and experience in health. In most cases, their experience was only in a medical specialty. Only two incumbents had a background in planning and health administration.

Table 6.2 Information on the background of the Health Undersecretaries (1989-2000)

\begin{tabular}{|c|c|c|}
\hline Term & Background & Managerial training \\
\hline $1989-1992$ & $\begin{array}{l}\text { Public Health } \\
\text { Administration }\end{array}$ & Trained and experienced \\
\hline $1993-1995$ & Clinician & Untrained \\
\hline $1995-11996$ & $\begin{array}{l}\text { Public Health } \\
\text { Administration }\end{array}$ & Trained and experienced \\
\hline 1996.1998 & Clinician & Untrained but had practical experience \\
\hline $1998-2001$ & Clinician & Untrained \\
\hline
\end{tabular}

Source: Interviews supported by other records.

Clarificarion: the level of training was measured by asking the undersecretaries abowt their attendance of training courses in monagenent, policy analysis, strategic planning and budgeting. If an whdcrsecretary had been in a leading position in health care or elsewhere earlier, helshe was considered experienced.

Previous background and experience are, of course, not the only important factors. A great deal also depends on the orientation and motivation of persons in senior leadership positions like that of the undersecretary. Although, formally the undersecretaries were responsible for the implementation of decentralisation in the public health sector through the transferral of authority, financial and human resources to the subnational levels, the speed and enthusiasm with which they did this strongly depended on whether they wholeheartedly supported the drastic reduction of the role and authority of the Ministry. Three of the five incumbents of the undersecretary position openly opposed decentralisation and did not believe in decentralisation of the devolutionary type. In their view, the subnational level lacked the capacity or willingness to perform their functions 
effectively. As a result, they did not treat the state or the local level government as autonomous entities but as appendages of the FMOH. They practiced deconcentration in their relationships vis-à-vis the lower levels, prevented the involvement of the states and localities in vertical programs and tried to recentralise decision-making on matters assigned to the states and the localities, using their powers in concurrent legislation. The other two incumbents were incapable of mobilising any political support for the implementation of decentralisation.

From our analysis we can conclude that the incumbents of the minister's post were not able to provide strong leadership or guidance to their staff, nor were they able to win support for the rapid implementation of decentralisation from the other federal agencies, in particular the Federal Ministerial Council. The incumbents of the post of undersecretary could not compensate these inadequacies, due to their own lack of experience in decentralisation policy and management. Even more importantly, they opposed the devolution themselves. These factors help to explain why the implementation of decentralisation failed in terms of the amount of time it took and its content. A gap gradually evolved between the initial intentions and promises of decentralisation and what occurred in practice.

\subsection{Structural change and compliance}

In the absence of strong guidance from the Federal Ministerial Council or the Federal Government Chamber, the response of the $\mathrm{FMOH}$ to decentralisation originated mainly from the personal vision of the Undersecretary of Health. However, there was a high turnover in this important post as can be seen in table 6.2. In addition, the undersecretaries were frequently untrained for their task. An exception to this was the appointment of the undersecretary in 1995 who had experience with the work involved as he had previously occupied the post between 1989 and 1.992 and also had a PhD in Public Health Administration. He was a proponent of the regime with some clout in political lobbies. Thus, theoretically he had the right credentials to carry out the reorganisation and reorientation of the FMOH in the right direction. However, his efforts were met with contradictory responses from within and outside the ministry.

His approach to reorganisation was to increase the number of senior positions in the ministry. This approach enhanced the promotion and appointment opportunities for senior staff with high political influence, particularly in the lucrative managerial positions of the vertical health programs financed by WHO and other foreign donors. There were others in the ministry that could not benefit from the reorganisation and, thus, were not enthusiastic about the changes. Those who had been previously appointed to these positions were afraid of losing the benefits that they had become accustomed to. As a result, reorganisation became an object 
of intra-bureaucratic politics within the FMOH rather than a means of further facilitating decentrallisation in the public health sector.

Since Sudan's independence, administrative reorganisation has often been used as a way to rid the government of unwanted supporters from the previous regimes or as a means of providing benefits to supporters of the new regime. It was not, however, used as a means for improving the administrative performance. This was achieved through manipulating the number of senior positions (undersecretary and directors-general of different directorates) or the requirements for these positions. As a result, the number of senior posts in the FMOH frequently changed. Since independence, it varied from six to fourteen and finally settled at ten in 1992 prior to introduction of the federal system.

In 1994, the FMOH submitted a new structure for the ministry to the Federal Ministerial Council for approval. The proposal maintained the pre-existing ten senior posts but with some changes in responsibilities. According to the decisionmaking procedures, it first needed the approval of the Ministry of Public Service and Labour Force before the Federal Ministerial Council could take a decision. In view of the bad economic situation and to minimise inter-ministerial conflicts on the number of senior positions, the Ministry of Public Service and Labour Force preferred to adopt a common hierarchical structure for each ministry with the same number of senior positions, irrespective of the magnitude and the nature of their work (personal interview with FMOH Undersecretary). The conflict between the two ministries lasted for more than two years (1994-1996). The Federal Ministerial Council Act 489 finally settled it in November 1996. This long delay illustrates that no one in the higher governmental leadership placed a high priority on the quick implementation of decentralisation despite the political rhetoric. Implementation of decentralisation was the victim of high-level political indifference and petty inter- and intra-bureaucratic politics.

\subsubsection{Consequences of structural change}

The new structure did not differ much from the previous situation. In compliance with the standard number of senior posts for each ministry, the number of senior posts in the FMOH was reduced to eight. This step involved combining the two directorates of Medical Specialities and Curative Medicine into one and converting the Directorate of Medical Supplies into an autonomous agency located outside the ministry. In the new organisation, the Directorate of Financial and Administrative Affairs was retained, though much of its work had to be transferred to the states. The new structure did not reflect the orientation of the National Health Strategy. Emerging issues such as environmental health, health promotion, nutrition and food quality control did not receive much attention and remained part of the oversized Directorate-General of Social and Preventive Medicine, which was also charged with the task of the eradication of diseases. 
This outcome can also be seen as the result of intra-bureaucratic politics between public health professionals and the medical doctors where the latter undermined the former.

Ultimately, the reorganisation hardly affected the internal structure of the FMOH. The Act 489 of 1996 reduced the number of directorates under certain directorates-general to reflect the decreased workload of the FMOH, but it was never implemented. For example, the Directorate-General of Preventive and Social Medicine retained its seven divisions instead of the three stipulated in Act 489 , and the PHC Directorate- General had eight directorates instead of the stipulated four. This can be explained by many factors such as the overemphasis during reorganisation on the number of posts rather than the performance of the incumbents of these posts. Other contributing factors were the continued hegemony of the vertical programs in the ministry and the tendency to approach decentralisation as if it were an incremental tinkering process rather than an opportunity to implement massive changes in federal-state health relations.

\subsubsection{Compliance of the directors-general}

An analysis of the FMOH's compliance should not only address the structural design of the ministry but also the process of planning, sharing information, staffing and budgeting all of which required major changes. We reviewed the planning documents from the various directorates from the period of 1994 to 1999 and also interviewed the directors-general. This revealed that the planning documents rarely referred to the new orientation underpinning federal decentralisation. The directors-general did not display a clear vision on the implications of the planned changes to their roles and tasks (FMOH, $1997 \mathrm{~b}$ ). Their activities remained as before, only generally stated and without any further specification of tasks, duties, priorities, criteria or schedules of execution. In addition, there was no specific training to prepare the staff for the changes in their functions (see tables 6.3 and 6.4).

Only one third of the directors-general were clear about what was expected of them in the new setting. They actually did introduce some changes in their plans, although these changes were not always relevant for decentralisation. However, not one directorate ever attempted to improve the qualifications of its staff in order to meet the demands of decentralisation.

Implementation was not only adversely affected by the insufficient backgrounds and the lack of motivation of senior political and administrative leadership, but also by the non-availability of full-time senior professional officers. In 1998, out of the twenty-six senior professional staff including the undersecretary, only seven could be presumed to be available full- time. The remaining nineteen had a part time job elswhere, for instance in a university, private clinic, pharmacy or other establishment (based on interviews and data collected by the researcher). 
Table 6.3 Analysis of the background and orientation of the directors-general towards the decentralisation policy (1996-1999

\begin{tabular}{|c|c|c|c|c|}
\hline DGs & Background & Orientation & Motivation & Power \\
\hline 1 & Community Medicine. & Supportive & Average & + \\
\hline 2 & Community Medicine. & Supportive & Average & + \\
\hline 3 & Pharmacology & Supportive & Average & + \\
\hline 4 & Epidemiology & Negative & Low & +4 \\
\hline 5 & Conminunity Medicine & Negarive & Low & $\frac{3}{3}+\frac{4+4}{18}$ \\
\hline 6 & Community Medicine & Indifferent & Low & +7 \\
\hline 7 & Hospital Administration. & Supportive & Average & + \\
\hline 8. & Pathology & Supportive & Low & $t$ \\
\hline
\end{tabular}

Source: Author"s interviews.

Clarification: Orientation was measured by asking the DGs about their attitude towards change. If the DG is familiar with decentralisation and has taken steps to support it, he is classified as supportive; indifferent means that he has not done anything to support or resist decentralisation; negative means that he has undertaken steps to resist decentralisation.

Motivation was measured as follows: Low motivation means that a DG only undertakes action when compelled to act. In case of moderate motivation, a DG undertakes action because of personal benefits (e.g. promotion, prestige, financial resources). A highly motivated DG does not only undertake action because of perceived personal benefits but also because of general political support for decentralisation.

Power is operationalised by the presence of political, financial and medical skills as well as relevant professional administrative background. Each of these characteristics was counted as a $(+)$

There was also much confusion amongst the staff of the various directoratesgeneral with regard to the nature of federal decentralisation. Some of them equated it with deconcentration, others with delegation and only a few with devolution. This can be deduced from the way they described their functions and those of the lower levels. The changes that took place were mostly instigated by external pressure coming from the Federal Ministry of Finance. 
Table 6.4 The compliance of the FMOH Directors with decentralization

\begin{tabular}{|c|c|c|c|c|c|}
\hline DGs & $\begin{array}{l}\text { Concept of Centre- } \\
\text { State Relations }\end{array}$ & $\begin{array}{l}\text { Structural } \\
\text { Change in } \\
\text { directorate }\end{array}$ & $\begin{array}{l}\text { Change in } \\
\text { plans of } \\
\text { directorate }\end{array}$ & $\begin{array}{l}\text { Change in relations } \\
\text { with lower } \\
\text { government's level }\end{array}$ & $\begin{array}{l}\text { Petsoninel } \\
\text { Change }\end{array}$ \\
\hline 1 & Unclear & No change & No & No & No \\
\hline 2 & Devolution & No change & No & No & No \\
\hline 3 & Devolution & No change & Yes & No & No \\
\hline 4 & Federalisn & $\begin{array}{l}\text { Reasonable } \\
\text { change }\end{array}$ & Yes & Yes & No \\
\hline 5 & Deconcentration & $\begin{array}{l}\text { Reasonable } \\
\text { change }\end{array}$ & Partial & Partial & No \\
\hline 6 & Federalism & No change & Yes & Yes & No \\
\hline 7 & Deconcentration & $\begin{array}{l}\text { Reasonable } \\
\text { change }\end{array}$ & Yes & Yes & No \\
\hline 8 & Federalism & No change & Partial & No & No \\
\hline
\end{tabular}

Source: Interviews with directors-general.

Clarification: concept of centre-state relations was measured by asking the DGs how they perceived decentralisation. Their answers were classified according to the classification of decentralisation as presented in chapter 2

Structural change refers to the changes in the directorate due to the implementation of decen. tralisation. The answers of the directors were cross-checked with the information in the documents. Reasonable change means that changes indeed did take place but they did not correspond with the changes required by the legislation.

Change in plons and change in relation with lower gowernment level were measured as follows. Yes means that changes did take place and were in accordance with the changes required. Partial means that changes did rake place but they were not in accordance with the changes required. No means that no changes could be recorded.

Persomel change refers to changes in the personnel of the directorate related to the implementation of federal reform.

\subsubsection{Compliance of the national program coordinators}

Vertical programs have been and still are an important part of the health service and health reform in Sudan because of their external funding, liberal provision and implementation in different parts of the country. In fact, they represent the only 'growth area' in health care, and most of the national health budget is committed to the existing programs. Table 6.5 gives a summary of the coordinators' practice in vertical programs up until 1993 and shows their compliance with federal decentralisation.

The responsibility of running these programs should have been transferred to the states, and the role of the national coordinators restricted to overall supervision and guidance. However, in reality more than $85 \%$ of the vertical programs are still under the control of national coordinators, without any involvement of the states. This can be explained by the inability of the state health ministries to 
manage programs to the satisfaction of the donors; consequently, some of the donors preferred to deal with the national coordinators rather than with the less experienced and distant staff of state ministries. In addition, the resistance and unwillingness on the part of national coordinators to give up their power or even share it with the states, together with the lack of pressure from the higher political and administrative leadership of the ministry were contributing factors.

Table 6.5 The change in relations due to the implementation of federalism between mational program coordinators and the lower levels of government (1999)

\begin{tabular}{|l|l|l|l|}
\hline Program & $\begin{array}{l}\text { Relation between National } \\
\text { Coordinator and lower levels of } \\
\text { government in 1993 }\end{array}$ & $\begin{array}{l}\text { Relation between National } \\
\text { Coordinator and lower levels } \\
\text { Of government after 1993 }\end{array}$ & Change \\
\hline $\begin{array}{l}\text { Basic development } \\
\text { needs }\end{array}$ & Direct & Direct & No \\
\hline Bamako Initiative & Direct & Direct & No \\
\hline $\begin{array}{l}\text { Expanded Proggarn for } \\
\text { Immunisation }\end{array}$ & Direct & Indirect & Yes \\
\hline $\begin{array}{l}\text { Health Areast } \\
\text { Control of Diarthoeal } \\
\text { Disease }\end{array}$ & Mixed & Mixed & Partial \\
\hline Leprosy & Indirect (through NGOs) & Indirect & No \\
\hline Malaria & Direct & Indirect & No \\
\hline Health Education & Direct & Direct & No \\
\hline AlDS & Direct & Direct & No \\
\hline Nutrition & Direct & Direct & No \\
\hline $\begin{array}{l}\text { Maternal and Child } \\
\text { Health Care }\end{array}$ & Direct & Direct & Yes \\
\hline
\end{tabular}

Source: Interwiews and FMOH Records.

Clarification: direct means that national coordinators remain in control of the vertical progan at the lower government level. The second column conveys information about the degree of cons. trol of the national coordinators before the introdwction of federal reform. The third column refers to the situation offer the introduction of federal reform. Indirect in this column means control cinter through NGO or control by the lower-level government; mixed refers to a combination of direct and indirect control. Note that the data were collected in 1999.

\subsection{Decentralisation and financial relations}

Prior to federal reform, all financing (including external grants) for health throughout the country was accommodated in the budget of the FMOH. Through Constitutional Decree No. 12 of 1994, all resources for the delivery of health services were to be directly transferred from the Federal Ministry of Finance to the state budgets (Mohammed Ibrahim, 1996a). For this purpose, the states had to prepare a budget proposal for the Federal Ministry of Finance within the state 
government budget. The new arrangement created a difficult situation. Generally speaking, in most developing countries responsibilities are transferred to lower levels without transferring resources (Moharir, 1986). In Sudan, however resources were statutorily transferred to the states without clarifying their policy tasks and responsibilities. Because of a lack of trained and experienced staff, many states, particularly the less developed and distanced states like Kordofan and Darfur, were unable to present budget proposals in a proper form to obtain funds.

The FMOH also received part of its resources from the Federal Ministry of Finance. Its budget was reduced drastically from 1993-94 onwards (Mohammed Ibrahim, 1996a) which compelled it to look for other revenues and to indulge in tricks and malpractices aimed at keeping the states away from certain sources of finance. For example, the FMOH did not allow the states to generate revenues through the main teaching hospitals, laboratory services or the export and import of important medicines. This resulted in a bitter conflict between the FMOH and Khartoum state in whose territory many of these institutions were located. Finally, the Federal Ministerial Council resolved the conflict in favour of the FMOH in 1996. But Khartoum state did not give up easily. As the most economically advanced state it made use of its political influence in the higherlevel political circles Finally, it

managed to reverse the decision in its favour. Thus, the constitutional provisions did not govern the centre-state relations, but political pull and push.

The FMOH also had access to other sources of health finance in the form of the National Health Insurance Fund, the National Support for Free Medical Treatment, External Funds for Health programs, the Recurrent State Support Fund and the State Support Fund for Development. Though these funds were not substantial, the Ministry of Health could use them to support the decentralised activities of the less developed states in the public health sector. But, this seldom happened. For example, 66\% of the National Free Medical Treatment Fund was spent in Khartoum state alone in 1998 (Federal Government Chamber, 1998; Gismallah, 2001).

Another strategy used by the FMOH was to undertake a number of executing activities themselves instead of leaving them to the states. In doing so, they were able to claim a higher proportion of the donor funds for vertical programs such as Tuberculosis Control Program, the Basic Development Needs Program or the Integrated Management of Childhood Illnesses Program (personal interview with WHO representative, 1999). These and other money grabbing activities eroded the true meaning and spirit of constitutional decentralisation in the public health sector (FMOH, 1997; FMOH, 1998).

$A$ further problem arose when the Federal Ministry of Finance ordered a centralisation of all government revenues to control cash flows in the market. The implication of this arrangement for the FMOH was that the revenue from 
hospitals and other health institutions had to be transferred directly to the Federal Ministry of Finance. The latter would then allocate financial resources to health activities according to its own judgement and circumstances. This not only curtailed the FMOH budget but also delayed the implementation of decentralisation (personal interview with FMOH Undersecretary). Because of its low political leverage, the FMOH was often the loser in such conflicts with other Ministries.

\subsection{Decentralisation and health planning}

One of the major responsibilities of the FMOH after decentralisation should have been planning. In the earlier regional system, overall planning was centralised in the National Ministry of Planning. Because of the lack of capacity in regional planning units, the National MOH centralised planning and control of the health budget for the entire country (Moharir \& Kwage, 1987). However, after the federal reform of 1993, the role of the Planning Directorate in the FMOH had to change. From here on, the FMOH would only be involved in general planning issues: the planning and running of concrete health services were left to the states and localities. Furthermore, the FMOH was charged with the overall coordination and supervision of planning.

The Planning Directorate-General has three directorates under the new administrative structure, namely planning, training and health information. It was staffed by three medical doctors, one professional planner, two assistant inspectors, one executive director and four clerks who are collectively responsible for all planning, monitoring and coordinating the work of the public health sector. The medical doctors in the planning unit did not have any training or expertise in systematic policymaking and planning. Therefore, to perform adequately in its role, the Planning Directorate requested additional staff, particularly experts in professional policymaking and planning (Table 6.6), but this request was not approved until the year 2000 . Consequently, both the number and the quality of the staff available present a problem for the Planning Directorate, given the vast area of Sudan. As a result the planning function is not being performed as foreseen in federalism (FMOH, 2001).

Because of the lack of capacity and expertise, the information system for planning, monitoring and coordination in the new system is still underdeveloped. The National Health Information Centre concentrates only on the collection of data on the curative services provided by specific institutions (Dargail, 1998). Information on the performance of specific projects in the public health sector is still missing. There is a small research unit, staffed by five persons and lead by a community physician, who reports directly to the undersecretary but this unit is not linked up with planning. We did not come across any study of the unit 
concerning decentralisation issues. Thus, planning, research and action are divorced in the present system.

Table 6.6 The proposed structure of the Directorate-General of Planning and Development

\begin{tabular}{|l|l|l|}
\hline Category of staff & Civil service grade & Number required \\
\hline Director-general & Grade one, level two & 1 \\
\hline Director & Grade two & 1 \\
\hline Division directors & Grade three & 3 \\
\hline Heads of units & Grade four and five & 8 \\
\hline First degree inspectors & Grades seven and eight & 12 \\
\hline Inspectors & Grade nine & 8 \\
\hline Administrative clerks \& supervisors & Grade ten & 3 \\
\hline Clerks and assistant technicians & Grade twelve & 11 \\
\hline
\end{tabular}

Source: FMOH, 1995 b.

\subsection{Decentralisation and coordination}

Under the new structure, the National Health Council was expected to ensure a coordinated approach to tackling the health problems throughout the country. A medical doctor was appointed as Secretary to the Council, but unfortunately he lacked relevant experience for his high profile position and remained without any supporting staff. In fact, he was appointed solely to make use of one of the surplus doctors after the restructuring of the FMOH. As a result, the Council was more or less defunct.

The Federal Government Chamber was also responsible for coordinating health relations between the federal government and the constituent states, but fulfilled its role in only a very limited way. It failed to resolve disputes between the FMOH and the Khartoum state and also between the FMOH and other federal departments such as Veterinary Affairs or the Institute of Quality Assurance (FMOH Undersecretary personal interview, 1999; Gismallah, 2001). The Chamber was also in charge of establishing the State Support Fund with national and donor contributions to help states, especially the less developed ones, with their recurrent and development budgets, The Federal Government Chamber took too much time to set up the fund and to establish the criteria and procedures for the states to benefit from it. Up until 1999, the impact of the fund was invisible, as most of the under developed states were unable to come up with proposals that fulfilled the FGC's criteria. Moreover, the fund was financed at a low level, and the public health sector had to share the available funds under "Social Services", often losing resources to education, the other main component of the social sector, due to its stronger political lobby.

The failure of the National Health Council and the Federal Government Chamber to coordinate health relations between the federal government and the constituent 
states was not compensated by the Federal Ministerial Council, the apex organisation of the government. The FMC usually referred health issues to its Social Committee, which paid more attention to the education sector and did not show much enthusiasm in expediting the implementation of health decentralisation.

In the absence of a strong and systematic coordination from external organisations, the success of decentralisation mainly depended on the Directorate of Planning and Development in the FMOH. But this directorate also suffered from serious weaknesses. Because of its low status and lack of sufficiently qualified and experienced planners to play the facilitative role vis-à-vis the states, it was unable to overcome the resistance of other directorates and steer them in the right direction. In fact, the Directorate of Planning and Development experienced resistance from the leadership of other directorates within the FMOH and health departments of the states as well. For instance, while Khartoum state was setting up a new heart centre, the Military Medical Department also initiated a procedure to set up its own centre, despite there was an existing one owned by the FMOH, which needs limited rehabilitation. Similarly in primary health care, there were three vertical programs supported by WHO and UNICEF, namely the Basic Development Needs Program, Health Area Development, and the Bamako Initiative. Each program had its own coordinator who proceeded without coordination with the Planning and Development Unit of FMOH. This frequently resulted in the duplication and waste of valuable resources.

In the absence of appropriate and adequate resources, the Planning and Coordination Directorate concentrated on building consensus through holding conferences, such as the El-Gadaref Conference of 1996 and the National Planning Conference of 1997 in Khartoum. The Federal Government Chamber sponsored these conferences, which were attended by high-level dignitaries including ministers, governors, and the vice-president. Many issues were discussed with the help of background papers on issues such as centre-state financial and health relations, the distribution of manpower between the different levels and health planning in a federal context. These discussions were often on the most general level, and there was no further follow up of recommendations and decisions taken.

Another strategy used by the Directorate of Planning and Development was to participate in annual planning meetings organised by other directorates in the FMOH with state representatives. The WHO and the UNICEF supported some of these, like those of the PHC Directorate. The Planning Directorate used these meetings to emphasize its overall planning and coordinating role. In general, these conferences and annual meetings were symbolic and ritualistic: they did not address the practical issues or come up with realistic solutions (our review of the 
recommendations of the conferences held between 1994 and 1998, including our personal participation in the 1998 conference).

Other mechanisms used for planning and coordination included the development of periodic plans for the public health sector, supporting planning initiatives of the states, and the control of external funds and projects. The Planning Directorate issued three plans based on the National Health Strategy between 1995 and 2000 . Although the Federal Minister of Health endorsed these plans, they were still not considered obligatory by the other directorates in the $\mathrm{FMOH}_{\text {, }}$ the managers of the vertical programs, or by the state health ministries. The Planning Directorate lacked the power, persuasion or direct influence to win active support from the higher-level political leaders for implementation.

\subsection{Decentralisation and supervision}

In general, the Planning Directorate played a passive role. For the purpose of supervision, the sixteen states of the Northern part of the country were divided into four geographical regions. The Board of Undersecretaries of the FMOH nominated a team lead by a director-general and two or three other directors for each region. However, the implementation of this measure was very sporadic and some teams did not execute a single supervisory activity during their office. The contributing factors for this were lack of finance for visits, lack of commitment from the directors-general, absence of guidelines for supervision and indifference of the political and administrative leadership of the FMOH towards the details of implementation. Even the periodical visits of the FMOH to different states had more of a symbolic role than real value.

\subsection{Capacity building for decentralisation}

Sudan, and many other developing countries, learnt from previous experience that the success of decentralisation strongly depends upon capacity building (Cheema, 1998). Capacity building involves many aspects, but the development of human resources is central.

\subsubsection{Capacity building at the federal level}

Capacity building in the FMOH itself was paramount, as the ministry had to initiate the implementation of health decentralisation thus enabling the states and localities to exercise their power and authority appropriately. For this purpose, its capacity needed to be developed and upgraded. The Health Manpower Development Policy was one means to achieving this end. The Conference for Comprehensive National Strategy stipulated the creation of a committee to focus on a long-term policy for the development of manpower and personnel over a 
ten-year period from 1992 to 2002 (FMOH, 1992). Table 6.7 shows the manpower requirements of the public health sector during this period.

The Committee concentrated mainly on professional health care staff rather than on new categories such as policy planning, management, health policy analysis, finance and accounting. The targets for each category over the ten-year period proved to be unrealistic. The capacity of the teaching institutions and the high level of migration of their available staff were completely neglected.

The required increase in numbers and manpower population ratios were based on international standards rather than upon the situation in Sudan. The targets were too ambitious and unfeasible from an administrative, financial and political point of view. The composition of the Committee partly explains this outcome. It consisted of six Sudanese medical doctors, one senior nurse and one senior paramedic, with no representatives from the Ministry of Manpower and Labour Force and no experts in capacity building, health planning or management (FMOH, 1992). The result was a partial, narrow, and technical approach to manpower development. The eleven general recommendations of the Committee were neither tailored to the needs of decentralisation nor based on a cautious appraisal of the existing capabilities of the country.

Table 6.7 The ratio of health manpower to population in 1992 compared to the targets set by the NHS to be realized by the year 2002

\begin{tabular}{|c|c|c|c|c|c|}
\hline \multirow{2}{*}{$\begin{array}{l}\text { Type } \\
\text { Medical } \\
\text { generalists }\end{array}$} & \multicolumn{2}{|c|}{$\begin{array}{l}\text { Healtin manpower: numbers and } \\
\text { population ratios in } 1992\end{array}$} & \multicolumn{2}{|c|}{$\begin{array}{l}\text { Health manpower: numbers } \\
\text { population ratios, targeted for } 2002\end{array}$} & \multirow{2}{*}{$\begin{array}{l}\text { Increase } \\
\frac{3.25}{\text { times }} \\
\end{array}$} \\
\hline & 1845 & 1 to 10000 & 6000 & 1 to 5000 & \\
\hline Medical specialists & 636 & 11050000 & 3180 & 1 to 10000 & 5.0 \\
\hline Medical assistants & 5102 & 2 to 10000 & 2551110 & 8 to 10000 & 5.0 \\
\hline $\begin{array}{l}\text { Technicians } \\
\text { (including sisters) }\end{array}$ & 1503 & 61010000 & 9018 & 13 to 10000 & 6.0 \\
\hline Nursing staff & 17122 & 6.4 to 10000 & 102722 & 38.4 to 10000 & 6.0 \\
\hline Maternity staft & 1145 & 0,5 to 10000 & 5725 & 2 to 10000 & 5.0 \\
\hline Village midwives & 5496 & 2 to 10000 & 27480 & 9 to 10000 & 5.0 \\
\hline Pharmacist & 771 & 7 to 200000 & 2313 & $1.15: 15000$ & 3.0 \\
\hline Dentists & 174 & 1.3 to 100000 & 522 & lo 33000 & 3.0 \\
\hline $\begin{array}{l}\text { Public health } \\
\text { oflicers }\end{array}$ & 257 & 1 to 100000 & 1285 & 1 to 10000 & 5.0 \\
\hline Sanitary overseers & 1926 & 7 to 10000 & 28890 & Ito 1000 & 15.0 \\
\hline $\begin{array}{l}\text { Nutrition } \\
\text { specialists }\end{array}$ & 1 & 1 to 26 millions & 20 & I to Million & 20.0 \\
\hline Nutrition officers & 9 & Bto 1 million & 1800 & 6 to 100000 & 200 \\
\hline Nutrition advisors & 143 & 5.5 to 1 million & 5720 & 19 tro 100000 & 40.0 \\
\hline
\end{tabular}

Source: MOH, 1992. 


\subsubsection{Manpower development}

The FMOH did not modify the National Health Manpower Strategy of 1992. The Federal Ministerial Council issued Warrant No. 122 in 1995 in order to transfer the responsibility for staff from grades 4 to 14 (lower and middle level staff) to the states where they were located, as part of the manpower and training initiatives of federal reform. The $\mathrm{FMOH}$ was restricted to providing guidelines and standards for recruitment and functions within these categories. State authorities were made responsible for planning, training, and management. However, the FMOH retained its control over the remaining staff of the states, which included university-trained professionals such as medical doctors and graduate medical technicians. Thus, the states, which were now entirely responsible for the delivery of the health services, did not have any control over higher-level professional staff.

\subsubsection{Federal directorate of manpower and training}

In the new FMOH structure the responsibility for manpower and training was downgraded from a directorate-general reporting to the undersecretary to just one of the many directorates in the Directorate-General of Planning and Development. Here planning and research functions received more attention than manpower development and training, which were both crucial to the success of decentralisation. Moreover, the directorate was understaffed with only three medical doctors, a senior nurse, a sister and two clerks. In addition it was lead by a medical doctor (in 1998) without a specific background or training in capacity building. The directorate limited its activity for capacity building largely to postgraduate training for new medical graduates to get their practicing licence. Hence, their contacts were mostly with teaching hospitals and the Medical Council, rather than with the states and localities.

The Ministry of Labour Force and Administrative Reform and the Ministry of Higher Education were the other federal agencies involved in manpower development and training. However, in the absence of any manpower development and training plan in the public health sector, activities like the allocation of seats to medical specialties, the choice of candidates for those specialties, and their placement in different parts of the country were left to the discretion of individual candidates and staff. There was no priority setting in this respect. As a result of this laissez-faire approach, it was possible that a large number of medical graduates were unemployed in some states, whilst at the same time there was a crying need for them elsewhere (Tag-Osman, 1999). In fact, the staff of the directorate was apathetic to the National Human Resources Policy and to the needs of federal reform.

With regard to capacity building of the paramedical staff, the directorate also continued its routine training activities without a specific orientation towards the 
needs of the less developed states. The responsibility for the paramedical training schools was transferred to the states, but the FMOH retained its control on the quality of graduates through the standard federal examinations. Different states used this authority in different ways. The Health Ministries of Khartoum and Gezeira States that were endowed with better ministers and directors-general came up with an innovative approach for upgrading the skills and approach of their paramedical staff by entrusting their training to the universities. However, the Directorate of Manpower and Training of the FMOH vehemently opposed this approach, as it went against the existing practice.

In general, the role played by the FMOH in manpower development and training in the public health sector was very weak. In spite of more than ten universities with medicall faculties throughout the country, there was still an acute shortage of public health and paramedical staff. This was because the new medical faculties concentrated on the lucrative task of educating medical doctors and paid very little attention to other health professionals.

\subsubsection{Contribution of NGOs in capacity building in public health sector}

The United Nations Agencies like the WHO, UNICEF and other international NGOs also contributed to capacity building for decentralisation. Their activities were largely directed towards the specific directorates of the FMOH and the vertical programs in which they had an interest. These activities included workshops, seminars and courses held as part of their technical assistance programs. Though important, they were sporadic and uncoordinated by the Directorate of Manpower and Training in FMOH. Moreover, they were organised mostly in Khartoum and the majority of the time their participants were comprised of the directors-general, directors, managers of vertical programs, and other senior staff of the FMOH (WHO, 2001). The main incentive for the FMOH staff to attend these activities was access to the per diem allowance, which was considered as a 'top-up' of their meagre salary. Often the activities of the workshops and seminars were project based and lacked a built-in evaluation system. There was no change in the approach and attitude of the staff: their link with federal decentralisation remained very remote.

The majority of support came from the WHO, which financed nearly 250 training activities in 1998 and 1999 that were attended by a total of 6818 participants from all levels including various health speciallists and 1030 national facilitators. Even up until 2000 the participants continued to be comprised of senior staff from the FMOH with very little representation of the states (FMOH, 2000). Because of the lure of the per diem payment, these workshops/seminars were gate crashed, often to the extent that people attended one event for several topics. On one occasion, a group of staff even attended three seminars conducted simultaneously on different subjects on different floors of the PHC building! 
Only a few of these workshops were aimed at decentralisation, such as "How to support PHC services in the federal context", "How to develop national guidelines for health information system?", "Supporting health legislation in the federal context?" and "Coordination of health planning within the federal system". However, there was very limited participation in these workshops from state representatives because of late notice, lack of finance and lack of awareness among state authorities.

\subsubsection{Improving capacity building through the redistribution of staff}

Despite the great importance of improving the capacity of the states quickly, the FMOH's efforts remained minimal. It did not initiate a well-designed program to transfer its own trained and experienced staff, particularly from planning, finance, and primary health care to the states. The only transfers that took place were those of lower and middle level staff who were already located within the boundaries of various states. Table 6.8 shows the types and the number of staff transferred from the FMOH to the states between 1993-1996.

Table 6.8 The type and number of staff transferred to the states (1993-1996)

\begin{tabular}{|l|l|l|l|l|l|}
\hline Type & Number & Type & Number & Type & Number \\
\hline $\begin{array}{l}\text { Medical } \\
\text { Doctors }\end{array}$ & 112 & Generalists & 18 & Medical Assistants & 1 \\
\hline Pharmacists & 6 & Technicians & 8 & Health Visitors & 3 \\
\hline \begin{tabular}{l} 
Sisters \\
\hline
\end{tabular} & 3 & Social workers & 2 & Public Health Officers & 3 \\
\hline
\end{tabular}

Source: Mohammed Jbrahim, $1996 \mathrm{~b}$.

We can see from this limited data that in total only 156 staff were transferred to twenty-six states over three years, which was not more than an average of six per state. This redistribution of staff was the result of voluntary action by individuals who showed an interest in transfer rather than the result of a planned initiative from the FMOH.

The FMOH's activities were not based on a well-designed program to implement federal reform in the public health sector. As a result, changes were incremental, ad hoc and arbitrary (Mohammed Ibrahim, 1996b). Some of the relevant issues were occasionally discussed in joint conferences between the FMOH and the State Ministers of Health (FMOH 1996b, 1997a). In 1996, the then Federal Minister of Health promised to redistribute staff within a year, but she failed to carry this through due to resistance from the staff and a lack of any political push at a higher-level. Consequently, the existing inequity in the distribution of medical staff remained unchanged with $70 \%$ of the medical specialists still working in Khartoum, $20 \%$ in three other urbanised states, and a paltry $10 \%$ in the remaining twenty two states with the bulk of the country's population 
(FMOH, 2001). Uitimately, the problem of inequity between the federal and the states levels in capacity building remained unsolved with obvious consequences for the performance of the public health sector in states and localities.

In addition, there was not much change in terms of the total availability of trained staff in the public health sector for the country as a whole, as can be seen in table 6.9. The table also clearly demonstrates hat for many categories the growth of staff fell short of the targets set for 2002. It can also be seen that supply of trained staff such as community health workers did not decrease in non-priority areas.

Table 6.9 The actual change in the numbers of various medical professionals compared to the National Health Manpower Committee's targets for the year 2002

\begin{tabular}{|c|c|c|c|c|c|}
\hline Professional category & $\begin{array}{l}\text { Base line } \mathrm{No} \text {. } \\
1992\end{array}$ & $\begin{array}{l}\text { No. in } \\
1993\end{array}$ & $\begin{array}{l}\text { No. in } \\
1997\end{array}$ & $\begin{array}{l}\text { Achieved Hill } \\
1999\end{array}$ & $\begin{array}{l}\text { Planned for } \\
2002\end{array}$ \\
\hline Medical doctors & 1845 & 1681 & 2592 & 2602 & 6000 \\
\hline Medical specialists & 636 & 531 & 616 & 814 & 3180 \\
\hline Pharmacists (public) & $\llbracket 71$ & 162 & 302 & 306 & 2313 \\
\hline Dentists & 174 & 185 & 205 & 222 & 522 \\
\hline Medical assistants & 5102 & 4580 & 5542 & 6193 & 25510 \\
\hline Technicians & 1503 & 1629 & 1961 & 2433 & 9018 \\
\hline Nurses & 17122 & 16006 & 16509 & 17526 & 102732 \\
\hline Public health officers & 257 & 251 & 275 & 365 & 1285 \\
\hline Public health overseers & 1926 & 2232 & 1937 & 2390 & 28890 \\
\hline Health visitors & 568 & 600 & 731 & 655 & 2840 \\
\hline Midwife & 6093 & 5881 & 7506 & 9290 & 30480 \\
\hline $\begin{array}{l}\text { Community health } \\
\text { worker }\end{array}$ & $2621(1991)$ & 2599 & 2383 & N. A. & 0 \\
\hline Nutrition advisor & 143 & 143 & 221 & N.A. & 5720 \\
\hline Nutrition officers & 90 & 71 & 96 & N.A. & 1800 \\
\hline
\end{tabular}

Source: MOH, 1992, FMOH, 1993, FMOH, 1997 and FMOH, 1999.

\subsection{Concllusions}

In this chapter we have analysed the implementation of federal reform at the FMOH level of the public health sector. Implementation resulted in a complete failure in all aspects that we have analysed. We have seen a failure in leadership, restructuring, planning, coordination, capacity building and transfer of financial resources, manpower and responsibilities to the states and localities. In this final section we will briefly review the process of implementation at the federal level on the basis of Grindle's model for implementation analysis. We shall begin with content analysis and continue with context analysis. 
Federal reform met with resistance at the federal government level. One important reason for this resistance was the belief of the federal players that reform would negatively affect their interests. The FMOH staff perceived the changes as a loss of control on resources and power. In addition, the high level political staff of the Federal Ministerial Council, the Federal Government Chamber, and the Federal Ministers of Health or their undersecretaries did not display much enthusiasm in implementing the reform. Political pressure to overcome this resistance to reform hardly developed at all.

One significant drawback of federal reform and the National Health Strategy is that it took long time for the benefits to materialise. The longevity of the implementation process gave the FMOH bureaucracy ample opportunity to manipulate the process in order to maximise its benefits at the expense of the policy goals. In addition, the details of the federal reform were not well planned, leaving a lot of room for interpretation. In fact, many serious conflicts arose from issues that originated from poor policy formation and were consequently transmitted to policy implementation. Obviously, this situation made it much easier for the opponents to damage the entire implementation process.

It is also important to consider the nature of federal reform. In chapter three we described federal reform as an example of a constitutional and redistributive policy. Federal reform aspires to change the decision-making structure. Furthermore, it is directed towards achieving another balance of power in the governance system: the decentralisation of policy-making to lower government levels where possible. Policymaking in many areas of public policy is affected by a constitutional and redistributive policy. However, these effects are not easy to predict and federal reform inevitably presents a major change in the government system rather than a marginal or incremental one. According to Grindle, major changes provoke more resistance than marginal changes because they create uncertainty and can have a substantial effect on the interests of the parties involved. Under these circumstances, it is not surprising that federal reform met with great resistance at the federal level. This resistance was also fuelled by the strong belief held by some policymakers and senior administrators in the FMOH that the states and localities were not capable of making their own policies. Consequently, they did not display any confidence in the policymaking and management capabilities of the states and localities.

The complexity of the administrative structure at the federal level (the site of implementation) was another contributing factor to the failure of federal reform. The following actors were involved at the federal level alone: the Federal Minister Council, the Federal Government Chamber, the FMOH, the Federal Ministry of Finance and the Federal Ministry of Public Service and Training. This administrative structure desperately required policy coordination that could not be provided, especially because these agencies often had different interests. 
The final two factors to consider from Grindle's model are the capabilities of the implementers and the resources dedicated to implementation. We can conclude from our analysis that the capabilities of the political and senior administrative staff at the federal level fell short of what was required to successfully implement reform in many respects. Many of them were not well trained or lacked the relevant experience to perform their tasks adequately. There was also a high turnover in these positions and political loyalty and history were often more important than professional expertise during recruitment. Another problem was that medical doctors usually occupied a dominant position in the implementation process. Their presence in the various committees had a particularly strong impact on how the National Health Strategy was actually created in practice. Implementation also failed because of the structural lack of resources committed to it. Insufficient attention was given to capacity building and federal agencies were often reluctant to transfer financial, human and other resources to the states and the localities. As a result, large discrepancies arose between the intended federal reform and its realisation.

The second box in Grindle's model is concerned with policy context and implementation and focuses on the following explanatory factors: the power, interests and strategies of the actors; the characteristics of the institutions and regime; and finally, compliance and responsiveness. In this chapter we discussed on several occasions how the political and senior administrative staff used their powers to obstruct the implementation process or sought to divert it in such a way that their personal interests were served best. We saw various examples of overt and covert resistance and attempts to delay the process. Opportunism and a more or less permanent 'guerrilla's war' between the agencies involved had a greater impact upon the course and results of the implementation process than the noble goals of federal reform.

Ass we have seen, the political regime played an important role in federal reform. Reform was envisioned as a political instrument to resolve internal political problems and to improve the country"s administration. But, unfortunately, federal reform was conceived at the top of the political hierarchy with only minimal consultation and involvement of the ministries. The appointments made to the senior posts were compromised for political patronage and perhaps most importantly, the regime lacked the political leadership and vision necessary to successfully implement federal reform and to overcome obstacles in the implementation process.

As a result, there was little compliance with federal reform at the federal level. The FMOH was insufficiently restructured to cope with its new tasks. Only a small proportion of FMOH staff was transferred to the states, and this was mostly achieved on voluntary basis. The staff's professional experience was unsatisfactorily developed. There was no one with expertise in policymaking, health planning and management, centre-state relations, capacity building, 
monitoring, et cetera, despite the twenty-eight senior staff in the FMOH. In a nutshell, the FMOH did not prepare itself or the twenty-sixconstituent states and 634 localities for the complex and difficult task of implementing federal decentralisation reform in the public health sector. The subsequent chapters will investigate what happened at the state and the locality level as a result of the actions and inaction in the FMOH. 



\section{Chapter Seven \\ Implementation at the state level}

\subsection{Introduction}

In chapter six, we analysed the process of the implementation of federal reform in the public health sector at the federal level. From our investigation we concluded that the implementation at this level was far from successful. The FMOH had to cope with various intractable problems, and there were many situations where implementation was met with indifference and even outright resistance. Another major problem was the low priority of the public health sector in political circles. The Ministry did not make much progress in the transferral of policy tasks and responsibilities to lower government levels as was intended with the introduction of a federal reform in Sudan.

In this chapter we will examine how federal reform in the public health sector proceeded at the state level. Of course, the chance of successful implementation at this level was expected to be rather small given the poor execution of the implementation process at the federal level. Many authors have correctly pointed out, that the execution of implementation at each government level will be influenced to a large extent by the success of implementation at other government levels (Grindle, 1980; Mills et al., 1990; Collins, 1996). Consequently, unsuccessful implementation at the federal level will reduce the chance of successful implementation at the state level. In addition to this, one would also expect the political and economic situation in each state to have an effect on federal reform in the public health sector.

This chapter focuses on the implementation of federal reform in the sixteen Northern states. The Southern states have been excluded from our consideration due to the on-going war. There is a particular focus on the implementation process in the four Northern states of Khartoum, Gezeira, Kassala and North Kordofan. These four states differed markedly in terms of financial and material resources, access to power, urbanisation (urban or desert), and overall development. In addition, they were relatively easy to visit considering the sheer size of Sudan, and, moreover, they possessed reasonable documentation to supplement our analysis.

Our empirical analysis is based upon interviews conducted with the main actors from various levels in the four states. These actors include senior policymakers (a governor and four ministers), representatives of the State's Assembly, the director-general and his directors in the State $\mathrm{MOH}$, and provincial commissioners.. We supported our interviews with two focus group discussions, which involved eight SHDGs and PHC directors from six states, (see annex for 
further information). Finally, we used information that was available at the federal and state level on the performance of the states in decentralisation.

\subsection{The role of the state in a federal structure}

The role of the government at state, regional or provincial level (sub-national level) in health policymaking can vary considerably. In some countries, it is substantial: the state, regional or provincial government has considerable autonomy in health policymaking within the national health policymaking framework. In other countries, the sub-national level of government plays a more limited role, operating as part of the bureaucratic hierarchy with little authority or power of its own (Mills et al., 1990). In a federal system, the state level is commonly charged with the key responsibilities of planning, allocating resources, building capacity, monitoring and supervising, and coordinating and delivering health services. Of course, state autonomy in these issues is never absolute: the state still has to operate within the general health policy framework at the national (federal) government (Mills et al., 1990; Adamolekun, 1999; Magzoob, 1999b; Collins, 2000).

In Sudan, legislation made the state responsible for social services (Constitutional Decree No. 11, 1993). Consequently, each state was charged with planning, financing, service delivery, management and regulation (Constitutional Decree No. 12, 1994). The Constitution of 1998 divided the responsibility for the public health sector into two categories: federal and concurrent. It did not, however, specify that any particular responsibility lay exclusively with the state (Minister of Justice Republic of Sudan, 1998). It was left to the Federal Ministerial Council (FMC), the Federal Government Chamber (FGC), and the FMOH supported by the Attorney General to define concretely the concurrent tasks and responsibilities of the Ministry of Health at both the federal and state level ( $F G C$, 1998). However, they were unable to provide further specification. Thus, the precise distribution of tasks and responsibilities between the federal and the state level remained ambiguous. Furthermore, many of the former laws such as the General Health Law of 1975 and the Environment Law of 1975 had to be rewritten to be in line with federalism (Abdel Hameed, 1998). The FMOH initiated several proposals for this purpose such as the General Health Laws of 1995,1997 and 1998. However, none of these were ever approved by the supreme authorities (Abdel Hameed, 1998). Nevertheless, the Constitution held the SMOH fully responsible for the health of its citizens (Minister of Justice Republic of Sudan, 1998). The absence of a concrete division of responsibilities in the public health sector allowed each state authority to interpret its tasks and responsibilities in favour of its own capabilities and interests. Whilst some states saw their position as totally subordinate to the FMOH, other states claimed their 
full constitutional autonomy and opposed any unconstitutional interference in health affairs.

We have already seen that the federal authorities incorporated a section on health in their Comprehensive National Strategy of 1992-2002. The main thrust of this so-called National Health Strategy (NHS) was the promotion of Primary Health Care (PHC) to achieve health for all by the year 2000. The NHS formulated an ambitious list of health objectives without setting priorities or considering their feasibility given the scarcity of financial and human resources for the public health sector (FMOH, 1997c). Moreover, there was no operational plan designed to enable the states to achieve these goals, despite the fact that the states were held accountable for the health of their citizens. Each state had to implement this poorly developed policy within its own region and, in addition, retain the responsibility for all health facilities within its region including environmental health activities. Furthermore, each state was held responsible for the training, recruitment and promotion of its paramedic staff (Federal Ministerial Council, 1996). Given the ambiguity in responsibilities, the lack of an operational plan, and the absence of sufficient resources for carrying out their tasks, it is hardly surprising to find that most states were far from capable of carrying out their responsibilities in a proper way. A huge gap developed between what was expected of the states and what they actually were able to achieve.

\subsection{Policy context in the states}

Policymaking in the states is affected by significant elements other than the general political and administrative context of Sudan (see chapters 4 and 5). These elements include the internal administrative structure, the power distribution therein, the status of physical and human resources and the priority of health care within the state. Some of these elements are common to all states, but others vary according to the situation in each state. We shall continue to elaborate on some of the common and differential elements that contribute to the context of policy making in the states.

Research into policymaking at the state level in Sudan should take into account that the states are a recent introduction to the Sudanese government's structure. As stated earlier, they were created in 1991, when the nine regions were converted into nine states. In 1993, these nine states were split into twenty-six states. Whilst some states were relatively well-developed, other states were totally underdeveloped and could not function as a state at all. In these underdeveloped states, the SMOH consisted of not more than a minister and a few assistants (see box 7.1). 


\section{Box 7.1 on the size of the SMOH}

During the regional government system there was a Regional Ministry for Social Servicen in each Region. It was responsible for Education, Health, Water, Sport and Youth and Religious Affairs. Khartoum and the Central Region were endowed with a separate MOH. This background affected the size and the readiness of each region to discharge its tasks in the federal context.

For instance, the $\mathrm{SMOH}$ of Khartoum inherited a reasonable infrastructure, an administrative system and the bulk of the health professionals. It boasted $75 \%$ of all public medical doctors, about $90 \%$ of the private medical practitioners and $85 \%$ of the NGOs' health ac tivities. In addition, the state benefited from the Health Salvation Program (HSP) of 1989 as a pilot area. Untike the rest of the states, the federal reform spared the state of Khartoun from further division, preserving its whole administrative and technical staff which exceeded 700 permanent employees and about half of this number as temporal ones.

Gezeira SMOH was less fortunate than $K$ hartoum $\mathrm{SMOH}$. Nevertheless it was far better equipped than the rest of the states for federal implementation. The Gezeira Agricultural Scheme, the Blue Nile Health Project (Japanese Fund) and the Faculty of Medicine in the University of Gezeira contributed significantly to consolidate the health system in the region. The number of health facilities, manpower and research capacity all increased. Federal arrangements divided the Central Region into three states. Each state had to build up at separate SMOH. Being the headquarters of the former Regional MOH, the SMOH of Gezeira benefited from its legacy in terms of staff, equipment and health facilities. Its headquarter staff exceeded 200 in number.

In North Kordofan, health affairs were placed under the Regional Minister of Social Services as a directorate headed by a regional health director (RHD). He coordinated technically with the Central MOH. The introduction of a federal set up in 199» promoted this directorate to a SMOH. The amendments of 1993 divided the new SMOH into three SMOHs.

Staff and other resources were divided into three parts without any additional input in whatever aspect of resources. The only addition was two ministerial posts. North Kordofan as the previous state headquarters retained the former director general, most of the previous staff, the infrastructure and the meagre logistics. The number of administrative staff in the headquarters did not exceed 30 with very limited qualifications. Nevertheless, it was in a better situation than its two sister States, namely West and South Kordofan.

Kassala SMOH underwent a similar course of development. It benefited from its previous status as headquarter of the former Eastem Region by retaining its buildings, logistics and some better-experienced staf. Nevertheless, in terms of adequacy of resources and health facilities, it was in a worse position when compared to its sister states, Algadaref and Red Sea. The SMOH did not receive any additional resources to face the federal arrangements. The only addition was the appointment of the State Minister and a Committee for the diviston of the then existing resources between the three states. The development of three health ministries out of one Eastern state squandered the available administrative and technical resources. The size of the administrative staff in the headquarters did not exceed 20 with questionable qualifications. This picture of variation between the four states reflects huge contextual differences. However, it does not give the complete picture of contrast. There were other States, where the SMOHs had to start from scratch with only three ot five administrative staff in their headquarters. 
The political history of Sudan should also be considered. In the past, sub-national government levels played quite a limited role in the political process because of the highly centralised political regimes that ruled the country. Despite great ideological variations, all of the former regimes adopted a form of central leadership, even during periods of decentralisation (Moharir, 1986; ElTahir, 1999).

In addition, most of the politicall, economic and social institutions as well as the elites were concentrated in the capital of Khartoum. Consequently, the political and administrative institutions of the states had only a limited possibility to influence high politics issues. They could only exert minimal influence on low politics issues such as health affairs.

Due to the weakness of the political institutions and parties at the state level, the state bureaucracy controlled the policy process concerning most issues. This is particularly true for public health because of its low political priority for state politicians. Most of the state politicians consider health affairs as a technical issue and resource demanding, hence they let it to the sole concern of medical professionals. Thus, health issues at the state level were neglected by both federal and state levels. First, the state was often not taken seriously in federal policymaking on health issues. Second, most state governments considered public health to be a low priority or even neglected it completely.

Despite the increased financial burden of introducing twenty-six new states in a constrained economic situation, the majority $(>75 \%)$ of the national revenue was spent at the federal level (Eisa, 2002). This left only $25 \%$ of the national resources for the states and localities. There were also limited physical and human resources available for the twenty-six states. However, in the new federal setting the states were held responsible for the financing of public health (Sudan Federal Chamber, 1998). Obviously, most of the states did not have the economic base to raise adequate revenue, which can be seen in the per capita expenditure and revenue in charts 7.1 and 7.2. Per capita revenue ranged between 5000 and 35000 Sudanese Denars (2-14 US\$) and per capita expenditure between 5000 and 60000 Sudanese Denars (2-12 US\$) with a considerable interstate variation (Magzoob, 1999a; Eisa, 2002).

Federal support to rectify the inequity between the states was also quite limited (see chart 7.3). the claim of health expenditure on the limited revenue per capita proved to be minimal (1-9\%). the financial burden resulting from the creation of new constitutional jobs for the states along with administrative posts, further exhausted the meagre resources. Moreover, most states possessed only limited planning skills to enable the optimal use of the scarce resources through prioritisation or other strategies (Gismallah, 2001; FMOH, 2001). Under these circumstances, the states were unable to develop a reasonable public health system. 


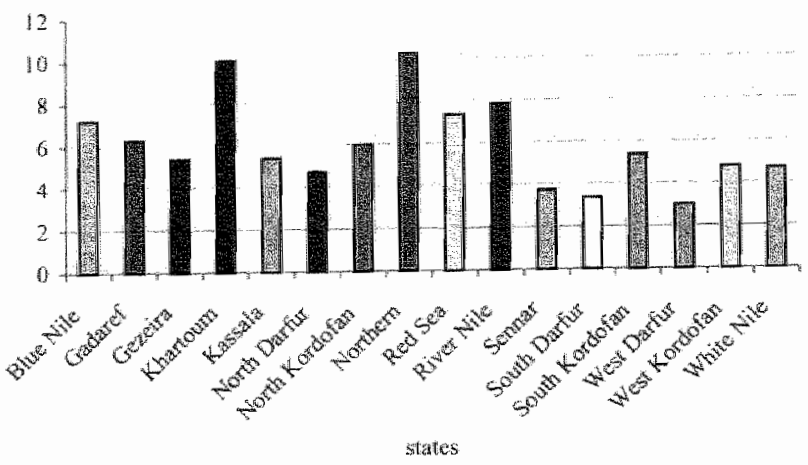

Source: federal ministry of finance, 1990-1999.

Clarification: the rate of exchange one dollar is equwalent to 2500 sudanese pounds.

Chart 7.2 Average per capita internal revenue of Northem States (1994-1999) (in US Dollars)

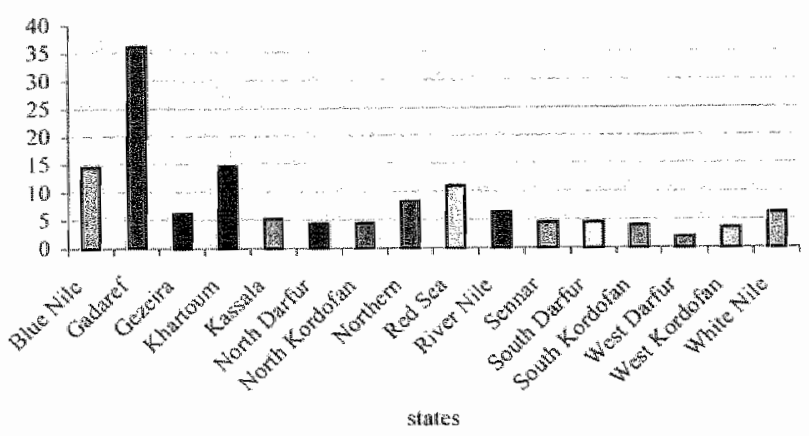

Source: Federal Ministry of Finance, 1990-1999.

Clarifoaton: the rate of exchange one dollar is equivalent to 2500 Sudanese Pounds.

The situation also depends on how politically significant the state is to central leadership, the strength of its political and administrative institutions, the political awareness of the community, the internal revenue, the competency of its political and administrative leadership, and the priority of the public health sector. All of these elements will have an impact and are likely to influence the implementation process. For example, Khartoum state as a centre and capital of the country has a political, administrative and financial influence that is reflected in the high priority given to the well-being of its inhabitants who have strong influence on public opinion concerning the government's performance. Khartoum's inhabitants are vocal and have better access to government decision- 
making than the inhabitants of other states. Due to the relatively high standard of living in Khartoum, health issues rank high in public opinion drawing greater attention to it. At the other extreme, in states like Southern Kordofan and West Darfur where illiteracy, poverty and war dominate, health issues are a low priority. Therefore, it is not surprising that the figures in charts 7.1 to 7.3 show high disparities in per capita revenue, subsidy and expenditure among the sixteen Northern States. This illustrates that one of the main objectives of the federal reform, namely to minimise the disparities between the different parts of the country, was never realized. In fact, it deteriorated further.

Chart 7.3 Average per capita recurrent federal support to Northern States (1994-1999)

(in US Dollars)

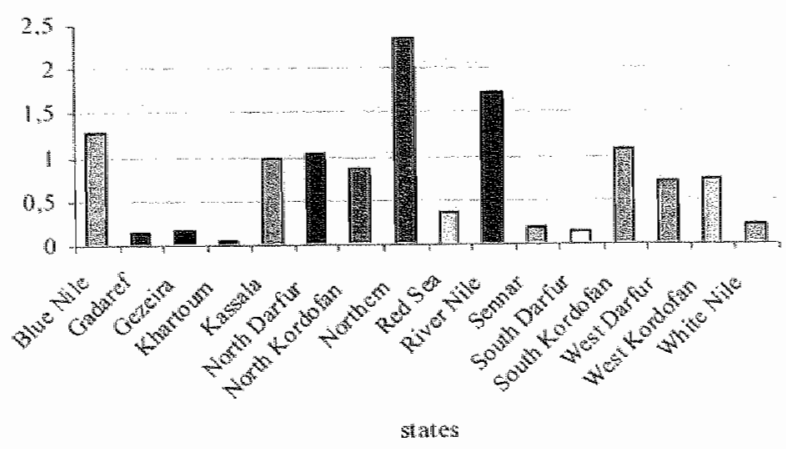

Source: Federal Ministry of Finance, 1990-1999.

Clarification: the rate of exchange one dollar is equivalent to 2500 Sudanese Pounds.

\subsection{State health leadership}

The implementation of a far-reaching program of decentralisation in the public health sector requires a strategy and an operational plan at the state level. The only federal guidance received at the state level was the NHS of 1992-2002, which had to be operationalised whilst taking into account the states own priorities, financial resources, and staff availability. A clear strategy or plan for the implementation of decentralisation in the public health sector was not found in any one of the states. The reasons for this will be considered in this and the following sections.

It is the task and responsibility of the State Health Minister (SHM) and the State Director-General for Health (SDGH) to give guidance in health policymaking. The background and orientation of State Health Ministers and SDGH are therefore critical in the implementation process. The selection of twenty-six wellqualified and motivated SHMs proved to be problematic due to the lack of 
experienced and qualified personnel in many states and the preference of the regime leadership to use appointments to placate different ethnic groups or dissolved parties rather than to improve the public health sector's performance. Many SHMs did not have a relevant background and were poorly qualified (see charts 7.4 and 7.5 ). More than $85 \%$ of the SHMs did not have any previous experience in relevant ministerial or other posts and $73 \%$ of were not previously involved in health affairs. In terms of education and background, the list of SHMs included primary and secondary school graduates that were appointed mainly to represent particular tribes and opposition groups, as the regime utilised these appointments to increase loyalty to the regime.

Chart 7.4 Background of the Health Minister in relation to health

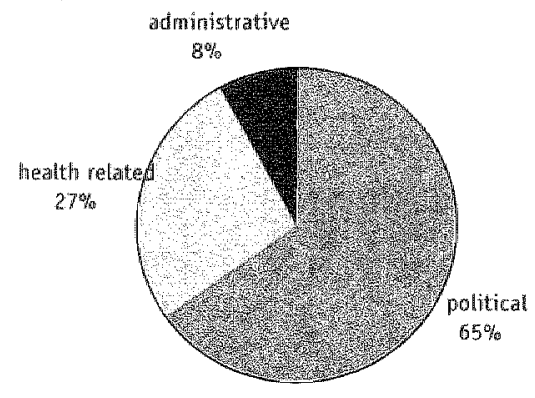

Source: Author's interviews and official records.

Chart 7.5 Justifications for the selection of the State Health Ministers

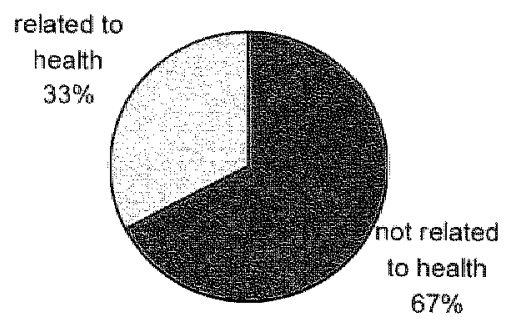

Source: Author's interviews and official records.

Furthermore, there was a large turnover that resulted in much instability. Over a five-year period Sudan had 76 SHMs! In one state the number of SHMs even amounted to six between 1994 and 1999 alone. Under these circumstances, it is difficult to provide consistent political guidance for health planming development. 
In such a situation, the role of the SDGH is vitally important in leading the SMOH. The SDGH should have compensated for the limitations of the incumbents of the ministerial posts. However, SDGHs did not meet the expectations of the SMOH. Even though the FMOH considered a community speciality in medicine as a condition for appointment to the SDGH, in reality appointments followed an ad hoc pattern. In most states a standard job description and specific criteria for selection were missing ( $\mathrm{FMOH}, 2001$ ). To appoint twenty-six suitable candidates as SDGH proved to be beyond the country's capacity. As a result, only $19 \%$ of the selected SDGHs could be considered as well qualified candidates with the relevant qualifications and experience for the post (see charts 7.6 and table 7.1). The remaining of the appointments were based upon minimum requirements and interests. In actual practice, the appointments included the continuation of the previous regional health directors in their office, only now they had the title of SDGH. The less fortunate new states that could not attract a skilled SDGH appointed one without previous experience or relevant preparatory training.

Chart 7.6 Percentage of adequate qualification among the directors-general

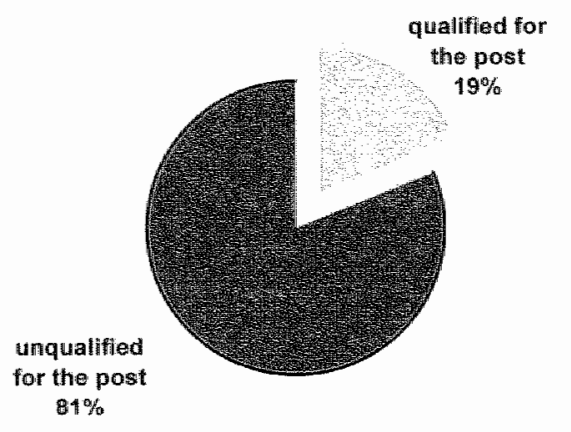

Source: Anthor's interviews and FMOH records.

Table 7.1 The personal data of 15 SDGHs in relation to required criteria

\begin{tabular}{|l|l|}
\hline Required criteria & $\begin{array}{l}\text { Number of State Directors-General in health who possess the } \\
\text { relevant criteria }\end{array}$ \\
\hline Adequately qualified & $6(37 \%)$ \\
\hline $\begin{array}{l}\text { Trained in planning and } \\
\text { management }\end{array}$ & $3(18.5 \%)$ \\
\hline Experienced in similar job & $6(37 \%)$ \\
\hline
\end{tabular}

Source: Author's interviews.

Clarification: adequately means that a SDGH meets the formal criteria set by the FMOH (specialisation in community medicine). Trained means that a SDGH has attended a course or training in planning and management. Experienced means that he had worked in a leading pasition earlier. 
The procedures used in the selection of SHMs and SDGHs resulted in major discrepancies in leadership of the public health sector across the sixteen states. In various states the SHM and the SDGH were not capable of giving the necessary guidance in implementing federal reform in the public health sector. Only a few of the states could find relatively skilled leaders with the relevant background and sufficient experience to lead the implementation process. Unfortunately, most of the states were not capable of competing for the skilled individuals, which resulted in poor leadership (see box 7.2).

\section{Box 7.2 Contrasts in leadership in four states}

The SMOH in Khartoum inherited the members of the National Health Salvation Committee for its health portfolio leadership. Its head became the state minister. He was a chest clinician with additional community medicine qualifications. His staff included more than twenty community physicians and public health specialists as a State Director-General, directors and senior subordinates. The SMOH also had enough supporting staff. The minister and his team remained in the ministry from 1993 until 2000 . This was a quite unusual stability in posts in current Sudanese context.

The SMOH in Gezeira had three Health Ministers during the same period with varying specialities, skills and capacities. The SDGH was a dentist having a diploma in public health. He had four subordinates who were medical generalists (one of them had diploma in public health), a pharmacist, ahealth visitor, a nutrition officer, a senior medical assistant, an immunisation officer, a specialist in health education and a few administrative officers.

The SMOH in North Kordofan had four consecutive ministers during the same period with variable qualifications. There were two directors-general specialised in community medicine. The directors included two medical generalists, a pharmacist, a senior medical assistant, a mutrition officer, an immunisation officer and a few administrative generalists.

The leadership of the $\mathrm{SMOH}$ in Kassala consisted of three consecutive medical doctors as ministers. They did not posses the relevant specialisation for the post. The director-general was a community physician. His subordinate directors consisted of two medical generalists, two nutrition officers, a senior medical assistant, an administrative officer and a public health inspector.

\subsection{Organisational reform of the state ministries of health}

Federalisation involved the transfer of various managerial, technical and service delivery functions from the federal level to the state level and added many of the previous functions of the province to those of the state (Constitutional Decree No. 11, No. 12 and No. 14, issued in 1993, 1994 and 1997 respectively). The increased responsibility of the states demanded a new organisational structure for the SMOH. 
With this in mind, the Directorate-General of Planning in the FMOH issued a standard structure to be implemented by each SMOH. This structure consisted of a SHM, a SDGH and six directorates (FMOH, 1995b). The State Health Council (SHC) was made responsible for overall health legislation, regulation, planning, and budgeting. The SHC was chaired by the SDGH and included several representatives from other sectors, e.g. agriculture, animal resources, medical faculties and education in order to promote intersectoral collaboration and to create a forum for the involvement of the community in public health affairs as envisioned in the NHS.

The organisational structure proposed by the FMOH was not very appropriate. In fact, it was more or less a copy of its own structure that consisted of five directorates, namely (i) curative medicine, (ii) preventive medicine, (iii) pharmacy and medicines, (iv) PHC, training and health education and (v) administrative and financial affairs. The proposed structure did not take into account that the FMOH and the SMOH had different roles in the federal system. The FMOH was expected to become less involved in direct administration, whereas the administrative activities of the SMOH were expected to increase. This structure aggregated the vertical programs under the state directorates without actually integrating them at the state and local level, which maintained their direct accountability to their federal coordinators. Hence, the situation frustrated the autonomy of the state health authorities and confused the state and local program managers, because they remained directly accountable to the federal vertical program coordinators rather than to the state health authorities and local councils. The dividing lines between curative, preventive and PHC services were quite unrealistic. At the operational level, PHC involved both curative and preventive services in addition to activities in health promotion.

It is of vital importance to the organisation of the SMOH that all levels of individual, group, and directorate activities are coordinated, if they are to work together and achieve common goals. The organisational structure proposed by the FMOH did not give clear mechanisms for the coordination of the SMOH and local health systems. Moreover, it did not pay attention to the planning of health services at the state level. All in all, it failed in meeting the objectives of the SMOH in the new federal context, because it undervalued the main functions of planning, coordination and participation and did not clarify roles or lines of accountability (figure 7.1 ). 
Figure 7.1 FMOH proposal for organization of State Ministry of Health

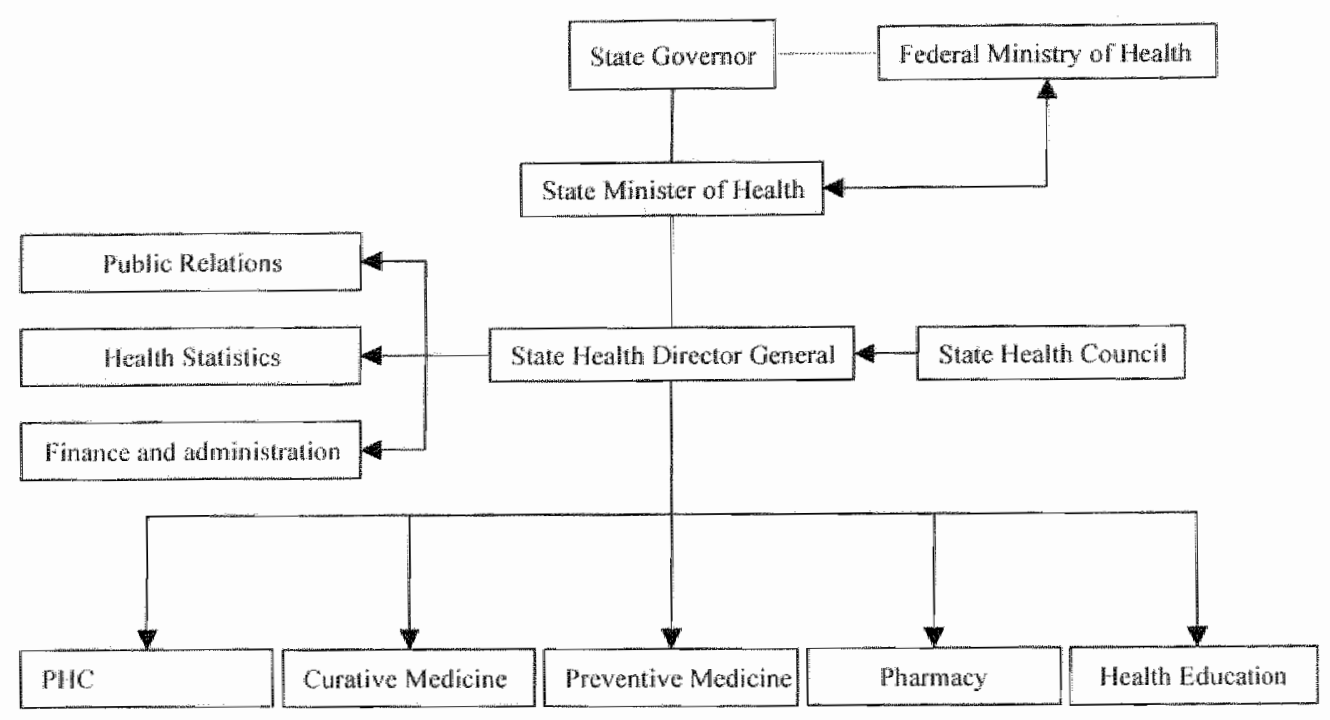

The response of the SMOHs can be categorised into three groups. The type of response elicited in each group depended upon the following factors: the type of leadership, the leaders' perception of the new role of the state in a fedleral system, and the availability of human and financial resources to carry out the state's new tasks.

Seven states did not implement any change in their organisational structure, namely Blue Nile, North Darfur, South Darfur, West Darfur, South Kordofan, North Kordofan and the Northern state. These states comprised the first group and lacked the leadership, motivation and capacity to introduce organisational change. The SMOHs in this group of states did not take in new staff and did not see any need for restructuring. On the contrary, they believed restructuring would only add another financial burden to their already scanty resources. The ministries in these states still have a very simple structure that rests mainly on individual interests. In most cases, the resistance to change originates from the fear of a change in financial benefits for the senior staff and the loss of power as the coordinators of state vertical programs.

The second group consisted of three states: Kassala, Gadaref and the River Nile. They introduced a structure similar to the model proposed by the FMOH and remained connected to the vertical program managers and Federal DirectorsGeneral (FDGs) in planning and tinancing.

The last group consisted of six states and included Khartoum, Gezeira, Red Sea, Sennar, West Kordofan and the White Nile. The structures developed by this group addressed in varying degrees most of the SMOH's basic functions as 
intended by the federal system. In this group, the Ministry of Health of Khartoum state has a pivotal role (see figure 7.2). It is clear that the structure of Khartoum SMOH is quite elaborated. It benefited from many factors such as the legacy from the previous regional system, oriented leadership, availability of staff that can fill the posts and experts in planning.

Figure 7.2 Health organization structure Khartoum State

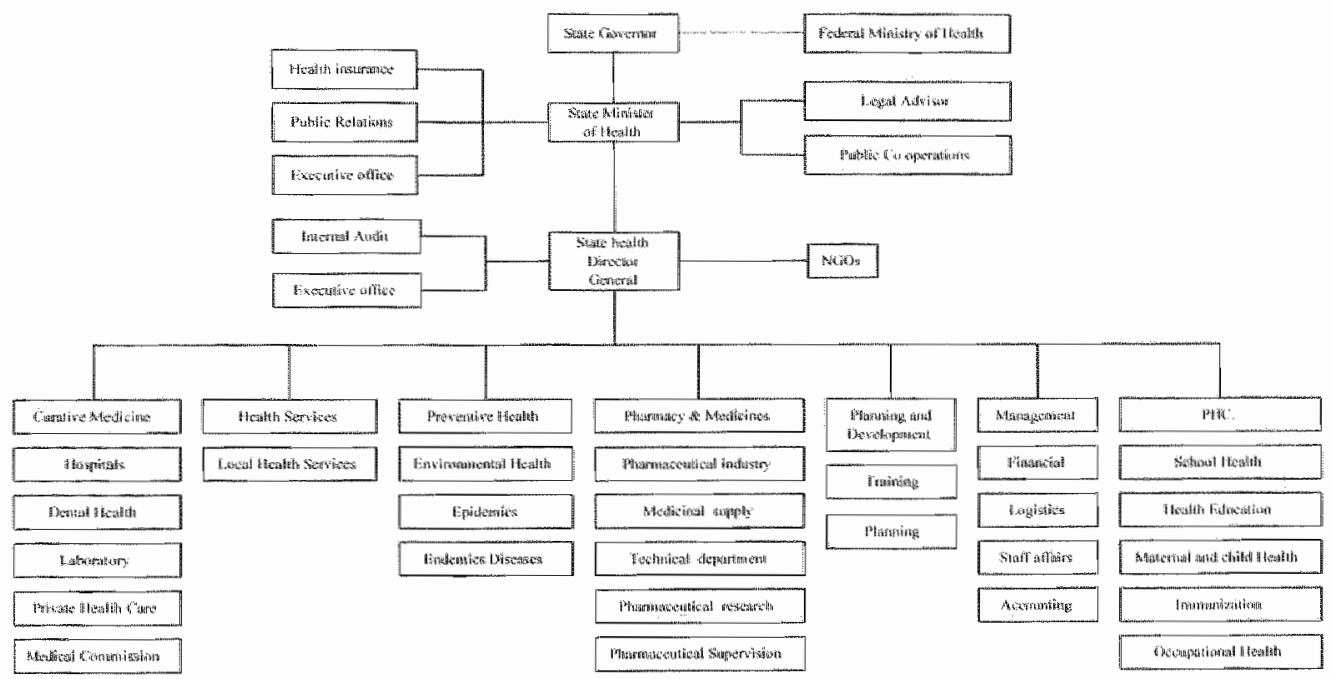

Source: Khartoum SMOH, 1997.

Gezeira SMOH structure (see figure 7.3) represents another example of this group. It reflected strong emphasis on the Health Area system, the implications of this difference will be analysed in chapter 8 . It also paid special attention to its local priorities represented in endemic and epidemic disease as the state is heavily burdened by water born diseases. 


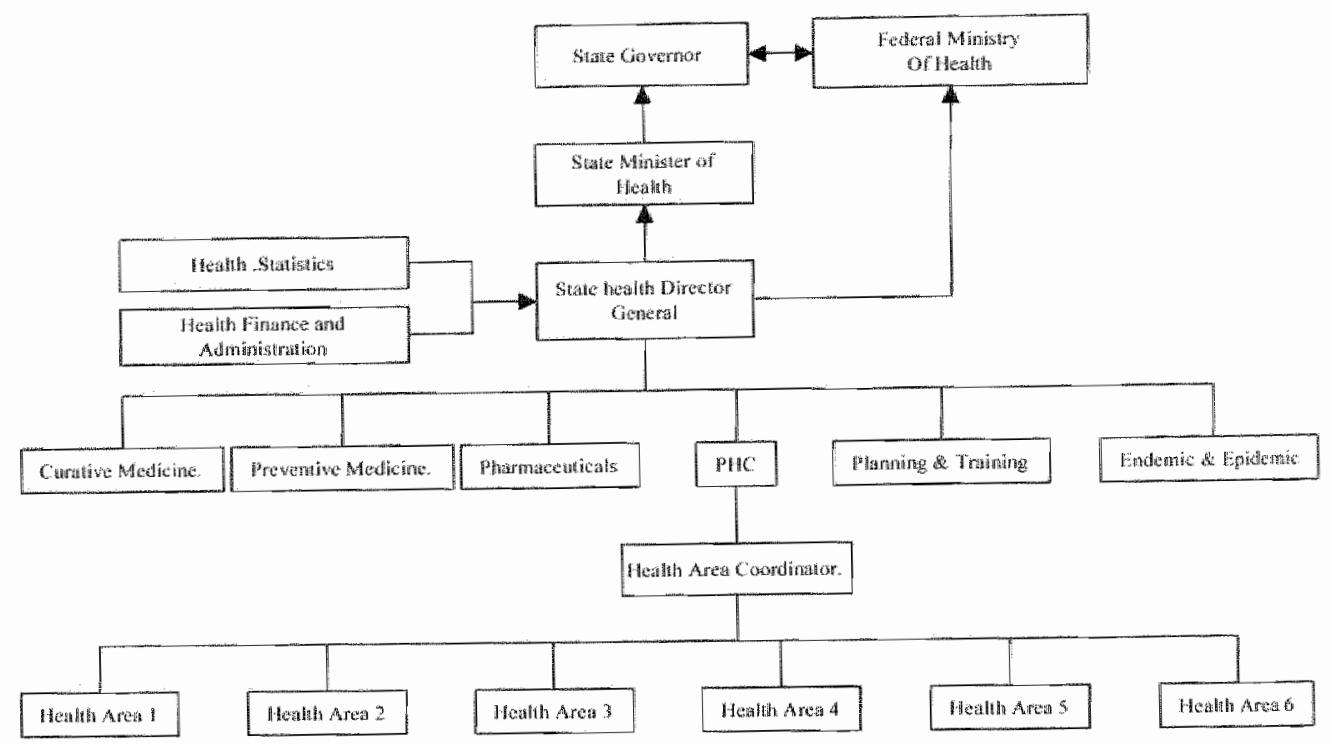

Source: Gezeira SMOH, 1996.

\subsection{The role of the state in planning}

Planning within a federal context requires collaboration between the federal and the state government (Constitutional Decree No. 12, 1994). However, the role of each government leve $\$ in planning remained vague and lacked consensus. On the division of responsibilities between the federal and state level for planning, the Federal Director-General for Planning stated in vague terms: "the federal level is responsible for macro planning and the states for micro-planning". This ambiguous description of the roles gave rise to many different interpretations and frequently resulted in conflicts and tensions in relations between the SMOH and the FMOH (see chapter 6). Some states such as North Kordofan and South Darfur were completely apathetic towards their role in planning.

The planning process at the state level involved operationalisation of the NHS, setting of specific priorities in the state health plan, provision of state resources and the development of an information system to assist evaluation and monitoring. It also entailed programming, budgeting and evaluation of the state health activities.

All states had to struggle with the scarcity and uncertainty of available resources in their planning. Fourteen of the SHDGs interviewed (about 90\%) described these problems as paramount. However, there was some variation in how the states approached planning. Generally speaking, we can classify these states into two groups. The first group consisted of Khartoum, Gezeira, Red Sea and to 
some extent North Darfur. These states demonstrated an understanding of their role in planning under the new constitution. They managed to operationalise the NHS into a state health plan with some priorities and a mission statement. The second group included the remaining twelve states that did not develop an operational state health plan. In these states, planning was seen as a means of securing the annual budget from the state government and other financial sources such as the national immunisation campaigns.

Considerable variation in planning procedures can be observed within each group (see table 7.2). With a few exceptions, the SMOH followed the stereotypical mechanisms for planning such as the top-down approach and the isolation of the community from the planning process. None of the states involved the State Health Council in the planning process, nor did they develop alternative mechanisms of involving the community in planning. The bureaucracy and professional elites monopolised the planning process.

The state program coordinators and directors submitted their proposals to their director-general. These proposals were discussed and then submitted by the State Health Minister to the State Ministerial Council for approval. In some States such as Khartoum and Gezeira, the proposal was presented to the State Legislative Council to be approved for execution as part of the annual budget. This last step could lead to some form of indirect community involvement. On the whole, no questions were asked concerning priorities or expenditures in the health budget, nor was there any follow-up or the progression on changes required in the future. The discussion usually remained superficial and symbolic with little attention given to the details of the health plan and programs.

Some states in the first group benefited from having a reasonably competent planning ability and past experience. They also involved experts from outside the $\mathrm{SMOH}$ in developing their plan. For example, Khartoum SMOH involved national health expertise and $\mathrm{NGO}$ professionals in developing its five-year health plan. Gezeira SMOH involved the University of Gezeira in the planning process. The rest of the SMOHs used international and national slogans to formulate ad hoc plans in order to meet the formal requirements of the funding agencies, thus securing resources for training programs and projects to help strengthen the PHC or to construct a new health facility. 
Table 7.2 The planning process in the sixteen states

\begin{tabular}{|c|c|c|c|c|c|}
\hline State & $\begin{array}{l}\text { Possesses } \\
\text { Overall Health } \\
\text { Plan }\end{array}$ & $\begin{array}{l}\text { Relevance to } \\
\text { NHS }\end{array}$ & $\begin{array}{l}\text { Involvememt of } \\
\text { Health Council }\end{array}$ & $\begin{array}{l}\text { Presence } \\
\text { of } \\
\text { Planning } \\
\text { Skills } \\
\end{array}$ & $\begin{array}{l}\text { Community } \\
\text { involvement }\end{array}$ \\
\hline Blue Nile & - & - & $\therefore$ & - & 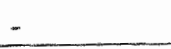 \\
\hline Gadaref & - & - & - & - & - \\
\hline Gezeira & + & + & - & - & + \\
\hline Kässala & - & + & - & - & + \\
\hline Khartaurn & + & + & - & $\frac{4}{a}$ & - \\
\hline $\begin{array}{l}\text { North } \\
\text { Darfur }\end{array}$ & + & 4 & - & - & + \\
\hline $\begin{array}{l}\text { North } \\
\text { Kordofan }\end{array}$ & - & . & - & - & - \\
\hline Northern & $\alpha$ & - & - & - & - \\
\hline Red Sea & + & + & - & - & - \\
\hline River Nile & - & $=$ & - & - & - \\
\hline Sinnat &. & - & - & - & + \\
\hline $\begin{array}{l}\text { South } \\
\text { Darfur }\end{array}$ & - & - & - & - & - \\
\hline $\begin{array}{l}\text { South } \\
\text { Kordofan- }\end{array}$ & - & - & - & . & . \\
\hline West Darfur & - & - & - & - & - \\
\hline $\begin{array}{l}\text { West } \\
\text { Kordotan }\end{array}$ & - & - & - & - & - \\
\hline White Nile & - & + & - & $=$ & - \\
\hline
\end{tabular}

Source: Author's interviews and official records.

Clarification: + present, - not present

\subsection{Financial relations}

The implementation of federal reform involved transferring the responsibility of the public health sector financing to the state governments (Constitutional Decree No. 12, 1994; Constitutional Decree No. 14, 1997). These alterations in financing are visualized in tigures 7.4 and 7.5. Prior to federal reform (see figure 7.4), the National Ministry of Health played key role in health care financing. All resources from the national Ministry of Finance and the United Nations Agencies were transferred to it. The national Ministry sponsored the regional health authorities and allocated financial resources to the vertical programs. This structure enabled the national Ministry to control and regulate the allocation of the bulk of public health sector's resources in the country. 
Figure 7.4 Financial health relations in the country prior to federalism

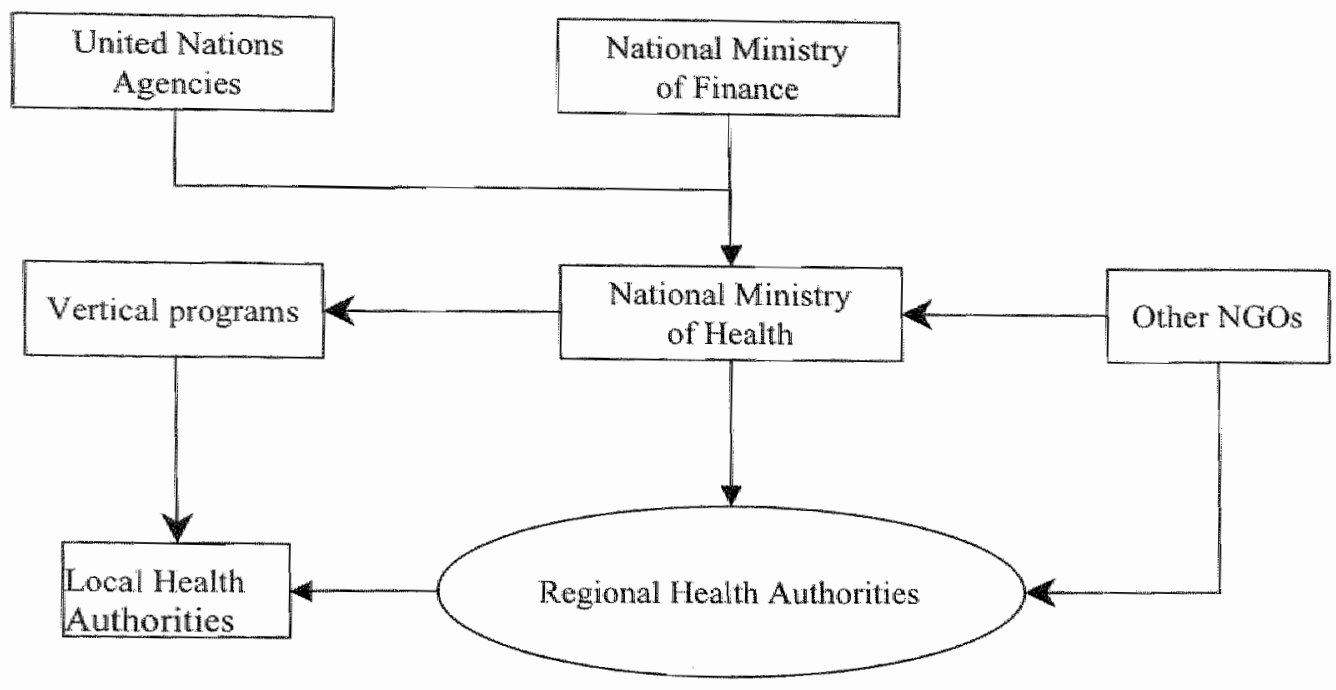

Figure 7.5 illustrates significant changes in financial relations involved in federal reform. The bulk of the federal resources for the public health sector were now to be directly transferred to the State Ministry of Finance and from there, depending on the political priority of health care, to the SMOH. The resources from the Federal State Support Fund were to follow the same pathway. In both cases the FMOH was bypassed. Therefore, compared to the previous situation the FMOH lost an important tool for the financial control of lower level government. From the viewpoint of the states the new financial arrangement meant that the FMOH had less opportunity to interfere in their internal affairs. However, in reality intergovernmental relations in health care finance were different.

To a large extent the FMOH managed to retain its strong position in the financing structure and its position as a national coordinator of public health finance. It remained directly involved in the financial management of the vertical programs. Furthermore, some states were so weak that they were almost completely dependent upon the FMOH in their negotiations with the federal financing authorities. Finally, the FMOH managed to keep a tight grip on the allocation of resources for public health from the Federal State Support Fund. As a result, the states" autonomy in health care finance was far less than federal reform intended. 


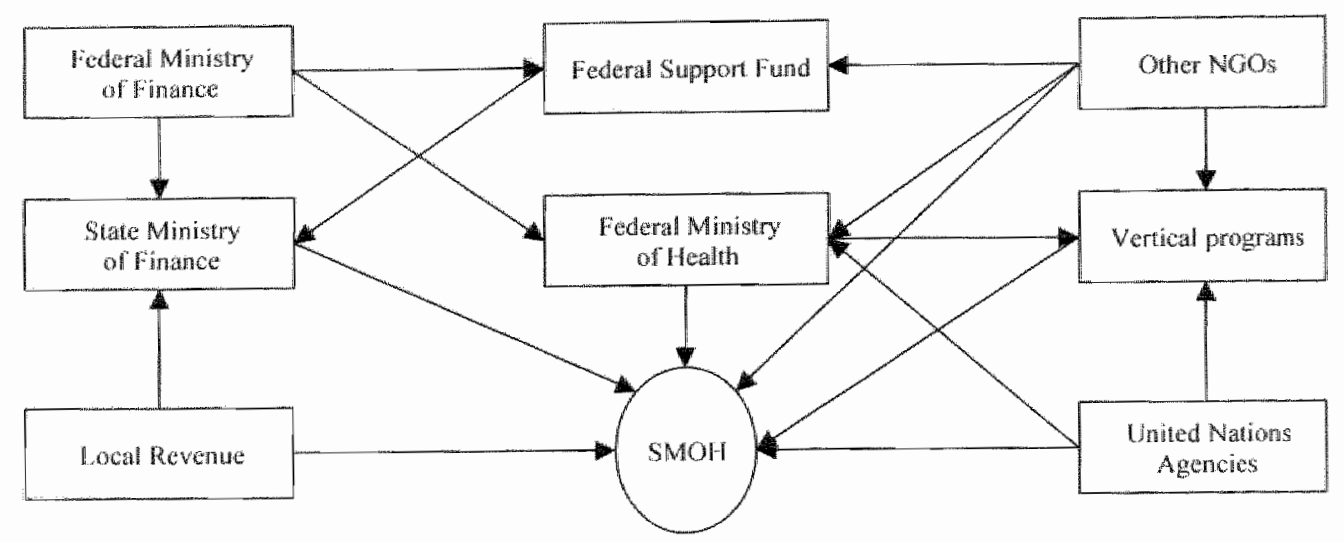

\subsubsection{Financial relations from the perspective of the states}

The sources of state public health sector financing can be categorised into internal state resources, direct federal transfers, and revenue from United Nations Agencies and other NGOs. The internal resources for public health sector funding include the State Ministry of Finance, local revenues obtained from fees charged for services in health facilities, and earmarked health tax revenues. The latter source depends on the economic capacity of the state and consequently, favours the wealthy states because of their larger capacity for revenue collection. Therefore, higher federal transfers are needed to compensate for the low revenue base of the poor states.

Direct federal transfers to the state for health care can be categorised into three subgroups: federal earmarked health funds, the Federal National Preventive Health Programs and the PHC strengthening Projects Funds. The last two include several vertical programs. The Federal Preventive Health Programs are an important source of state public health sector financing and include many programs such as leprosy, tuberculosis, AIDS, or malaria program. Bamako, IMCI and BDN are examples of PHC strengthening projects. Federal coordinators control all resources for these vertical programs. The federal earmarked health funds include the health insurance fund, the Free Medical Treatment Fund (intended for very poor and emergency cases) and Rural Health Support from the African Bank and the Islamic Cooperative Development Bank. The new financial arrangements do not enable the majority of states to meet the health needs of their citizens. This was due to the failure of the Federal State Support Fund to compensate effectively for interstate economic disparities. The federal financial support received by the states is mostly spent on public health sector wages and employees' compensation. The federal health funds received by the states lack the transparency needed to guarantee an equitable distribution 
(Magzoob, 1999a). Moreover, allocations from these funds are based on the location of hospitals and other medical facilities. As a consequence, many resources flow to the relatively rich states, i.e. Khartoum. This practice only exacerbates the already skewed distribution of resources to the benefit of wealthier states and reinforces the unequal allocation of resources across the country (see tables 7.3 and 7.4).

Table 7.3 Sources of healith finance in the sixteen Northern States

\begin{tabular}{|c|c|c|c|c|c|c|c|}
\hline Statle & $\begin{array}{l}\text { State } \\
\text { Support } \\
\text { Fund }\end{array}$ & $\begin{array}{l}\text { State } \\
\text { Government }\end{array}$ & $\mathrm{MGOs}$ & $\mathrm{FMOH}$ & $\begin{array}{l}\text { User } \\
\text { Charges }\end{array}$ & Investhent & $\begin{array}{l}\text { Community } \\
\text { Contribution }\end{array}$ \\
\hline Blue Nile & - & + & + & $\infty$ & + & - & - \\
\hline Gadaref & - & + & + & - & + & - & - \\
\hline Gezeirati & + & + & 4 & 4 & + & - & + \\
\hline Kassalca & + & + & + & + & + & - & sing \\
\hline Khartoum & + & + & + & + & + & 4 & + \\
\hline $\begin{array}{l}\text { Morth } \\
\text { Darfun }\end{array}$ & + & + & + & - & + & + & - \\
\hline $\begin{array}{l}\text { North } \\
\text { Kordofan }\end{array}$ & + & + & + & - & 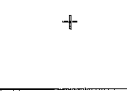 & - & - \\
\hline Notihern & - & + & 4 & - & + & - & - \\
\hline Red Sea & - & + & + & - & $t$ & - & - \\
\hline River Nile & - & + & + & - & + & - & 4 \\
\hline Simmar & - & + & - & + & + & - & + \\
\hline 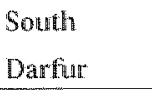 & - & + & + & + & + & - & - \\
\hline $\begin{array}{l}\text { Soudth } \\
\text { Kordolatu }\end{array}$ & + & + & + & - & + & - & - \\
\hline $\begin{array}{l}\text { Wast } \\
\text { Dorrifur }\end{array}$ & 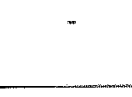 & + & - & + & H. & - & + \\
\hline $\begin{array}{l}\text { West } \\
\text { Kondofan }\end{array}$ & + & + & + & - & + & + & - \\
\hline Whate Nile & - & + & + & + & 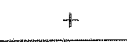 & - & + \\
\hline
\end{tabular}

Soutce: Author's interviews.

Clarification: + present; - not present

\subsubsection{Managing additional financial resources for health}

In general, the implementation of federal reform was not supported by special financial allocations. The states showed a variety of responses to the new financial arrangements in an attempt to rectify the situation. The data displayed 
in table 7.3 illustrate that all state governments are trying to actively participate in the financing of their public health sector. The bulk (approximately 70\%) of the state health funds is spent on expenses such as wages and salaries leaving very little for direct spending on health services. Furthermore, all states collect additional resources for health care by charging patients for the health services they receive. This revenue takes many forms and includes the fees charged for issuing certain health certificates and the drugs revolving funds. This revenue is mainly spent on the daily expenses involved in running health services. The sum of these resources depends on the number of health facilities present (theses are usually concentrated in the wealthier states) and the ability and willingness of the population to pay for them.

In addition to the traditional pattern of public health sector financing, some states such as Khartoum, Red Sea, and Gezeira developed alternative strategies to find additional resources. These strategies involved investing in revenue generating projects, direct contact with the NGOs and lobbying the federal authorities. They favour the richer states because they have more capable leadership that is required to develop such strategies. Thus, the wealthier states use their political and administrative leadership and larger capacity to increase the financial resources available to them for the public health sector. The poorer states that actually need more resources lack such leadership and suffer as a result.

\subsubsection{Benefits from the federal health funds}

The states also differ markedly in their ability to secure benefits from the health funds that are controlled by the FMOH and revenues from the Federal State Support Fund. The first group of funds includes the "ear-marked" health funds from the Federal State Support Fund. Table 7.3 demonstrates that certain states, namely White Nile and Kassala, benefited from all of the available funds while others benefited from only one. The distribution of theses funds was not based on proper criteria, but in most cases depended on informal relations, internal politics and the personal interests of the main actors. 
Table 7.4 Distribution of FMOH controlled funds

\begin{tabular}{|c|c|c|c|c|}
\hline State & $\begin{array}{l}\text { Federal } \\
\text { Earmarked } \\
\text { Funds" }\end{array}$ & $\begin{array}{l}\text { PHC Strengthening } \\
\text { Projects }\end{array}$ & $\begin{array}{l}\text { Federal Prexentive } \\
\text { Health Projects }\end{array}$ & Total \\
\hline Biuge Nile & 2 & 4 & 3 & 9 \\
\hline Gadaref & 1 & 3 & 2 & 6 \\
\hline Gezeira & 1 & 4 & 4 & 9 \\
\hline Kassala & 4 & 3 & 3 & 10 \\
\hline Khatroum & 2 & 5 & 4 & III \\
\hline North Darfur & 2 & 2 & 1 & 5 \\
\hline North Kordofan & 2 & 3 & 2 & 7 \\
\hline Northem & 2 & 2 & $\mathbb{1}$ & 5 \\
\hline Red Sea & 1 & 3 & 4 & 8 \\
\hline River Nile & 2 & 4 & 1 & 7 \\
\hline Sinnar & 2 & 4 & 4 & 10 \\
\hline South Darfur & 2 & 4 & 2 & 8 \\
\hline South Kordofan- & 1 & 3 & 3 & 7 \\
\hline West Darfur & 2 & 3 & 2 & 7 \\
\hline West Kordofan & 2 & 3 & 2 & 7 \\
\hline White Nite & 4 & 4 & 2 & 10 \\
\hline
\end{tabular}

Clavification: "Federal Earmarked Funds inchide Islamic Cooperative Bank, African Development Bank, Free Medical Treatment Support and Health Insurance.

"Federal PHC Strengthening Funds include HA (WHO), MCHC (UNCEF), MMC (UNTCEF). Bamako (UNICEF), and BDN (WHO).

"Federal Preventive Funds include Bulharsiasis (UNICEF and WHO), Malaria (WHO and FGov.). ADS (UNFPA and WHO), T.B. (WHO) and Leprosy (WHO).

The other federally controlled resources are grants from the NGOs, namely the United Nations Agencies, such as WHO, UNICEF, UNFPA, other international organisations and a few national ones. These funds are intended to support PHC and preventive health activities by providing technical assistance that is mainly related to the vertical programs. In most cases they are controlled by the FMOH. Some states such as Blue Nille, South Darfur and West Darfur receive nothing from these funds. This can be explained by the fact that there are no standard criteria for the allocation of these resources. Other states like Khartoum have direct relations with foreign organisations. They manage to bypass the FMOH and directly negotiate with WHO and UNFPA for grants for PHC and their matemal and child health programs. However, other states like Gezeira lobby with the FMOH and the NGOs for pilot projects such as the Health Area, BDN and Bamako Initiative.

Generally speaking, the FMOH represented by its directorates-general, directorates and the vertical program coordinators did not enable all states to make appropriate use of the aforementioned funds. As far as donor funds were 
concerned, the donor agencies themselves decided which state they would fund, yet the FMOH managed to exert a strong influence on the selection procedure. It sought to retain control of these resources and to continue its direct control. This behaviour conflicted with the principles of federal reform, as it was the states that were required to implement the vertical programs. The FMOH's influence undermined the implementation of the new financial arrangements. In this respect, it is important to consider that the external assistance programs represent about $35 \%$ of public health expenditure. They could have played a considerable role in minimising the inequalities in state resources, but that did not happen. Most assistance was given in the form of projects run by different managers, usually without any coordination. This practice resulted in the further accumulation of resources in some states to the exclusion of others. The final result was that some states such as Khartoum and White Nile received great share of external assistance in the form of numerous projects with different names, while other states like West Darfur and. Southern Darfur were not even aware of these projects.

The establishment of the National Fund State Support did not contribute to correcting the disparity because most states were incapable of submitting applications that met the fund's requirements. Moreover, the prevailing situation in the public health sector served the interests of the main bureaucratic actors in the FMOH and the wealthy powerful groups in some advanced states. Less developed states such as Kordofan, Darfur and Blue Nile did not benefit much from the centrally controlled NFFS, and neither the top political leadership nor the federal institutions tried to correct this situation.

\subsection{Developing capacity building in the states}

Paul (1995) argues that one of the main causes for the failure of the most reform programs in developing countries is the low priority given to capacity building issues. During the implementation of federal reform the states require functional institutions and the development of human resources, infrastructure, and financial resources in order to discharge successfully their new responsibilities. Prior to planning capacity building, an assessment of existing capacity is essential in order to determine what needs to be accomplished. (Cheema, 1998). In terms of human resources, states require trained leadership, planners, administrative and managerial skills, health informatics, financial personnel and technical health professionals including public health and medical staff alike.

Due to the variations in state leadership and availability of resources, the SMOHss vision of how to build capacity varied considerably. Our interviews with the state SDGH and the focus group discussions revealed that $75 \%$ of the interviewees were aware of the importance of building capacity. However, their awareness did not result in a uniform vision on how to build capacity. The majority of them interpreted the concept as the availability of technical health 
professionals and well-equipped health facilities. Only $40 \%$ of the interviewees mentioned managerial, planning and technical aspects of capacity building. Only two states developed a plan to build their capacity. All the rest of states lacked such a plan and made themselves dependent upon ad hoc technical training courses that were a part of the technical assistance offered within the vertical programs. They also routinely upgraded posts and provided promotions, as result of individual interests.

Table 7.5 Capacity building in sixteen states

\begin{tabular}{|l|c|c|c|c|}
\hline Parameler & Awareness & Needs assessed & Plan prepared & Plan started \\
\hline Human resources & 12 & 7 & 4 & 4 \\
\hline Physical resounces & 10 & 5 & 3 & 3 \\
\hline Health instifutions & 4 & 3 & 2 & 2 \\
\hline
\end{tabular}

Ten of the SHDGs interviewed emphasised the importance of building the capacity of physical resources (health facilities) and financial resources. A quarter of them also acknowledged the importance of institutional capacity to enable the state ministries in financial management, planning, information management and supervision of lower levels. The number of states that actually assessed their capacity in terms of human resources, physical resources and institutions was seven, five and three respectively (table 7.5). However, the federal authorities conducted these assessments for most states to allocate the available resources between the former and the new states. Assessments were not performed in order to facilitate the process of building capacity. In addition, no new funds were made available for this process.

\subsubsection{The development of human resources}

In the absence of an active federal role in the process of building capacity, the states' internal situation strongly influenced their approach to capacity building. States like Khartoum and Gezeira inherited a reasonable number of qualified personnel, a multitude of health facilities, training institutions and financial resources to develop new personnel. Western states such as Darfur and Kordofan and some others lacked these resources as well as the capacity to develop new ones themselves. In general, the states that hosted the headquarters of the former regions inherited most of the available resources, which included the former SDGH, relatively skilled personnel and the best of the infrastructure and logistics.

The contribution of the NGOs such as the WHO and UNICEF in providing technical assistance to states represented the main input for human resources development. The absence of priorities for apportioning the available funds led to bias in their allocation in favour of the individual interests of the vertical program 
coordinators. They favoured the vocal states with good access to the FMOH and the $\mathrm{NGOs,}$ which explains why $75 \%$ of the workshops, seminars and training activities supported by the WHO were mostly held in Khartoum. In addition, $80 \%$ of the participants came from the FMOH and Khartoum state (FMOH, 1999).

Khartoum state is the only state that has a relatively comprehensive plan for building the capacity of human resources. The plan involves planning of managerial, medical and public health staff at all levels, and it includes training programs, compensation and incentives for the trainees for their participation (Khartoum SMOH, 1997). The remaining states such as Gezeira only partially developed plans that focused on training Health Area Management Teams and other ad hoc activities. Most of the less developed states performed very poorly.

Table 7.6 presents an overview of how human resources evolved in the Northern states between 1994 and 1999. Generally, a decrease in the density of medical doctors was observed in most states with the exception of Blue Nile, Sennar, South Kordofan and the Northern state. However, the increase in the density of medical doctors in these states does not represent a growth in the number of medical doctors but reflects a decline in the size of the population due to displacement and migration. The situation in Khartoum was completely the reverse. In this state the increase in the population exceeded the growth in the number of medical doctors. Surprisingly, the fall in the density of medical doctors occurred when the number of graduates was increasing. This was due to the bureaucratic procedures involved in recruitment. Furthermore, the figures of Khartoum are somewhat misleading. States like Khartoum used to appoint temporary personnel from their external resources, and these appointments were not recorded by FMOH. Neither was the number of health personnel in the large teaching hospitals of Khartoum that were directly accountable to the $\mathrm{FMOH}$, in police and military hospitals, or the medical personnel of roughly 135 NGOs working in Khartoum were taken into account.

A few states, namely Northern, River Nile and White Nile managed to improve the capacity of their PHC personnel. However, this was more due to the efforts of individual citizens who had influence at the higher levels of government rather than the plans of the SMOH. 
Table 7.6 The change in rate of selected human resources per 100,000 population in the Northern States between the years 1994 and 1999.

\begin{tabular}{|l|c|c|c|c|}
\hline State & Medical Doctors & Medical Assistants & Healh Visitors & Medical Technicians \\
\hline Blue Nile & 0.5 & -3.1 & 0.9 & 2.4 \\
\hline Algadaref & -0.7 & 4.1 & 0.4 & 2.3 \\
\hline Gezeira & -2 & 0.3 & 0.8 & 0.8 \\
\hline Kharioum & -1.1 & -3 & 1.8 & -21.5 \\
\hline Kasalla & -1.8 & 15.7 & -1 & 29.1 \\
\hline North Darfur & -0.8 & 6.5 & -3.4 & 1.4 \\
\hline North Kordofan & -0.3 & -0.8 & -0.9 & -0.3 \\
\hline Northern & 2.5 & 9 & 6 & 1.3 \\
\hline Red Sea & -0.5 & -2.1 & 0 & 2.5 \\
\hline Riwer Nile & -2.3 & 7.5 & 11.6 & 0.3 \\
\hline Sennar & 0.8 & 5.5 & 0 & 1.7 \\
\hline South Darfur & 0 & 0.2 & -5.4 & 0.5 \\
\hline Solth Kordofan & 0.4 & -4.7 & 1.2 & 0.6 \\
\hline Wesit Darfur & 0 & -0.3 & 0.3 & -0.1 \\
\hline West Kordofan & -3.7 & 0.7 & 0.6 & -2.1 \\
\hline White Nile & -9.6 & 5.5 & 1.8 & 0.1 \\
\hline
\end{tabular}

Source: FMOH, 1994 and FMOH, 1999.

\subsubsection{Capacity building of physical resources}

The resources of most states were barely enough to cover the salaries of the state employees. Therefore, states requested central support to be able at least to pay their employees' salaries (FGC, 1999). Ultimately, this made the states' capacity to finance physical resources quite inadequate. Only a few rural health centres were constructed supported by the donations from the Saudi Development Bank, the African Development Bank, the Islamic Development Collaborative Bank, local self help community contributions for aid projects and by individual donations. The FMOF could not even meet the meagre local contributions to these funds, which led to delays in development of new facilities (Interview with Federal Director-General for Planning, 1999).

Yet, there were some exceptions. States like Khartoum and Geziera possessed a substantial number of health facilities enabling them to provide a reasonable level of health care. Some SMOHs developed financing strategies that involved investments, popular participation, service charges, direct contacts with the NGOs, and lobbying the central government authorities. In this manner, some states such as Northern, River Nile, White Nile, Northern Darfur, South Kordofan and Khartoum were able to provide a considerable increase in the health facilities. In the case of Khartoum this is understandable due to the state's relatively well-designed operational processes. Other states such as Northern, 
River Nile and White Nile were also relatively successful in extending their health facilities. However, this was not due to the quality of their organisation or planning, but to their ability to obtain additional resources as a result of their access to higher government circles and profitable personal relations. The success of South Kordofan can be explained by the tremendous support received from a NGO (Al-Bir International Foundation). In the remaining states, the number of health facilities increased, but there was a decrease in the availability of hospital beds (Sennar, Kassala, Red Sea and Algaddaref). This can be explained by the poor maintenance of health facilities. Some states including North Darfur and North Kordofan even struggled to maintain the availability of minimal facilities due to ad hoc maintenance programs (see table 7.7).

Table 7.7 The change in number and rate of public health facilities in Northern States between the years 1994 and 1999 (in Northern States in percentage)

\begin{tabular}{|c|c|c|c|c|c|c|}
\hline \multirow[t]{2}{*}{ State } & \multicolumn{2}{|c|}{ Hospitals } & \multicolumn{2}{|c|}{ Hospital beds } & \multicolumn{2}{|c|}{ Health centres } \\
\hline & No. & $\%$ & No. & $\%$ & No. & $\%$ \\
\hline Blue Nile & 2 & 40 & 10 & 4 & 4 & 67 \\
\hline Algadaref & 4 & 57 & -134 & -16 & 6 & 40 \\
\hline Gezeira & 0 & 0 & -50 & -2 & 2 & 2 \\
\hline Khartoum & 1 & 3 & 1216 & 26 & 37 & 49 \\
\hline Kasalla & 1 & 10 & -108 & -9 & 5 & 16 \\
\hline North Darfur & 2 & 29 & -24 & -4 & 15 & 107 \\
\hline North Kordofan & 1 & 8 & 34 & 3 & 4 & 14 \\
\hline Northern & 1 & 4 & 199 & 16 & 48 & 200 \\
\hline Red Sea & 0 & 0 & -163 & -19 & 5 & 71 \\
\hline River Nile & 3 & 18 & -20 & -2 & 7 & .7 \\
\hline Sennat" & 2 & 18 & -408 & -43 & 8 & 47 \\
\hline South Durfur & 0 & 0 & -24 & -3 & 7 & 87 \\
\hline South Kordofan & 2 & 33 & 19 & 90 & $\Perp$ & 8 \\
\hline West Darfur & 1 & 33 & -9 & -4 & 1 & 20 \\
\hline West Kordofan & 0 & 0 & 3 & 3 & 3 & 17 \\
\hline White Nile & $\mathbb{1}$ & 7 & 32 & -3 & 21 & 62 \\
\hline
\end{tabular}

Source: FMOH, 1994; FMOH, 1995a; FMOH, 1996a; FMOH, 1997a; FMOH, 1998b; FMOH, $2000 \mathrm{~b}$.

Clarification: the percentages are calculated in relation to the mumber in 1994.

\subsection{Conclusions}

In this chapter we analysed the process of the implementation of federal reform in the public health sector at the state level. The objective of federal reform at the state level was to create well-structured SMOHs that were capable of fulfilling their new responsibilities. The tasks included planning, financing, building 
capacity, supervising and providing support to the local health authority. As we predicted in the previous chapter, the implementation of the federal reform at the state level was anything but successful. In this concluding section, we will review the implementation process at the state level using Grindle's analytical model for implementation analysis.

In chapter 5 we concluded that the development of health policy in Sudan followed a top-down approach. The federal reform developed in a similar way. The majority of the states did not have access to policymaking on federal reform. This lack of involvement had a strong influence on how they participated in the implementation process and how federal reform was shaped at the state level. The political drive and haste of the regime resulted in a reform program that was only stated in global terms and clouded with ambiguity. The federal authorities failed to operationalise federal reform in many respects (chapter 6). As a consequence, states were left to their own devices even though they lacked the necessary skills and capacity for the majority of time. This had a tremendous impact upon policy implementation.

We can conclude that the implementation of federal reform by the states took place in quite different contexts. We found great variation between the states in their financial resources, availability of human and physical resources, and access to high-level policymaking circles. Whereas some states already had a history as a separate administrative unit in the government system, other states had been recently created and had no history of their own to rely on. They had to start from scratch with minimal resources and could not benefit from political and administrative experience. In reality, the situation was even worse than this. What happened was that the states with economic resources and political influence were able to benefit much more from federal reform than the poor states with little or no political influence. In fact, federal reform did not remove inequities between the states, but actually reinforced them.

These variations in contexts affected the way each state perceived the benefits of federal reform. Some states were sceptical and not motivated to implement it. They developed a passive attitude and often displayed serious disinterest. These states did not believe that federal reform would actually materialise or that they could benefit from it. The ambiguity in federal reform together with its top-down approach with minimal state involvement reinforced their scepticism and lack of motivation. As a result, the implementation of federal reform in these states was sluggish and bleak. Other states (mainly Khartoum and Gezeira) adopted a more proactive approach in proportion to their capacity and undertook activities to implement federal reform in the public health sector. Their main challenge was restraining federal interference in their affairs. A short-term benefit of federal reform for all the states was the creation of new ministerial positions and promotion opportunities for the senior staff. Thus, federal reform was blighted by political, bureaucratic and private interests. 
Federal reform aimed to significantly change the administrative structure. The original nine states were divided in twenty-six. Furthermore, a number of policy tasks and responsibilities had to be transferred from the federal to the state level. However, these changes were not very realistic in terms of financial and human resources. The increase in the number of states proved to be a very expensive decision that exceeded the country's financial and human capacity. As a result, the qualifications of the senior policymakers in most states were inadequate. Furthermore, the actual transference of tasks and responsibilities to the states was never matched with the transfer of equal resources. The lack of resources hindered policy implementation, although some states were more affected than others.

The state implementing agencies lacked the necessary qualifications. But in addition, the coordinating agencies running the vertical programs preferred to keep their separate status and consequently did not show any interest in integrating their services to form a state health policy. Their main drive was to safeguard their position through collaboration with the federal coordinating agencies.

Federal reform entailed a change in power relations between the state and federal level. The response of the actors involved at the state level was influenced by several determinants: leadership, community awareness, political lobby, financial capacity, and personal interests and strategies. Most of the states failed to employ the appropriate strategies to achieve policy targets. The only clear example of a relatively successful performance was the SMOH of Khartoum. It performed well in planning, capacity building, financing and set up well structured and institutionalised organisations.

Federal reform also led to an ongoing power struggle between the federal and state level. A clear example of this was the policy of the FMOH to retain its corrurit on Tinanciail resources. The result was that most states remained heavily dependent upon the FMOH for their resources. Few states like Khartoum and Gezeira resisted the efforts of the FMOH to retain its control. They developed strategies to bypass the FMOH and attract additional resources.

Regime characteristics also played a prominent role in the implementation of federal reform in the state public health sector. The closed top-down approach in policymaking marginalized the states, which resulted in the poor orientation and lack of enthusiasm of state health authorities towards reform. The regime also compromised the posts of State Health Ministers to support its popularity. Political loyalty was more important than professional expertise. At the same time, it showed only little interest in the appointment of the SDGHs. This practice reveals their lack of interest in creating optimal conditions for the states to improve public health sector. The result was that most SMOHs were unstable and poorly equipped to adequately fulfil their responsibilities. This is not surprising, since the objectives of the regime were to increase the number of the 
ministerial posts rather than to improve the health care. The regime's agenda also predominated when it granted priority to the state of Khartoum to avoid political pressure. It listened more to the state of Khartoum than to any other state.

The characteristics of implementation in the state institutions reflected the regime characteristics at the federal level. For instance, the standards and criteria for the appointment of senior staff, specifications of tasks and distribution of resources were completely absent at both levels. In addition, personal interests and power were paramount in the allocation of resources and accountability.

The compliance of state health authorities to policies depended to a large extent on how their state leaders perceived federal reform. Some states aimed to reduce the role of the FMOH as much as possible and their interpretation of federal reform was shaped by this objective. Other states were not interested in autonomy as long as they enjoyed a honeymoon relationship with the federal vertical program coordinators. 



\section{Chapter Eight \\ Implementation at the Local Level The Health Area Policy}

\subsection{Introduction}

The local level of government is expected to benefit most from decentralisation because the decision-making process is brought closer to the people. According to the Sudan Constitution of 1998, the Local Government Act of 1995 (modified in 1998) and the Health Ministerial Act of 1990, each state is responsible for the organisation of its local health system, based upon the principles of the Health Area Policy (HAP), which emphasises PHC (Abdel Rahim et al., 1992). This chapter presents an analysis of the implementation of the HAP that was introduced nationally in 1990. We begin with a general overview of the HAP and how it was affected by federal reform. We also examine the involvement of the FMOH in the implementation of the HAP. We continue with an investigation of the implementation of the HAP in the four states of Gezeira, Kassala, North Kordofan and Khartoum (the same states that were used for illustrations in the previous chapter). Finally, we examine the local level's experience with the HAP.

Our analysis is based upon official HAP records. We conducted interviews with the policy makers and senior executives of the FMOH and SMOH, members of the Health Area Management Teams, Local Council officials, local health providers, and local community leaders. Furthermore, we organised focus group discussions with the main actors involved at each government level. The set-up of the interviews, and the list of interviewees together with the guidelines for the focus group discussions can be found in appendix (see annex 3 ).

\subsection{An overview of the HAP}

The commitment of WHO to primary health care in 1978 and the Health For All policy (HFA) of 1981 represented an important turning point in the development of health care systems. The initiative to promote PHC introduced many new concepts such as decentralisation, integration, intersectoral collaboration and community participation, all of which required a substantial reorganisation of the health care system (WHO, 1978). The interregional meeting on District Health Systems held in Harare Zimbabwe in 1987 motivated the participant countries to revise their health care systems. Their reflection highlighted an urgent need for the strengthening health care management at the district level (WHO, 1987). Against this background, the Sudan Ministry of Health (Sudan MOH) conducted a number of studies in the 1980s to evaluate the performance of its health care system $(\mathrm{MOH}, 1987 \mathrm{~b})$. These studies revealed many shortcomings. The most important were the centralistic governance structure in health, the absence of ef- 
fective leadership at the local level, low community participation, a dichotomy between preventive and curative health services and resistance to decentralisation at the national level. In addition, health care suffered from a serious shortage of health resources across all levels of government. In response to these shortcomings, the MOH initiated a series of discussions in collaboration with Gezeira University. The principal result of these discussions was a recommendation for the development of a Health Area Policy to address the problems in health care at the local/peripheral level (Abdel Rahim et al., 1992). For this purpose, in 1988 and 1989 the Sudan MOH launched a number of pilot projects to apply the principles of the HAP. It did so in collaboration with Gezeira University, South Darfur's Regional MOH and Gezeira's Regional $\mathrm{MOH}$ and with the assistance of some NGOs. The promising results motivated the then Minister of Health to issue a Ministerial Decree in 1990 for the national adoption of the HAP. Accordingly, the PHC Director-General of $\mathrm{MOH}$ requested the Regional DirectorsGeneral to implement the HAP in their region.

The Health Area Policy aims to create decentralised peripheral units across the country that are governed by local councils, to provide health services to the inhabitants of the locality (Mahhallia). The HAP should be based upon the principles of PHC. It should result in an integrated delivery of health services; consequently the national vertical health programs would have to be integrated into the local health system and there should be community involvement.

A health area is a geographical unit defined by the administrative borders of a local council. The HAP encompasses all health care institutions within the Mahhallia as well as all public, private and voluntary health workers. In an ideal situation, each health area would have a rural hospital with fifty to hundred beds, serving up to 30,000 citizens. The hospital would be surrounded by smaller health units providing immunisation, antenatal care, advice on nutrition as well as first aid and sanitary health services (MOH, 1990).

Health areas were chosen as the geographical basis of the HAP because, in the view of the policymakers, they constituted a unit that was small enough to manage the health care services efficiently but big enough to form a satisfactory basis for the rational utilisation of health care resources. Health areas were also seen as an appropriate managerial level for the coordination and the integration of health care services with other government agencies and sectors.

From this brief description it can be concluded that a philosophy of decentralisation underpinned the HAP from the very beginning. The policymakers came to the conclusion that the effective delivery of health care services across the country could only be achieved if the local government had a key role.

\subsubsection{The administrative structure of the health area}

The administrative structure of each health area consists of three main bodies: the Health Area Management Team (HAMT), the Health Area Council (HAC) and 
the Village Health Committees (VHC). Table 8.1 shows the organisation of each health area.

Each area has one HAMT, consisting of 7 to 9 members that represent the senior technical health expertise of the locality. The HAMT is led by a medical doctor and has managerial responsibilities, one of which is to maintain regular professional contact with the provincial health authorities. The HAC represents the community's interests at the locality level and must exercise democratic control over the HAMT. The VHC is another institution that represents the community's interests at the village level. It is responsible for the preparation of health care plans for the support of the health care workers and the mobilisation of community support for the implementation of the health care plans.

Table 8.1 The structure of a health area.

\begin{tabular}{|c|c|c|c|}
\hline Item & $\begin{array}{l}\text { Health Area Management Team } \\
\text { (HAMT) }\end{array}$ & $\begin{array}{l}\text { Health Area Council } \\
\text { (HAC) }\end{array}$ & $\begin{array}{l}\text { Village Health Com- } \\
\text { mittee (VHC) }\end{array}$ \\
\hline Membership & $\begin{array}{l}\text { Medical doctor (chaiman) } \\
\text { Public health officer } \\
\text { Senior paramedical staff }\end{array}$ & $\begin{array}{l}\text { HAMT members Policy } \\
\text { activists in local councils } \\
\text { Officials from other sec- } \\
\text { tors }\end{array}$ & $\begin{array}{l}\text { Members of popular } \\
\text { health committees } \\
\text { A vailable heatiln staft } \\
\text { in villages }\end{array}$ \\
\hline Functions & $\begin{array}{l}\text { To manage health services } \\
\text { To initiate local health planning } \\
\text { To execute health plans } \\
\text { To supervise first line health provid- } \\
\text { ers and support village health } \\
\text { committees }\end{array}$ & $\begin{array}{l}\text { To approve health plans } \\
\text { To provide financial } \\
\text { resources } \\
\text { To mobilise voluntary } \\
\text { efforts } \\
\text { To support HAMT }\end{array}$ & $\begin{array}{l}\text { "To plan health ser- } \\
\text { wices in villages } \\
\text { To support health } \\
\text { workers in the villages } \\
\text { To promote commu- } \\
\text { nity participation }\end{array}$ \\
\hline Accountable & Provincial Health Authority & Provincial Council & $\begin{array}{l}\text { Village Popular } \\
\text { Committee }\end{array}$ \\
\hline
\end{tabular}

Source: Abdel Rahman \& Elfraki, 1997.

\subsubsection{The impact of federal reform on the HAP}

When the HAP was introduced, a federal structure had not yet been introduced to Sudan. At that time the country was divided into nine regions that were run by a regional government. Furthermore, each region was divided into a number of provinces. The influence of this governance structure can be seen in the organisation of the HAP: the Health Area Management Teams were accountable to the Provincial Health Authority and the Health Area Councils were accountable to the Provincial Council.

The first amendment to the federal structure in 1993 had a serious impact on the HAP. First, the number of localities was increased more than threefold from 187 to 634 . This also meant that the number of health areas had to be increased. Sec- 
ond, the state was created and the role of the province was terminated. The SMOH was made responsible for the following activities:

o To operationalise the HAP in the state within the general framework set down by the FMOH;

- To support the health areas in terms of human, financial, material, and other resources;

o To motivate the health areas in playing their role properly and taking their responsibility seriously;

o To monitor and supervise the activities of the health areas.

Third, federal reform emphasised the key role of the locality in the HAP. The Health Area Council would no longer be responsible to the Provincial Council but, instead, to the Local Council, which was in line with the Local Government Act of 1995. This Act was a revision of the Local Government Act of 1991 that made the Local Council responsible for planning, management, finance, coordination and the delivery of social services including the health care. Thus decisions on health care services would be brought closer to the people that use them. It was also hoped that the Council would be more responsive to the demands of the local population, a principle that most authors emphasise in many other countries (Mawhood, 1987; Burns, Hambelton \& Hogget, 1994; Collins, 1996).

\subsection{Federal measures for HAP implementation}

The FMOH created a Federal Health Area Unit (FHAU) within the PHC Directorate- General to coordinate the implementation of the HAP nationally. The FHAU, assisted by the WHO, developed a National Plan of Action for the implementation of the HAP. The plan proposed to initiate implementation in three or four selected health areas in each state. The implementation strategy included the organisation of workshops on the HAP at the state level; the selection of health areas in each state; the selection and training of HAMT members; the orientation of HAC and VHC members; the organisation of local level orientation workshops; the integration of the vertical programs in the HAP; and, finally, the development of a community participation structure, namely the Health Area Councils (HACs) and the Village Health Committees (VHCs).

The FHAU launched the implementation process by a three-day workshop in 19 of the 26 states during the period of 199!-1995. In the workshop, FHAU representatives explained the goals, organisation and operation of the HAP, and the role of each partner. Participants in the workshops included state politicians, state community leaders, and SMOH officials. Furthermore, the FHAU began the process of selecting health areas in each state. Eventually, fifty-seven health areas (including those of the Equtoria) were established. However, due to manpower constraints, some states did not propose an adequate number of health areas for development. 
Table 8.2 Training activities of the HAMT staff (1991-1995)

\begin{tabular}{|c|c|c|c|c|c|c|}
\hline \multirow[b]{2}{*}{ Staties } & \multicolumn{3}{|c|}{ HAMT Training activity } & \multicolumn{3}{|c|}{ Local Orientation Workshops } \\
\hline & No. HA & $\begin{array}{c}\text { HAMT members } \\
\text { trained }\end{array}$ & Year & No. HAs & No. Workshops & Period \\
\hline Gezeira & 4 & 28 & 1991 & 4 & 4 & 1992 \\
\hline Kassala & 4 & 28 & 1991 & 4 & 4 & 1993 \\
\hline Khartovim: & 4 & 28 & 1993 & 4 & 4 & 1993 \\
\hline White Nile & 4 & 21 & 1993 & 4 & 3 & 1993 \\
\hline North Kordofan & 4 & \multirow[t]{3}{*}{42.} & \multirow[t]{3}{*}{1993} & 4 & 4 & $1990-1992$ \\
\hline South Kordotan & 2 & & & 2 & 2 & 1992 \\
\hline West Kordofan & 2 & & & 2 & 2 & 1993 \\
\hline Noth Dartur & 2 & \multirow[t]{3}{*}{42} & \multirow[t]{3}{*}{1993} & 2 & 0 & - \\
\hline West Darfur & 1 & & & 3 & 0 & $=$ \\
\hline South Darfur & 3 & & & 1 & 0 & - \\
\hline River Nile & 4 & 14 & 1993 & 4 & 1 & 1993 \\
\hline Red sea & 4. & 23 & 1994 & 4 & 4. & 1994 \\
\hline Northern & 4 & 22 & 1995 & 4 & 0 & 1995 \\
\hline Blue Nile & 4 & Not done & - & 4 & 0 & \\
\hline Sennar & 3 & 21 & 1995 & 3 & 3 & 1995 \\
\hline El-Gadaref & 4 & 28 & 1991 & 4 & 1 & 1993 \\
\hline Equatoria & 4 & 28 & 1994 & 4 & & 1995 \\
\hline Total & 57 & 325 & & 57 & 32 & \\
\hline
\end{tabular}

Source: FMOH Records and author"s interviews.

Table 8.2 provides some information regarding the training of HAMT. The contract for training of the HAMTs was awarded to Gezeira University, because the FHAU's capacity (two medical doctors, one public health officer and a clerk) was far from sufficient to give the training itself. Gezeira University had expertise in PHC and had also played a key role in the HAP initiative. The University of Khartoum was also selected to train the HAMT's of Khartoun and White Nile States. The training consisted of three-week courses that emphasised the managerial aspects of PHC, effective teamwork and the philosophy underpinning the HAP. The entire training program was conducted between the years of 1992 and 1997. During this period, $80 \%$ (325 out of 420 ) of the HAMT members were trained. The shortfall of $20 \%$ can be explained by the fact that some states were unable to install a complete HAMT because of inadequate hunan resources. Supported by the SMOH and the FHAU, the trained HAMT members in turn initiated the process of organising workshops at the local level. The number of local workshops held amounted to 32, whereas 57 had been planned (see table 8.2). The total number of participants was 2800 out of a target group of 3150 . The participants included community leaders, civil servants, representatives from other 
sectors and public health sector personnel. The FHAU did not pay much attention to the quality and accessibility of the workshops in the states.

It deserves mentioning that a considerable part of the FHAU's activities during implementation were financed by the WHO. Additional resources came from several vertical programs, mainly the Bamako Initiative $(\mathrm{BL})$ and the Basic Development Needs program (BDN).

In general, the FMOH played a rather passive role in the implementation of the HAP. Up until 1997, its activities resulted in the creation of only fifty-three health areas in the North (the four health areas in Equatoria are not included in this figure). This is a low percentage ( $24 \%$ ) when compared to the total number of HAS needed in the Northern states (see table 8.3). The selection of health areas was also biased. Wealth and proximity to the political centre meant that states like Khartoum and Gezeira were favoured, whereas others that desperately needed support such as West Darfur and West Kordofan received much less attention. The states of Khartoum and Gezeira also had the best contacts with the FHAU.

The FHAU also proved to be problematic in other respects. It tended to monopolise control of the implementation process. Furthermore, it did not put much energy into creating the facilities and conditions required for the successful implementation of the HAP at the local level. Important dimensions of sustainability such as building the capacity of leadership, developing incentives for successful implementation and providing adequate budget supervision were neglected.

One of the main objectives of the HAP was to integrate the vertical health programs at the health area level. The FMOH had more control over this process than the states' MOH. The FHAU was charged with coordinating the activities of the national vertical program coordinators in order to realise the HAP objectives. Even though the FHAU and the program coordinators occupied the same building in order to coordinate, not a single attempt at coordination of National Vertical Programs was ever recorded. The FHAU's poor performance obviously frustrated the process of integrating the vertical programs in the health areas.

Due to the centralistic attitude of the FHAU, preparatory steps such as the organisation of workshops and training for the HAMTs took place over a long period (1991-1995). The FHAU lacked the necessary human and financial resources to organise the workshops itself. However, in the beginning the FHAU was reluctant to delegate the organisation of the workshops because it did not want to relinquish its hold on the external financial resources of the WHO. The FHAU trainers had a personal interest in keeping hold of these resources. As a result, there were many delays that distorted the implementation process. In fact, these delays could have been easily avoided if the FHAU had delegated the responsibility for the training programs to other institutions. After all, the training 
program was short and easy enough for many institutions in the country to nun it, had they been involved.

Table 8.3 Implementation of health areas in the sixteen Northern states till end of 1998

\begin{tabular}{|c|c|c|c|c|c|}
\hline State & $\begin{array}{c}\text { Localities (targets } \\
\text { for } M A s)\end{array}$ & $\begin{array}{l}\text { No. of } \\
\text { HAs. }\end{array}$ & $\begin{array}{c}\text { State } \\
\text { Suppont }\end{array}$ & $\begin{array}{l}\text { Additional } \\
\text { Support } \\
\text { (extermal) }\end{array}$ & $\begin{array}{l}\text { Community } \\
\text { Participation }\end{array}$ \\
\hline Blue Nille & 17 & 4 & - & Bamako & - \\
\hline Giadares & 23 & 1 & - & Bamatico & + \\
\hline Grezeina & 51 & 51 & $+4+4$ & Bamako- BDN & ++ \\
\hline Kasalla & 17 & 7 & +4 & Plan Sudan & +4 \\
\hline Khartoum & 36 & 1 & + & $\therefore$ & + \\
\hline Morth Darfur & 24 & 24 & $4+$ & - & 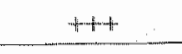 \\
\hline Worth Kondofan & 27 & 4 & - & Bamalko & + \\
\hline Worthem & 23 & 0 & - & - & - \\
\hline Red Sea & 19 & 3 & - & - & - \\
\hline Rejuer Nile & 34 & 1 & - & Bamrako & - \\
\hline Seminat & 21 & 2 & + & Bamako & + \\
\hline South Digrfur & 38 & 1 & - & Bamako & - \\
\hline South Kondofan & 30 & 4 & - & Bamako+ Bir & - \\
\hline West Darfur & 31 & 0 & - & - & - \\
\hline West Kordofan & 23 & 2 & - & Bamako & - \\
\hline White Nule & 21 & 4 & - & Bamako & + \\
\hline Tolat & $435^{*}$ & 109 & & & \\
\hline
\end{tabular}

Source: Interviews with State Directors-General of Health, 1998; FMOH and SMOH Records. Clarification: the presence of political, legislative, financial, and administrative support is denoted in the table by $a(+)$ sign, and its absence by $(-)$ sign. The presence of community parricipation including participation in finance, contributions in kind, planning, and admintstration or wher activities is denoted in the table by a $(+)$ sign and its absence by a $(-)$ sign. The number of $(+)$ is an indication of the state 's relative strength. The toral number of 109 health areas includes the 53 areas created by the FMOH as pilot projects

The poor performance of the FHAU had a negative impact on the results of the HAP. It demotivated the states in playing their role adequately in the implementation of the HAP. Table 8.3 demonstrates that only a few states developed a strong commitment to the HAP. The Directors-General for Health in the majority of the states reported a low level of political commitment to the HAP with exception of Gezeira. In their view, community participation at the local level was only slightly improved.

As a result, the HAP soon began to disintegrate and many health areas vanished shortly after their establishment (Abdel Rahman \& EIFaki, 1997). In only a few areas, the health services were somewhat improved. But this was not due to the 
HAP but to external financial, technical and administrative support of the NGOs (ElFatih, 1996).

\section{Box 8.1. Successful experiences of HAP implementation}

Despite the odds there were some health areas that managed to realise reasonable success in improving their health services. To begin with, there were four pilot projects conducted in 1990 by the $\$$ MOH of Gezeira, namely in Marengan, Ehoash, Massalmia and Omequra. The evaluation of these areas over the period 1991 to 1994 confirmed the completion of all operational processes, such as dexelopment of structures, training, maintenance of infrastructure, finance and planning. This resulted in an improvement of the immunisation coverage, better monitoring of child growth, improved availability of medicines, the organisation of regular malaria eradication campaigns, sanitary health activities and health education programs.

The success rested upon collaboration between the Gezeira SMOH, the Irish Fund Program, the Universily of Gezeira and the FMOH (Gezeira SMOH, 1996).

The State of South Kordofan winessed another example of a successful implementation of the HAP. The Benevolence International Foundation took the lead and set up a consortium involving the FMOH, SMOH, UNCEF, WHO and community leaders. Despite the backwardness of the state and the ongoing civil war, implementation was quite successful. There was an intensive community mobilisation as well as completion of all operational tasks in a short period of time. The introduction of a state PHC coordinator did work well. The evaluation recorded several improvements in accessibility to PHC services, immunisation, antenatal care, leprosy case detection, health education and introduction of the periodic mobile specialised clinics (EIKhalifa, 1998).

A third example of successful implementation was seen in the Elrahad Health Area in North Kordofan. Implementation involved a joint effort of the WHO, UNICEF, the FMOH and the North Kordofan SMOH. The group forged a combination of the BAMAKO and the HAP. The outcome of this combination led to an improvement in accessibility to health serwices. However, this did not continue for long due to a lack of monitoring by SMOH (EIFatih, 1996).

The relative sucess stories underline the fact that in the same unfavourable socio-econonic context. some states are able to realise policy objectives, thanks to motivated political and administrative leadership and the catalytic role played by donors and NGOs.

\subsection{Implementation of the HAP in four states}

In this section we will present an analysis of the implementation of the HAP in four states: Khartoum, Gezeira, Kassala and North Kordofan. Our analysis is based upon a random sample of seventeen health areas from Gezeira, six from Kassala, and three from North Kordofan state. Khartoum is also included in our 
analysis, although it did not create a single health area in its complete form until the end of 1998.

\subsubsection{State support for the MAP}

In the absence of clear guidelines from the FMOH on how to put the HAP into practice within the Local Government Act of 1991, each of the four states developed its own approach. After 1993, their approach had to follow the principles of federal reform. The implications of federal reform for the HAP were far reaching. Each lacality (fifty-one in Gezeira, sixteen in Kassala, twenty-seven in North Kordofan and thirty-six in Khartoum) had to create a health area and the newly established local councils were to be made responsible for the implementation of the HAP at the local level. This required the states to have a well thought implementation strategy in terms of resource allocation, staffing, accountability, capacity building and community participation.

In order to be successful, the HAP needed a strong political and administrative support from the SMOH. Table 8.4 shows the political position of the state leaders on the HAP. The state governor, the State Minister of Health, the State Minister of Finance, two provincial commissioners and two representatives of the state legislative committee for health were interviewed.

The political context was more favourable for the implementation of the HAP in Gezeira than in any of the other states. This result is not surprising as Gezeira played a key role in the initiation of the HAP. Furthermore, the University of Gezeira took a keen interest in PHC and the FHAU had set up four pilot projects in the state. In addition, Gezeira maintained good relations with the FMOH and was also a favourite of external aid agencies.

Khartoum, being in the best position with regard to ministerial, administrative and professional leadership, and having much stronger resource bases, also could have made a success of the HAP. However, its political leaders did not trust grass roots democracy. They did not consider the local authorities experienced enough to carry the HA.P responsibilities. Even though the political leaders showed a good understanding of the HAP concept and formally placed a high priority on health care, in reality they preferred to use the deconcentration model of the past era to implement it. Hence, the political leaders of Khartoum including the Health Minister and the legislature only gave lukewarm, moderate support for the HAP. Consequently, only limited resources were made available for its implementation. Hence the expansion of the HAP in Khartoum was an extremely slow process. 
Table 8.4 The position of state political leaders on the HAP

\begin{tabular}{|l|l|l|l|l|}
\hline Item & Giezeira $N=7$ & N. Kordofan $N=7$ & Khartoum N=7 & Kassala $N=7$ \\
\hline Understanding & High & Low & High & Moderate \\
\hline Commitment & High & Low & Moderate & Moderate \\
\hline $\begin{array}{l}\text { Legislative } \\
\text { support }\end{array}$ & High & Low & Moderate & Low \\
\hline Financial support & Moderate & Low & Low & Low \\
\hline Political support & High & Low & Moderate & Low \\
\hline Priority of health & High & Low & High & Moderate \\
\hline
\end{tabular}

Source: Author"s interviews, 1999.

Clarification: understanding means that respondents were capable of defining the heal h area objectives, the organisational set up and their responsibilities in this respect. High understanding means that more tham 5 respondents meet the criteria of understanding; moderate means that 3-5 respondents meet the criteria and low understanding that less than 3 meet the criterta. Commitment is measured as high when more than five respondents are involved in activities related to the health area; moderate means that $3-5$ respondents are involved in these activilies and low that less than 3 are involved.

High legislative support refers to the approval and implementation of the legislation on locat heal h area by the respondents. Moderate legislative support means that they did approve the legislation but did not implement it. In the case of low support even the approval of legislation is absemt.

High financial support means that the state has spen some money on the locat heath area. Moderate financial support means that a budget has been approved but was not spent. In the case of low support, there was even no approval of any budget for the local health area. Political support is measured as high when the stare political leaders have mobilised the community for the implewewation of the health area. Moderate support means that the state political leaders approve the local health area plan but did not mobilise the community to support it Low political support refers to the situation where there is even no approval. Priority of health is classified in the category high when health is mentioned as the first or second priarity by the state political leader, as moderate when it is mentioned as the third priority and as low when it does not betong to the three first mentioned priorities.

Kassala, bordering Eritrea and having major problems with refugees, war and annual floods, displayed only moderate commitment to the HAP which was not translated in the transferral of resources and legislative support. In fact, it was only mentioned as a priority in order to secure external funding. The shortcomings and limitations of the state were compensated to a large extent by the NGO Plan Sudan, which not only provided financial resources but also made some of its professional staff available to further advance the implementation of the HAP. The political leadership's understanding, commitment and support for the HAP were at their minimum in North Kordofan. Despite being one of the least developed states in Sudan and desperately in need of improving local health services, the state"s political leadership placed low priority on health care because of the absence of any lobby for health care matters and, consequently, very little finan- 
cial and political support. This was to some extent compensated by financial and professional help from the Bamako Initiative.

Table 8.5 Position of SMOH directors on HAP

\begin{tabular}{|c|c|c|c|c|c|c|c|c|}
\hline \multirow[t]{2}{*}{ Aspect } & \multicolumn{2}{|c|}{$\begin{array}{l}\text { Gezeira } \\
N=10\end{array}$} & \multicolumn{2}{|c|}{$\begin{array}{c}\text { Kassala } \\
N=8\end{array}$} & \multicolumn{2}{|c|}{$\begin{array}{l}\text { North Kordofin } \\
\qquad \mathrm{N}=6\end{array}$} & \multicolumn{2}{|c|}{$\begin{array}{c}\text { Khartoum } \\
N=12\end{array}$} \\
\hline & + & - & + & - & + & - & + & - \\
\hline Clarity of policy & $100 \%$ & $0 \%$ & $75 \%$ & $25 \%$ & $100 \%$ & $0 \%$ & $100 \%$ & $0 \%$ \\
\hline Commiment & $100 \%$ & $0 \%$ & $62 \%$ & $38 \%$ & $50 \%$ & $50 \%$ & $100 \%$ & $0 \%$ \\
\hline Support & $100 \%$ & $0 \%$ & $62 \%$ & $38 \%$ & $50 \%$ & $50 \%$ & $100 \%$ & $0 \%$ \\
\hline Perception & $100 \%$ & $0 \%$ & $100 \%$ & $0 \%$ & $100 \%$ & $0 \%$ & $100 \%$ & $0 \%$ \\
\hline Involwement & Direct & & Direct & & Indireet & & Indirect & \\
\hline
\end{tabular}

Source: Author's interviews, 1999.

Clarification: $N$ equals the total number of SMOH directors present in the corresponding state.

The design and success of an implementation strategy depends to a large extent on the attitude of the senior professional health staff in each state. Table 8.5 shows the political orientation of the SMOH directors towards the HAP. One can see that the senior professional staff of the Health Ministries of Gezeira and Khartoum displayed the most favourable orientation to the HAP. All directors said that they were well informed about HAP and also showed their commitment and support. Furthermore, they expressed a positive view of the HAP. However, there was a big difference between Gezeira and Khartoum. Contrary to Gezeira, the SMOH of Khartoum preferred a model in which health areas were not treated as autonomous corporate bodies but instead made subordinate to the province, thereby negating the federal policy and getting away with it. In Kassala and North Kordofan, not all the SMOH directors expressed their commitment and support for the HAP.

\subsubsection{The implementation strategies of the four states selected}

This section gives a brief overview of the strategy adopted by each of the four states for the implementation of the HAP. Each state developed its own unique strategy. The state of Khartoum did not immediately create health areas. Instead, it opted for the development of so called catchment areas around a health services centre as the first step towards the development of health areas. It placed high apriority on better management and control rather than on popular participation in delivery of local health services. After developing a sound information base and an infrastructure for communication and health facilities, several catchment areas could be grouped together to form one health area. The SMOH appointed the members of the Catchment Area Team (CAT) and made them responsible for management. It was not until 1999 that the state of Khartoum began 
to introduce health areas. The directors of the SMOH were not closely involved in the implementation of the HAP and participated only in the ministerial board meetings on the HAP. The implementation of the HAP remained a low priority for Khartoum, due to the political leadership's lack of commitment to the project. The Legislative Council of Khartoum devolved the responsibility for environmental health services to the local councils in 1996, despite resistance from the $\mathrm{SMOH}$. However, the devolution was withdrawn within a year due to insufficient capacity at the local level. During this period, the high incidence of diseases like malaria only increased the SMOH's preference for deconcentration rather than devolution. This highlights the importance of capacity building at the local level prior to the implementation of the HAP.

The dual responsibility for health services presented a particular problem for Khartoum. The SMOH's director of health services was responsible for managing the provincial health services. However, the Director of PHC was responsible for the implementation of the HAP. Thus, within the Ministry two parallel yet separate structures existed for the management and supervision of the local level provision of health services in the state. This inevitably resulted in a poor coordination and integration of health services at the local level.

Gezeira"s implementation strategy placed great emphasis on the creation of health areas to cover all of its 51 localities. However, Gezeira lacked a detailed plan of implementation based upon an analysis of the actual situation in the local councils and a clear strategy for resource development, community participation and integration of health care services. It began with the status quo and developed each health area incrementally focusing on HAMT, HAC, and VHC staff training. The Minister of Health appointed himself the members of the HACs, thus, compromising a democratic approach. However, the SMOH systematically monitored health areas during monthly meetings.

Kassalas's implementation strategy was also incremental. Being aware of the limitations of its own professional staff, the SMOH decided to rely on Plan Sudan, not only for financial resources but also for the operationalisation of the implementation process. It intended to provide all sixteen localities in the state with health areas by the year 2000 . However, this was an ambitious plan in view of the serious resource constraints, and not surprisingly, by 1999 only seven health areas had been established. Kassala"s SMOH supported devolution but it also issued guidelines on local planning and integration of health services.

North Kordofan's implementation strategy involved the integration of two policies namely the HAP and the Bamako Initiative aimed at PHC improvement. This approach promised better coordination and opened up the possibility of developing a sector wide approach. However, this did not happen due to the approach of North Kordofan's political leadership and the lack of capacity at the local level. In fact, instead of ambitiously announcing a bigger target, the state leadership preferred not to increase the number of health areas but ensure that the existing four health areas used external resources more efficiently. 


\subsubsection{Organisational change}

One of the most important responsibilities of the states and localities was to promote PHC as it was the comerstone of the National Health Strategy. The HAP was intended to bring PHC closer to people. This process called for organisational change in the $\mathrm{SMOH}$, in particular the creation of a separate unit in the ministry responsible for the HAP. Khartoum and Gezeira did introduce such a unit, but North Kordofan and Kassala did not. Gezeira State Ministerial Council took a very unique stand that it dissolved the provincial health authority and developed a Health Area Coordinator at the SMOH level. Kassala, the directorgeneral was responsible for monitoring the activities of the health areas. However, North Kordofan neither created a unit in the SMOH responsible for the HAP nor appointed a senior member of staff specifically to monitor the implementation process.

The HAMT was the most important structure in the health area. Its incorporation into the local government system and its accountability to the local councils were a prerequisite for successful implementation. In reality, however most of the HAMTs were accountable to the SMOH and not to the local councils. Khartoum did not install a HAMT until the end of 1998.

\subsubsection{Capacity building for the HAP}

Capacity building at the state and local level was crucial for the success of decentralisation in general and the HAP in particular. Unfortunately, all of the states paid little attention for capacity building for the implementation of the HAP. Neither the federal nor the state governments employed a systematic approach to increase capacity. They restricted their activity to the training of the members of the HAMT, the HAC and the VHC. A special fund to capacity building was not created. Even the training activities remained limited, most of them being undertaken by external agencies like WHO, UNICEF and other NGOs.

This state of affairs had a negative impact upon the implementation of the HAP. The target number of health areas could not be reached, especially in the disadvantaged states. Our investigations revealed that none of the four states selected had accurately estimated the capacity needed to realise the HAP. Local organisations were underdeveloped, understaffed and insufficiently trained (table 8.6). 
Table 8.6 The availability of health care prerequisites according to medical directors of HAMTs

\begin{tabular}{|l|c|c|c|c|c|c|}
\hline \multirow{2}{*}{ Requirements } & Gezeira $(\mathrm{N}=17)$ & \multicolumn{2}{|c|}{ Kassala $(\mathrm{N}=6)$} & \multicolumn{2}{|c|}{ North Kordofan $(\mathrm{N}=3)$} \\
\hline & + & & + & & + & - \\
\hline Heallh facilities & $82 \%$ & $18 \%$ & $83 \%$ & $17 \%$ & $100 \%$ & $0 \%$ \\
\hline Health manpower & $77 \%$ & $23 \%$ & $33 \%$ & $67 \%$ & $67 \%$ & $33 \%$ \\
\hline Administrative manpower & $23 \%$ & $77 \%$ & $33 \%$ & $67 \%$ & $33 \%$ & $67 \%$ \\
\hline Financial resources & $29 \%$ & $71 \%$ & $83 \%$ & $17 \%$ & $100 \%$ & $0 \%$ \\
\hline Drug supplies & $41 \%$ & $59 \%$ & $33 \%$ & $67 \%$ & $100 \%$ & $0 \%$ \\
\hline Means of trangportation & $29 \%$ & $71 \%$ & $33 \%$ & $67 \%$ & $67 \%$ & $33 \%$ \\
\hline
\end{tabular}

Source: Author's interviews.

Clarification: Khartoum is not included because it followed a different strategy; the percentages in the table give the percentage of directors who were positive and those negative on respective elements of capacily.

The details differ from one state to another. Gezeira gave relatively more attention to capacity building than the other states selected. The process was facilitated by the availability of PHC training facilities at Gezeira University and the support of the FMOH. Members of thirty teams of the HAMTs were trained between 1995 and 1997; however this was still much less than what was needed. To try to improve the situation, the SMOH devoted some of its own staff to train the HAMT members and reduce the duration of training in order to accelerate the training process. However, according to some of our interviewees, these modifications came at the expense of the quality of the training course. The SMOH asked the localities to cover $20 \%$ of the training cost to ensure their commitment. Actually, these costs were covered by the FMOH, because many of the localities did not have the resources to cover them. By 1998 , out of the target number only $78 \%$ of the HAMT members, $65 \%$ of the HAC members, and $15 \%$ of the VHC members had been trained.

Capacity building in Kassala was supported by the Plan Sudan. The HAMT staff received three types of training: basic, refresher and experience sharing workshops. The basic training took place at the universities of Gezeira and Shandy outside the state and followed the standard curricula developed by the FHAU. The refresher training and workshops held for the localities were organised in the state itself with the help of Plan Sudan. The realisation rate for the HACs and the VHCs was more than $80 \%$.

The building of capacity in North Kordofan was supported to some extent by the Bamako Initiative. However, due to the high turnover of staff, only $44 \%$ of health area staff was trained. The state also benefited from the training offered in immunisation, malaria control, child and mother care by the vertical programs. However, North Kordofan did not receive preferential treatment for being a peripheral and less developed state. 


\subsubsection{Financial arrangements}

Financial resources are an important consideration during the implementation process. The HAP goals could have only been achieved if sufficient resources were available in each health area. This was not the case at all. When the HAP was launched, it completely lacked a strategy to fund its implementation. In fact, the HAP came into being mostly due to the encouragement and some funding of external agencies. This external assistance was a significant factor in the success of the earlier HAP pilot projects. In addition, the FMOH and the SMOH did not allocate funds to the HAP from their own resources. Staff salaries were covered by the regular budget, but no specific arrangements were made to pay for infrastructure, equipment, travel, medicines or capacity building. Even the FHAU concentrated mostly on the financing of preparatory activities like training and orientation workshops. For other expenses, the health areas remained dependent upon external donors as well as the priority placed on the HAP by state leadership.

This resulted in an unequal and uncertain availability of resources. The use of multiple funding sources also gave rise to coordination problems. Khartoum used multiple funding sources but placed a high priority on the financial support of the provincial health department rather than the health areas. Gezeira, in line with the FHAU practice, only covered the finance of the training programs and the payment of the medical doctors of salaries. It provided no financial support for the infrastructure, medicines, and other goods and equipment. The state wrongly assumed that the local councils were capable of meeting these operational expenses themselves. The general economic and financial situation in Sudan had deteriorated to the extent that in 1999 only three of Gezeira local councils were able to pay staff salaries, let alone cover the operational or development budget.

The situation in Kassala was similar to that in Khartoum and Gezeira. This state used various sources of funding but also tried to supplement them by introducing a service fee and entry tickets to health centres. External funds from Plan Sudan and UNICEF helped most of the health areas to maintain their essential functions. However, their performance was negatively affected by a lack of funds for the maintenance of buildings, repair of equipment, transport, and recruitment of additional health staff.

The situation in North Kordofan was more positive. This was mainlly due to its limited number of health areas (4) and financial assistance from WHO, UNICEF, the Bamako Initiative, funds from vertical programs and self help initiatives. But, eventually, the lack of resources prevented the further expansion of health areas in the state. 


\subsection{The results of the HAP at the local level}

In this section we will briefly discuss some important results of the HAP implementation in the health areas.

\subsubsection{Health Area Management Teams}

Table 8.7 provides some information on the HAMTs. The data in the table originated from interviews and federal/state data on the implementation of the HAP. Khartoum was omitted from our analysis, as it had not installed HAMTs at the time of our field visits.

Table 8.7 The position of the Health Area Management Team

\begin{tabular}{|l|c|c|c|c|c|c|}
\hline \multirow{2}{*}{ Aspect } & \multicolumn{2}{|c|}{$\begin{array}{c}\text { Gezeira } \\
\mathrm{N}=51\end{array}$} & \multicolumn{2}{c|}{$\begin{array}{c}\text { Kassala } \\
\mathrm{N}=13)\end{array}$} & \multicolumn{2}{c|}{$\begin{array}{c}\text { North Kordofan } \\
(\mathrm{N}=9)\end{array}$} \\
\cline { 2 - 7 } & + & $\cdots$ & + & - & + & - \\
\hline Understanding of the HAP & $86 \%$ & $14 \%$ & $100 \%$ & $0 \%$ & $100 \%$ & $0 \%$ \\
\hline HAMT completion & $88 \%$ & $12 \%$ & $84 \%$ & $16 \%$ & $100 \%$ & $0 \%$ \\
\hline Training of the HAMT menbers & $55 \%$ & $45 \%$ & $100 \%$ & $0 \%$ & $44 \%$ & $56 \%$ \\
\hline Regular meetings & $60 \%$ & $40 \%$ & $77 \%$ & $23 \%$ & $67 \%$ & $33 \%$ \\
\hline Effective supervision & $60 \%$ & $40 \%$ & $69 \%$ & $31 \%$ & $67 \%$ & $33 \%$ \\
\hline Plan & $40 \%$ & $60 \%$ & $71 \%$ & $29 \%$ & $67 \%$ & $33 \%$ \\
\hline Accountable to the SMOH & $87 \%$ & $13 \%$ & $100 \%$ & $0 \%$ & $89 \%$ & $11 \%$ \\
\hline Accountable to the local councils & $13 \%$ & $87 \%$ & $0 \%$ & 100 & $11 \%$ & $89 \%$ \\
\hline
\end{tabular}

Source: Author's interviews and actual data of FMOH/SMOH.

Clarification: Understanding means that the respondent is informed about the definition and objectives of HAP and his responsibilities in this respect. HAMT completion means that the state has completed the mentioned percentage of the required number of the HAMTs. Training of the HAMT members refers to the percentage of the respondents who were actually imolwed in HAP raining course. The percentage in the category regular weetings meastres the percentage of respondents who participate in regular meetings concerning $H A P$. The percentage in the caregories 'Effective supervision' and 'Plan' measures the percentage of respondents who believe that they are well supervised by their superiors and that they have a plan for the implementarion of HAP. The percentage in the caregories 'Accowntable to the SMOH' and 'Accountable to the lacal councils' measures the percentage of respondents who believe that they are accoumable to SMOH or local councils respectively.

It is fair to conclude that the HAMTs dominated the implementation of the HAP at the local level. Although the Health Area Councils and Village Health Committees were created to mobilise popular participation and to exert democratic control, their activities were not substantial enough. In most health areas the HACs and the VHCs were not even elected. No one attempted to provide resources for their activities. Moreover, their membership did not provide any tangible benefit. As a result, democracy in the rural areas developed very slowly. 
In addition, it is important to note that the HAMT members were also members of the Health Area Council where they were situated. Such an arrangement obviously undermined the democratic process. The HAMT members also played a dominant role in the $\mathrm{HAC}$ discussions because of their superior knowledge and capabilities.

Most interestingly, the great majority of the HAMT members reported that they felt themselves accountable to the SMOH rather than to the Local Council. This result contradicts the objectives of the HAP. One of the main principles of the HAP after federal reform was that the Local Council would take the political lead and have a substantive interest in local health matters.

\subsubsection{The first line health providers}

The first line health providers played a crucial role in the realisation of the HAP's objectives, particularly in the rural areas. Table 8.8 summarises the results of our interviews with them in Gezeira, Kassala and North Kordofan states. The overall picture is not very positive. As a considerable number of first-line health providers felt no strong involvement in the HAP.

Table 8.8 The position of first line health providers

\begin{tabular}{|c|c|c|c|c|c|c|}
\hline \multirow[t]{2}{*}{ Aspect } & \multicolumn{2}{|c|}{$\begin{array}{l}\text { Gezeira } \\
(N=51)\end{array}$} & \multicolumn{2}{|c|}{$\begin{array}{l}\text { Kassala } \\
(\mathrm{N}=\mathrm{I} 8 \mathrm{O})\end{array}$} & \multicolumn{2}{|c|}{$\begin{array}{l}\text { North Kordofan } \\
\qquad(N=15)\end{array}$} \\
\hline & + & - & + & - & + & - \\
\hline Awareness of the HAP & $58 \%$ & $42 \%$ & $67 \%$ & $33 \%$ & $53 \%$ & $47 \%$ \\
\hline Understanding & $47 \%$ & $53 \%$ & $56 \%$ & $4.4 \%$ & $47 \%$ & $53 \%$ \\
\hline Positive view upon HAP & $42 \%$ & $58 \%$ & $56 \%$ & $44 \%$ & $53 \%$ & $47 \%$ \\
\hline Patticipation in training & $27 \%$ & $63 \%$ & $50 \%$ & $50 \%$ & $33 \%$ & $67 \%$ \\
\hline Commitment & $42 \%$ & $52 \%$ & $50 \%$ & $50 \%$ & $53 \%$ & $47 \%$ \\
\hline Integration of services & $22 \%$ & $78 \%$ & $44 \%$ & $56 \%$ & $33 \%$ & $67 \%$ \\
\hline Relation with heatth villages & $29 \%$ & $61 \%$ & $22 \%$ & $78 \%$ & $27 \%$ & $63 \%$ \\
\hline Relations with the HAMT & $44 \%$ & $56 \%$ & $67 \%$ & $33 \%$ & $47 \%$ & $53 \%$ \\
\hline
\end{tabular}

Source: Author's interviews with first line health providers.

Clarification: awareness meang that the respondent has some knowledge about the HAP. Understanding means that the respondent is informed about the definition and objectives of HAP and his responsibilities in this respect. Commitment means that the respondent is actually involwed in HAP. The percentages in the category integration of services measwre the percentage of respondents who think that HAP positively influences integration. The percentages in the categories 'Relations with health willages' and Relations with the HAMT" measure the percentage of respondents who believe that they have a relation with the health village and HAMT respectively.

If the total percentage is less than 100\%, some respondents did not give an answer. 


\section{Box 8.2 HAMT}

One of the HAP targets was to create leadership and support for thealth care in the peripheral areas. The HAMT was the main instrument for this. The medical doctor in the rural hospital headed the HAMT. This arrangement was not favourable for adequate implementation. Firstly, the medical doctor in the rural hospital was intensively occupied with curative and administrative tasks in the hospital. Secondly, he had no relewant training in planning, administration and leadership. Thirdly, he only served for a limited period of the in the rural hospital (a temporal stay in a rural hospital was needed for the fulfiment of the requirements for his job development).

In addition, he had no incentive to stay there. On the contrary, he was often in haste to return for specialisation or to travel abroad for better prospects of work. In many cases the heads of the HAMT were trained but their areas collapsed after their short period of work. This explains the fact that only $55 \%$ and $44 \%$ of the existing HAMT members in Gezeira and Noth Kordofan were trained respectively.

\subsubsection{The local council}

Local councils constitute the third political and administrative layer of the federal government. They are responsible for overseeing local development in all sectors including the public health sector. The local council consists of ten to fourteen members depending upon the size of its population. $75 \%$ of its members are elected and the remaining $25 \%$ are appointed. The councils are supported by administrative and technical bureaucratic staff. The public health sector is not directly represented in the local council. An executive director of the locality heads the administrative group. He acts as the Secretary General of the local council and as the linking pin between the executive and the legislative body. The executive director is accountable to the president of the council and is assisted by the technical staff in all sectors such as education, health and agriculture (Elsheikh, 2000). The local council is responsible for the local health services and, therefore, must play an important role in the implementation of the HAP.

The federal system of Sudan held the local councils responsible for local health services. They had to ensure a more equitable access, better quality and the integration of all health services in the area of the council. To carry out their tasks properly, local councils required a reliable source of finance; furthermore, they had to increase their capacity in order to fulfil their new responsibilities. To a large extent, the individual situation of each council should has shaped its role in the implementation process (see box 8.3 ).

In reality, common factors such as frequent changes in the Local Government Acts (1991, 1995 and 1998), inadequate financial and administrative support, and the lack of sufficient democratisation and discontimuities in political parties also frustrated the role of the local councils. 


\section{Box 8.3 The local council}

Since the 1951 Ordinance the councils witnessed variations in context, as they categorised into rural and urban councils. The variation related to disparities in level of development, financial and administrative status and quality of social services needed. They influenced the implementation of HAP in each local council. There were only a few councils as in Khartoum and Gezeira that possessed adequate resources, health facilities, more than one medical doctor and other staff to install a HAMT and supportive community, which gave a high priority and contributed actively to health. On the other hand, many other councils as in North Kordofan missed similar supportive conditions. For instance, they did not have a rural hospital or a well-equipped health centre. Other councils possessed a hospital but lacked a regular presence of a medical doctor. The previous number of 187 health areas was reasonable insofar it took account of the presence of the required facilities. The more than three fold increase of the local councils to 634 on mostly political basis, created numerous disabled councils, which could not effectively implement the HAP. In addition the frequent changes in the Local Government Acts 1991, 1995 and 1998 disturbed the bor ders and stability of the local council. This made the council in continuous uncertainty* which influenced their resources, personnel and performance.

Table 8.9 provides some information on the local councils of the three states of Gezeira, Kassala and North Kordofan. One can see that the situation in all three states was unsatisfactory. However, the situation in North Kordofan was at its worst. The local councils were given a prominent role in the federal system and the HAP, but were not provided with sufficient resources and staff. Consequently, they never managed to play a guiding role in the implementation of the HAP. Most councils did not want the financial burden of health care in general and the HAP in particular. They perceived health care and the HAP as technical issues for the concern of medical doctors and the state government, in which they should not intervene. In addition, some council leaders felt responsible purely for environmental health issues. As we have already seen, even in a more advanced state like Khartoum the local councils failed in this function.

Table 8.9 Status of local councils, with regard to prerequisites

\begin{tabular}{|c|c|c|c|c|c|c|}
\hline \multirow[t]{2}{*}{ Aspects of comparison } & \multicolumn{2}{|c|}{$\begin{array}{c}\text { Gezeira } \\
N=17\end{array}$} & \multicolumn{2}{|c|}{$\begin{array}{c}\text { Kassala } \\
N=6\end{array}$} & \multicolumn{2}{|c|}{$\begin{array}{l}\text { North Kordofan } \\
\qquad N=3\end{array}$} \\
\hline & $\#$ & - & + & - & + & - \\
\hline Sufficient financial resources & $12 \%$ & $88 \%$ & $16 \%$ & $84 \%$ & $0 \%$ & $100 \%$ \\
\hline Offer high Priority for health & $41 \%$ & $59 \%$ & $67 \%$ & $33 \%$ & $33 \%$ & $67 \%$ \\
\hline Comprehensive council plan & $\| 2 \%$ & $88 \%$ & $16 \%$ & $84 \%$ & $33 \%$ & $67 \%$ \\
\hline Possess sufficient administrative staff & $29 \%$ & $71 \%$ & $33 \%$ & $67 \%$ & $33 \%$ & $67 \%$ \\
\hline Feel responsible for health services & $24 \%$ & $76 \%$ & $67 \%$ & $33 \%$ & $0 \%$ & $100 \%$ \\
\hline
\end{tabular}

Source. Author's interviews with leaders of the local councils and field observations: Khartoum abstained from installing local councils. 
Table 8.10 The orientation of local leaders in Gezeira to the HAP

\begin{tabular}{|c|c|c|c|c|c|c|}
\hline \multirow[t]{2}{*}{ Aspect } & \multicolumn{2}{|c|}{$\begin{array}{c}\text { Executive direc- } \\
\text { tors } \\
N=17\end{array}$} & \multicolumn{2}{|c|}{$\begin{array}{c}\text { Chairs of locali- } \\
\qquad \begin{array}{c}\text { ties } \\
N=17\end{array}\end{array}$} & \multicolumn{2}{|c|}{$\begin{array}{l}\text { Other sectors } \\
\qquad N=17\end{array}$} \\
\hline & + & - & + & - & + & - \\
\hline Awareness of the HAP & $10 \%$ & $30 \%$ & $65 \%$ & $35 \%$ & $29 \%$ & $71 \%$ \\
\hline Understanding of the $\mathrm{HAP}^{3}$ & $59 \%$ & $41 \%$ & $47 \%$ & $53 \%$ & $29 \%$ & $71 \%$ \\
\hline Perceived direct responsibility & $41 \%$ & $59 \%$ & $41 \%$ & $59 \%$ & $11 \%$ & $89 \%$ \\
\hline Support: & $59 \%$ & $41 \%$ & $47 \%$ & $53 \%$ & $29 \%$ & $71 \%$ \\
\hline Devote priority to the HAP & $18 \%$ & $82 \%$ & $23 \%$ & $77^{\%} \%$ & $6 \%$ & $94 \%$ \\
\hline $\begin{array}{l}\text { Perceived positive change due to introduction } \\
\text { of HAP }\end{array}$ & $29 \%$ & $71 \%$ & $29 \%$ & $71 \%$ & $47 \%$ & $53 \%$ \\
\hline
\end{tabular}

Source: Author's interviews.

Clarification: awareness and understanding hawe been measured in the same way as in table 8,8

Tables $8.10,8.11$ and 8.12 provide more details on how local key leaders and senior officers perceived the HAP. These tables illustrate the variety in the awareness and understanding of the HAP showed by the local leaders and senior officers.

Table 8.11 The orientation of local leaders in Kassalla to the HAP

\begin{tabular}{|c|c|c|c|c|c|c|}
\hline \multirow[t]{2}{*}{ Aspect of comparison } & \multicolumn{2}{|c|}{$\begin{array}{c}\text { Executive direc- } \\
\text { tors } \\
N=6\end{array}$} & \multicolumn{2}{|c|}{$\begin{array}{c}\text { Chairs of coun- } \\
\text { cils } \\
N=6\end{array}$} & \multicolumn{2}{|c|}{$\begin{array}{l}\text { Other sectors } \\
\qquad N=6\end{array}$} \\
\hline & + & - & + & - & + & - \\
\hline Awareness of the HAP & $100 \%$ & $0 \%$ & $100 \%$ & $0 \%$ & $83 \%$ & $17 \%$ \\
\hline Understanding of the HAP & $83 \%$ & $17 \%$ & $67 \%$ & $33 \%$ & $67 \%$ & $33 \%$ \\
\hline Perceived direet responsübility & $67 \%$ & $33 \%$ & $67 \%$ & $33 \%$ & $50 \%$ & $50 \%$ \\
\hline Support & $67 \%$ & $33 \%$ & $67 \%$ & $33 \%$ & $67 \%$ & $33 \%$ \\
\hline Devote priority of the HAP & $67 \%$ & $33 \%$ & $67 \%$ & $33 \%$ & $50 \%$ & $50 \%$ \\
\hline $\begin{array}{l}\text { Perceived positive change due to the introduc- } \\
\text { tion of HAP }\end{array}$ & $83 \%$ & $17 \%$ & $67 \%$ & $33 \%$ & $67 \%$ & $33 \%$ \\
\hline
\end{tabular}

Source: Author's interwews.

Clarificarion: awareness and understanding have been measured in the same way as in table 8.8 
Table 8.12 The orientation of local leaders in North Kordotan to the HAP

\begin{tabular}{|c|c|c|c|c|c|c|}
\hline \multirow[t]{2}{*}{ Aspect of comparison } & \multicolumn{2}{|c|}{$\begin{array}{l}\text { Executive Directors } \\
\qquad N=3\end{array}$} & \multicolumn{2}{|c|}{$\begin{array}{l}\text { Chairs of Couneils } \\
\qquad N=3\end{array}$} & \multicolumn{2}{|c|}{$\begin{array}{l}\text { Other Sectors } \\
\qquad \mathrm{N}=3\end{array}$} \\
\hline & + & - & 4 & . & + & 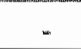 \\
\hline Awareness of the HAP & $33 \%$ & $67 \%$ & $67 \%$ & $33 \%$ & $33 \%$ & $67 \%$ \\
\hline Understanding of the HAP & $33 \%$ & $67 \%$ & $67 \%$ & $33 \%$ & $0 \%$ & $100 \%$ \\
\hline Perceived direct responsibility & $33 \%$ & $67 \%$ & $67 \%$ & $33 \%$ & $0 \%$ & $100 \%$ \\
\hline Support to the HAP & $33 \%$ & $67 \%$ & $67 \%$ & $33 \%$ & $0 \%$ & $100 \%$ \\
\hline Dewote priority of the HAP & $33 \%$ & $67 \%$ & $33 \%$ & $67 \%$ & $0 \%$ & $100 \%$ \\
\hline $\begin{array}{l}\text { Perceived positive changes due to the intro- } \\
\text { duction of the HAP }\end{array}$ & $67 \%$ & $33 \%$ & $67 \%$ & $33 \%$ & $0 \%$ & $100 \%$ \\
\hline
\end{tabular}

Sounce: Author's Interviews.

Clarification: awareness and understanding have been measured in the same way as in lable 8.8

\subsubsection{The integration of health services}

One of the objectives of the HAP was to integrate the health services at the local level, thus avoiding duplication and reducing costs. Under the federal reform, local councils were made responsible for all local services, including health care. This arrangement was expected to integrate health care facilities with the other local services, thus enhancing intersectoral collaboration and improving efficiency. This integration process was expected to forge health programs together, enhancing horizontal coordination and minimising the influence of the vertical programs.

These, aims were only partly realised. Integration was not achieved in Khartoum because of the parallel structure described earlier. Gezeira attempted to promote integration through its multidisciplinary supervisory teams for the health areas. it developed a reporting system with checklists to assess the performance of the health areas and a unified training scheme for all the HAMT members. However, it failed to overcome the interests of the vertical program managers. Moreover, the State Health Minister transferred the responsibility for the hospitals from the health areas back to the SMOH as the local councils failed to run them appropriately.

In Kassala and North Kordofan, the local councils did not manage to bring all of the local health services under their leadership. The vertical program managers were successful in keeping control of these programs. Neither the constitutional provisions nor the creation of a special unit in the FMOH for the HAP in could overcome the interests of a small number of the FMOH staff. 


\subsubsection{Community participation}

Community participation at the local government level was an objective of the HAP. The HAP institutionalised community participation through the HAC and the VHC. In theory, the members of these bodies were elected whereas the members of the HAMTs were nominated by the SMOH. In practice, however, the situation was quite different. As stated earlier, in many areas the HACs were not installed at all and in those areas where they were installed, the HAMT members constituted a major part of the HAC and dominated decision-making. In reality, the HAMTs did not feel accountable to the local councils, but to the SMOH. Thus, institutionalised community participation was not really achieved.

Nevertheless, all of the states in our sample developed their own means of encouraging indirect community participation. Volunteer groups and self-help groups were the most popular non-institutitionalised mechanisms of community participation (see table 8.13). Community participation in planning and decisionmaking was very limited with the exception of Kassala, due to the impact of NGOs. In some of the programs run by external agencies such as the Bamako Initiative and the Basic Development Needs program, community participation resulted in the establishment of popular pharmacies, a drug revolving fund, and the rehabilitation of the health infrastructure.

Table 8.13 The various means of community participation in the health areas

\begin{tabular}{|l|c|c|c|c|c|c|}
\hline \multirow{2}{*}{ Means of participation } & \multicolumn{2}{|c|}{ Gezeira $\mathrm{N}=17$} & \multicolumn{2}{l|}{ Kassala $\mathrm{N}=6$} & \multicolumn{2}{c|}{ North Kordofan $\mathrm{N}=3$} \\
\cline { 2 - 7 } & + & - & + & - & + & - \\
\hline Volunteers group & $88 \%$ & $12 \%$ & $100 \%$ & $0 \%$ & $100 \%$ & $0 \%$ \\
\hline Financial support (self-help) & $40 \%$ & $60 \%$ & $67 \%$ & $33 \%$ & $67 \%$ & $33 \%$ \\
\hline In kind support (self-help) & $34 \%$ & $66 \%$ & $50 \%$ & $50 \%$ & $100 \%$ & $0 \%$ \\
\hline Planning and administration & $40 \%$ & $60 \%$ & $100 \%$ & $0 \%$ & $33 \%$ & $67 \%$ \\
\hline Health education & $12 \%$ & $88 \%$ & $67 \%$ & $33 \%$ & $67 \%$ & $33 \%$ \\
\hline
\end{tabular}

Source: Author's interviews with HAMT Chairmen.

The failure of attempt to institutionalise community participation in the health care is mainly a result of the instability and weakness of local government, the dominance of the local elites in decision-making and the absence of organised societal interests in form of political parties or other forms of democratic organisation. It also demonstrates the tendency of administrators to consider community participation as a means of reducing government costs and not of involving the community in decision-making on local affairs.

\subsection{Conclusions}

In this chapter we analysed the implementation of HAP in the context of a federal government. The HAP was intended to create decentralised local health units 
(Health Areas) that operated on the principles of $\mathrm{PHC}$, the integration of health services, and the direct accountability to elected local councils acting as representatives of the population. Federal reform and the new Local Government Acts of 1991,1995 and 1998 aimed to strengthen the autonomy of local councils by integrating the health services with the local councils. However, implementation failed to achieve the policy targets. Below we employ Grindle's model to consider possible explanations for the failure of the HAP's implementation.

To begin with, the HAP and the Local Government Acts were developed through a top-down approach. They ignored the orientation and the capacity of the implementers at the local level as well as the local socio-economic situation. For instance, while already the implementation of the HAP was facing difficulties in the eighty-seven existing localities, the new local government acts increased their number to more than 634. From an implementation perspective this was quite an unrealistic move. In addition, the local government acts were frequently changed. Before an Act had been put into practice, a new one was issued, creating uncertainty and confusion. Finally, policies were developed by two separate central bodies without any coordination. The Federal Government Chamber was responsible for the Local Government Acts development whilst the FMOH was responsible for the HAP development. This created a great potential for misunderstanding and problems in integration, coordination and accountability at the local level. In addition, the local government acts were quite broadly formulated providing only a general framework. The state authorities should have provided more information. However, this did not happen. In most states no action programs were developed. With the exception of Gezeira, none of the states defined the role of the local councils in health: in many states their role was restricted to environmental health only.

Content wise, both the HAP and the frequent changes of the local government acts affected the interests of the actors and agencies involved. These changes aimed to shift resources from the federal government level to the local level via the states. They also made the local council accountable for health services as representatives of the local community. The health services were expected to meet the demands of the local community leading to improvement in status of health care. However, benefits of this type would take time to materialise, which hardly motivate the local conmunity actors. On the other hand, there were also benefits for the local staff in terms of training, incentives, new posts and power. The HAP and local government acts demanded that the health care system and local government change simultaneously; in addition, they also required changes in attitude and culture. For example, the principles of integration, accountability to the community and democracy involved in the changes all required long time plaming and training.

Both the HAP and the local government acts did not pay serious attention to the issue of resources. The HAP was implemented hastily without adequate consid- 
eration for financial and human resources. Apart from the limited technical assistance received from the WHO and other NGOs, no other operationall budget was made available. Implementation remained dependent upon multiple, but uncertain resources. Although the local councills were allocated some financial revenue by legislation, it was not enough for an adequate implementation of the HAP. Furthermore, most councils lacked the administrative capacity to collect the revenue by themselves.

The HAP and the local government acts also provoked a power struggle. The FMOH and most of the SMOHs were not willing to relinquish the required resources or transfer responsibilities to the health areas and the local councils. They developed diverse strategies in order to maintain their strong hold, which included direct involvement in implementation and control of access to training and finance.

To some extent, the attitude of the local councils facilitated this centralistic tendency. In most cases the local councils were not involved in the process of implementation. Some of the local councils lacked the capacity and confidence to manage health affairs and tried to escape the burden of expenditure on health care. The HAMT members, the crucial actors in the HAP were also a cause of the failure in the devolution process. They preferred to look directly to the central and state agencies for supervision and guidance rather than to the local councils. As medical doctors, they preferred to remain in direct contact with their professional colleagues in higher government circles rather than with the members of the local council. These upward contacts could also bring them personal financial benefits. Thus, the personal interests of important actors at the local level did not favour the implementation of HAP.

In the previous chapters we already discussed the centralistic nature of the regime and how it shaped policymaking at the federal and state level. We have also seen how it shaped policymaking at the local level. This level was completely ignored in the implementation process, which resulted in a lack of resources, capacities, correct orientation and of interest in the local community and first line health providers. The only exception being a handful of actors who represented the local elite. However, they dominated local politics to serve their personal interests rather than those of the community.

The regime's centralistic attitude also resulted in the unjust distribution of resources between the federal, state and local levels with the latter benefiting the least. This situation was further compounded by inefficient local councils and the low priority placed on health care by the local political leaders in the context of general political uncertainty, a deteriorating economic and financial climate, a big drop in external aid and, finally, an exodus of medical doctors. The local situation deteriorated further because of the lack of effective, transparent and accountable local institutions such as the $\mathrm{HAC}$, the VHC and the local government. 
Many of these problems resulted from a tremendous difference in the knowledge, capacity and power of the actors at the federal, state and local level.

The design of the HAP did not pay attention to problems of implementation, nor were the requirements and federal context of Sudan taken into account. Local Councills had neither the capacity nor the willingness to compensate this. Most of the actors involved believed that the policy would have a negative effect on their personal or group interests. Also, the HAP and the local government acts did not provide any means to compensate those who would be adversely affected. The community was also indifferent to the situation, which inevitably resulted in a lack of compliance. The local community did not perceive these policies as an adequate solution to their requirements, as they were not involved in policy development, and the policymakers at all of the government levels rarely listened to them.

Eventually, the HAP failed to meet its expectations. The health areas failed to be established in the local councils and improvements in both quality and integration of health care services did not materialise. The local councils did not take the ownership of the HAP. This resulted in the continuation of centralisation via the vertical programs, and a failure of the federal and state governments to transfer resources and staff to the local areas. To conclude, the accountability of the government to the community was not realised. In the absence of a central political will to develop the local community and sustainable capacities and resources, one can hardly be surprised on this outcome. 

. 


\section{Chapter 9}

\section{Conclusions: the Implementation of Federal Decentralisation in the Public Health Sector}

\subsection{Introduction}

In this research we have analysed the process of decentralisation in the public health sector of Sudan within the context of the introduction of federal reform in 1993. This chapter summarises the process of decentralisation with the intention of providing answers to our research questions. First, we give a summary of Sudan's past experience of decentralisation and its ramilications for the public health sector. Second, we provide a brief overview of the development and design of the present federal reform. Third, we summarise how the current federal reform was implemented in the public health sector at the federal, state and local level. We will also describe to what extent the objectives of the federal reform in the public health sector have been realised so far. Fourth, using the framework of Grindle's model, the causes of the failure of the federal reform so far will be explained. Finally, we will close with some concluding remarks.

The research questions of this research were:

1. How was federal decentralisation in the public health sector implemented in Sudan?

2. To what extent did federal decentralisation in the public health sector achieve its objectives?

3. Which factors affected the implementation of federal decentralisation in the

public health sector and help to explain its achievements so far?

In order to answer these questions, we performed an exploratory investigation of how federal decentralisation has been implemented in Sudan. For that purpose, we conducted a multi-level case-study. The implementation of federal decentralisation was not only studied at the federal level, but also at the state and local level. An extensive description of the selection of states and local areas can be found in the annexes 1 to 3 . These annexes also give details on the data collection process (which political leaders, senior civil servants and other persons were interviewed? How were they selected? What were the topics of discussion in the interviews? Who participated in the focus group discussions?). We also collected a great number of legislative documents, reports, statistical records and forms of written information. Thus, one can speak of a research strategy of triangulation which enhances the validity and reliability of our findings and conclusions. In this respect we emphasize that an important goal of the focus group discussion was to verify the results of our interviews and analysis of the documents. In our 
view, the strategy of triangulation is an appropriate method to study such a complex phenomenon as the implementation of federal decentralisation in the sector of public health.

\subsection{Development of federal reform}

\subsubsection{Past experience}

The history of decentralisation in Sudan reveals a persistent interest of all regimes in decentralisation and the repetitive failure to realise them. A.t the time of independence in 1956, Sudan inherited a multiparty regime and a devolutionary type of local government at the district level. Elected local councils were entrusted with the development of many economic and social functions at the local level. Just three years after independence, however, the military seized power and centralised all decision-making. The newly introduced Provincial Act of 1960 abolished the autonomy of local councils. Devolution was replaced by deconcentration. The brief second democratic government from 1964 to 1969 maintained the system as it was.

In 1969, the military under the leadership of Nimeri seized power and introduced a one party regime with the Sudan Socialist Union (SSU) being the only party. The regime introduced the People's Provincial Council System and the Local Government Act of 1971. This was partly to increase its legitimacy and partly to mobilise popular support for the implementation of its economic and social development plans. Later in the $1980 \mathrm{~s}$, the system was further developed into regional governments with semi-elected and appointed regional councils. These were charged with the substantive functions of economic and social development but received no extra financial assistance or human resources. In addition, the appointment of the regional governments' heads by the President, their accountability to him, and the centralistic one party restricted the regional government's autonomy. The local councils continued to exist, but in the course of time their separate corporate identity and autonomy were abrogated. In addition, their budgets were merged with those of the regions. All decision-making was centralised in Khartoum.

All these political developments did not bring any solution to the problems in the public health sector. In fact, the continuous changes aggravated these problems. The central health bureaucracy maintained its grip on human and financial resources and resisted the changes required by decentralisation.

The system of regional and local government continued until 1984. Neither the Transitional Military Government of Swar-Eldahab (1984-1985) nor the elected government of Saddiq Mahadi (1985-1989) introduced any major change into the government system. In 1989, once again the military seized power in the name of the Salvation Revolution led by General Al-Bashier. The revolution regime abol- 
ished all political parties and centralised all decision-making in the Military High Council of which Al-Bashier became the President.

\subsubsection{Federal reform}

Despite its military origin, the Salvation government of Al Bashier announced a major program of drastic economic and political change. The program included the introduction of a far-reaching devolutionary type of decentralisation that was based on a federal system. For that purpose, the country was divided into twentysix states, sixteen in the north and ten in the South. State governments and elected state assemblies were entrusted with all governmental responsibilities with the exception of defence, security, foreign affairs and economic and monetary policy.

To provide a participative mechanism in place of the abolished party system, the regime conducted several conferences for a limited and symbolic debate on various issues including the proposed framework of the federal system. Thereafter, federal reform was pushed through via various consecutive Presidential Decrees. There were several motivating factors for this step: the regime desired to quickly boost its legitimacy, to bring about the cessation of the ongoing civil war and the acceleration of development, but at the same time it wanted to keep centralistic control of political decision-making. The symbolic process of holding conferences culminated in the Comprehensive National Strategy Conference in 1992. The Comprehensive National Strategy (CNS) of 1992-2002 provided the "road map" of the major socio-economic program of the new regime. It included a section on a National Health Strategy (NHS).

\subsection{Implementation of federal reform in the public health sector}

\subsubsection{Implementation at the federal level}

Federal decentralisation was expected to bring decision-making on health services closer to the citizen. With the responsibilities of health planning, financing, and health services delivery being entrusted to the states and the localities, substantial improvements in the delivery of health services were expected. But the realisation of this expectation depended greatly on the federal agencies. They were required to facilitate the states and localities in fulfilling their new responsibilities through the provision and transfer of resources, equipment, staff and capacity building activities.

The FMOH failed to fulfil its facilitative role. Neither the ministers nor the senior staff of the FMOH showed any interest in giving up their control of resources and various pivotal functions. The system of centralised decision-making on health services continued to exist through the vertical programs and the control on the utilisation of external resources. None of the federal institutions showed 
any interest in expediting the implementation of decentralisation in the public health sector. Despite the illusion of visible political support, the bureaucratic interests and politics of the FMOH influenced implementation. The change in structure, planning, strategies and attitude of the FMOH appeared only marginal. A drastic reorganisation of its responsibilities was not realised. Its role in health policymaking, in fact, remained unaltered.

Also, other federal agencies failed in their role. The FMOF did not intervene in the implementation process to ensure the reallocation of responsibilities and resources among the centre, states and localities in accordance with the new legislative provisions. The newly created Federal State Support Fund (FSSF) failed as a tool in the reallocation of resources from the richer to the poorer states to compensate for the inequalities between them. As a result, the better off states like Khartoum, Gezeira and White Nile not only received greater overall central subsidies and increased local revenues, but also secured a disproportionately large share of the central funds including foreign aid.

The members of the FGC, the constitutional body, which was supposed to be the watchdog of federalism, did not involve state representatives directly in its composition. Its deliberations did not show significant evidence of any critical examination of the progress in implementation. It also failed to take any concrete measure to compensate for the states" meagre financial and human resources and the neglect of capacity building. Nor did it exercise much pressure on federal ministers to overcome the obstacles created by the way states performed in their functions.

\subsubsection{Implementation at the state level}

Most of the twenty-six states began implementing federal reform with a big handicap. The shift from nine regions to twenty-six states had considerable implications for the availability of resources: the demand was simply beyond the limited economic and financial capacity of the country. In reality, the federal government kept a disproportionate share of total revenues and the bulk of the staff, including the most qualified and experienced, for itself. Additional financial and human resources that were transferred by the federal government to the states remained very insignificant. The financial, equipment and human resources of the former nine regions were thinly distributed over the twenty-six states. The new states that lie within the boundaries of the former regions' capitals were in a better situation with regards to leadership and resources than the newly created states. This meant that states like Khartoum, Gezeira, North Kordofan and Red Sea more or less retained the greatest share of resources. This had a devastating impact on the other states, particularly the less developed ones. Because of the continued acute economic situation, the possibility for raising more local resources was also limited. The impact of this was felt much more in the public 
health sector, where most of the new states inherited only a few of the existing health institutions and were unable to establish new ones due to the lack of resources. Moreover, in most states $80-90 \%$ of the health budget was spent on salaries and wages, leaving very little room for the maintenance of the existing health care facilities and development of new ones. The lack of motivated and qualified political and administrative leadership in the state health sector further exacerbated the situation.

\subsubsection{Implementation at the local level}

Federal reform was expected to support the implementation of the Health Area Policy (HAP), which was introduced nationally in 1990. The HAP aimed to provide integrated basic health services at the local level based on the PHC principles.

The overall performance of the local councils in health was seriously hindered by a lack of trained administrative and professional staff, motivated political leadership, adequately organised financial resources, and low priority on health care. As a result of a long period of one party and military rule, the political process at the local level was more or less defunct. Local social elites and opportunists monopolised the local decision-making process. The long-standing local bureaucracy also facilitated this. In addition, the local legislatures were not representative of all groups and not active enough to hold the executive accountable. The local political leaders considered themselves accountable upwards to the state and the federal level rather than to their own people. Available resources were mostly spent on salaries, incentives, and the maintenance of existing health institutions rather than on extending their scope to areas without any access to health care or on improving the quality of existing services.

Although the public health sector touches each and every family at local level, it did not have political "sex appeal" to the local council leaders. Thus, formal decentralisation at local level did not lead to an increase in local health expenditure, an integration of health services, more community involvement or a shift in accountability to local councils.

\subsection{Federal reform outcomes}

In general, one can conclude that federal reform in the public health sector did not create optimal conditions for improving health care at each level. The processes at the federal level failed to set up required structures, develop appropriate plans, build capacity, establish adequate financing systems and provide facilitation and support to the other levels. The failure at the federal level had an adverse impact on the state level.. Consequently, the states failed to operationalise federal reform and to use their autonomy to serve the interests of the local population 
rather than those of the federal level. As such, the outcomes of the reform at the state level were poor and provided inadequate input for the local level in achieving its outcomes of the reform. Thus, it was natural that the local level failed to set up relevant structures, build the required capacity, integrate the health services, provide satisfactory funds and involve the community and, most importantly, shift the accountability for health services from the SMOH to the local councils. Due to the failure of federal reform to achieve these intermediate outcomes at all three levels, it is plausible to assume that its impact on the status of health was negative. Based on the five-year period of implementation one can conclude that the policy was a failure: a failure in terms of policy design and implementation.

\subsection{Explanation of the policy failure}

\subsubsection{Influence of policy formulation on policy failure}

Successful implementation depends upon the policy formulation stage where major decisions are taken concerning objectives and instruments of the policy, the division of responsibilities and resources between the different levels of government, the identification of the organisations and groups that are to be involved in implementation, and how the policy will be monitored and evaluated. In the case of federal reform policy formulation and policy design were suffering from the following problems:

o Policymaking was not intended as a means of improving the policy-making process (e.g. in public health), but as a means of building political legitimacy and political patronage.

- The top-down characteristic of the decision-making process: those who had to implement the policy or its beneficiaries were not involved in it.

o The lack of consultation or involvement of the legislature, interest groups and research scholars in the actual design of the policy.

o Federal reform was not introduced in one document but scattered across different consecutive presidential Decrees and Acts, which made implementation coordination very difficult.

- Federal reform was very ambitious because of the jump from nine regions to twenty-six states and the creation of 634 localities of disparate sizes, without adequate financial and human resources. Moreover, the policy intended to cover the entire country and had to be implemented in a very short period of time.

- The design of federal reform did not provide incentives or sanctions for the implementing agencies to encourage effective implementation. 
- There was no estimation and adequate provision of financial and human resources as well as activities to build capacity in order to compensate for the inadequate inheritance especially at the sub-national levels of government. In conclusion, the policymakers did not pay much attention to the reality of the implementation of their plans. They had given an 'un-implementable' policy to the implementers. Thus, the policy makers failed to formulate the policy successfully.

\subsubsection{Influence of implementation on pollicy failure}

In this section we will explain why implementation was unsuccessful and consider the negative impact of the stage on the policy's success. We will follow Grindle's model.

\section{Interests affected}

Federal reform in Sudan is a clear example of a constitutional policy with substantial redistributive consequences. It redistributes power, benefits and resources between the federal, state and local government levels across various fields of public policy including health.

In this study we have seen that the higher government levels in particular FMOH and SMOH were not really willing to give up their power base, benefits and resources in health. Federal reform conflicted with their interests. Thus, it is no surprise that we found at many places in our study that the implementation was characterised by lack of enthusiasm as well as overt and covert opposition. This pattern of implementation was found both at federal and state level. Importantly, we also found a lack of interest at local level. Lack of enthusiasm and opposition could perhaps have been overcome by strong political leadership at the federal and state level. But with a few exceptions, such leadership was completely lacking.

\section{Type of benefits}

Health services are not considered as a 'material benefit' by most members of the Sudanese population. People will happily push their representatives for an improvement in housing or the provision of commodity subsidies. The majority of the population turns to the traditional remedies or limited private practitioners particularly in the rural areas where by default health facilities lack skilled staff and medicines for the treatment of their health problems. Also, the state and local level politicians do not see any immediate personal or political gain by allocating resources for the improvement of health services. The benefits of good health service will only be enjoyed in the long run. Thus, the present policymakers cannot immediately gain from investing time and money in the health services. As a 
result the state and local level political leaders are not interested in using their limited political capital to improve health services. They also perceive health as a complex technical matter that should be left to physicians. Therefore, the benefits of federal reform in the public health sector were mainly felt by the bureaucratic staff in terms of personal gain or loss of jobs and resources.

\section{Extent of change envisioned in reform}

The change envisioned in the federal health reform was different for each stakeholder. Federal reform presented a very drastic change for the $\mathrm{FMOH}$. It meant the loss of its power and control of resources and opportunities for patronage. The reform also demanded major structural changes. As most of the health services would be provided by the states and localities, the medical doctors would have to relocate to the rural areas where facilities and living conditions were not to their taste. In Sudan, medical doctors constitute a major political lobby and occasionally play an active role in national politics.

The change envisioned for state health leadership was also comprehensive. It included the establishment of twenty-six SMOHs fully staffed and with other requirements. They became responsible for the planning and execution of all the health services in their state and also for the general health status of the population. This called for major changes in the organisational structure of the ministry as well as changes in planning, resource allocation and intergovernmental relationships. However, because of the low visibility of the public health sector and the lack of sufficient financial and human resources, these changes did not take place, with the exception of the four wealthier states. The new mandate for the public health sector required a qualified, experienced and highly motivated State Minister of Health. However, it was not possible for the government to find twenty-six individuals with these qualities.

Significant changes were also required at the local level. The HAP and Local Government Acts made the locality primarily responsible for health. This was a major change in terms of accountability, devolution, capacity building and the democratic process. This in turn depended on the population awareness of health issues and upon its participation in planning and financing. Our analysis has demonstrated that the required change was beyond the capacity of the local council's existing manpower and outstripped financial resources. Moreover, it demanded a kind of cultural change that needed time to materialise. These changes did not take place in most of the states with the exception of one or two wealthier states. Consequently, the local level's attitude towards the health of the population at large remained unaltered.

\section{Site of decision-making}

The content of a policy also determines the site of implementation. Implementation of a policy like federal decentralisation is not restricted to one or even a few 
sites, where the process can be relatively easily controlled or steered in the right direction.

Implementation of federal reform was fragmented across a number of federal government agencies and institutions such as the FMC, FMOH, FMOF, FGC, the federal parliament, twenty-six SMOHs, 634 local councils, and the NGOs. The difficulties involved in coordinating the implementation process could have been expected, had the following factors been taken into account:

0 The vague and general provisions on federal reform in the Constitution and the Presidential Decrees.

- The totally inadequate performance of decentralisation in the past.

- The resistance of the federal health bureaucracy to reform.

o A totally new and inexperienced political and administrative leadership at the state and local level.

o The acute scarcity of resources.

a Limited political support for implementation.

- The lack of effective monitoring procedures: absence of strong incentives and presence of disincentives for reform.

Because of the nature of the political regime and the domination of political institutions by opportunists and supporters of the regime, many important issues concerning the federal reform of the public health sector did not interest political institutions outside the executive branch. All decision-making and implementation procedures were kept within the executive branch. These processes were predominantly characterised by intra-bureaucratic politics at all levels of government. None of the federal and state legislatures, media, academics, or state and national level interest groups showed any interest in the effective implementation of decentralisation in the public health sector.

\section{Impact of program implementers' background}

Due to the lack of interest shown by the higher-level political agencies in the public health sector, the responsibility of federal reform rested with the implementers within the public health sector. In this period of drastic change, the FMOH required political and senior administrative leadership with an adequate background, experience and motivation. However, the Ministers and Undersecretary of the FMOH were appointed during this period mainly for their loyalty to the regime. Moreover, there was a high turnover with an average stay in office of 1.5 years for the minister and 2 years for the undersecretary.

The FMOH's Directors-General were not available full-time, as many of them had part-time appointments and private activities to increase their income. This practice diverted their attention from implementing health decentralisation and prevented the states and localities from fulfilling their responsibilities effectively. The FMOH's internal politics prevailed over the stated objectives of the federal reform. Medical professionals dominated the senior decision-making positions in 
the FMOH. They were responsible for the planning, policymaking, implementation and monitoring; however, they were insufficiently equipped to perform these difficult and crucial tasks adequately. Moreover, the majority of them were concentrated in Khartoum and a few urban centres. Therefore, the states and localities did not receive adequate professional support.

The implementers at the state level did not perform any better. Only a limited number of State Ministers of Health and SDGs were qualified. The rest were mostly selected for political patronage or other non-health related considerations. There were a few fortunate states, where both the political and administrative leadership in the public health sector was of a relatively acceptable level and somewhat compensated for the federal level's poor performance in the implementation process. They managed to acquire reasonable staff and financial resources, establish the required structures and developed relatively concrete plans. It should also be mentioned that some states did not benefit from NGOs" efforts to compensate for the lack of experienced implementers and sufficient resources. The situation was at its worst at the local level. Local councils lacked the relevant orientation and generally showed little interest in health. In most cases, Health Area Councils (HACs) were never established. The Health Area Management Teams (HAMTs) faced a lack of suitable staff. The local elites displayed a complete ignorance of the HAP's principles. Due to the lack of harmony between various institutions and resources the effects of decentralisation could not be felt by the local level. Even with implementation of the HAP, the training opportunities were monopolised by the federal and state level civil servants. The local level did not have real access to these opportunities.

\section{Allocation of resources}

A major reform like federal decentralisation involving twenty-six new states and 634 local authorities was very expensive to implement. The timing of the reform was highly questionable from an economic and financial viewpoint. The country had almost reached the level of bankruptcy. High inflation, draught, civil war and an undeclared donor boycott aggravated the situation. Despite the rhetoric, it was not feasible to transfer substantial resources to the states and local levels. This percentage dwindled even further in real terms because of an increase in the population and inflation.

Federal reform did not include an explicit financial commitment to funding implementation in the public health sector. The only resources allocated to the public health sector were those that already existed. They were hardly sufficient to cover salaries. As a result, there was a gate crashing by the FMOH for control over the limited external funds, which were donated by donor agencies. Khartoum and some other urban centres were capable of preserving their resources, but most other states lacked the minimal resources required to cover their basic salaries. 
The backward states such as West Darfur, Blue Nile or North Kordofan did not possess the number of medical doctors required to lead the HAMT. In addition, most of them had no access to secondary and tertiary health services.

Our analysis leads to the conclusion that, from the perspective of resource allocation, federal policy makers only paid lip service to decentralisation. Only small number of states benefited from the reform. Decentralisation only provided a handful of state and local level elites with access to relatively better financed government positions in the states and localities. The population at large did not experience any positive change. Instead the burden on them increased through additional taxes imposed by state and local authorities and fees charged for receiving certain health services.

\section{Power, interests and strategies}

The implementation process and the impact of health decentralisation were also influenced by the power, position, interests and strategies of the main actors. The salvation regime came into power through a military coup and replaced the elected multiparty government in 1989 . The regime wished to prove itself as a good substitute for the former inefficient multiparty democratic system, through boosting its legitimacy and popularity. In order to achieve this, the regime focused on high politics issues such as the civil war in the South, macro-economic issues and the political organisation to compensate for the dissolution of the multiparty system. In this context, development issues particularly conceming public health were considered low politics issues.

During implementation neither the President nor the other central government institutions showed a keen interest in ensuring the successful implementation of federal reform in the public health sector. The parliament and National Health Council also did not put any pressure on the central executive to expedite the implementation.

The regime also compromised the health ministerial appointments in order to ensure allegiance to its rule. Ministers were mainly chosen for political patronage in order to placate opposition groups or reward loyal proponents. Consequently, they became a burden on the public health sector rather than inspirational leaders with the vision and skills required to support federal reform. Other federal agencies and ministries concerned with reform, understanding the regime's real intentions, also became indifferent to implementation of the reform. In this political vacuum much of the initiative laid within the bureaucracy, particularly of the FMOH, which used the reform to benefit its own staff.

Our analysis has revealed that central political and administrative leadership in general and of the public health sector in particular did not display any enthusiasm towards the implementation of the reform. It failed to reduce its staff accordingly and adopt its structure to its new tasks devoid of any executive service functions. In addition, it failed to develop its staff's skills. The opportunity for 
reorganisation was used only to juggle the number of senior positions in order to accommodate all existing senior staff members in the new structure. No new expertise or skills were brought in through fresh recruitment or developed through training. The existing training facilities provided by international agencies like the WHO were monopolised by the FMOH's staff and used as a means of topping up their meagre salaries.

State level political leadership was also weak. Only a few states possessed ministers and SMDGs with an appropriate background and their turnover in posts was low. Most state ministers compromised their autonomy in order to gain resources. They preferred to remain accountable to the vertical health programs directors and FDGs. The local councils were indifferent to health. The professional health staff of the HAMTs also chose to remain accountable to state health authorities and vertical health programs. This strategy offered them greater resources and personal benefits. They ignored the local council from which they had little or nothing to gain.

\section{Institutions and regime characteristics}

Despite formal statements on decentralisation, Sudanese politics has always been dominated by centralistic forces, regardless of whether the country was governed by a military regime or a democratically elected government. Political participation of the population was limited to central elites and controlled by the members of the single party. Even during the long period of regional government rule, centralised control of all decisions continued.

The present regime introduced federal reform as a means to overcome political and development problems. However, it was used as a tool to bypass the political elites of the former powerful parties in Khartoum, and establish a direct relationship with the regional and local political elites. The reform was also used to overcome the extreme scarcity of resources by shifting responsibilities from the central to sub-national levels. Hence, the regime placed a high priority on federal reform, pushed it on the political agenda and received approval from the parliament in a very short period of time. All opposition from the bureaucracy, the trade unions and other stakeholders was overcome during their participation in symbolic conferences. Also, the new regime established its hegemony over all important government structures and institutions by nominating loyal individuals to head them.

As a result of these characteristics, decentralisation has been used by all regimes as an instrument to realize un-stated political objectives rather than for economic and social development and popular participation. Thus, in reality federal reform did not change the distribution and control of resources, the content of sectoral policies including public health, or the genuine participation of the population. The powers and autonomy of the states and localities remained to a great extent 
'empty shells'. This situation led to more frustration than ever before, given the absence of financial and human resources.

\section{Compliance and responsiveness in policy implementation}

In achieving policy goals, officials face two subordinate problems that highlight the interaction between the program's environment and the program's administration. Officials must address the problem of how to achieve compliance with the ends enunciated in the policy. The other side of the problem of achieving policy and program goals within a specific environment is that of responsiveness. To achieve compliance, policy makers require the support of the politicians and the compliance of implementing agencies, lower level political elites and the intended beneficiaries of their program. This calls for a high level of expertise and motivation, excellent negotiation skills, and the top-level political and administrative leadership of the public health sector. In this studly, we found at many places that the leadership in the public health sector failed to display these attributes during the formulation and implementation of the policy. Neither the Ministers nor Undersecretaries of Health actively tried to win the support of other high level politicians for the decentralisation of the public health sector.

This was not compensated by the administrative leaders because they, too, did not identify themselves with the content of the reforms. They did not see any benefit for themselves in implementing enthusiastically, only loss.

The concept of responsiveness to beneficiaries is in general missing from administrative practice in Sudan. Despite the FMOH's stated support for the PHC, which emphasises active beneficiary participation, the implementation of health decentralisation has not shown any substantive changes in the priorities placed on health programs, the integration of vertical health programs, or the involvement of local health providers as a means of increasing access to health services in the rural areas. Wherever participation was encouraged, it was mainly to mobilise self-help contributions for health services, rather than to actively involve beneficiaries in the planning and delivery of health services. None of the political executives, political parties or other groups in society took active steps to make the civil servants of the public health sector more responsive.

\subsection{Looking back at federal decentralisation: some reflections.}

Our analysis of the implementation of federal reform in Sudan's public health sector has revealed a discrepancy between the stated policy objectives and their actual realisation during implementation. The situation is not very different from the decentralisation experience in other developing countries, particularly in Africa. Generally speaking, the main pre-requisites for achieving such far-reaching change are not present. They include political consensus on basic values, a reasonably developed economy to sustain extra expenditure on multiple tiers of 
government, the availability of a reasonably skilled administrative and professional staff at all levels, and a participative democratic process. None of these conditions were actually met in Sudan.

This observation brings us back to the political intentions of decentralization. In the Western literature on decentralisation it is often argued that the declared objectives of decentralisation by devolution are to increase popular participation in the policy process (more democracy) and to increase the effectiveness of service provision (more efficiency). In the developing countries one finds that these objectives are secondary objectives at the best. The hidden agenda of decentralisation is to serve the interests of the political elites. Sudan presents an excellent example of this phenomenon. Decentralisation was a political tool to enhance the legitimacy of the political regime. Under these circumstances it is hardly surprising that the political elite has little interest in creating the conditions for a successful implementation of decentralisation. This is also illustrated by the absence of a strong and motivating leadership during the implementation process. It seems that the political elite is not interested at all in a successful implementation. A similar lack is also found at lower levels of government.

A comparison of decentralisation in developing countries with decentralisation in the developed countries is also interesting in this respect. Decentralisation in developed countries is often the government's response to a strong bottom-up demand for more decision powers at lower government levels. The situation in developing countries is often just the opposite. Decentralisation in these countries is initiated as a top-down process without a strong bottom-up demand for it. The political elite is also less interested in the participation of political and societal groups in the political decision-making process. It generally takes all important decisions on the timing, scope and form of decentralisation. Despite slogans suggesting the contrary, it is not interested in any form of participatory decentralisation.

In most developing countries reforms directed at decentralisation are ambitious in scope. Sudan proved no exception in this respect. It was the intention to decentralise substantive responsibilities to the sub-national units. Furthermore, decentralisation had to be accomplished in a very short period of time without adequate financial and manpower resources. Again, the difference with decentralization in developed countries is striking. In the latter countries decentralisation is usually considered a process of change over a longer period of time. Decentralisation is not an one-off operation. The style of political decision-making can often be best described as 'We should run while others walk'. Governments in developed countries also better understand than governments in developing countries that any decentralisation is empty if a transference of decision powers is not accompanied by a corresponding transference of financial and other resources.

We also want to make a comment on the literature on policy implementation in general. The case of Sudan reflects an approach to policy implementation that is 
typical for developing countries. Implementation is generally considered a technical process. This view upon implementation is consistent with the "linear approach" to the policy process. But in practice, implementation appears a nonlinear process. Problems that were underestimated or not recognised at all in the political decision-making process can no longer be avoided during the implementation process. The same is true for all problems which were deliberately displaced by the political leaders during the political decision-making process to policy implementation. The infeasibility of vague and ambitious declarations about decentralisation becomes inevitably manifest during the implementation process. The interactive approach is a much better approach for the description and analysis of implementation process, in particular in the developing countries. Grindle's model of implementation has been very helpful in this respect.

If the conditions for a successful decentralisation are not met, why then do the leaders of developing countries insist on decentralisation? A pessimistic answer to this question is that the political leaders of most developing countries do not introduce decentralisation as a strategic tool for economic and social development and popular participation but as a means for establishing political legitimacy or diverting attention from other more pressing problems. In their view, the implementation of decentralisation need not be taken seriously, particularly when it threatens their hegemony, their control over resources and their tangible benefits.

A more optimistic explanation is that political leaders understand quite well that they lack the required financial, human, and political resources for the effective realisation of decentralisation and that decentralisation should be introduced only when these conditions are fulfilled. However, they feel that somehow they have to introduce these changes despite the fact that their prerequisites are not fulfilled. They are aware of the problems involved with implementation but believe that you have to start somewhere and that somehow solutions will be found.

In this study we have stressed the persistent low political priority of public health in Sudan. The fact that public health misses 'sex appeal' is not characteristic at all for Sudan. Because of its lack of 'sex appeal' public health is a policy sector in Sudan with one of the lowest budgetary resources. With exception of Nimeri, in the early PHC era, no political leader in the history of independent Sudan ever made public health an important issue in his political campaign. No political party has ever included public health as a major issue in its political manifesto or election campaigns. No rising ambitious minister wants the portfolio of health, because it is not something that will provide him or her with political visibility, prestige or opportunities for an advance in the political hierarchy. Even in the Sudanese protocol list, the Federal Minister of Health comes very near to the bottom.

In our opinion, the present custodians of the health services in developing countries are themselves to blame for this situation. In most developing countries, in- 
cluding Sudan, the decision-making in the public health sector is dominated by medical professionals who are not interested in policymaking or its politics. Although they occupy senior positions in health ministries, where they are required to plan and oversee implementation and to interact with other agencies and interest groups, they are not prepared for these tasks. They never received the appropriate training. As a result, they approach decision-making on health issues from a purely technical, medical perspective. They do not consider them from an interdisciplinary perspective or from the perspective of effective policy formulation and implementation. Unfortunately, they are not even aware of the limitations of their background and do not allow the administrative generalists in the health ministries to supplement and compensate for their shortcomings. Most of them are biased in favour of curative medicine and distrust preventive medicine and other public health programs because they are generally staffed by less welleducated staff. It is ironic that Sudanese medical professionals in the past tried to influence national politics through strikes, but failed to see the significance of the political process in decision-making on public health. Most medical professionals fight for their working conditions and higher salaries rather than for the development of public health.

In view of this, public health has to be put on the public agenda by creating an awareness of the need for good health and effective decentralised health services of good quality supported by adequate financial resources and manpower. If public health and decentralisation inside the government are a low priority then Sudan needs extra-governmental forces, for example from civil society groups, to push health and decentralisation onto the political agenda. We hope that this study contributes to this development.

\subsection{How to achieve better results?}

In this study we have analysed the policy process of federal decentralisation reform in Sudan. We have found many causes of the failure of the reform process. These causes concerned the policy formation process and the content as well as context of the policy implementation process. In order to achieve better results with federal decentralisation in the sector of public health (and other policy sectors as well), the following policy recommendations can be formulated:

- Implementation should be taken seriously. Political leaders should be aware that implementation is not a technical process. This is a priori true for the implementtation of federal decentralisation.

o Successful implementation requires a strong political will for success. Political leaders should feel committed to decentralisation and, if necessary, be willing to undertake efforts to overcome political and administrative opposition at all levells of government.

- Successful implementation requires political stability.

- Successful implementation requires a high political priority of public health. 
- Successful implementation requires a transference of an adequate level of financial resources to lower-level governments.

- Successful implementation requires a major investment in human resource capacity and institution building at lower-level governments.

o Successful implementation requires serious attention for the whole policy process, policy design, policy instruments, operationalisation and implementation.

o Successful implementation requires implementation structures for monitoring and evaluation.

o Finally, we strongly recommend that the financial resources spent on the civil war should be redirected to concrete programs for health and education. 


\section{Samenvatting}

Deze studie betreft een empirisch onderzoek naar de invoering van een federale bestuursstructuur (federale decentralisatie) in Soedan in de sector van de volksgezondheid (public health). De federalisatie dateert uit 1993. De probleemstelling omvat de volgende vragen:

Hoe verliep de uitwoering van de federale decentralisatie in de sector van de volksgezondheid in Soedan?

In hoeverre werden de doelstellingen van de federale decentralisatie in de sector van de volksgezondheid bereikt?

Welke factoren waren van invloed op de uitvoering van de federale decentralisatie in de sector van de volksgezondheid en dragen bij tot een verklaring van de tot dusver bereikte resultaten?

Soedan heeft al een lange geschiedenis op het terrein van de decentralisatie achter de rug. Sinds de onafhankelijkheid in 1956 volgden de plannen tot decentralisatie van het bestuur elkaar in hoog tempo op. Daarbij werd steeds weer een andere weg ingeslagen en veelal $k$ wamen de veranderingen neer op centralisatie in plaats van decentralisatie van de bestuurlijke verhoudingen. Zo makte de hervorming in 1960 (Provincial Act) een einde aan de autonomie van de lokale raden. De in 1969 aan de macht gekomen Nimeri voerde het eenpartijsysteem in, een stap met een sterke centraliserende werking. Verder werd er voor gekozen voor een stelsel van provinciale volksraden dat in de jaren tachtig werd uitgebouwd tot een systeem van regionale regeringen die met allerlei taken op het gebied van de sociaal-economische ontwikkeling werden belast, overigens zonder daartoe de benodigde financiële middelen te krijgen. Het centralistische karakter van het besturingssysteem kwam vooral tot uitdrukking in het feit dat het hoofd van de regionale regering door de President werd benoemd en ook aan hem verantwoording verschuldigd was. Voorts bestond er vanaf 1971 ook een systeem van regeringen op lokaal niveau maar hun autonomie werd steeds meer uitgehold.

Beziet men de ontwikkelingen tot aan het eind van de jaren tachtig, dan kan men niet anders concluderen dat er van de decentralisatie weinig is terechtgekomen en de bestuurlijke hervormingen geen enkele bijdrage hebben geleverd aan de aanpak van de problemen op het terrein van de volksgezondheid. Integendeel, zij verergerden deze problemen alleen maar.

$\mathrm{Na}$ een korte interimperiode met een burgerregering kwam in 1989 wederom een militaire regering aan de macht onder leiding van generaal Al-Bashier. Het nieuwe revolutionaire regime schafte alle politieke partijen af en voerde een verdere centralisatie in het landsbestuur door. Alle macht kwam te liggen bij een Militaire Hoge Raad onder voorzitterschap van de President (Al-Bashier). Toch was het diezelfde Al-Bashier die in 1993 de weg insloeg van een federalisering van het bestuur in Soedan. Volgens de plannen zou veel bestuursmacht worden gedecentraliseerd naar de deelstaten. Het aantal deelstaten werd uitgebreid van 9 naar 26. De federale decentralisatie had vooral tot doel om de legitimiteit van het nieuwe regime te ver- 
sterken en om een einde te maken aan de burgeroorlog in het Zuiden. Om steun te winnen voor de nieuwe plannen en enige ruimte te bieden voor participatie van de bevolking in de besluitvorming (politieke partijen waren niet toegestaan) werd een aantal grote conferenties georganiseerd. Deze conferenties dienden primair een symbolisch doel. Het geheel resulteerde in een Alomvattende Nationale Strategie waarvan de Nationale Gezondheidsstrategie weer een onderdeel vormde.

In deze studie wordt de invoering van de beoogde federale decentralisatie in de sector van de volksgezondheid op drie verschillende niveaus geanalyseerd, namelijk het federale niveau, het niveau van de 26 staten en het lokale niveau. Er is dus sprake van een multi-level casestudy. Op federaal niveau werd een groot aantal politici en ambtenaren geïnterviewd. Op het niveau van de deelstaat werd eveneens met politici en ambtenaren in 16 noordelijke deelstaten gesproken. Verder werden vier deelstaten geselecteerd voor een onderzoek in de diepte. Deze staten waren: Khartoum, Gezeira, Kassala en Noord-Kordofan. Van deze vier deelstaten zijn de eerste twee relatief het meest welvarend. $\mathrm{Zij}$ hebben op grond van hun ligging ook de beste contacten met de machthebbers in Khartoum. Voorts is ook de invloed van de federale decentralisatie op de uitvoering van het Health Area Plan (HAP) op lokaal niveau geanalyseerd. Deze analyse bleef beperkt tot de vier voornoemde deelstaten.

Uit de analyse van de invoering van de nieuwe bestururstructuur in de sector van de volksgezondheid op het niveau van de federale overheid komt het beeld naar voren dat er van de beoogde federale decentralisatie weinig is terechtgekomen. Hieruit kan worden afgeleid dat de doelstellingen van de federale decentralisatie in deze sector evenmin zijn bereikt. Het Federale Ministerie van Volksgezondheid faalde in alle opzichten om de federale structuur te laten slagen en om de deelstaten en het lokale niveau met het oog op een succesvolle invoering te faciliteren. Er bestond weinig steun om daadwerkelijk politieke beslissingsbevoegdheden en middelen aan lagere bestururslagen over te dragen. In feite bleef sprake van een sterk gecentraliseerde bestuursstructuur. De federale overheid behield ook de zeggenschap over het merendeel van de financiële middelen. De beoogde aanpassing van de departementale structuur en de overheveling van expertise van het federale niveau naar het niveaw van de deelstaten mislukte. Voorts bleek in de praktijk weinig terecht te komen van het fonds dat tot doel had om middelen van de rijkere naar de arme deelstaten te heralloceren. In feite profiteerden vooral Khartoum, Gezeira en Witte Nijl van dit fonds terwijl het nu juist niet voor deze deelstaten was bedoeld.

Ook op het niveau van de deelstaten was de invoering van de federale bestuursstructuur een mislukking. Hierbij moet worden bedacht dat een groot aantal deelstaten nieuw was en nog niet of nauwelijks over bestuurlijke ervaring en expertise beschikten. In feite, zo kan men betogen, vergde de beoogde federale bestuursstructuur een inspanning die in geen enkele verhouding stond tot de beschikbare mankracht en financiële middelen. De relatief welvarende staten die tevens relatief over veel bestuurlijke ervaring beschikten verkeerden in een veel gunstiger positie dan de nieuwe staten zonder financiële middelen, bestuurlijke ervaring en goede politieke contacten met het machtscentrum. 
Uit de analyse blijkt dat ook op het niveau van de deelstaten weinig steun bestond voor de beoogde federalisering van de bestuursstructuur in de sector van de volksgezondheid. Deelstaten bleken niet of nauwelijks bereid om eigen middelen te steken in de versterking van de volksgezondheid op lokaal niveau. Het ontbrak de deelstaten ook aan voldoende gemotiveerd en gekwalificeerd personeel alsmede effectief politiek leiderschap dat streefde naar een succesvolle invoering. Daar kwam nog bij dat de volksgezondheid in Soedan zeker geen beleidsprioriteit is. De volksgezondheid ontbreekt het aan 'sex appeal'. De politieke leiders kunnen er niet mee scoren. Dit probleem deed zich overigens niet alleen voor op deelstaatniveau maar ook op het federale en lokale niveau.

Tenslotte werd de invloed van de federalisering op het HAP geanalyseerd. Dit programma dat al in 1990 in uitvoering werd genomen beoogde een geïntegreerd aanbod van basisgezondheidsvoorzieningen op lokaal niveau tot stand te brengen (in totaal telt Soedan 634 lokale overheden). Uit de analyse komt naar voren dat de uitvoering van het HAP onder meer vastliep op een gebrek aan middelen en voldoende gekwalificeerd personeel alsmede de afwezigheid van een sterke politieke wil om de witvoering tot een succes te maken. Een ander opvallend resultaat was dat de politieke leiders en artsen in leidinggevende posities meer geneigd waren naar boven (het niveau van de deelstaat) te kijken dan naar het lokale niveau. Deze houding moet vooral worden gezien tegen de achtergrond van de centralistische bestuurscultuur in Soedan. Een 'verticale' opstelling vergroot de kansen op promotie en het verwerven van financiële en andere middelen.

In het onderzoek is ook aandacht besteed aan de verklaring voor het falen van de invoering van de federale bestuursstructuur. Daartoe is gebruik gemaakt van het model van Grindle voor de analyse van de invoering/uitvoering van beleid en de invloed hiervan op de beleidseffecten. In dit model wordt onderscheid gemaakt tussen drie clusters van factoren die op de beleidsinvoering van invloed zijn: het proces van beleidsvorming, de inhoud van het uit te voeren beleid en de context van de beleidsuitvoering.

Voor wat betreft het proces van beleidsvorming werd onder meer geconstateerd, dat met de federale decentralisatie in feite helemaal niet gemikt werd op een versterking van de beleidsvorming. De verborgen doelstelling was vooral de legitimiteit van het regime te versterken. Voorts valt het top-down karakter van de politieke besluitvorming op alsmede het daarmee samenhangende feit dat het parlement, belangengroepen en wetenschappers niet werden geconsulteerd. Andere problemen betroffen het irrealistische ambitieniveau en het gebrek aan effectieve incentives en sancties om een succesvolle invoering te bevorderen. Eigenlijk kan men stellen dat de politieke besluitvorming over de nieuwe bestuursstructuur plaats vond zonder een duidelijke notie van de aard en omvang van de invoeringsproblematiek op alle bestuursniveaus. Deze problematiek bleek volkomen verwarloosd.

De inhoud van de beoogde federalisering belemmerde de invoering eveneens. De politici en ambtenaren in het Ministerie van het Volksgezondheid op federaal en deelstaatniveau achtten een overdracht van beslissingsmacht en middelen naar het 
lagere niveau in strijd met hun particularistische belangen. Daar kwam nog bij dat de nagestreefde veranderingen in de bestuursstructuur door vele betrokkenen als radicaal werden ervaren. Het mislukken van de federale decentralisatie in de sector van de volksgezondheid hield ook verband met de lage prioriteit voor de volksgezondheid. Er bestond geen sterke lobby voor het belang van de volksgezondheid en voorzover zij bestond, was zij afkomstig van de medische professie. Andere factoren die bijdroegen aan de mislukking van de federalisering betroffen het grote aantal partijen dat bij de uitvoering betrokken was, de gebrekkige professionele achtergrond van de uitvoerende partijen op deelstaat en met name lokaal niveau en tenslotte het gebrek aan financiële middelen op lokaal niveau. Decentralisatie van beslissingsbevoegdheden zonder dat de lagere overheden beschikken over de benodigde personele, bestuurlijke en financiële middelen is per definitie gedoemd te mislukken.

Voor wat betreft de context van de invoering werd aandacht besteed aan de machtspositie, belangen en strategieën van de betrokken partijen. In feite werden door het politieke topniveau nauwelijks pogingen ondernomen om de invoering van de federale bestuursstructuur te bespoedigen. Politieke overwegingen bepalden de selectie van politici en hoge ambtenaren. De staf van het Ministerie van Volksgezondheid op federaal en deelstaatniveau bleek vooral geïnteresseerd in eigen belangen. Voorzover reorganisaties plaatsvonden, dienden die vooral om de eigen mensen tevreden te stellen, bijvoorbeeld door uitbreiding van het aantal senior posities. Operationalisering van beleid, het tot stand brengen van een bestuurlijk en goed getraind kader op de lagere bestuursniveaus, het beschikbaar stellen van voldoende financiële middelen kregen nauwelijks serieuze aandacht. De sterke centralistische bestuursstructuur en cultuur op federaal niveau belemmerden een succesvolle invoering eveneens. De vraag kan worden opgeworpen of de politieke machthebbers ooit serieus van plan zijn geweest om daadwerkelijk een federalisering van de bestuursstructuur door te woeren. Tenslotte liep de uitvoering ook vast op een gebrek aan medewerking en soms actieve tegenwerking op alle bestuursniveaus. Op het lokale niveau liet de bekendheid met de decentralisatie eveneens vaak te wensen over.

Samenvattend, kan worden geconcludeerd dat de invoering van de federale decentralisatie in de sector van de volksgezondheid door toedoen van factoren op federaal, deelstaat en lokaal niveau als een mislukking moet worden beschouwd. Uit de mislukking van de invoering kan worden afgeleid dat de doelstellingen van de decentralisatie niet zijn bereikt. De decentralisatie heeft geen constructieve bijdrage geleverd aan de aanpak van de grote problemen op het terrein van de volksgezondheid. 


\section{Annex 1: Overview of Data collection at the federal level:}

\section{A: Interviews conducted at the Federal level}

1. We thad open-ended interviews with the senior political heads of all relevant federal ministries, federal statutory bodies and senior civil servants concerned with the planning and implementation of the federal decentralisation reform.

2. The total number of persons interviewed at the federal level is 50 . Of them 27 worked in the FMOH. The other persons worked in other ministries and bodies. Interviews were arranged in advance; the topics of discussion were also communicated in advance. The length of the interviews varied from 30 minutes to 2 hours. In some cases the person was visited twice or even three times for further discussion or for getting some additional documentation. Discussions were taperecorded in tapes and worked out in written summarised form as soon as possible (often the same day). The interviews covered the following issues:

- Personal data and experiences of the respondent.

- The concept of decentralisation and federal reform.

- The concept of health and health services; general view on health services in Sudan.

o The respondent"s involvement in health policy development, particularly in federal reform.

- The implementation of federal reform in public health sector in general with special emphasis on: (a) legislation; (b) structural reorganization; (c) planning; (d) capacity building; (e) financial relations; (f) proponents and opponents of the reform; (g) problems of implementation and suggestions for improvement; (h)other relevant comments.

The following persons were interviewed:

Group I: Political leadership

- Present Federal Minister of Health.

- Two former Federal Ministers of Health.

- Chaiman of the National Health Salvation Committee.

- Four Federal Ministers involved in the selection of State Ministers of Health.

- Minister of State, Federal Ministry of Finance.

- Minister for the Federal Government Chamber.

- Health Coordinator, Humanitarian Aid Commission, Ministry of Social Affairs.

- Chairman, State Support Fund, Federal Govermment Chamber.

- Two Ministers of State, Federal Government Chamber.

- Sectetary General for Health Salvation Committee.

- A former State Minister of Health who previously in three states.

- Chairman, Committee on Federal Government Affairs, National Assembly.

o Chaiman, Committee on Social Affairs, National Assembly.

Group IL: Representatives of health-related international organizations in Sudan

- Chief Representative of WHO in Sudan, Khartoum.

- Chief Representative of UNICEF in Sudan, Khartoum.

- Representative of heallh-related NGOs in Khartoum.

Group III: Senior civil servants

- Present and former three Undersecretaries in the Federal Ministry of Health. 
- Undersecretary, Federal Government Chamber.

- Coordinator, Health Sector, Federal Government Chamber.

- Four ex-Directors-General, Federal Ministry of Health.

- Eight Directors-Gieneral, Federal Ministry of Health.

- Six Directors an Head of Vertical Programmes, Federal Ministry of Health.

- Director of Human Resource Development in Directorate General of Planning.

- Director of Rural Health and Health Area Policy, Federal Ministry of Health.

- General Secretary, National Health Council.

- Director for National Health information Centre.

- Director of Planning Directorate in the Directorate-General of Health Planning and Development.

All persons who were invited for an interview accepted the invitation. There was no non-response.

B: Official Documents and Reports:

Reports and other documents were collected at the following places

- Federal Ministry of Health (including all the Directorates-General).

- Federal Government Chamber and State Support Fund.

- Federal Ministerial Council.

- Republican Palace.

- National Council (Parliament).

- Federal Ministry of Finance.

o WHO office in Khartoum.

- UNICEF office in Khartoum.

- High Humanitarian Aid Commissioner.

- Three Active Health Related NGOs' offices.

- Development Studies and Research Centre, University of Khartoum.

\section{C: Focus Group Discussions}

Focus group discussions were a third method to collect data. The data were mainly used for the purpose of verification of other data and findings. We organised two focus group discussions. The first group involved five Directors-General, two former ones and one director:

- Director-General for PHC.

- Director-General for Epidemics' Control and Environmental Sanitation.

- Director-General for Planning and Health Development.

- Director-General for Curative Medicine.

- Director-General for International Health.

- Director for the National Centre for Health Information.

- Ex-Director-General for Planning.

Ex-Director General for Epidemics' Control and Sociall Medicine.

Topics of group discussion:

Suitability of Federal Reform for the Public Health Sector in Sudan

- Legislation, reorganisation, planning, capacity building, financial relations and coordination with other ministries and states

- Problems of implementation and possible solutions. 
The second focus group discussion at the federal level included six vertical program coordinators:

- Health Area Policy Coordinator.

- Nutrition Supplement Coordinator.

- Expanded Program for Immunisation Coordinator.

- BAMAKO Initiative Coordinator.

- Basic Development Needs Coordinator.

- Health Education Coordinator.

Topics of group discussion:

- The influence of federal decentralisation on vertical programs.

- Changes in the management of vertical programs since the introduction of the federal reform.

- Coordination with the State Ministries of Health in terms of finance, planning, training and supervision.

- Problems of implementation and possible solutions.

Some persons invited did not participate in the focus group discussion, because they were not present in Khartoum at the time the discussion was organised. There were no refusals.

D: Participation in Conferences, workshops and Seminars:

In addition to the above-mentioned strategies for data collection a number of conferences, workshops and seminars in FMOH were attended:

- Annual PHC planning conference of 1998.

- The second National Conference for the Local Government 1999.

- Workshop: Strengthening Health Legislation in Federal Context.

- Workshop: School Health.

- Seminar: PHC in the context of federal decentralisation.

- Seminar: Health Information System in the federal context.

- Meeting of Federal Committee for the development of HAP guidelines based on the 1997 evaluation. 


\section{Annex 2: Overview of Data collection at the state level:}

\section{A: Interviews conducted at State level}

1. Open-ended interviews with 16 Northern-State Directors-General of Health (each SDGH accepted the invitation for an interview). The purpose of these interviews was to collect information on their experiences and views upon the problems in implementation of the federal reform in the health sector. Main topics of discussion:

- Personal data, qualifications and experiences.

- Changes in the structure of State Ministry of Health.

- Functioning of State Health Council.

- Professional, administrative health staff.

- Priorities in the health sector.

- Relations with the Federal Ministry of Health; authority and functions transferred to the state.

- Federal guidelines on implementation of reform.

- State level health planning.

- Capacity building including human resource development, health facilities and financial priorities.

- Monitoring and supervision of state health plans; working of local health system; community participation in the health sector.

2. Open-ended interviews with the State political leaders in the four selected states ( 28 in total).

- State Governor.

- Two representatives of the Social Services Committee, the State Legislative Council including the Chair.

- State Ministers of Health.

- State Ministers of Finance.

- Two representatives of the Provincial Commissioners.

The total number of interviews per state: Gezeira (7), North Kordofan (7), Kasala (7), and Khartoum (7). There was no non-response.

Main topics of discussion with the political leaders were:

- Personal data and experiences.

c Priority of health in the state.

a Understanding of federal reform in the public health sector and HAP objectives; responsibility for health in the new setting.

- Problems of implementation of federal reform in public health in the state, in particular the HAP.

- Commitment to HAP.

- Legislative, financial and political support to HAP.

3. In addition, all directors in the Health Ministry in the four selected states were asked to participate in an interview with a semi-structured questionnaire (in Arabic). The response was as follows:

a Gezeira (10).

- North Kordofan (6).

- Kassala (8). 
All persons invited participated; no non-response.

\section{Main topics of discussion:}

- Personal data and experience

- Changes due to the introduction of federal reform.

- Integration of vertical programs.

- Community involvement in the health sector.

- Awareness and understanding of HAP.

- Commitment to HAP.

- Degree of support for HAP.

- Assessment of HAP so far.

- Involvement in HAP activities.

All persons invited did participate.

\section{B: State Documents and Reports}

The following documents and reports were collected in the four selected states:

- State health plans.

- State health budgets and expenditure.

- State lists of professional and administrative staff.

- Training courses and training institutes.

- State PHC reports including reports on vertical programs.

- State health documents related to the implementation of HAP.

C: Focus Group Discussion at State level:

One focus group discussion was organised. The following senior civil servants of the State Ministries participated in it:

- State Director-General of Health Khartoum, Gezeira, Kassala, North Kordofan, North Darfur, River Nile, South Kordofan, Sennar

- Director of Primary Health Care in Gezeira, Red Sea, Sennar, South Kordofan, North Kordofan, Western Kordofan.

All persons invited accepted the invitation to participate.

Topics of group discussion:

o State Health System within the federal context.

- PHC activities within the State Ministry of Health.

- Integration of vertical programs.

- Issues of financing, capacity building, planning, supervision.

- Community involvement in health sector.

- Pros and cons of decentralisation in the public health sector, particularly the HAP

- Problems of implementation in HAP.

The data collected by interviews, questionnaires and focus group discussion were summarized in notes. In the case of personal interviews and focus group discussions we used tape recorders as an additional tool for making notes. 


\section{Annex 3: Data collected at the local level (HEALTH AREA POLICV)}

1. The implementation of the Health Area Policy (HAP) was discussed with the political and civil servants" leadership at the federal and state level along with other issues of implementation of federal decentralization in the public health sector (see annex 1 and 2). All interviews were conducted by the researcher.

2. In addition, we collected data through questionnaires in the three selected states, namely Gezeira, North Kordofan and Kasala. In Gezeira we drew a random sample of 17 health areas out of a total of 51 areas. In Kassala we included all 6 areas in the sample and in North Kordofan all 3 areas. The state of Khartoum did not create health areas.

In each health area the following persons were selected:

- Members of Health Area Management Team.

- Chairman Health Area Management Team.

- First Level Health Providers.

o Local leader in the health areas.

We developed a standard questionnaire. We also selected three teams of people from the Federal Ministry of Health and Gezeira SMOH who used to work in PHC research. Each team was given an interview training of one day. The questionnaires were pretested in three health areas. Two of the three teams were led by a medical doctor who was familiar with PHC. He was visited by the researcher at least twice. The third team was accompanied by the researcher.

\section{List of respondents:}

- Members of Health Area Management Teams:

Three members of each area in Gezeira $(\mathrm{N}=17 \times 3=51)$, North Kordofan $(\mathrm{N}=$ $3 \times 3=9$ ), Kassala $(N=6 \times 3=18)$. In Kassala 5 persons did not respond (they were not present in the health area at the scheduled moment of the interview).

- We developed a separate questionnaire for the chairman of the HAMT. All chairmen participated: Gezeira (17), North Kordofan (3), Kasala (6).

o First Line Health Providers.

The total number of these providers ranges from 8 to 18 per health area. We decided to involve one third of the providers in each area: Gezeira (51), North Kordofan (15), Kasala (18). Khartoum was excluded because it did not establish health areas.

- Community leaders at locality level:

This group involved the chair of the local council, its executive director and a third representative. The number of the respondents were: Gezeira $(N=17 \times 3=$ $51)$, North Kordofan $(N=3 \times 3=9)$ and Kasala $(N=6 \times 3=18)$.

Issues addressed in interviews with members of HAMT:

- Awareness of HAP concept.

- Organisational arrangements for HAP.

- Strategy of realisation.

- Finance of HAP.

Composition and training of HAMT members.

- Relations of HAMT with state and federal health ministries, village health committees, local councils and NGOs. 
- Frequency of meetings and their follow-up.

0 Community involvement in the work of HAMT.

- Integration of health services at local level.

- Health information system.

- Implementation problems.

Issues addressed in interviews with chairman of HAMT:

- Awareness of Health Area Concept.

- Relationship with Health Area Management Tear, PHC Directorate at the State level and Vertical Program managers.

- Responsibility towards Village Health Committee.

- Change in the content and style of working after the introduction of HAP.

- Problems of HAP implementation.

Issues addressed in interviews with first-line health providers

- Awareness of Health Area concept.

- Composition and establishment of Health Area Council.

- Functions of the Council.

- Link between village health committees and Health Area Council.

- Accountability of Health Area Teams.

- Priority for health in resource allocation.

- Integration of health plans within the local council plan.

- Major health problems in the area.

- Nature and quality of health services provided.

- Environmental health and health education activities.

- Problems facing the HAP implementation.

Issues addressed in interviews with community leaders:

- Awareness of strategy to realize objectives of health area policy.

- Background data on the boundaries and differentiation of health areas.

- Information system on area health problems.

- Supervision and guidelines from the state and federal ministries of health.

- Authority to whom concerns on strategy are directed at.

- Preparation and execution of manpower development plan.

3. Finally, we organised a focus group discussion at local level but only in Gezeira (in the other states it proved practically impossible to organise a similar discussion).

The following persons participated:

- PHC Director.

- HAP coordinator.

12 Chairmen of HAMT Chairs.

Topics of discussion:

- HAP concept and its feasibility.

- Training courses and their value in terms of content and benefit.

- Relations with the local councills, State Ministry of Health and vertical program coordinators

Implementation problems facing HAP. 


\section{References}

Abdel Giadir, F. (1981). Democracy and govermment efficiency in the 1971 Local Government Act. The Sudan, a critical appraisal. Birmingham: Birmingham University.

Abdel Hameed, M. (1998). The healih legislation in the context of federalism. Khartoum: Federal Ministry of Finance.

Abdel Rahim, I., Alkaki, M., Elsayed, A., Nalder, S., \& Gorosh, M. (1992). Smaller health areas for a better service. World Health Forim, 13, 31-37.

Abdel Rahman, A., \& ElFaki, A. (1997). Evaluarion of health area policy (unpublished report)

Adamolekun, L. (1999). Decentralisation, sub-national governments and intergovemmental relations. In L. Adamolekun (Ed.), Public administration in Africa (pp. 49-67). Boulder: Westriew Press.

Ahmed, M., Elbrair, A., Elnaeem, A., Yasein, A., Norel Deen, A., Coat, I, et al. (2002). Srucwres, authorifies and relations under the federal system. Khartoum: Federal Government Chamber.

All Assam, M. (1983). Regional government in Sudan. Public Administration and Development. $1983(3), 11-120$.

AlTeraif, A., \& Idris, M. (1987). Decentralization origins and development: decentralization in Sudan. University of Khartoum: Graduate College Publications.

Anderson, J. (1975). Public policy making. London: Nelson.

Ayee, A. (1996). The measurement of decentralisation: the Ghanian experience 1988-92. Afrcan Affairs, $97(378), 31-50$.

Bakheit, G. (1969). The administrative effectiveness and socio-economic change in the Sudan. Khartoum: Khartoum University Press.

Bak heit, G. (1971). The functional and popular framework of people's local goverwment. Khartoum: Khartoum University Press.

Bakheit, G. (1974). The administrative revolution and the people's local government. Khartoum: Ministry of Local Government.

Barker, C. (1996). The health care policy process. London: Sage.

Baroudi, M. (1984). Primary health care program in Sudan, 1977/78-1983/84. (umpublished document).

Barrett, S., \& Fudge, C. (1981). Policy and action: essays on the implementation of public policy. London: Methuen.

Bayoumi, A. (1979). The history of Sudan health services. Nairobi: Kenya Literature Bureau.

Bennet, R. (1994). Local government and market decentralisation; Experiences in industrialised, developing and former Eastem Block Countries. Tokyo: United Nation University Press.

Bloss, J. (1968). Assigmment peport, evatwation of health services in the Studan. Alexaidria: World Health Organisation.

Borgenhammer, E. (1993). Looking after life: organisation, ethics and quality. Stockholm: SNs Forlag.

Bossert, T. (1996). Decentralisation. In K. Janovsky (Ed.), Health policy and systens development. An agenda for research: decentralisarion (pp. 147-159). Genewa: World Health Organisation.

Bossert, T., \& Beauvais, J. (2002). Decentralisation of health systems in Ghana, Zambia, Uganda and the Philippines: a comparative analysis of decision space. Health Policy and Plonning. $17(1), 14-31$.

Bowling, A. (1997). Research methods in health: inwestigating health and health services. Buckingham: Open University Press. 
Braton, $M_{,}$\& Rothschild, D. (1992). The institutional bases of governance in Africa. In $G$. Hyden, \&. Bratton (Eds.), Governance and politics in Africa (pp. 263-284). Boulder: Lynne Rienner.

Brewer, G. (1973). Polinicians, bureaucrats, and the conswliants. New York: Basic Books.

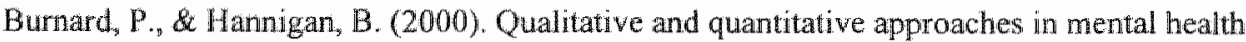
nursing: moving debate forward. Jow nal of Pychiatwic and Mental Healh Nursing, 7,1 6.

Burns, N., \& Grove, S. (1987). The practice of nursing research, conduct, critique and utilizathon. Philadelphia: WBSaunders.

Burns, D., Hambleton, R., \& Hogget, P. (1994). The politics of decentralization: revitalising local democracy. London: Macmillan.

Carter, N. (1989). Performance indicators: back seat driving or hands off control?. Policy and Politics, 17(2), 131-138.

Cassels, A. (1995). Health sector reform: key issues in less developed countries. Journal of $n$ temotional Development, 7(3), $329-347$.

Cheema, G. \& Rondinell, D. (1983). Decentralisation and development. Beverly Hills: Sage.

Cheema, G. (1998). Capacity development. UNDP: management development and governance division. New York: Bureau for Policy Development.

Chikulo, B. (1989). The Zambian Local Administration Act 1980: problems of implementation. Planning and Administration, 16(1), 62-67.

Cob, R, \& Elder, C. (1983). Participation in American politics, the dynamics of agenda building. Baltimore: John Hopkins University Press.

Collins, C. (1989). Decentralisation and the need for political and critical analysis. Health Pol icy and Planning, 4(2), 168-171.

Collins, C., \& Green, A. (1994). Decentralisation and PHC, some negative implications in developing countries. International Journal of Health Services, 24(3), 459-476.

Collins, C. (1994). Management and arganisation of developing health systems. New York: Oxford University Press.

Collins, C. (1996). Decentralisation. In K. Janowsky (Ed.), Health policy and systems development An agenda for research: decentralisation (pp. 161-177). Geneva: World Health Organisation.

Collins, C. (2000). The process of decentralisation of health sector in Brazil and the need for political and critical analysis. Healih Policy and Planning, 14(2), 168-171.

Constitutional Decree No. 4 (1991).Khartoum: National Assembly.

Constitutional Decree No. 10 (1993). Khartoum: National Assembly.

Constitutional Decree No.11 (1993). Khartoum: National Assembly.

Constitutional Decree No. 12 (1994). Khartoum: National Assembly.

Constitutional Decree No. 14 (1997). Khartoum: National Assembly.

Conyers, D. (1981). Decentralisation: for regional development; a comparative study of Tanzania, Zambia and Papua New Guinea. Public Administration and Development, 1981(1), 107-120.

Conyers, D. (1983). Decentralisation: the latest fashion in development administration. Public Administration and Dewelopment, 1983(3), 97-109.

Conyers, D. (1984). Decentralisation and development: a review of the literature. Public Administration and Development, 1984(4), 187-197.

Conyers, D. (1986). Implementation strategies: preparing a sector for decentral isation. Retrieved October 30,2001 , of http/Www.mdpesa.co.zW/pubs/implement.htm

Crabtree, B., \& Miller, W. (1992). Doing qualitative research: research methods for primary care. Newbury Park: Sage.

Dargail, F. (1998). The importance of information system at federal level. Khartoum: UNFPA and Federal Ministry of Health (umpublished paper). 
Davey, K., Gleutworth, G., Khalifa, M., \& Idris, M. (1976). Local governnew and developmen in the Sudan: the experience in southern Darfur province. Biminghan: Instiute of Local Government Studies.

De Leeuw, E. (1989). Health policy. An exploratory inguiry who the development of polioy for the new public health in the Netherlands. Maastricht: Savannah/Datawyse.

Dror, Y. (1989). Public policy-making re-examiwed. New Brunswick: Transaction Publishers.

Eisa, M. (2002). The fiwancial resources under the federal system. Khartoum: Federal Government Chamber (unpublished Arabie version).

ELArif., S. (1978). The local government and local participation in rural development in the Sudan. Khartoum: Development Studies and Research Centre University of Khartoum.

EIBeely, A. (1999). Reproductive health and fowily planning. Khartoum: National Population Council in collaboration with the United Nations Population Fund.

Elfatih, A. (1996). An evalwation of the Bamako initiative based health program in El-Rahad healsh area. Khartoum: University of Khartoum.

EIKhalifa, M. (1980). The application of the People's Local Government Act 1971 in the Sudan. In Sudan Institute of Public Administration Group (Eds.), Proceedings of joint study seminar for Senior Goverwment Inspectors (pp. 37-50). University of Birmingham: Birmingham.

EIKhalifa, M. (1998). Evaluation of PHC activities introduced by Benevolence International Foundation in South Kordofan State. Khartoum: Benevolence International Foundation (unpublished).

Ellis, S. (1996). Africa now: people, policies a instinutions. The Hague: Ministry of Foreign Affairs.

Elnaeem, A. (1999). Authorities in federal goverment, distribution, felations, implementation and future vision. Khartoun: National Assembly (unpublished Arabic version).

El-Rayah, A., \& Taban, A. (1979). Decentralization: power to provinces. Sudan Now (News Magazine), March, 9-14.

Elsheikh, B. (2000). Towards organizational model for the locality (Mahalliah). Khartoum: Federal Government Chamber.

EITahir, A. (1999). The co-ordination of relations berween the vertical executive levels of the federal govermment system in Sudan. Khartoum: National Assembly (unpublished Arabic version).

European Commission (1996). Regional project 7th EDF All ACP: stpport for the reform of health systems. Brussels: European Commission Directorate-General V111 Development.

Fadalla, A. (1979). Sudan: a quest for a model. Los Angeles: University of Southern California.

Fadala, A. (1996). Decentralization reform in the Sudan past experiences and future trends with perspectives on community participation in development. AAPPSO Quarterly: Development and Socio-Ecomomic Progress, 65, ill-26.

Fadalla, O. (1986). Financial relations in the Sudan with during decentralization times Sudan. In P. der Wel, \& M. Ahmed (Eds.), Perspective on developmen in the Sudan (pp. ). Den Hang: ISS.

Federal Government Chamber (1998). Guidelines for federal government Khartoum: Federal Government Chamber.

Federal Government Chamber (1999). State support fund records. Khatoum: State Encyciopaedia.

Federal Government Chamber (2002). Evaluation and monitoring for the federal government 1994-1999. Khartoum: Federal Govemment Chamber.

Federal Ministerial Council (1996). The Federal Ministerial Decree No. 489. Khartoum: Federal Ministerial Council Records.

Federal Ministry of Finance (1990-1999). Annual Statistical reports. Khartoum: Federal Ministry of Finance.

Federal Ministry of Health (FMOH) (1992). The national commitee for health hwan development for the national health strategy (1992-2002). (unpublished document). 
Federal Ministry of Health (1993). Heath State Report. (unpublished document).

Federal Ministry of Health (FMOH)(1993 a), Health Annual Statistical Report, National Health Information centre. Khartoum.

Federal Ministry of Health (FMOH) (1993 b). Sudan Matemal and Child Health Survey. 1992/1993. National Centre of Health information.

Federal Ministry of Health (FMOH) (1994). Annwai healh statisnical report. Khartoum: National centre of Health Information.

Federal Ministry of ffealth (FMOH) (1995a). Anwual health statishical report. Khartoum: National Centre of Health Information.

Federal Ministry of Health (FMOH) (1995b). The Ministry of Health records: DirectorateGeneral for Planning and Dewelopment. Khartoum: Federal Ministry of Health.

Federal Ministry of Health (FMOH) (1996a). Annual heath statistical report. Khartoum: Nam tional Centre of Health Information.

Federal Ministry of Health (FMOH) (1996b). The reality of health services in Sudan. Khartoum: Federal Ministry of Health (unpublished report).

Federal Ministry of Heatth (FMOH) (1997). Environmental Health Law. Khartoum. Federal Ministry of Health.

Federal Ministry of Health (FMOH) (1997a). Anmual healt statistical report. Khartoum: National Centre of Health Information.

Federal Ministry of Heal h (FMOH) (1997b). The conference for heallh planning and development in the context of federal govermment under the slogan: "coordinated national efforts for integrated health services'. (unpublished Arabic version).

Federal Ministry of Health (FMOH) $(1997 \mathrm{c})$. The Minister of Health report for the National Assembly. Khartoum: Federal Ministry of Health.

Federal Ministry of Health (FMOH) (1998a). The Minister of Health report for the National Assembly. Khartoum: Federal Ministry of Health.

Federal Ministry of Health (FMOH) (1998b). Anmual health satistical report. Khartoum: National Centre of Health Information.

Fedieral Ministry of Health (FMOH) (1999). National Technical Assistant Statement Report Intemational Relations Directorate. Khartoum: Federal Ministry of Health.

Federal Ministry of Health (FMOH) (2000). Anwal heath statistical report. Khartoum: National Centre of Health Information.

Federal Ministry of Health (FMOH) (2001). Study of the Health Services Reality and it matching with PHC principles. Khartoum: Federal Ministry of Health.

Foltz, A. (1996). The policy process. In K. Janowsky (Ed.), Health poilcy and systems development. An agenda for resedrch (pp. 207-223). Geneva: World Health Organization.

Fudge, C. \& Barrett, S. (1981). Reconstructing the field of analysis. In S. Barrett, \& C. Fudge (Eds.), Policy and acion (pp. 249-276). Methuen: London.

General Heath Law (proposal) (1998). Republic of Sudan.

General Law for Public Services (1997). Republic of Sudan.

Gezeira State Ministry of Health (1996). The guidelines for health. Khartoum: International African University Press.

Gilson, L., \& Mills, A. (1995). Health sector teforms in sub-Saharan Africa: lesson for the last 10 years. Heath Policy, 32, $215-243$.

Gilson, L., Kilima, $P_{*}$ \& Tanner, M. (1995). Local government decentralisation and the health sector in Tanzania. Public Administration and Development, 1995(14), 451-477.

Gismallah, A. (2001). The impoct of federal system on the heal thector. A paper prepared for the evaluation of the impact of federal system upon the health sector. (unpublished paper).

Godinho, J. (1990). Tipping the balance towards primary health care: managing the change at the local level. International Journal of Health Plaming and Management, 1990 (5), 41 52.

Govermment of Sudan (1995). Local Govemment Act of 1995. Sudan: Ministry of Justice. 
Grindle, M. (1980). Polinics and policy implementation in the Thind World. New Jersey: Princeton University Press.

Grindle, M., \& Thomas, J. (1991). Public choices and policy change. Baltimore: John Hopkins University Press.

Ham, C. (1992). Health policy in Britain, the politics and organization of the National Heall Services. London: The Macmillan Press.

Hamid, M. (1988). Centre-region relations in the Sudan the federal origin. Khartoum: University of Khartoum.

Hogget, P. (1991). A new management in the public sector?. Policy and Politics, 19(4), 243256.

Hogwood, B., \& Gum, L. (1984). Pollcy anaystis of the real warld. Ox ford: Oxford University Press.

Howell, J. (1974). Local government and politics in the Sudan. Khartoum: Khartourn University Press.

Hyden, G. (1983). No shortcuts to progress: African development management in perspective. Berk: University of California Press.

Ibrahim, A. (1999). The cultural and social influences in the application of federal system in Sudan. Khartoum: National Assembly (unpublished Arabic version).

Ibrahim, M. (1982). Trends and issues in local government finches in the Sudan. Birmingham: University of Birmingham.

Mohammed Ibrahim, M. (1996a). Financial relations between FMOH and States" Ministries. Gaderif: FMOH and State Ministries of Health.

Mohamned Ibrahim, M. (1996b). Movements of health workers. Gaderif: FMOH and State Ministries of Health.

Iglesias, G. (1978). Implementation: a case book of Asian experiences. Manila: Eropa.

Karsany, A. (1998). Federal system in Sidon. Khartoum: Khartoum University Press.

Khairy, A. (1992). Mentorandum on the national health strategy. (unpublished Arabic version).

Khartoum State Ministry of Health (SMOH) (1997). Human resource development plan in Khartoum State for the period 1997-2002. Khartoum: State Ministry of Health.

Lee, K., \& Mills, A. (1982). Policy making and planning in the heath sector. London: Croom Helm.

Leonard, D., \& Marshall, D. (1982). Institutions of rural development for the poor. Berkeley: University of Califormia.

Lindblom, C. (1959). The science of muddling through. Public Administration Review, $1959(19), 79-88$.

Lyden, F., \& Miller, E. (1972). Planming, programming \& budgering. Chicago: Markham.

Macrae, J., Zwi, A., \& Birungi, H. (1993). A healthy peace? Restrwcrwing and reform of the health sector in a post conflict situation-the case of Uganda. (unpublished report).

Maddick, H. (1964). Democracy decentralisation \& development. London: Asia Publishing House.

Maddick, H. (1981). Major approaches and strategies in decentralisation for development. (unpublished).

Magzoob, A. (1999a). Views on the distribution of resources between the levels of federaland state level. Conference paper presented in mational conference: Evaluation of Federal system by the National Assersbly. (unplished Arabic version).

Magzoob, $T$. (1999b). Division of powers. Conference paper presented in mational canference: Evaluation of Federal system by the National Assembly (unplished Arabic version).

Malik, J. (1982). Financial management in the area conncils: decentralization. Juba: Regional Ministry for Decentralization Affairs.

Marshall, A. (1949). Repom on local govermen in Sidan. Khartoum: MacCorquadale.

Mawhood, P. (1983). Local government in the Third World. Experience of decentralization in tropical Africa. Chichester: John Wiley. 
Mawhood, P. (1984). The politics of survival federal states in the Third World. International Political Sclence Review, 5(4), 521-531.

Mawhood, P. (1987). Decentralisation and the Third World in the 1980s. Planning and Admini. stration, $14(1), 10-22$.

Mawhood, P. (1993). Local government in the Third World. Experience of decentratization in tropical Africa (second version). Chichester: John Wiley.

Miles, M., \& Huberman, A. (1994). Qualitative data analysis. Califomia: Sage Thousand Oaks.

Mills, A., Vaughan, J, Smith, D., \& Tabibaadeh, I. (1990). Healh systems decentralisation. concepts, issues and couniry experiences. Geneva: WHO.

Mills, A. (1994). Decentralisation and accountability in the health sector from an international perspective: what are the choices?. Public Administration and Development, 1994(14), 281.292.

Ministry of Finance (1980). Budgets of provincial executive councils, fiscal year 1979/1980. Khartoum: Ministry of Finance.

Ministry of Finance (1996). Economic Survey - Health Budget Data. Sudan: Ministry of Finance.

Ministry of Health (MOH) (1970). The five year plan of econowic and social development of the Democratic Republic of Sudan for the period 1970-1971 to 1974-1975. Khartoum: Ministry of Health.

Ministry of Health (MOH) (1981). Primary health care in-depth review. (unpublished study).

Ministry of Health (MOF) (1985). Overall evaluation of the primary health care in Sudan (1977-1984). Khartoum: MOH.

Ministry of Health (MOH) (1987a). Anmal statistical report. Khartoum: Heal th Statistics and Research Department.

Ministry of Health (MOH) (1987b). In-depth review of the primary healh care in Sudam. (unpublished study).

Ministry of Health (MOH) (1988). Annual statistical report. Khartoum: National Centre of Health Information.

Ministry of Health (MOH) (1990). Annual statistical report. Khartoum: Health Statistics and Research Department.

Ministry of Health (MOH) (1992). The national committee for health manpower development. (umpublished Arabic report).

Ministry of Health (MOH) (1983). Annual statistical report. Khartoum: Health Statistics and Research Department.

Minster of Justice Republic of Sudan (1998). Sudan Constitution of 1998. Khartoum. Presidentral Press.

Ministry of Locall Government (1971). Local Government Act 1971. Khartoum: Ministry of Local Government.

Ministry of Planning (1983). National human development report. (unpublished report).

Mogedal, S., Steen, H., \& Mpelumbe, G. (1995). Health sector reform and organisational issues at the local level: lessons from selected African countries. Journal of Internotional Development, 7(3), 349-367.

Moharir, V. (1986). Decentralized policymaking and centre-region rellations in the Sudan with special reference to eastern Sudan. In P. der Wel, \& M. Ahmed (Eds.), Perspective on development in the Stadon. Den Hagg: Institute of Social Studies.

Moharir, V., Kawge, S. (1987). Administrative reforms and development planning in the Sudom (1956-1975). Khartoun: University of Khartoum.

Mukwena, R. (2001). Situating decentralisation in Zambia in a political context. Affican Administrative Studies, 57, 35-48.

Norris, M. (1983). Local government and decentralization in the Sudan. Public Administration and Development, $1983(3), 209-222$.

Olowu, D. (2001). African decentralisation policies and practices from 1980 and beyond. Den Haag: Institute of Social Studies. 
Paley, J. (2000). Paradigns and presuppositions: the difference between qualitative and quantitative research. Scholarly Inquiry for Nursing Practice, 14(2), 143-155.

Paul, S. (1995). Capaciry bulding in healh sector reform. Geneva: WHO.

Republic of Sudan (1961). Report on the commission on coordination between the central and local goverwment. Khartoum: Government Printing Press.

Rondinelli, A. (1981a). Administrative decentralization and economic development: the Sudans experiment with devolution. Journal of Modern African Stwdies, 19(4), 595-624.

Rondinelli, A. (1981 b), Government decentralisation in comparative theory and practice in developing countries. International Review of Adninistrative Sciences, 47(2), 133-145.

Rondinelli, A., \& Cheema, S. (1983). Implementing decentralisation policies: an intoduction. In S. Cheema, \& A. Rondinelli (Eds.), Decentralization and development: policy developmen in developing countries (pp. 9-34). Bevery Hills: Sage Publications.

Rondinelli, A. Nellis, R. \& Cheema, S. (1983). Decentralisation in developing coumivies. A review of recent experience. Washington: World Bank.

Rondinelli, A., McCullough, S., Johnson, W. (1989). Analysing decentrahisation policies in developing countries: political econowy fromework, development and change, 20(1), 57 87.

Saide, M. \& Stewart, D. (2001). Decentralisation and human resource management in the health sector: a case study (1996-1998) from Nampula province, Mozambique. International Health Planning and Management, 16(2), $155-168$.

Salih, K. (1989). The Kordofan region of the Sudan, 1980-1985: case study of the problems of regionalism. Khartoum: Development Studies and Research Centre University of Khartoum.

Saltman, B., \& Figureas, J. (1997). European health care reform: analysis of current strategies. Regional Publications, 72. pages.

Seaman, C. (1998). Research methods. principles, practice and theory for varsing. Buckingham: Open University Press.

Segall, M. (1983). Planning and politics of resource allocation for primary health care: promotion of meaningful national health policy. Social Science and Medicine, 29, 395-402.

Smith, B. (1979). The measurement of decentralisation. International Journal of admimistrative sciences, 45, 214-22.

Smith, B. (1985). Decentralisation: the territorial dimensions of the state. London: Allen and Unwin.

Stewart, F. (1991). The many faces of adjustment. World Development, 19, 1847-1864.

Strauss, A. (1978). Negotiations. San Francisco: Jossey-Bass.

Sudan Academy for Administration Studies (1990). Organtsational strdy for the Ministry of Health and Social Services. (unpublished report).

Sudan Federal Chamber (1998). Guidelines for fedenal goverment. Khartoum: Federal Govermment Chamber.

Sudan Medical Association (1990). Steering commitee proposals for health salvarion. (unpublished report).

Sudan Ministerial Council (1964). Resolution No. 17. Sudan Ministerial Council: Khartoum.

Sudan Republic (1992). The comprehensive national strategy (1992-2002). Khartoum: Sudanese Colour photos Laboratories Prints.

Sudan Republican Palace (1999). Presidential Act of Dovision of Resources. Khartoum: Sudan Republican Palace.

Sudan Socialist Union (1980). Report of the technical committee for regional gowermment. Khartoum: Sudan Socialist Union.

Stone, D.A. (1997). Policy paradox and political reason. New York: Harper Collins.

Tag-Osman (31 July, 1999). Al-Roy Al Aam Newspaper. Issue 700.

UNDP (2002). Arab human development report creating opportunities for future generation. Alexandria: Regional Bureau for Arab States/ UNDP. 
United Nations (1965). Decentralization of nationd and local development. New York: United Nations.

Van Meter, D. \& Van Horn, C. (1975). The policy implementation process: a conceptual framework. Administration and Society, 6(4), 446.

Walt, G., \& Gilson, L. (1994). Reforming the health sector in developing countries: the central role of policy analysis. Healh Policy and Plaming. 9(4), 353-370.

Walt, G. (1994). Health policy: an introduction to process and power. Johannesburg: Witwatersand University Press.

Walt, G. (1996). Policy analysis: an approach. In K. Janovsky (Ed.), Heath policy and systems development. An agenda for research: decentratisation (pp. 225-239). Genewa: WHO.

Wells, L., Martin, K., Moorhouse, A., Craig, D., \& Foley, M. (1999). An integrated model of discharge planning for acutely ill elderly patients. Canadian Joumal of Nursing Leadership, $12(3), 6-12$.

World Bank (1983). World development report. Washington: Oxford University Press.

World Bank (1987). Financing health services in developing cownties: an agenda for reform. Washington: Oxford Uniwersity Press.

World Bank (1993). Investing in health: world development report 1993. Washington: Oxford University Press.

World Bank (2000). World development anmal report. Washington: Oxford University Press.

World Bank (2003). Sudan: stabilisarion and reconstruction, conntry economic memorandum. Washington: World Bank.

World Health Assembly (1977). Resolution 30.43 on "Health for all by year 2000". Genewa: WHO

World Health Organisation (WHO) (1978). Primary health care. Geneva: WHO.

World Health Organisation (WHO) (1981). Development of indicators for monitoring progress towards health for all by the year 2000. Geneva: WHO.

World Health Organisation (WHO) (1987). WHO women and children health through the funding and management of essential drugs at community level: Bamako initiative. Geneva: WHO

World Health Organisation (WHO) (1987a). Operational support for PHC, the role of the district level in accerlating health for all Africans. Brazzaville: WHO Regional Office for Africa.

World Health Organisation (WHO) (1988). The challenge of implementation: district health systems for primary health care. Geneva: WHO.

World Health Organisation (WHO) (1997). The role of local government in health: comparative experiences and major issues, division of strategic support ro countries in greatest need. Geneva: WHO.

World Health Organisation (WHO), Sudan Office (2001). National technical assistants Sudanstatement report. (unpublished report).

World Health Organisation (WHO) (2002). The world health report, statistical annex. Geneva: WHO.

Wunch, I., \& Olowu, D. (1990). The failure of the centralised state: institutions and selfgovernonce in Africa. San Fransisco: Institute for Contemporary Studies.

Yin, R. (1989). Case stwdy research: designs awd methods. California: Sage Thousand Oaks. 


\section{Curriculum Vitae}

Mohammed Ali Yehya Elabassi was born in Nayala, South Darfur, Sudan on June 2, 1958. He had his pre-university education in South Darfur. Following his graduation at the Faculty of Medicine, University of Gezeira (FMUG), Sudan in 1984, he worked in the Wad Medani and Omdurman Teaching Hospitals as a house officer. At the end of 1985 he was appointed as medical officer in the Sudan Ministry of Health. In this position he worked in Omdurman Teaching Hospital, Central Police Hospital in Khartoum, Tigany Elmahy and Ibn-Sina hospitals, till 1992.

In 1993 he was seconded to work as a medical Director in the Al-Birr Humanitarian Organisation. After three years of work in humanitarian aid he jointed the Master of Public Health Program in Maastricht University, September 1995/1996. After the completion of his Masters, he developed an interest in doing research and worked out a proposal for PhD study which has been approved and accepted as a joint program between Government of Sudan and Maastricht University. Currently, he is employed by the Government of Sudan as a PhD researcher in Maastricht University Department of Health Policy, Organization and Economics (HOPE). 



\section{Acknowledgements}

The way from my early childhood in a nomadic context in western Sudan to the finalisation of my PhD project in Western Europe, in Maastricht where the Maastricht Treaty on the European Union was signed in 1992, has been very long. It was full of risks, hazards, problems and a lot of fortune. Many individuals contributed to the successful end of my long path through their direct or indirect efforts, sometimes even in an ad hoc way. I should emphasise that the $\mathrm{PhD}$ project is not only the fruit of the years that were spent on the research project in Maastricht. In fact, it is the cumulative consolidation of life long experience. So, whoever contributed in my life-long path is a real participant in the ultimate fruit and deserves my acknowledgement and appreciation.

Above and before all, it is to Allah, my God, the Most Gracious, Most Merciful that praise should really be forwarded. Though Allah needs no praise. His unlimited and infinite bounties and grace of faithfulness, care, guidance and health are least not to be denied if not worth all praise and gratitude.

My promoter, Prof. dr. Hans Maarse, played an important role this project. Despite his overburdened schedule, he has given me an unlimited support in several ways. I will never forget his inspiration, enthusiasm and helpful suggestions as well as his humour and jokes. The thesis benefited greatly from his ideas, suggestions, comments and high confidence. His proposals for radical short cuts I will never forget. To some extent, they express a difference in culture.

Dr. Vasant Moharir, my co-promoter, facilitated lot in bringing the project to a happy end. I greatly benefited from his knowledge in the field public policy and administration, his research experience in developing countries in general and particularly in Sudan. He has shown a lot of patience and dedication despite his severe health challenges. He is humble and great man.

I would like to thank my colleagues at the University of Maastricht, the Department of Health Organisation, Policy, and Economics (HOPE). Here I would like to mention Prof. dr. Wim Groot, the head of the Department. I am also grateful to Jan van Emmerik and Will Vangangel whom I often consulted for urgent computer support. Brother Mushtaq, the sincere friend from whom Il learnt a lot, some of which was a mixture of Pakistani and Muslim culture in a Dutch environment. From him I really tasted the value of the proverb "Your friend in need is your friend indeed ". Catelijne, Regien, Sandy, Aggie, Isabella, Suzan, Anna, Melana among others should be mentioned as helpful colleagues. Will Buntinx, Sandra and Martijn were helpful roommates. I am also grateful Dr. Mukhyer, Dr. Habbani and Dr. Ibinouf, my Sudanese Ph. D. Colleagues for their kind assistance and encouragement. I am also much indebted to the secretary of HOPE: Peggy, Astrid, Isel and Hilde. I also thank Marieke van Velden, Julia Fountain 
and again Jan van Emmerik for their help in the final editing of my thesis. From the Office of International Relations my thanks should be passed to Tom Kuiper and Lori Mees.

During my study and research I have witnessed seven patches of the MPH course. During each patch we used to have four to six Sudanese participants, most of whom I did not know before. Their companionship was an invaluable educational process. They and their families have become real social and academic capital. I owe great debts to them for their contribution, encouragement and concern. My sincere brother Dr. Isam Mohamed Abd Alla is an example of them.

I am grateful to the Govemment of Sudan, the Birr International Foundation, Ministry of Interior, Police Hospital, Department of National Training, the Sudan Embassy in the Netherlands, the University of Maastricht and my uncle Ibin Omer for their support without which my study could never have been realised.

The study also benefited from about five hundred individuals in Sudan who helped me in the collection of my data. They worked at different government levels in several states. Their contributions were the fuel for this thesis. Their hospitality was reflected in the warm reception services, the quantity of data provided as well as other aspects of assistance. I am much indebted to them. I mention only a few of them as representatives: Prof. dr. Kabbashy from the Ahfad University, Prof. dr. Qurashy of the Ismail ElAzhary University, Dr. Khairy of Office of Strategic Planning, Prof. dr. Albeely from the Ahfad University, Dr. Abd Alla Seid Ahmed of the Khartoum State Ministry of Health, Dr. Elsadig Gismallah of Gezeira State Ministry of Health, Dr. Salah ElBadawy, Mr. Mohy Eldeen, Ms. Duria of Federal Primary Health Care Directorate General, Dr. Somaya Elfadil of the Gezeira State Ministry of Health, Ms. Nemmat of the Kassala State Ministry of Health, Dr. Suleiman Abd $\mathbb{E} 1$ Rahman, Dr. Gism Elbaary of the North Kordofan State Ministry of Health and colleagues from Ribat National University, namely Prof. Dr. Abd El Lateif Ashmaig.

Many friends showed a great concern, sympathy, encouragement and support during my study period. Their efforts and prayers expressed their real loyalty and sincerity and facilitated many things in my path. I have to pass my gratitude to them too. Some of them were even able to visit me in Maastricht. When we speak about friends, many persons of the Sudanese community in the Netherlands, in particularly in Maastricht, offered my family and me a supportive environment. El-Fadil Burhasn and his family devoted a kind care and assistance in several ways. Bashier Reisk and all our brothers from Egypt were good examples of friendship and help. I will never forget the assistance I have received from Moroccan community in Maastricht, namely my friend Asjjad and his family. I an grateful to them all. Some brothers and friends from Amsterdam extended their support and encouragement. Dr. Tarig Mukhtar and his wife sister Waffa Abdelgadeir, Dr. Isam Haj Musa and his wife sister Mona, Abdomonem Artoli 
and Mohamed Basheir and wife Makka are to be mentioned as source of social support and assistance. Sister Waffa in particular assisted in the diagrams and editing tasks and so did Isam. They all deserve my gratitude and prayers.

Finally, my gratitude goes to my mother, brothers and sisters as well as my mother, brothers and sisters in law for their moral support and continuous encouragement. Here, $\mathbb{I}$ have to extend my prayers for my beloved father who during his life appreciated the value of education. He was a principal and unforgettable character in my life.

Last but not least, no words are ever sufficient to express my feelings for my wife Goot Elgoluob. She was not a wife only, but a sister, a friend and more too. Her unfettered patience and sacrifice, preservation, support and prayers for me, and other great debts are beyond repay in this world. Our son Musab and daughter Noon represented the basic social asset during our stay in Maastricht. Although they were quite young, they showed me the wisdom and patience of an adult. They sometimes compelled me to comply with some elements of Dutch culture, such as transparency, vacations and out walking. They and their mother were the essence and spirit of success. 